SF 375
S845
Copy 1




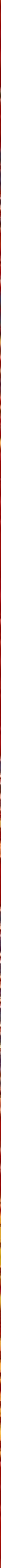




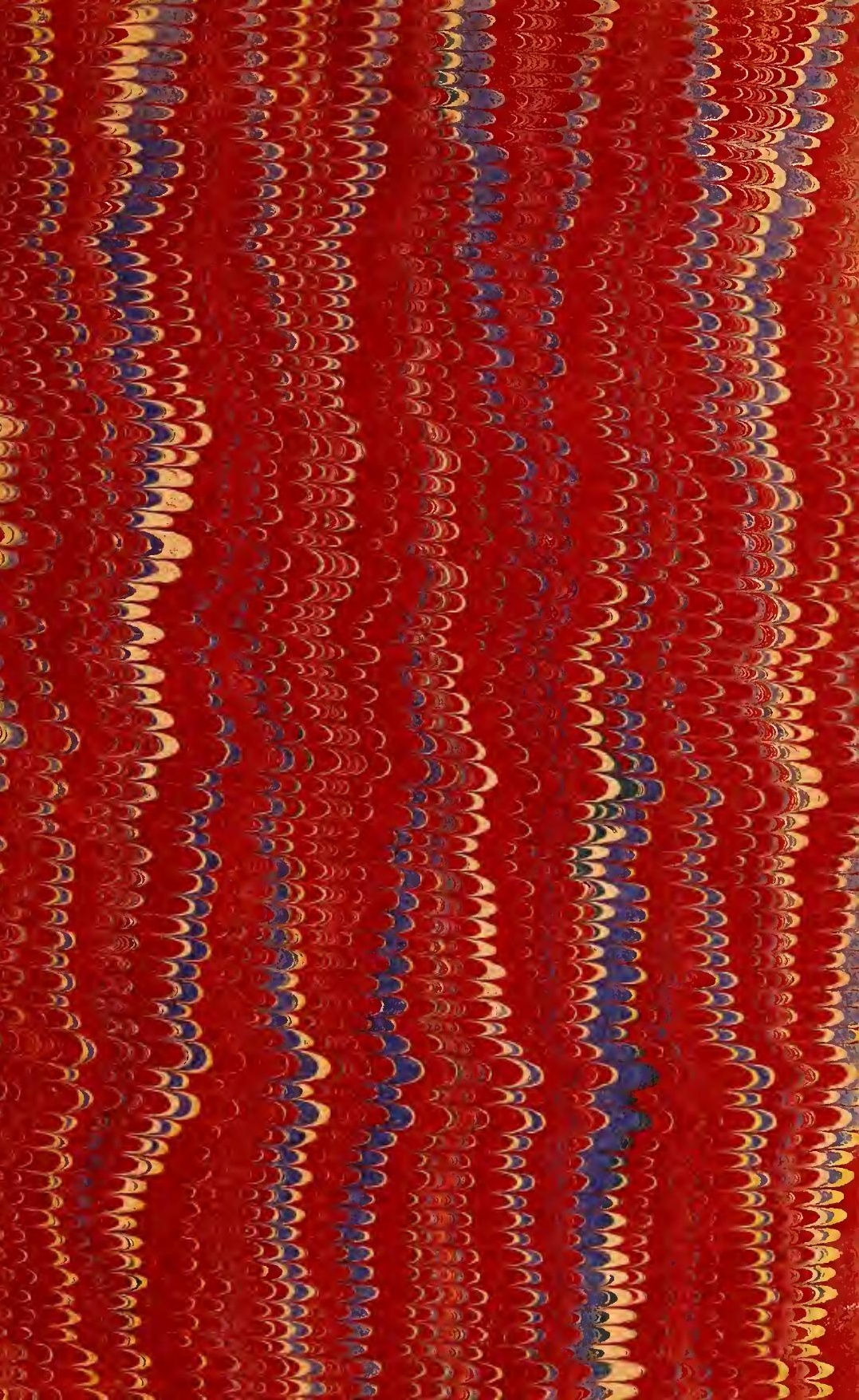









\section{The Shepherd's Manual.}

A PRACTICAL TREATISE

ON

\section{THE SHEEP.}

DESIGNED ESPECIALLY FOR AMERICAN SHEPHERD3.

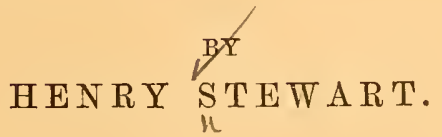

I I U S T R T ED.

NEW EDITION.-REVISED AND ENLARGED.
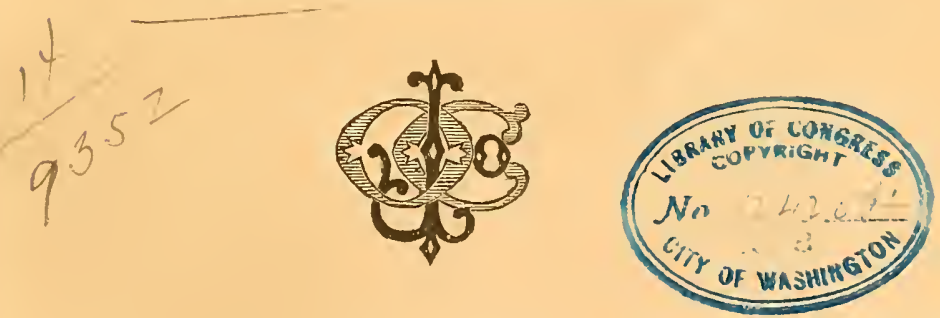

NEW YORK:

ORANGE JUDD COMPANY,

$245 \mathrm{BROADWA}$.

1879. 


\section{SF}

Entercd, according to Act of Congress, in the year 1si8, by the ORANGE JUDD COMPANY,

In the Ofiec of the Librarian of Congress, at Washington. 


\section{O N T E N T S.}

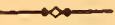

PAGE.

Preface

CHAPTER I.

The Sheep as an Industrial Product................. 8- 11

Antiquity of Sheep Husbandry-The Future of Sheep Husbandry-Its Effeets upon Agrieulture-Demand for Mutton Sheep-Value of the Wool Product-Extent of Pasturage in America.

CHAPTER II.

The Sumier Management of a Flock.................. 11-33

Selection of a Sheep Farm-Effects of Soils upon the Health of Sheep-What is a Good Pasture?-Value of Certain Grasses-The Western Plains as Shcep PasturePastures-Fodder Crops-Root Crops-Folding ShcepDog Guards.

CHAPTER III.

Management of Ewes and Lambs..................... 33- 49

Marking Sheep-Record for Breeders-Management of Rams-Care of Ewes-Carc of Lambs-Seleeting Lambs for Breeders-Prevention of Discasc-Dipping Preventive of Parasites.

\section{CHAPTER IV.}

Winter Management of Sheep. $49-81$

Barns and Sheds-Feed Racks-Feeding Value of Different Fodders, Roots and Grains -Experiments in FeedingProfit of Feeciing-Raising Early Lambs for MarketFeeding Sheep for Market-Value of Manure-Markets for Sheep.

(3) 
CHAPTER V.

PAGE.

BreEd ING $\Lambda$ ND Breeds of SHEEP.................. 81-14?

How Breeds are Established-Improvement of FlocksCross Breeding-Breeding for Sex-Maxims for Breeders - Native Breeds-Improvement of the Merinos-The Merino Fleece-Long-Wool Breeds-Medium and Short-Wool Breeds-Foreign Breeds-Cross-bred Sheep-American Cross-breeds.

\section{CHAPTER VI.}

The Structure and Uses of Wool $142-167$

The Method of Growth of Wool--Its Peeuliar Strueture -Its Composition-The Yolk-Classification of WoolsCharacter of Merino Wool-Washing Wool-ShearingPackiug and Marketing the Fleeces-Production of Wool in the World-Comparative Values of Wool in Diffe:ent Countries-Farorable Conditions for Produeing Wool in the United States.

\section{CHAPTER VIL.}

The Avatomy and Diseases of the SHeep..............168-249

Physiology of the Sheep-The Teeth-The Boncs-The Vital Funetions, Respiration, Circulation, and DigestionThe Causes and Prevention of Diseases of the Sheep-Diseases of the Respiratory Organs, of the Digestive Organs, of the Blood-Enzoötic Diseases-Epizoötic DiseasesDiseases of the Urinary and Reproduetive Organs, of the Brain-Parasitical Diseases of the Intestines, of the Skin -Diseases of the Feet-Diseases incident to LambingSpecial Diseases-Diseases of Lamibs.

Table of Approximate Equivalent Measurgis..............

\section{APPENDIX.}

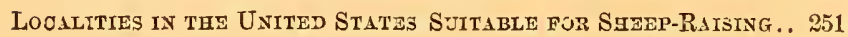




\section{PREFACE TO THE SECOND EDITION.}

The favorable comments by the agricultural press, and the numerous letters from private parties to the author, acknowledging indebtedness for the assistance receired from this work, have been very gratifying, and with an acknowledgement of the kindness of his readers, the author offers a new edition of the work to the public. The recent enormous growth of the stock interests of the far West, and the many inquiries which have been made as to the various localities most favorable for sheep-keeping, have made it desirable to add to the book an entirely new chapter, devoted altogether to a review of the advantages offered by different sections of the country, for the rearing of the various races of sheep suited to them. An enlarged experience, since the first publication of the volume, has only confirmed the views of the author in regard to some subjects then touched upon with much diffidence, but in honesty of judgment, and with deliberation. There is nothing in the views expressed in the first edition that he would materially modify, and the author feels that he can still more confidently than before encourage the young shepherd to accept this little manual as a guide and a counsellor.

Hackensack, N. J., 1878.

\section{PREFACE TO FIRST EDITION.}

The following Manual is designed to be a hand-book for American shepherds and farmers. It is intended to be so plain that a farmer, or a farmer's son, who has never kept a sheep, may learn fro:n its pages how to manage a flock successfully, and to be so 
complete that cven the experienced shepherd may gather some suggestions from it. When the author, some years ago, began to keep shcep, he sought in vain amongst the published works a simple practical, comprehensive book upon sheep and sheep keeping, suited to his necessities. The excellent works upon the Merino and Fine Wool Husbandry by Mr. Randall, were the only ones to be obtained that were adapted for the use of an American shepherd, and these referred to a special branch of sheep husbandry which is becoming every year a less and less prominent one. The other books on this subject then extant, were eitlier English works or compilations from them, and were out of date and incomplete. None of the works gave a description of the modern improved breeds of sheep which have of late become so deservedly popular; or any full or satisfactory account of the diseases of sheep, and the remedics proper for them under the modern systems of treatment which have grown out of the more accurate scientific knowledge of the present day; nor could any information as to the vastly increased scope of this branch of agricultural industry in America, be found in any book. It was necessary to learn by experience-in this case, as in all others, a costly teacher-how to meet the needs of the modern improved sheep in our climate and under our methods of culture. The results of personal experiences of some years witl the characters of the various modern breeds of sheep, and the sheep-raising capabilities of many portions of our extensive territory and that of Canada, most of which have been visited with a view to the effects upon our sheep of the varying climate and different soils; and the careful study of the diseases to which our sheep are chiefly subject, with those by which they may eventually be afflicted through unforeseen accidents; as well as the methods of management called for under our circumstances, wcre finally gathered into the shape in which they are here presented to the shepherds of America, with the hope that they may be as acceptable and as useful to them as they would have been, when he first undertook the care of a flock, to

The AUthor.

New York, $18 \% 6$. 


\section{The Shepherd's Manual.}

\section{CHAPTER I.}

\section{THE SHEEP AS AN INDUSTRIAL PRODUCT.}

From the earliest ages the sheep has been a scurce of profit to mankind, and its keeping and rearing an important industry. Abel, the second son of Aclam, chose sheep-herding as his employment, and although his elder brother chose to cultivate the soil, the pastoral life became the favored occupation of the human race in its early periods, and the more toilsome tillage of the ground was followed from necessity rather than from choice. With a sparse population, a scarcity of labor, but at the same time an ample territory, the cultivation of flocks became in early times the readiest means of providing food and clothing, increasing the comforts of man and of accumulating transferable wealth. Although at first sight it is a singular circumstance, yet on reflection it is seen to be a necessity of the case that the territory upou which the flocks of the ancient patriarchs were fed and tended, is still the home of shepherds, and that there, for forty centuries, flocks have wanciered from pasture to pasture under the care of their nomadic proprietors. Where the physical features of the country were favorable to pasturage, there the first civilized occupation was that of keeping sheep, and so it remains to this day.

In view of its bearing upon the future of sheep busbandry in the United States, it is important to remember this fact, that where peculiarly farorable physical features of the country were present, and the shepherd occupied the land, there the shepherd and his flock retain possession until this day. Thus, at the time of the conquest of Spain by the ancient Romans, that country was celebrated for its flocks and the quality of its wool, and to-day the 
Spanish Merino is equally celebrated, although through adventitious circumstances, but chiefly political disturbances, its pre-eminence has been lost to Spain, and other countries enjoy its fruits.

As civilization progressed stage by stage, and garments of man. ufactured wool displaced those of skins, careful breeding began to improve the fleece, and varieties among sheep became fixed in type. Before the Christian era the fine wools of Italy were noted, and the fineness of the fleece was cultivated to a degree unknown to us of the present day. 'The sheep of that period were housed and elothed, their skins were oiled and moistened with wine, and their fleeces were combed and washed repeatedly, in order that the quality of the wool might be refined as far as pessible. Although this excessive refinement destroyed the vigor and impaired the constitution of the sheep, yet their descendants, inferior in form, as might be expected, are still fine-wooled sheep. Thus far the improvement in sheep operated oniy towards refining the fleece, and the carcass was a secondary object, only cared for so far as it could serve as a vehicle for carrying the wool. The lamb of the flock was considered a choice morsel, but the mature sheep was neglected as an article of food. It is only in recent times that the excellence of mutton has been made an object in the improvement of sheep. At the present it is only in sparsely populated ccuntries that sheep are cultivated for wool alone, while in densely peopled localities the production of mutton is of greater consideration than that of wool, or at least is of equal value to it. At the present time, proximity to, or distance from market, decides the choice of breeds, and in fact this consideration alone has in some cases been the moving influence in the creation of new varieties or breeds specially adapted to certain localities. In a similar manner the necessities of sheep-breeders have led them to make some important modifications in their methods of agriculture, so that while the character of their flocks has been changed for the better, their agriculture has been improved, the product of the land increased, and its value advanced, until profitable sheep culture has become synonymous with the most profitable farming. In fact, the character of the farm has been indexed by the character of the flock reared upon it. This improvement has in greater part occurred only in connection with the rearing of mutton sheep. To feed these heavy bodied sheep profitably, it has been found necessary to raise large crops of cheap roots and luxuriant green crops; and to raise these crops, the most skillful tillage, the cleanest culture, and the most liberal manuring have been requisite. In this way the product of the soil lias been vastly increased, and the 
sheep, directly and indirectly, has been both the gainer and the means of gain.

The demand for mutton as an agreeable and cheap food is steadily increasing. The markets of the city of New York alone require more than one million sheep per annum. Farmers formerly habituated to the daily use of pork are becoming mutton eaters, and the convenience of a ferw sheep upon the farm merely to supply the family table is now appreciated to a much greater extcnt than ever before. This cultivation of sheep for mutton alone is a branch of agriculture which is yearly becoming more important. As yet we possess no native variety of mutton sheep. The carcass of the "native" sheep, so called-but which is really a heterogeneous mixture of all those breeds which have been brought to this country, and which having been permitted to increase promiscuously, have perpetuated only their poorest qualities-is unwortly the name of mutton; and those flocks of imported sheep of beiter character, such as the Southdowns, Leicesters, or Cotswolds, a..e either allowed to deteriorate, or are kept for breeding purposes. It is very true that a really good carcass of mutton rarely finas its way to our markets, except from Canada, where almost the sole attention is given to breeding sheep for mutton. At the same time there is a demand for mutton, both of that substantial kind which is represented by legs of 16 to $20 \mathrm{lbs}$. in weight, handsome saddles and gcod shoulders, and that more delicately flavored kind represented by the small legs or quarters of the Welsli sheep.

Unfortunately this fact is not generally known to farmers, and if it were, it is equally unfortunate that we as yet bave not the kind of shrep to meet the demand. Before this excellent and wholesome food can become as popular as it onght to be, and sheep keeping can become as profitable as it may be, farmers must be better informed as to the character of the sheep needed, the manner in which they may be bred, and the methods by which they may be fitted for the market. This necessary information must include a knowledge of the modern breeds which have usurped the place of the old kinds, and the peculiar management of the new races of sheep, as woll as of the special crops needed for folder, and the methods of cultivating them. Heretofore in place of this practical information, American farmers have been treated to long dissertations upon the origin and history of the shecp, and descriptions of foreign breeds which are of no possible value or interest to them.

The sheep, in addition to its value as a food producer, yields to its owner an annual tribute in the shape of its flece, which in the 
aggregate is a most important contribution to the comfort and industry of the people. In $18 \% 0$ there were nearly 30 millions of sheep in the United States, and the wool production in that year amounted to 120 millim pounds, estimating the average weight of the fleeces at 4 pcunds each. The value of this wool in the farmers' hands would reach at the lowest estimate, $\$ 40,000,000$. But so far from being anywhere equal to the demand for this staple, the supply was less than our yearly needs by a quantity equal to a value of more than $\$ 40,000,000$, and wool to this amount is annually imported from foreign countries. Besides this in wool, there is annually imported with it the value of $\$ 20,000,000$ in foreign labor, which has been expended in manufacturing wool into cloth and other woolen goods. Our own necessities, thcrefore, demand an increase in the supply of wool equal to our present production. This wool, if produced here, would not only use up a large quantity of corn now thrown upon the markets of the world, and therefore eniance the value of that which would remain for disposal; but its manufacture into cloths and goods would employ a large number of persons who are now engaged in raising agricultural products for sale, and are therefore in active competition with other farmers. The encouragement of sheep cultivation, therefore, has a national importance, and is a subject which bears directly upon the interests of farmers. To increase the wool product to a par with the necessities of the country at the present time, would alone involve the passage through their hancis of $\$ 60,000,000$ yearly -an immense sum, which now goes into the pockets of foreigners, instead of those of our own people.

The scope for an increase in our wool product is comparatively boundless. A full third of the territory of the United States is a grand sheep pasture of the most favorable character. Vast plains bearing abnndance of the most nutritious herbage, in the most healthful climate, and the very best conditions for the profitable breeding of fine and midlle wool sheep, and which are valueless for any other than pastoral purnoses, stretch from the 100th mcridian for 500 miles west to the Rocky Mountains, and from north to south for 1,500 miles. In addition to th is vast tract, upon which a hundred million sheep could feed and thrive with ease, there are immense mountain ranges, extensive valleys, and again beyond these, great plains, altogether covering a still larger area, of which a great portion is admirably fitted for the pasturing of sheep. With so great a scope for the cheap production of wool, it seems to be a strange thing, that instead of exporting largely of this staple, as we might and should do, the United States on the conirary is one 
of the largest buyers in foreign markets. Again, on the Atlantic seaboard there are millions of acres of land now useless that would, if cleared and cultivated, make excellent sheep farms for the production of the choicest mutton sheep. There are numberless salt marshes upon which sheep, naturally fitted through long years of adaptation for just such pasturage, could be made to yield mutton of the most delicate flavor. There are also hills and rocky mountains upon whose sweet herbage hardy races of sheep could be made to thrive with profit; and further inland, highly cultivated farms, where heavy crops of green fodder and roots could be raised, that might carry flocks of large framed sheep, yielding combing wool-now so much used in clothing materials for both sexes, and the demand for which is always ahead of the supply. And further south, where it is possible to pasture sheep the year round, but where those which are now kept are so neglected that some of them are never shorn, there is also vast room to change the overdone cotton production for the equally easy but more profitable production of wool which in that climate, by the exercise of proper care, may be grown of the finest quality of staple. What a vast field opens upon our view when we consider the extent of the territory which we possess suitable for sheep cul. ture; and what profit and increase of national wealth is there in this business to those who undertake it as the occupation of their lives-not only for a short period and intermittingly, and then to be abandoned for some other temporary speculative business-but with a desire and detcrmination to succeed through the exercise of patience, perseverance, and skill.

\section{$\rightarrow \infty$ \\ CHAPTER II.}

SUMMER MANAGEMENT OF SHEEP.

The selection of a suitable farm should be the first care of a person who intends to devote his time and capital to the rearing of sheep. To become a successful shepherd, requires that a pcrson should have a liking for the business, and possess tact, patience, and perseverance suficient to resist the temptations which may arise at seasons of depression to abandon it for some other temporarily more promising pursuit. Having $\approx$ determination to stick 
to his flock, he must have a farm suited to its special needs or it will not thrive. Sheep cannot bear damp; and undrained pastures are fatal to their welfare. Luxuriance of herbage is not generally favorable unless the land is heavily stocked and the pasture kept short and closely cropped. Old permanent meadows, in which a variety of grasses are found, are better than artificial meadows which form part of a rotation with other crops. With a portion of such permanent meadow, there may be many cultivated crops grown upon the other portions of the farm upon which the sheep may be folded with benefit both to themselves and the land.

The land most suitable for sheep is one that is naturally drained, with a sandy loam or gravelly soil and subsoil, and which bears spontaneously short, fine, herbage, largely mixed with white clover. It should be rolling, and may be billy in character rather than flat and level. Any low spots or hollows in which aquatic or marsh plants grow, are very objectionable, and should be thoroughly clrained. One such spot upon an otherwise admirable farm may infect a flock with deadly disease. No domestic animal is more readily affected by adverse circumstances than the sheep, and none has less spirit or power to resist them. Virgil, the ancient poet, a ciose observer of such matters, says of them, "Oves semper infevix pecus," (Sheep are al ways an unhappy flock), and many shephercis since his day have found reason to hold the same belief. But the experienced sheepmaster has no fear on this score. He knows that a reputation for suceess with sheep is "never gained without merit, nor lost withont deserving," and that failure is not want of luck, as is so frequently declared, but the consequence of ignorance or bad management. The careful shepherl will not wait to cure, he is prompt to prevent ; and every defeat is made a new lesson for study and an example for future avoidance. It is by long experience that shepherds have learned that the first requisite for suecess in their business is, the choice of a farm upon which their flocks will enjoy perfect health, and that dryness of soil and of air is the first necessity for their well being. By a careful and judicious choice in this respect, most of the ills to which shecp are subject, with all their contingent losses to their owncrs, are avoicied.

The cliaracter of the soil upon which sheep are pastured has a great influence in modifying the character of the sheep. Upon the kind of soil of course depends the character of the herbage npon which the flock feeds. Certain soils, such as those consisting of decomposed granite or feldspar, and which are rich in potash, are not generaliy favorable for sheep. Even turnips raised on 
such lands sometimes affect the sheep injuriously, producing disease under which they waste away, become watery about the eyes, fall in about the flanks, and assume a generally unhealthy appearance. Upon removal to a limestone, or a dry sandstone soil, sheep thus affected, improve at once and rapidly recover. The lambs, as might be expected, are most easily affected, and many are yearly lost by early death upon lands of an unfavorable character. As a rule, lands upon which granite, feldspathic or micaceous rocks intrucie, or whose soils are derived from the degradation of such rocks, should be avoided by the shepherd. Such soils are, however, not without their uses, and fortunately are excellently adapted to the dairy. The soils most to be preferred are sandstone and limestone lands, of a free, dry, porous character, upon which the finer grasses flourish. The soils which are derived from rocks called carboniferous, which accompany coal deposits, or are found in the regions in which coal is mined, are those upon which sheep have been bred with the most success. The original home of the Leicester sheep, as well as that of the famous Shropshires, is on the red sandstone; the Lincoln is raised on the alluvial soils based on limestone; the Cotswold has had its home for centuries on the limestone Cotswold hills; the Southdown, Hampshiredown, and Oxforddowns, are native to the chalk hills and downs of southern England; the Scotch Cheriot and the hardy black-faced Scotch sheep thrive on sancistone hills and mountains of trap rocks which rise amongst them; the fine wools of Yorkshire are produced on magnesian limestone soils; and to come to our own soils, we find the American Merino reaching perfection on the limestone hills of Vermont, beneath which fine marbles are quarried. Unfortunately this is the only instance we possess of luaving given a local Labitation to a race of sheep in America; but how soon we shall have prodused or acclimated several breeds of sheep, which will take their peculiarities from the locality in which they are bred and raised, is only a question of time. Peat or marsh lands are unfavorable for sheep farms. Salt marshes near the coast, lowever, may ba excepted from this general condemnation, as the saline herbage acts as a specific against some of the parasitic diseases-the liver-rot mainly-to which sheep are subject upon marshy pastures. The Romney-marsh sheep of England are bred successfully upon the alluvial soils of reclaimed marshes, and produce good wool and a heavy carcass. The gigantic Liucoln, the largest sheep bred, originated and thrives in perfection upon drained alluvial soils.

Toc dry, friable nature and porous character of the soil has as 
much to do with the health and growth of sheep as the geological character of the rocks upon which it is based, or from which it has been derived. The census returns of England show that the highest percentage of sheep to the 100 acres, is found precisely where the soil is naturally drained and dry, and the lowest, where clay abounds, and damp, cold soils with rank, coarse herbage are general. In our own country, although the time has been far too short as yet for this condition to operate largely, we find the same fact curionsly developed, and Ohio and western Pennsylvania, with their extensive coal bearing formations underlying dry rolling fields, possess more sheep than any other district, while New York, Illinois, Indiana, and Michigan, which cover an extensive deposit of limestones and sandstones, with naturally dry soils, come next on the list. The vast stretch of prairies in the Mrississippi Valley, and of plains west of the Missouri to the Rocky Mountains, chiefly underlaid with limestones and sandstones, and especially remarkable for a dry, porous soil, which bears a rich carpet of the best sheep pastures in the world, have already proved themselves to be well adapted to the successful growth of flocks bearing fine and medium wools. The rich alluvial valleys of the eastern rivers where naturally or artificially drained, have been found to be fitted for the production of large bodied sheep bearing the lustrous combing wools. All these localities with the bills and valleys of the Middle States will in course of time have their flocks suitable in character to the circumstances in which they are kept. But it will only be in consequence of persistence in careful breeding and culture, that the final type for each locality will be reached; for while the effects of soil and locality are unavoidable and imperative, the shepherd must be able to discover these effects and aid in giving them their due development if early success is to be secured. But in whatever locality it may be, if the soil is not naturally drained, profitable sheep farms may be sought in vain. The profit from sheep raising as a special business will not permit of high-priced lands. Where sheep are kept only as a branch of general farming, it may pay to drain the soil artificially ; but without drainage, natural or artificial, sheep cannot thrive. The sheep must have a dry foot or disease follows.

The character of the herbage depends upon that of the soil, and the character of the sheep is governed by that of the pasture. It is a very casual observer who thinks that all kinds of grass are the same, and are equally proper for sheep. The sheep itself knows better thau this, and every shepherd has learned that his sheep will seek particular spots in preference to othcrs ia the 
same field. It has been well said that " the dead earth and the living animal are but links of the same chain of natural existences, the plant being the connecting bond by which they are tied together." The flesh and wool of the sheep, therefore, are but products from the soil, and contain nothing but what has existed in the plants which the sheep have consumed. When wool is clean and dry, 100 pounds of it contain 17 pounds of nitrogen, and 5 pounds of sulphur. When the pasture is sufficiently nutritious and the sheep is in good health, a quantity of soapy, gressy matter, called yolk, adheres to the fleece. When this is aburdant it is a proof that the food of the sheep is healthful and sufficient. When it is deficient, and the wool is harsh and dry to the touch, it is a sign that the sheep's health is suffering from defective nutriment. This yolk contains a large proportion of potash. To be properly nutritious, the food must contain this needed sulphur and potash, along with nitrogen and other necessary matter's. A fair test of the requisite quality of the food of the sheep may be taken from the composition of the flesh and blood of the animal, for there is nothing in the flesh, skin, bones, or wool that does not exist in the blood. The following are the inorganic or mineral materials contained in the ash of the blood and flesh of an animal:

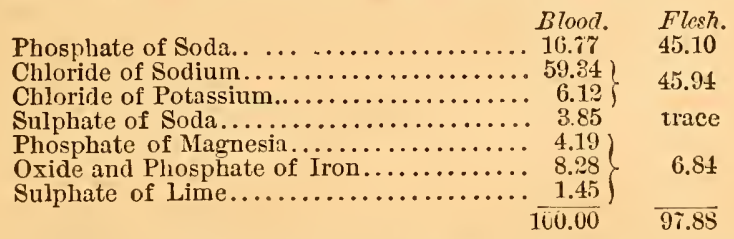

The bones of the sheep contain from 60 to 70 per cent of phos phate and carbonate of lime, with a little magnesia. The excrement, both solid and liquid, of the sheep contain a large variety of mineral elements, which are also necessary to the healthful animal economy. The urine contains two per cent of mineral matter, and the dung $13 \frac{1}{2}$ per cent, the composition of which is as follows: ASI OF URINE.

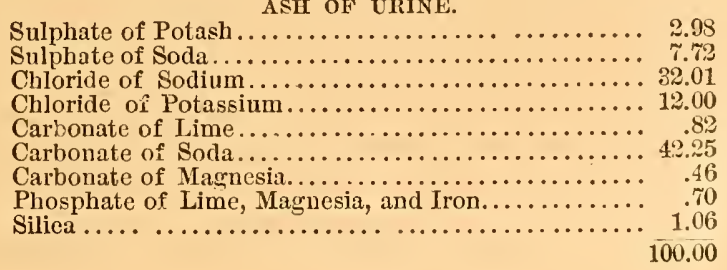


ASH OF DUTG.

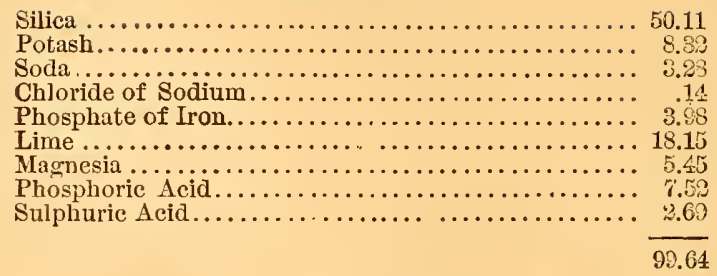

When it is seen how much earthy matter is needed to build up a healthy organism, and supply the waste of the sheep, it is evident that the food must be of a character consistent with these demands, and if by reason of deficiency in the soil, these matters are not supplied, the animal suffers, or is not fully developed. The grasses or other herbage upon which the sheep subsist, must therefore be such as will supply the peculiar needs of the animal, or they must be supplemented by additional food. When sheep feed upon grasses deficient in the required earthy matters, they become weak in constitution, and predisposal to disease. To prevent disease and keep the flock in health, the pasture must bo supplcmented by other feed which will supply the deficiency, and thus the cost of maintaining the flock is increased. A pasture that will supply all the necessary nutriment must contain those varictics of grasses that have been found by experience most suitable for sheep. Of the common grasses there are several varieties which liave a high reputation for this purpose. The best of these are of a low growth and ereeping babit, with fine, short herbage. The grasses knowu as Phleum pratense, (Timothy); Arrhonatherum avenaceum, (Tull Oat Grass); Poa annua, (Annual Spear Grass); Poa pratens.s, (Kentucky Blue Grass); Festuca oxina, (Sheep's Fescue); Poz serotina, (False Red-Tep); Agrostis vulguris, (Red-Top); Dactylis glomerata, (Orchard Grass,) when closely pastured; Alop:curus pratensis, (Mexdow Foxtail,) with Trifulium repens, (Whits Clover); or Plantago lanceolata, (the Narrow-leaved Plantain or Rib Grass,) and some other common plants, form a dcsirable herbage for sheep. The Buffalo Grass and the species of Bouteloux, conmonly called mesquit grasses of the west, with the large variety of leguminous wild plants, make up a pasture that cannot be excelled. The occasional dressing of pastures with bonc-dust, salt, and sulphate of lime, is of great service, and furnishes a supply of those mineral matters which are indispensable.

The value of the different pasture grasses are shown by the fol- 
lowing table of analyses made by Professor Way. These are of the green, fresh plants as taken from the ficld when in full growth.

COMPOSITION OF NATURAL GRASSES, (100 PARTS,) TAKEN FRESH FROM THE FIELD.

\begin{tabular}{|c|c|c|c|c|c|c|}
\hline NAMES OF GRASS. & 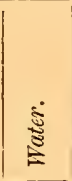 & 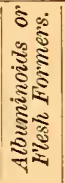 & 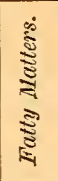 & 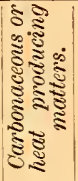 & 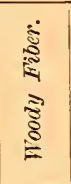 & 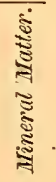 \\
\hline $\begin{array}{l}\text { Sweet-Scented Vernal, } \\
\text { (Anthoxanthum odoratum). }\end{array}$ & 80.35 & 2.05 & .67 & 8.54 & 7.15 & 1.21 \\
\hline $\begin{array}{l}\text { Meadow Fostail, } \\
\text { (Alopecurus pratensis)... }\end{array}$ & 80.20 & 2.44 & .52 & 8.59 & 6.76 & 1.55 \\
\hline $\begin{array}{l}\text { Tail Oat Grass, } \\
\text { (Arrhenatherum avenaceum). }\end{array}$ & 72.65 & 3.51 & .87 & 11.21 & 9.37 & 2.36 \\
\hline $\begin{array}{l}\text { Yellow Oat Grass, } \\
\text { (Avena flavescens).......... }\end{array}$ & 60.40 & 2.93 & 1.01 & 18.66 & 14.22 & 2.62 \\
\hline $\begin{array}{l}\text { Quaking Grass, } \\
\quad(\text { Briza media }) . . . \ldots \ldots \\
\text { Orchard Grass, }\end{array}$ & 51.85 & 2.92 & 1.45 & 22.60 & 17.00 & 4.17 \\
\hline $\begin{array}{l}\text { (Dactylis glomerata).... . } \\
\text { Hard Fescue, }\end{array}$ & 70.00 & 4.06 & .94 & 13.30 & 10.11 & 1.59 \\
\hline $\begin{array}{l}\text { (Festuca duriuscula)..... } \\
\text { Timothy. }\end{array}$ & 69.33 & 3.70 & 1.02 & 12.46 & 11.83 & 1.66 \\
\hline $\begin{array}{l}\text { (Phleum pratense)........ } \\
\text { Blue Grass, }\end{array}$ & 57.21 & 4.86 & 1.50 & 22.85 & 11.32 & 2.26 \\
\hline $\begin{array}{l}\text { (Poa pratensis }) \ldots \ldots \ldots \ldots \ldots \ldots \ldots \ldots \\
\text { Wbite Clover, }\end{array}$ & 61.14 & 3.41 & .86 & 14.15 & 12.49 & 1.95 \\
\hline 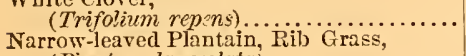 & 79.71 & 3.80 & .89 & 8.14 & 5.38 & 2.08 \\
\hline & 84.78 & 2.18 & .53 & 6.03 & 5.10 & 1.32 \\
\hline
\end{tabular}

Several of these grasses-the oat grasses, quaking grass, orchar 1 grass, timothy, and blue grass, for instance-are seen to be of high nutritive value, but yet some of the other grasses and plants found in good pastures are not to be despised on account of their seemingly defective character as shown by these analyses. Some of the less nutritious kinds are greedily eaten by shsep, and in furnishing a change of diet, as well as by reason of their aromatic properties, help to stimulate the appetite and preserve the health.

Besides the grasses and other plants mentioned, there are several having an aromatic or astringent character, which are purposely introduced into pastures for their medicinal effect upon the sheen. Parsley, Yarrow, and Wormmood are the plants chiefly so used. Parsley, (Carum Petroselinum, or Petroselinum sativum, of the older authors), is a biennial plant well known as a garden herb. It is greedily eaten by sheep, and acts upon the liver and kidneys, or is so supposeil to act; for this reason it has been considered and recommended by shepherds as a preventive of those 
diseases known as "rot," and red water. Hares and rabbits, which are also subject to the rot, and the presence of the accompanying parasite, the "liver fluke," will travel long distances in quest of this lerb, and ground upon which it abounds will very soon be eaten bare by them. For these reasons it is usual in England to sow one pound of seed per acre in permanent pastures where it reproduces itself from seed. It is a biennial plant seeding the second year of its growth.

Yarrow, (Achillea Millefolium), a plant of the order to which chamomile belongs, is a perennial bitter astringent herb naturalized in this country from Europe. Sheep are greedily fond of it, and it is not to be doubted that this instinctive desire is prompted by a natural need for it, not so much as a food, but as a medicine and a tonic. It is usually sown in out of the way places on the border's of pastures or lanes to which sheep have access, and where they can go when instinctively desirous of the plant without being driven, and so that it may not become troublesome as a weed by unduly spreading in the pasture. It thrives best on sandy banks or the hilly borders of woods upon sandy soil. The Ox Eye Daisy, (Chrysanthemum Leucanthemum), a plant of the same botanical order with the Yarrow, is also readily cropped by sheep, the blossoms being especially attractive to lambs. Another related plant, the weli known Mugwort, (Artemisia zulgaris), sometimes, but improperly, called worm wood, also naturalized here from Europe, is greedily eaten by sheep. It is also bitter and aromatic and tonic rather than nutritive. But these aromatic plants must not be supposed to be worthless as food, for the analysis of yarrow shows it to be possessed of nutritive qualities; 100 parts of the dry herb contain, according to Professor Way, as follows :

ANALYSIS OF YARROW.

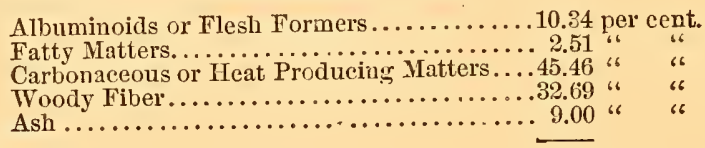

$\overline{100.00}$ " "6

Amongst other common plants readily eaten by sheep is goosefoot, or "Lamb's-quarters," (Chenopodium album), which grows plentifully all over our states and territories, being one of the most common weeds upon newly broken prairies west of the Mississippi, and which belongs to the same botanical order of plants as the beet and the mangel wurtzel. In addition there are several varieties of sea weed and other maritime plants which grow upon 
the shores that are useful for the subsisterce of sheep. These plants are rich in the mineral constituents of common salt, in starch and albumen, and in some localities, flocks of sheep upon the sea coasts and islands exist wholly upon this adrentitious pasturage. A notable case is stated in a recent publication, of a large flock of several hundred sheep which, for years, has subsisted and thrived wholly upon sea weed and wild herbage on an island off the coast of Maine, and there are many others in which farmers adjacent to the sea coast in that state and other parts of New England, subsist their sheep chiefly during the winter upon the sea weed which is cast upon the shores. These cases, however, are only valuable as showing how these really hardy and easily acclimated animals may be made to thrive and yield their valuable products of food and clothing, under the poorest conditions as surely, if not with equal profit, as under the most farorable circumstances.

The value of the herbage which covers the wide plains of the west cannot be predicated as yet from any chemical analysis or scientific examinations. In the light of practical experience we do not need these useful aids and helps. The fact that the grasses which cover those plains have supported and fattened countless millions of buffalo and antelope, and the experience already gained in keeping sheep on the plains, are amply sufficient to attest the nutritive value of thosa grasses. The Bufinlo-grass, (Buchloë dlctyloidss), is one of the most nutritious of all grasses. Its creeping root stems are always green and of great sweetness. It is low in its habit as suits a pasture for sheep, and furnishes good feeding the year roun 1 . Stock that have fod upon it without any help from $o^{\text {ther }}$ feal have been found in spring fat and in condition for the butcher. Meat produced upon this pasture has a delicate flavor, is tender, and has solid fat. Milk from cows fed upon it bears a cream of the richest character and the highest color. It prefers dry, light soils, which are the very best soils for sheep pastures, and it forces its roots to a depth, or several feet beneath the surface, where it finds moisture even upon the dry plains where the annual rain-fall is scarcely equal to 10 inches. One of the several kinds called "Bunch-grass," (Festuen scabrella), is another valuable grass common in these regions. It is exceedingly nutritive and cures on the stalk, thus affording winter pasture. Other species of Festuca are common, "Sheep's-fessue" already noted, being abunclant. For hay for winter use there are many rarieties of highly nutritious grass. Indian or Wood-grass, (Sorghum nutens), is four to five feet in hight, and is full of a rich, sweet juice, which is very palatable and nutritious. There are several other grasses of almost 
equal value which enable the flock-master to provide abundant supplies of hay to carry his stock over those short periods when pasturing is prevented by snow storms. The variety of native grasses suitable for sheep pastures is thus seen to be ample, and no country in the world is better provided, while fer countries are so well supplied with them, as are the United States and territories over the whole length and breadth of their vast surface.

The stocking of the pasture must be closely looked to. Overstocking causes scarcity of pasture, and a deficient supply of nutriment. It also causes the sheep to take up nuch sand and earth into their stomachs with their food, which gives them an unthrifty appearance, and sometimes incluces disease and death. Sheep pastured on overstocked fields may be recognized by the worn condition of their teeth, and cases have occurred in which this test has indicated a difference of two years in their age. Four-yearold sheep have exhibited the worn mouths of six-year-olds. Understocking is an error on the other side. Uniess the pasture is closely cropped, the herbag 3 becomes hard, unpalatable, and indigestible, and the sheep do not thrive upon it. It is a well proved adage that " 24 hours' grass is best for a sheep, and 8 days' grass for an ox." This indicates that the close bite of a sheep should be accommodated by a very close herbage. The tender growth of a thick, short pasture is precisely what is wanted, and if the flock is not numerous enough to keep it short, the field should be divided into plots, and those not cropped closely should be pastured down by cattle or left to be mowed. For the betier stocking of the pastures it would be well, if practicable, to divicie the flock, sorting lambs and yearlings from wethers and aged ewes, and putting the former upon the best and tenderest pasture. This is a point of great importance in the management of a flock, and should be dcn? whenever the welfare of the younger or less vigorous sheep requires it. Where the range is extensive, and ample pasture is provided, any supplementary provision further than an occasional feed of corn, oats, bran, or nil-meal, is unnecessary. These additional foods should be supplied whenever the condition of the pasture requires it, and constant watchfulness should be exercised to discover the moment when the pastures fail. It is not that the growth of the sheep is arrested then, but the quality of the wool suffers from the moment that the condition of the sheep begins to deteriorate. The secretion which supplies the matter of which the wool is formed, is then lessened, and the fiber is weakened at that particular spot. If the adverse condition continues for some aays $r$ r weeks, the weakened fiber forms what is called a "break" 
in the wool. When the wool comes to be carded or comber, the tension overcomes the resistance of the fiber which breaks at this weak spot, and the broken fibers go to waste. "Break" in the wool greatly rednces its value, and as it is wholly caused by deficient nourishment or excessive exposure, it is a loss readily avoided by proper care. The extra supply of food must be judicionsly proportioned to the needs of the sheep, as over supply will result in an equal disadvantage by unduly stimulating the condition and lating to a reaction when the stimulus is withdrawn. Evenness i: the fleece, although it may be of poor quality, is better than unevezuess, for even if there be only one short break in a fiber otherwise of general excellence, the whole is reduced by this single break to one-half its proper length. One neglect of a few clays duration is really worse for the fleece than comparatively poor fasding, if it is only adlered to with regularity. Poor feeding and general care, result in a gradually diminished growth and weight of fleece, but yet may not affect the health, while irregular fceding affects the health and ruins the flock completely.

The supply of water is of the greatest importance. A living spring or a clear flowing stream with dry gravelly banks is the best source of supply. Wells are better than ponds or pools. Stagnant water is exceedingly objectionable. Hard water is better than soft, and water containing much saline or otler mineral matter, is a valuable help to the pasture as furnishing many necessary substances. When water is exposed to the atmosphere it deposits the greater part of any mineral matter it may contain, and becomes soft. It is then rendered of less value for stock purposas. There are some waters that contain potash, lime, soda, magnesia, iron, and sulphur in combination with oxygen, carbonic acid, and chlorine to the amount of 15 to 20 grains per gallon, and such water is a source of nourishment to sheep. Pond or marsh water is highly injurious, as is also running water in which aquatic plants are found. It is from drinking such water, as much as from pasturing on undrained soils, that the liver flukes, parasites always accompanying the disease termed the rot, gain aecess to the stomac's and intestines of the sheep. A deficiency in the necessary mineral matiers may be obviated by giving the sheep stated supplies of a mixture of common salt, sulphur, saltpeter, sulphate of m gnesia, (epsom salts), phosphate of lime, boue-dust, or fine bone, witi a small portion of sulphate of iron, (copperas). A small teaspoonful of this mixture given once a weck to each sheep will help greatly to a healthful condition, and resist the tendency to disease caused by iuferior pasture or soft water. The study of the plants 
suitable for a pasture, the charactar of soils, and the water, should be part of the education of every shepherd.

The exposure of the pasture is another important consideration. Long continued cold wiuds are productive of great discomfort and sickness, and often cause serious loss amongst the flock. On the sea coast, exposure to the moist sea breezes injures the quality of the wool, and renders it harsl and deficient in quantity. Of two adjoining flocks upon opposite sides of a hill facing north and south, the sheep exposed to the north winds will be several pounds less in weight, and their wool will be whiter, harsher, more uneven, and less healthy looking, than those of the flock upon the south side. This experience is very common. The lambs will also be less thrifty. Of this, many notable cases occur every season where sheep and lambs are pastured and fed for the markets. The small size of sheep raised upon mountain pastures is a case in point.

Where the pasture is circumscribed or poor, it may be supplemented by sowed green crops to be fed on the ground, or cut and fed in racks upon the pasture, or cut and carried to yards and fed there at night in racks. Of these, rye, clover, mustard, rape, tares, and oats and peas mixed, furnish an abundant supply. Rye is sown early in the fall for winter and early spring feeding. For this purpose it should be sown thickly, three bushels per acre being a fair allowance upon fairly good soil, early in August up to the middle of September. The sheep may be turned upon the crop in December, and at intervals as may be found proper, up to April, when it may be plowed down for a spring crop. Upon light lands, where the winters admit of it, as in some of the middle and southern states, this may be made an excellent means of improving the soil ; some additional feed, as bran, pea-meal, corn, or cotton-seed-meal, (freed from the hull which is indigestible and injurious), will much assist in this improvement of the soil as wcll as in bettering the condition of the sheep.

After rye, clover sown the "previous spring, but not pastured, will come in turn. This will furnish pasture through the summer if kept well stocked down, and a choice pcrtion should be fenced off for the lambs. By changing from one part of the field to another, as one portion is eaten down, the new grow th will be tender and fresh. After June a part of the clover will run to seed, and when the field is plowed in August or September, the seed will help to re-sow the ground, which may then be sown to wheat or rye. This makes an excellent preparation for these crops on lands of a somewhat light character.

White Mustard, (Sinapis alba), may be sown in May or Jane for 
feeding in August and until rye is ready. It is difficult to eradicate from the soil when it once becomes a weed and has been allowed to take possession. But a careful farmer will have no trouble if he manages the crop so as to prevent the seed being shed. When sown in August, mustard affords valuable feed during the winter, and although the ground may be covered with several inches of snow, the sheep will scrape off the covering and get at it. In this way a plot of mustard may furnish a green bite all the winter where the snow fall is light. In the spring it should be plowed down early and not allowed to blossom, and a spring crop taken so that the ground is plowed again in the fall. Treated thus, the plant cannot ripen and shed its seeds and become troublesome. Mustard has a pungent flavor, and contains a large proportion of sulphur; it is on this account a healthful fodder for sheep, and is very much relished by them. It belongs to the botanical order of Cruciferce, to which the cabbage, rape, and turnip, belong: a family of plants rich in sulphur, lime, phosphoric acid, and other mineral matter demanded for the sustenance of sheep. Two pecks of mustard seed per acre are sown, and for a heavy crop cf fodder rich soil is required.

Rape, a variety of Brassica campestris, is a very hardy plant, and produces a heavy burden of fodder which is readily eaten by sheep. It is very similar in habit to mustard, and should be fed of in the fall and winter or early in spring. Two pecks of seed are required for an acre. For fall feed it should be sown in July or early in August. Both mustard and rape succeed very well in the northern, western, and middle states, and would thrive equally well in most of the sonthern states if sown somewhat later and fed off during the winter. These plants when sown late ripen their seed early in the second year.

Turnips are a very frequent fodder crop in those parts of England where sheep are largely raised, but the practice of allowing them to be fed off from the ground is fast becoming obsolete, and the plan of taking up the crop and cutting and feeding the roots in troughs upon the fields or in yards is substituted in its place. But the English climate is excessively moist, and rain falls $t w o$ days out of three on the average. It is for this reason, and the injurious effect upon the sheep of the exposure upon muddy ficlds to cold wintry rains, that the practice is falling into disuse. In parts of the United States we have every advantage for making use of so cheap and convenient a plan of feeding sheep upon these root crops that are not injured by moderate frosts. Where the fall of snow is light and soon melts away, as iz Virginia, Ten- 
nessee, Missouri, and the states south of these, this system of winter feeding has been practiced for many years by the better class of farmers with success. Mr. C. W. Howard, of Georgia, a highly trustworthy gentleman, a farmer and a frequent writer upon agricultural topies, and who has given much attention to the culture of fodder crops, communicated some time ago to the Rural Carolinian the following directions and facts in regard to the culture of turnips for sheep feeding in the open field in the south: "Take a field, plow it deeply with a two-horse plow, subsoil if possible, harrow thoroughly and roll. Lay off the land in rows two-and-a-half feet apart, with a wide and deep furrow. If there be not stable manure, apply three to five liundred pounds of Ammoniated Saperphosphate of Lime; the addition of some potash would be nseful; throw the dirt back with two furrows, and level the ridge with a board. Use the Weathersfield drill, or some other, costing about nine dollars. Sow with it two ponnds of seed to the acre. The Weathersfield drill opens the furrow, drops the seed, covers, and then rolls it by one and the same process. When the plants have formed the third leaf, which is rough, thin them out with the hoe and hand to about eight iuches apart, give them a good plowing with a narrow scooter, and the cultivation is completel. The cultivation of an acre of turnips will cost as follows:

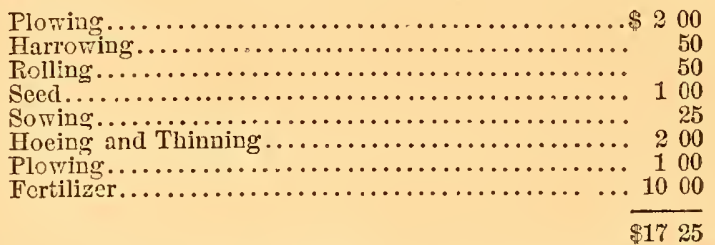

"Tinc result will vary according to the soil, the season, and the cultivation. Five hundred bushels is a poor crop. One thousand bushels is a good crop. Fifteen hundred bushels is an extraordinary crop. This number of bushels, $(1,550)$, was made last year by Dr. Lavender, of Pike County, Ga. That gentleman took the premium at the last Georgia State Fair. His statements deserve implicit reliance. They were made under oath. His process of obtaining this remarkakle yield was as follows:

" "The soil was a sandy loam. Turned over a heavy clover sod in June with a Dixie plow; harrowed twice with a Nishwitz harrow on the 21st of August; ran twice in the furrow, deposited in the bottom of the furrow 3,600 pounds of stable manure, com- 
pounded wit's 100 pounds of the Stono Phosphate; let it stand six weeks, then applied as above stated. Cultivated with a cultivator by horse power-no hoeing; left about six plants to the yard; had only one rain on them after plowing, and that a light shower. Sowed two pounds of seed to the acre; planted ly liand throngh a guano bugle, and then rolled.'

"What cloes it cost to raise a bushel of iurnips? If we make 500 bnshels to the acre, the cost will be about four cents per bushel; if 1,000 , the cost will be about two cents per bushel. This does not include gathering, storing, and marketing, becanse the use that it is proposad to make of the turnips involves none of these expenses.

"What use, then, is to be made of the crop? Feed them off on the land with sheep, the process ordinarily known as folding. For this purpose a purtable fence is necassary. (These are described hereafter).

"The fold should not include more turnips than the sheep will eat off clean in twenty-four, or, at the utmost, forty-eight hours. If it be larger, the turnips will be wasted. Sheep not accustomed to turnips, may at first refuse to eat them. But let them get quite hungry, and then sprinkle some salt upon the turnips. After they once get a taste of them the only difficulty will be to get enough of them. One thousand sheep will consume an acre of turnips in twenty-four hours; one hundred in ten days and nights. With these data, the size of the pen can be graduated. One-tenth of an acre should be the size of the fold or pen per one hundred sheep. One acre of turnips will support one hundred sheep for ten deys, three acres one month, nine acres three months. This is not theory, but the result of actual experiment. The enemy of the turnip is the fly. There are two means of preventing the ravages of this troublesome insect. One is very thick seeding, the other is dusting the young plants as soon as they are above ground, with unleached ashes, or air-slacked lime. After they reach the rough leaf there is no further danger from this scurce. The thinning should talse place as soon as the rough leaf is formed. If this thinning is delayed, the crop will be seriously injured."

For the northern states the culture of the turnip, ruta-baga, sugar beet, mangel, and cabbage, is as follows: the preparation of the ground being alike for all, the time of sowing alone being differcnt. Sugar beets and mangels are sown from April to Junc, the carly sown crop being invariably the heaviest. Ruta-bagas are sown June 15th to July 1st. Cabbage for late crop is sown in seed beds in June to be transplanted in July. Yellow Abcrdecn 
turnips are sown in July, and white turnips in July or August. The soil is prepared by previous plowing and menuring, and made fine and mellow; the seed is sown in drills 30 inches apart, and thinned out to 12 to 18 inches apart in the rows. A crop of roots grown 18 inches apart, each root weighing 6 lbs., will yield 34 tons, or 1,100 bushels to the acre. For beets or mangels, $4 \mathrm{lbs}$. of seed per acre is required if sown with a drill; of ruta-bagas and turnips 2 lbs. of seed is sown. The best beet is Lane's Improved Sugar Beet; the best mangel, the Long Red; the best ruta-baga, the

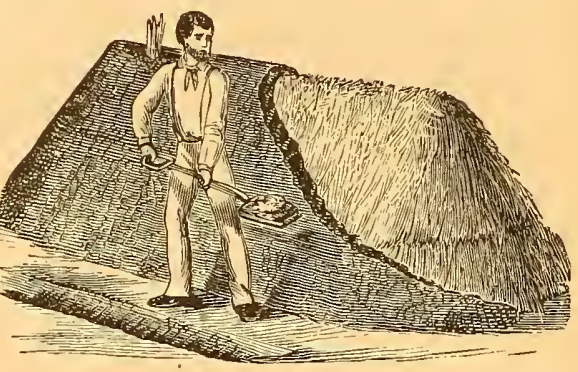

Fig. 1.-PIT For ROOTS. Purple-top Swede; the Aberdeen turnip is better than the white, and nearly as good as the ruta-baga; the white turnip has the ad-

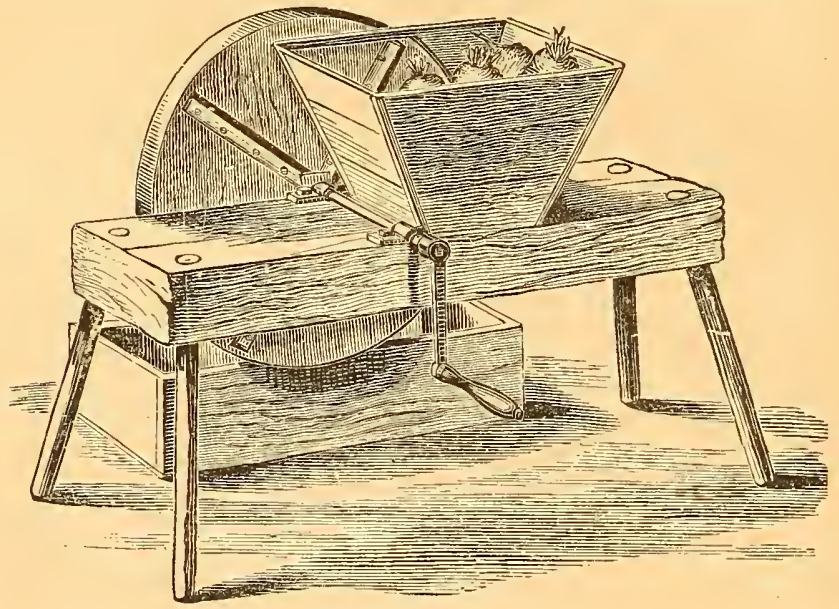

Fig. 2.-ROOT-CUTTER.

vantage that it can be sown late and follow an oat, barley, or rye crop. The harresting is done by eutting off the tops with a sharp 
hoe and plowing a furrow on one side of the row of roots, when they may be pulled from the ground with the hoe or by ??rawing a dull harrow over the field. The crop is saved by keeping the rocts in cellars or pits. Pits are simply conical heaps covered with straw and earth sufficient to keep out the frost, a font of straw and a few inches of earth being sufficient protection, (see fig. 1). Roots should be sliced or pulpel when fed, as they are more readily enten, and there is no danger of the sheep choking by swallowing too large pieces. A simple cutting machine is shown in fig. 2. It consists of a wooden wheel furnished with long knives set at an angle similar to the iross in a plane, which cut the roots into thin slices. Fig. 3 is a pulper in which, insteacl of knives, there are 144 sharp chisel

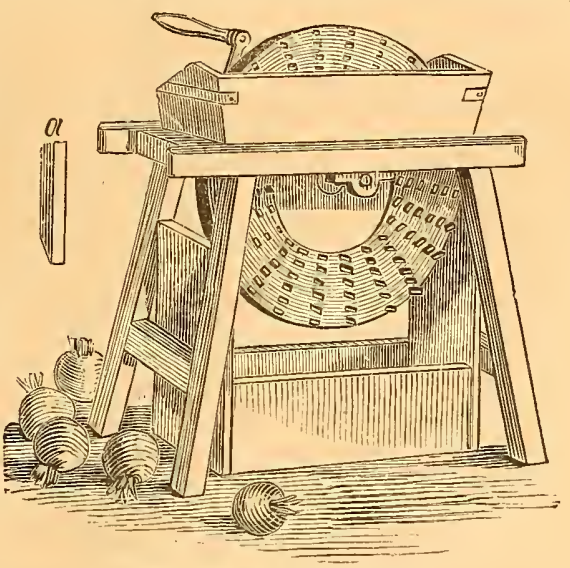

Fig. 3.-ROOT PULPER. points made of quarter-inch steel, (see $a$ ), loy which the roots are torn into shreds and reduced to pulp.

When crops are fed upon the ground, a special arrangement of temporary fences is used. These are constructed of hurdles, of which there are several kinds. One of the most readily constructed hurdles is made of light stakes pointed at the ends and fastened together with bars of split or sawed saplings or laths, such as are shown at fig. 4. These are made in panels about nine fect long, with stakes five and a half feet high. A line of these hurdles is set across the field, enciosing a plot in which the sheep are confined, until the crop on the ground is consumed. The shepherd takes a light pointed iron bar with which lie makes holes in the ground to receive the pointed lower ends of the stakes, and drives them down firmly by striking the tops with a wooden mallet. $\Lambda$ s the crop is eaten, the line of hurdles is moved along the field until the whole is consumed. Huch economy in labor of sctting the hurdles may be exercised by laying out the plots in a certain manner. For instance, if a square field of ten aeres is to ine fed off, the 
plan shown in fig. 5 will be found very convenient. The distance across the field is 220 yards. This is the least length of hurdles that can be used. But if the field is divided off into strips across, the whole of the hurdles must be mored each time, and if the field

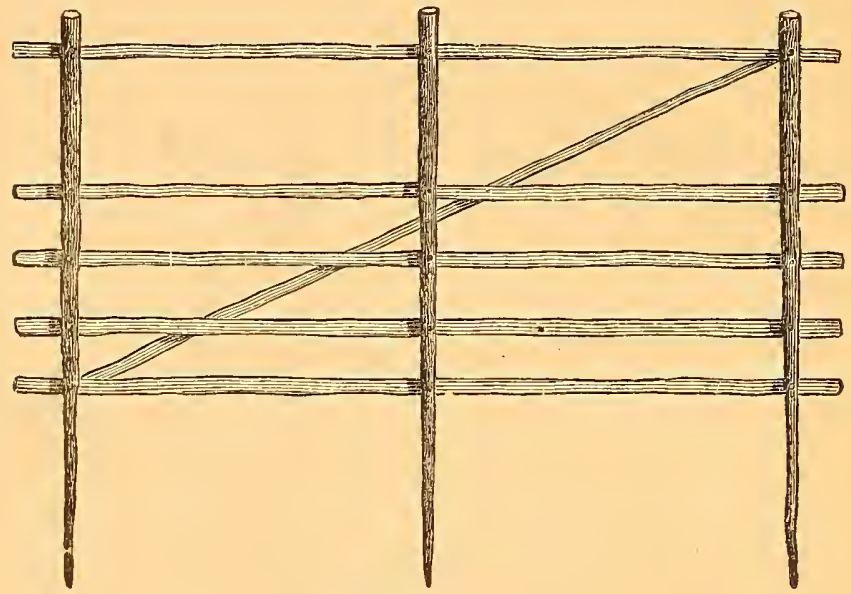

Fig. 4.-HURDLE.

is divided into eight strips, there will be seven removals of every hurdle, or the whole length of netting. In the plan here shown, only half this work is necessary, and a field may be divided into eight sections by moving half the hurdles seven times. For instance, plot 1 is fed by placing the liurdles from $a$ to $b$, and from $c$ to $d$. Plot number 2 is fed $b_{\vec{y}}$ moving the line from $c, d$ to $b, e$. The next setting of the hurdles is from $c$ to $f$, the next from $b$ to $g$, the next from $h$ to $i$, the next from $b$ to $k$, the next, and last, from $l$ to $m$. There will be eight settings of 110 yards cach, instead of seven of 220 yards each, which would be necessary should the field be fed off in the usual manner of strips across it.

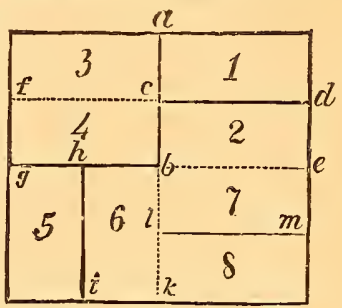

Fig. 5.-PLAN FOR SETTING HITRDLES.

In place of these liurdles, netting of cocon-nut fiber or hempen cord is often used. This is supported by stakes driven into the ground and hooks, (see fig. 6). Netting of this lind is made in 
England in length of 100 yards, and widths of 4 feet, at about $\$ 9$ the 100 yards. At this price it conld be imported with profit, and probably cheaper than it could be manufactured here. Another form of hurdles not quite so portable, but more easily moved and set is illustrated at fig. 7. They are 12 feet long, and are made of a stout pole borel with two series of holes 12 inches apart. Stakes six feet long are put into these holes, so that they project from them three feet on each side of the pole. One series of holes is bored in a direction at right angles to that of the other, and when the stakes are all pro. perly placed, they form a hurdle the end of which looks like the letter $\mathrm{X}$. The en gra.ving shows how these hurdles are made and the method of using them. A row is placed across the field. A strip of ten feet wide is set off upon which the sheep fecd. They eat up all the herbage upon this

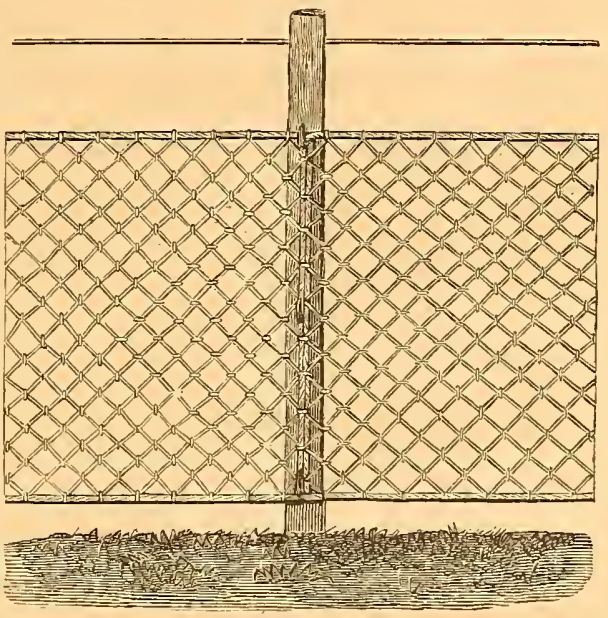

Fig. 6.-SHEEP NETTING. strip and that which they can reach by putting their heads through the hurdles. The hurdles are then turned over, exposing another strip of forage. When this is fed off the hurdles are again turned over, and so on. The chevaur-de-frise presented by the hurdles prevents any trespassing upon the other side of them, and by using two rows the sheep are kept in the narrow strip between them. Their droppings are therefore very evenly spread over the field, and it is rery richly fertilized by them. At night the shcep are taken off, and when the field has been fed over, they are brought back again to the starting point and commence once more to eat their way alung. When the crop is cut and fed to the sheep, a somewhat different arrargement is made. This may be made a valuable means of improving land. $\Lambda$ badly run-down ficld infested with weeds, may be eleared of rubish, fertilized, and 


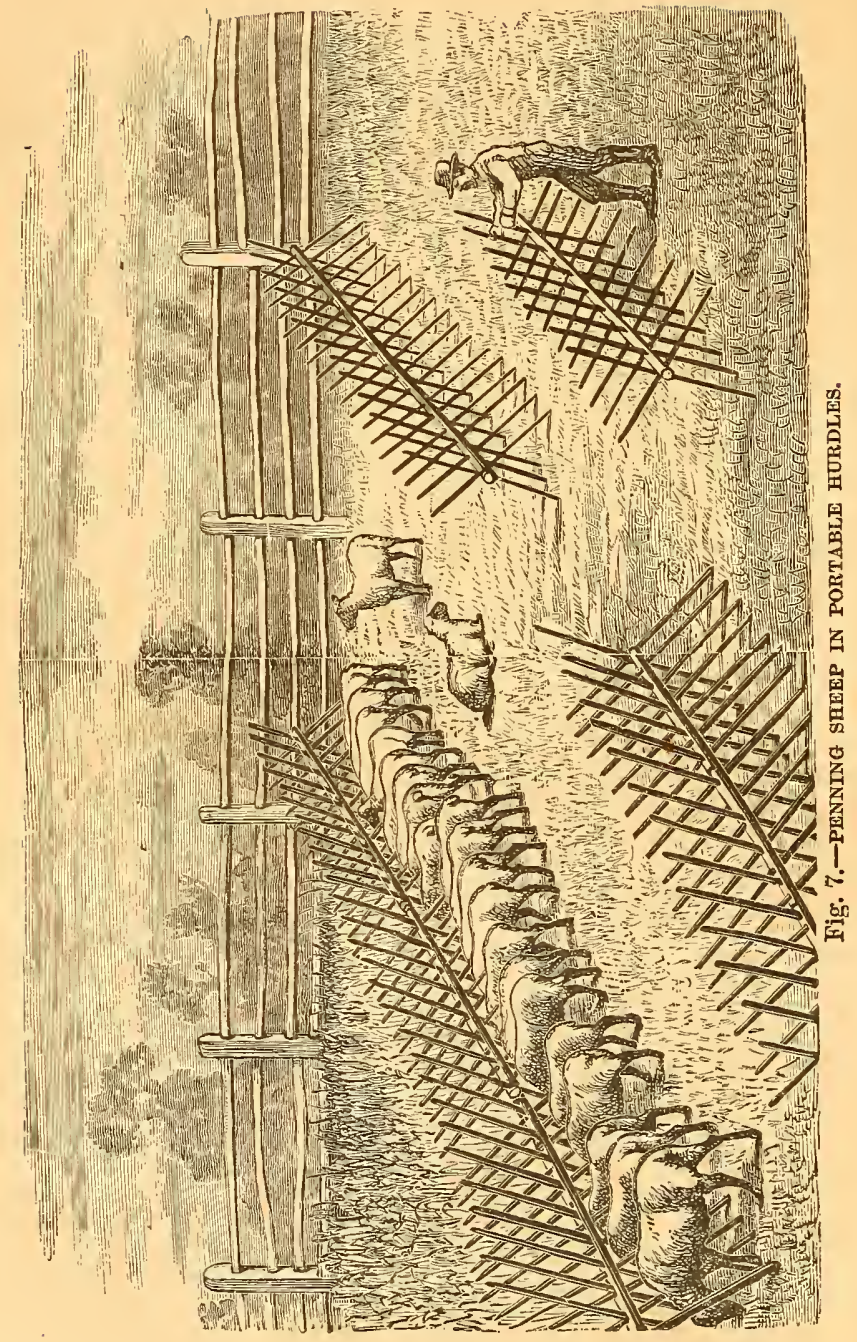


brought into grass or clover by judicious management in this way. Portions of such a field may be set off with hurdles as before described, a rough shed erected in which the sheep may be secured at night, and in which an ample supply of bedding or dry earth, or other absorbent is placed beneath them, and here the crop grown upon another part of the farm, ailed by purchased food, if such be available, is fed in portable trourhs or racks. A very convenient rack is the one shown in fig. 8 . This is extremely portable, and may be moved from one part of the field to another with great ease. Where sheep are permanently kept, and fixed arrangements are made for the flock, it is frequently found convenient to provide a permanent and safe shed, in a central position, in which they may be confined at night, and from which they can be turned into different fields or portions of the farm. A shed that has been found very convenient in use is shown at fig. 9. It is built at the center of four fields, and has doors opening into each of them, and is so arranged that it may be entirely closed from all but the one which may be in use at the time.

For the protection of the sheep at night, small paddocks may be fenced in around this shed, and safety from dogs secured by the use of dog guards. These consist of wires made to run above the fence or at right angles with the top of it, as shown at figures 10 and 11.

The separation of the flock into parts consisting of ewes and lambs, weaned lambs and weaklings, and rams and wethers, is very necessary. Ewes and nursing lambs should be provided with

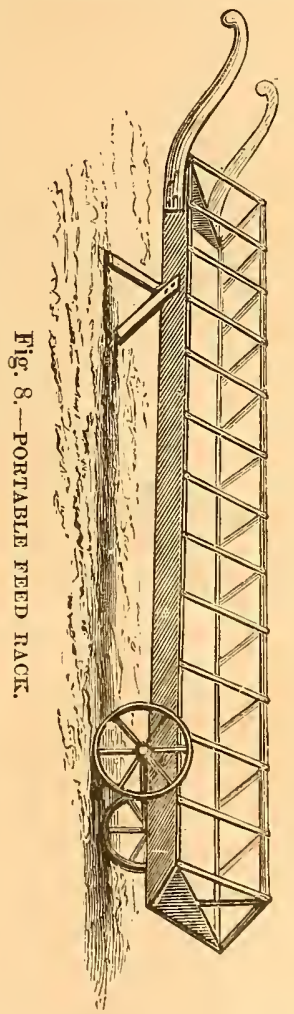
the best and tenderest pastures; the weaned lambs and reak sheep should have a place where they can be furuished with some extra feel without interference from stronger neighbors, and rams and wethers may do well enough on the conser herbage. A frequent change of pasture is very advantageous for the flock. Sheep naturally love change, and after they liave wandered over a 
field will become restless, and try to escape. The best method of keeping them contented and quiet, is to change their pasture as soon as they are observed to wander about restlessly. They are

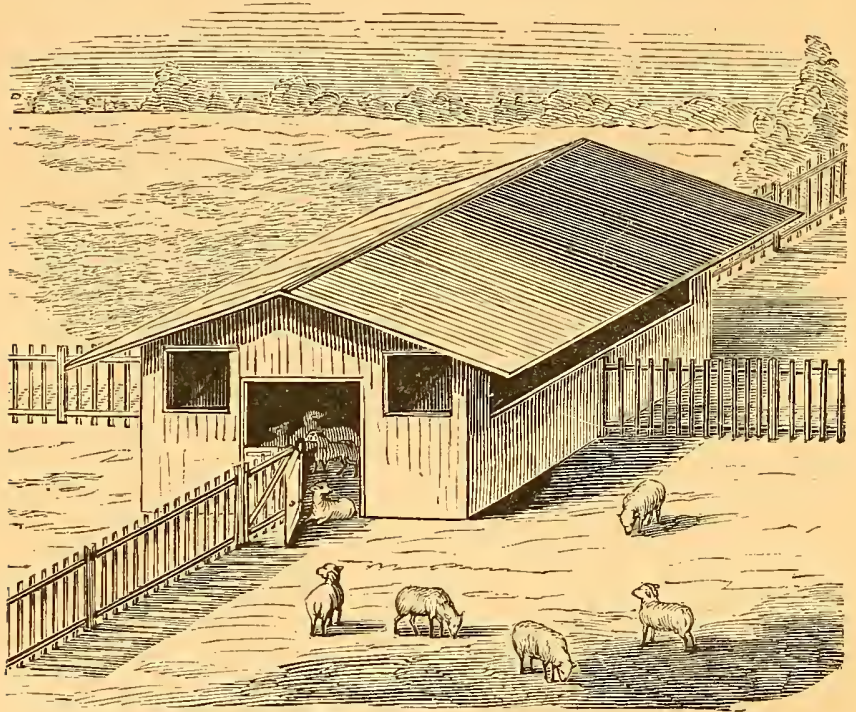

Fig. 9,-SHEEP SHED.

then losing flesh. To restrict sheep to one kind of fond for a period of more than thirty days, has been found to seriously impair their health. "Fresh fields and pastures new" are therefore necessary to their welfare, and their health cannot be maintained

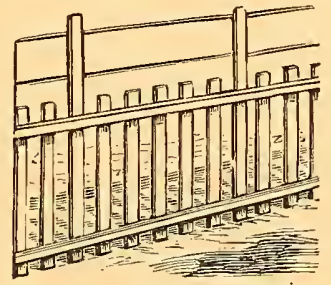

Fig. 10.-DOG GUARD.

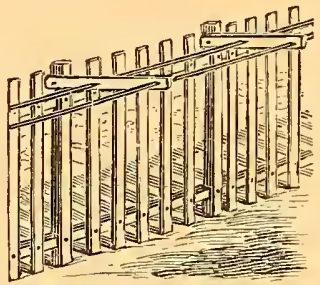

Fig. 11.-DOG GUARD.

unless this peculiarity is recognized and accommodated. It is better to divide fields into paddocks where small flocks are kept, 
and where the pastures are extensive, to reduce the size and in. crease the number of the fields. Where the pasture is an open, unfenced tract, the flock shonld be driven some distance to a new locality every month.

The attention of the shepherd during the summer season will be constantly exercised in seeing that every portion of the flock receives a proper share of the pasture, that the pastnre is not overstocked; that proper shelter is provided from midday heats; that failure in pasture is immediatcly remedied by a supply of fresh green fodder or extra food, such as wheat-bran, oil-cake-meal, or corn-meal; that pure water is supplied at least twice a day; that a certam portion of salt, or a mixture of salt and sulphur is provided and given regularly; that on the first symptom of indisposition, affected sheep are removed from the flock to some place where they may receive proper care and medicine; that the attacks of flies are warded off by proper preventives; that parasitic enemies are destroyed, and in short in caring in every possible way for the welfare of his charge, watching closcly for the most minute evidence of the first symptom of trouble that may occur, always remembering that "an ounce of prevention is worth a pound of cure." To this end he should study closely the habits of his sheep in health, make himself thoronghly acquainted with the symptoms of disease and the habits and methods of attacks of those living cnemies which trouble the flock, and be prepared by adequate and exact knowledge of the proper preventives and remedies, to apply them instantly, correctly, and effestivcly.

\section{CHAPTER III.}

\section{MANAGEMENT OF EITES AND LAMBS.}

In the managemsnt of sheep, how to prosure the most profit from the flock is the greatest consideration. It is not exactly how to increase the flock most rapidly, nor to produce the herviest carcasses or ficeces, but to produce such animals as will return the most money for the expenditure and labor involved. In some localities the sale of an early lamb will bring in more money than that of the mother with its fleece. Where there is a market for lambs, it is evidently the most profitable to keep such sheep, 
and to keep them in such a way as will produce the highest priced lambs. Where mutton is the most profitable, there a different management must be adopted, and frequeritly a different breed of sheep must be kept. Where wool only is the object, still another different course will be chosen. Whichever end is to be gained, the care of the breeding ewes and the lambs will be a subject of much solicitude. But what would be a proper course in one case would not be at all proper in another. A few general principles are involved in the management of ewes and lambs, which will first be explained, after which the special management proper to be adopted for each special case will be considered.

The period of gestation of the ewe is 150 to 153 days. Five months in round numbers may be taken as the period during which the erre carries a lamb. The coupling of the ewes and rams should be so timed, that the lambs may ho dropped at the mosi desirable season. It will be found a great convenience to mark the rams and erres, or such of them as may be selected to breed stock animals from. Where a small flock only is kept, or where special care is given to the improvement of the breed, erery sincep should be marked by a number, that the time of its coupling may be 110 ed, and the date of the expected birth of

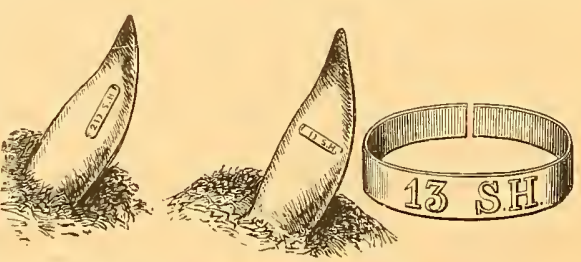

Fig. 1?.-METALLic EAR-MARKs.

the lamb be known. The best method of marking is hy means of metallic ear marks, (fig. 12), made by C. H. Dana, of West Lebanon, N. H., inserted in the ear in different ways, to distingruish the sexes easily. The method of keeping these records may be as follows: A book is provided which is ruled with six columns. At the head of these columns are witten the number of the ewe, that of the ram, the date oi service, the expected time of the lamb's appearance, the date when it is actually dropped, and any remarks worthy of note. The following diagram exhibits this clearly:

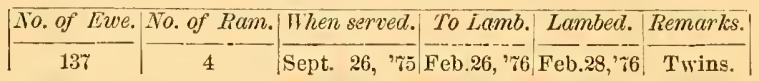

Under the head of remarks should be written anything that may be desirable to remember in regard to the character of the produce of the animals coupled. A ewe that produces a fine, large, active 
lamb, that is a good nurse, and that rears a profitable market lamb, or that rears twins successfully, is a valuable animal to retain in the flock so long as she remains productive. Such ewes have been kept until 10 or 12 , or even 16 years old, and to be able to identify a ewe of this kind is rery necessary when the greatest profit is the object sought, and more especially in those cases when the special business is to rear market lambs or increase the flock rapidly. No more than 30 ewes should be apportioned to one ram in any season, unless he be a full grown one and in vigorous health, and it would be well to observe the rules laid down in a succeeding chapter espacially deroted to breeding, for the management of the ram at this season. If the ram is equal to the work, 50 ewes may be given to him, but it is better to err on the safe side in this matter, as overwork simply means barren ewes and loss of lambs. At the breeding season the ram should be smeared upon the brisket every day with a mixture of raw linseed oil and red ocher, so that he will leave a mark upon each ewe that may be served. As the ewes are served they are to be drafted from the flock and placed in a field or yard by themselves. Two rams should not be kept together in a smail breeding flock, as quarreling and fighting are certain to result and great damage may occur. If two rams are necessary, each may be used on alternate days. Wethers are a nuisance in a flock of ewes at this season, disturbing them and keeping them and themselves from feeding. A plan followed with advantage where the flock consists of heary bodied sheep, and where the necessary attention can be given, is to keep the ram in a yard or padidock by limself, out of sight of the ewes, and to allow a wether to run with them. As each ewe comes in season, the wether singles her out and keeps company with ber. On the return of the flock from the pasture at night, the ewe or ewes in season are turned in to the r:im until they are serveci, when they may be removed at once, or left wit'. him until the morning. In the morning, if any ewes have come into heat during the night, they may be served before the flock is turned into the pasture. This is continue until it is known that all the ewes are in Iamb. By this method a ram may be made to serve double the number of ewes that he would if allowed indiscriminate access to them, and exhanst himself in useless and needless repeated exertions.

As soon as the ewes have been served, the time of each is entered in the record as previously described. They are carefully preserved from all worry by dogs and needless driving or handling. Peace and quietness at this season will tend to the proctuction of 
quiet and docile lambs. The shepkerd should make himself very familiar with them, and by giving salt or meal in the hand, or a small dish, reduce them to a condition of perfect docility. Any ewes that have either refused the ram or have failed to breed, should be dosed with two ounces of epsom salts and be stinted in their feed for a few days to reduce their condition. This will generally be effective in bringing them into season. Good fair condition is better than an excess of fat, but ewes in poor condition cannot be expected to produce other than poor, weak lambs; r.either will an excessively fat ewe produce a strong lamb. Some extra food will now be needed by the ewes, and should be given at first in small quantities. Bran, crushed malt, and crushed oats and corn mixed, are the best kinds of food. Oil-cake, either of cotton-seed or linseed, unless used with great caution, is not always a healthful food for ewes in lamb. Any food that actively affcets the bowels, either way, is to be avoided. Half a pint a day may be given of the first mentioned foods, and a change from one to another may be frequently made. So long as pasture is to be had, this allowance will be sufficient. When the winter fecding commences, the ration of grain should be gradually increased until, at the period when lambing time approaches, a pint daily is given. Cold watery food is highly dangerous at this time, and rocts should not be given in large quantities, nor at all unless pulped and mixed with cut hay and the grain. Turnips or other roots that have beez highly manured with superphosphate of lime has been said by several experienced English breeders to be productive of abortion. Water should be given in small and frequent quantities. It is best to have running water or water from a well always at hand for the ewes. If the ewes have not heretofore been kept apart from the rest of the flock, they should now be separated. The ganeral treatment of the ewes up to this time should be such as will keep them free from all excitcment, and in good, healthful condition. The record should now be consulted, and as the ewes near their time they should be removed into a part of the stables or sheep barn, where each one can have a small pen to hersalf. These pens should be made so that light can be shut out if desirect. Here they are permitted to drop their lambs in perfect quiet; by this means few ewes will disown their lambs, and no lambs will be lost by creeping into feed racks or out of the way places. The pens should not be larger than $5 \times 4$ feet. As soon as the lamb is dropped and the ewe has ommed and licked it, and the lamb has once sucked, all danger, except from gross carelessness, is passed. The ewe will be greatly helped by a drink of 
slightly warm, thin oat-meal gruel well salted. The lamb will be benefitted by a teaspoonful of castor oil, given in new milk, if the first evacuations do not pass away freely. These are apt to be very glutinous and sticky, and by adhering to the wool to ciose the bowel completely unless removel. Warm water should be used to soften and remove these accumulations. The anus and surrounding wool should then be smeared with pure castor oil. If the lamb is not sufficiently strong to reach the teats and suck, it should be assisted once or twice. Any locks of wool upon the ewe's udder, that may be in the way, should be clipped. If the lamb is scoured, a teaspoonful of a mixture of one pint of peppermint water and one sunce of prepared chalk should be given every three hours, until it is reliered. When the erve refuses to own the lamb, she may be confined between two small hurdles, as shown in fig. 13. Two light stakes are driven in the ground close together to confine

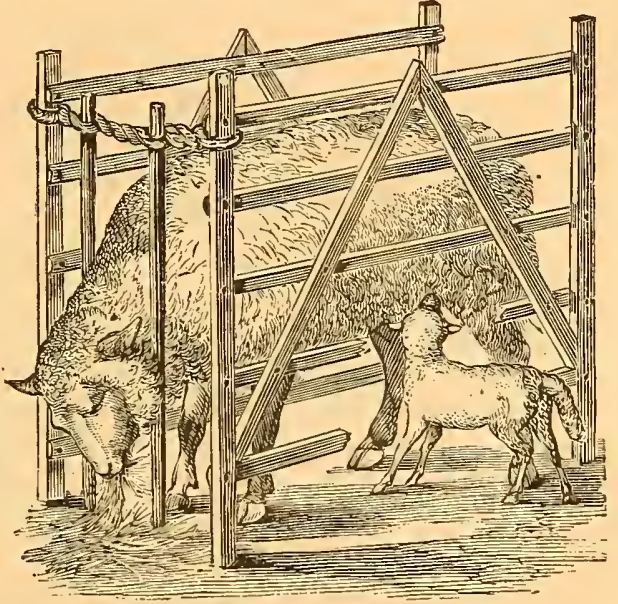

Fig. 13.-HURDLES FOR EWE. the ewe's hexd and keep her from butting the lamb. If she is disposed to lie down, as some obstinate ones will do, a light pole is passed through the hurdles resting upon the lower bar beneath her belly. Thus confined during the day, she is helpless, and if the lamb is lively, it will manage to get its supply of food. The ewe should be released at night. One day's confinement is often sufficient to bring an obstinate ewe to reason.

A twin lamb, or one deprived of its dam, that may need to be reared by hand, may easily be fed upon cows' milk. A frcsh cow's milk is the best fitted for this purpose. Ewe's milk is richer in solid matter than that of the cow, and the adcition of a teaspoouful of white refined sugar to the pint of cow's milk will make it more palatable to the lamb. $\Lambda$ t first not more than a 
quarter of a p.nt of milk should be given at once. The milk should be freshly drawn from the cow, and warmed up to 100 degrees before it is fed. A convenient method of feeding milk to a lamb is to use a small tin can with a long spout, such as is used for oil. An air-hole is punched in the cover or cork and a piece of sponge covered with a cloth is tied upon the end of the spout. The flow is thus made easy and equal, and the lamb sucks in a natural man. ner. The accompanying illustration, (fig. 14), shows the method. A very short time is sufficient to familiarize the lamb with this kind of foster mother. To encourage the flow of milk in the ewe

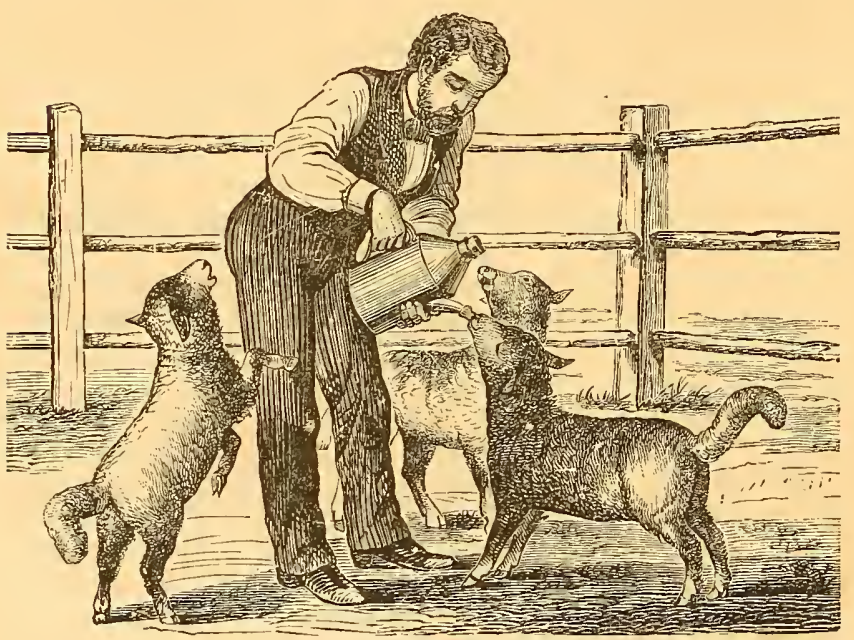

Fig. 14. - FEEDING LAMBS.

and the corresponding growth of the lambs, the food of the ewes should be of the best character. Clover hay, bran, and crushed oats, with some pea-ineal, are the most preferable foods, producing a rich milk in abundance. The ewes must not be allowed to fall off in condition, or the lambs will fail. During mild weather, sugar bects may be given in moderate quantity with advantage, but mangels or Swede turnips, (ruta-bagas), should be avoided as too watery and deficient in nutriment, and productive of scours in the lamb. In cold weather roots are apt to reduce the temperature of the animal too suddenly if given in any but small quantities, and conseqnently decrease the flow of milk. Pea straw is a favorite and nutritious food for sheep, but it will be found profit- 
able to give only the rery best at hand to nursing ewes. The after growth and condition of the lambs will greatly depend upon the maintenance of a thrifty and continuous growth during the first three months of their existence.

At the age of a week the operations of docking and castrating the male lambs, may be safely performed. At this age the young animal suffers but little, there is no loss of blood, and the wounds heal by the first intention. The rough and ready method of elipping off the tail an inch from the rump, first drawing the skin upwards, and of clipping off the scrotum and testicles altogether with a pair of sharp sheep-shears, will be found perfectly safe if done before the lamb is two reeks old. The nerves being very slightly sensitive at this time, the painful, and when later performed, dangerous operation of emasculation is only slightly felt, and within an hour a lamb bereft of tail and generative organs will frequently be seen skipping playfully in the sunshine. To dock an older lamb is a more troublesome operation. To clo this wit's facility, a block of wood about a foot high, a sharp, broad chisol, and a wcoden mallet, are required. The operator stoops with bended knees, the block being in front of him, takes the lamb with its head between his knees and its tail in his left hand, holding the chisel in his right hand. Backing the lamb's rump up close to the block, he lays the tail upon it, and draming back the skin of the tail up to the rump, holds the chisel lightly upon the tail close to and below the fingers of the left hand. When all is ready he directs on assistant to strike the chisel smartly with the mallet, by which the tail is instantly severed about two inches from the root. A pinch of powdered blucstone (sulphate of copper), is placed on the wound, and the lamb is released. To castrate an old lamb with safety, the scrotum should be opened by a long free incision with a sharp knife at the lower point, the animal being at the time turned upon its back and secured in that position. The scrotum should be held in the hand tightly enough io keep the skin tense. The cut should be made only through the skin and conts of the testicle, and not into the gland, by which a great deal of pain is spared to the animal. The gland will escape from the scrotum at once if the opening is made large enough. It may be taken in the left hand and the cord and ressels seraped apart, not cut, by which bleeding is prevented and healing made more certain and rapid. The opening being made at the bottom of the scrotum, allows the blood and any pus that forms in the wound, to escape freely. It might probably be beneficial to insert a small plug of tow in the wound, projecting out of 
it a short distance to prevent the edges from healing until the inflammation has subsided. This method of operation is a safe one, and if it is neatly done, the losses need not be one per cent, while frequently three lambs cut of five may be lost by any other method.

While the lambs are still with the ewes, and although the ewes may be well fed with a special view to the thriftiness of the lambs, yet a supply of additional food for the latter will be of great advantage to them. To furnish a young animal with all the focd that it can digest, and that of the choicest characser, is to creatc a sturdy, thrifty, strong constitutioned animal that will be prolific in reproduction and long lived. To advance the maturity of an animal is also to lengthen its life, for it matters not at which part of its productive career we add a year, it certainly, so far as profit is concerned, lives a year longer for us. If a yearling ewe can be made to produce a healthful, strong lamb, or a lamb can be brought by care to maturity for the market at eighteen months instead of thirty months, this result is simply equal to a profit of 40 per cent. And feed is the agent by which this profit is secured, of course made available by proper care in selecting the breeding stock. To provide the means whereby the lambs may procure the extra fee 1 needed for their rapid development, many contrivances have been brought into use. Generally these are modifications of the plan of providing a pen or yard adjoining that in which the ewes are kept, with "creep holes" in the fence through which the lambs can gain access to it. In this yard some feed, consisting of oats, rye, and wheat bran ground together very finely, is placed in troughs or boxes, and lightly salted. They will soon find this, and will resort to it several times a day. A very simple and convenient "lamb creep" is figured at fig. 15, and has been illustrated and described in an English journal, the Agricultural Gizette. It is very frequently used by English farmers, and is worthy of being adopted by us. It consists of a small double gate or two half gates set at such a distance apart that the lamb can easily force itself through between them. An upright roller on each side of the opening assists the lamb in getting through the space, and prevents it from rubbing or tearing its wool. The gates are piroted at top and bottom, so that they will open a little either way; a wooden spring being fixed so as to kcep them closed after the lamb has passed in or out. The lambs pass in or out at will. Creeps of this kind can be made so as to occupy a panel of fence or a gateway, and of a portable character, so that they can be easily fixed to the fence-post on exch side by a wire or withe, and removed 
when no longer needed. But, by whatever means it may be done, the lambs should be supplied with some additional concentrated and nutritious feed. As a gentle laxative in case of constipation, a few onnces of linseed oil-cake-meal will be found sufficient, and far better than physic. Linseed oil, (raw), or castor oil, a teaspoonful of either at a dose, will be found safe and effective for either constipation or diarrhea, unless of a serious character.

As lambs progress towards the period for weaning, the extra

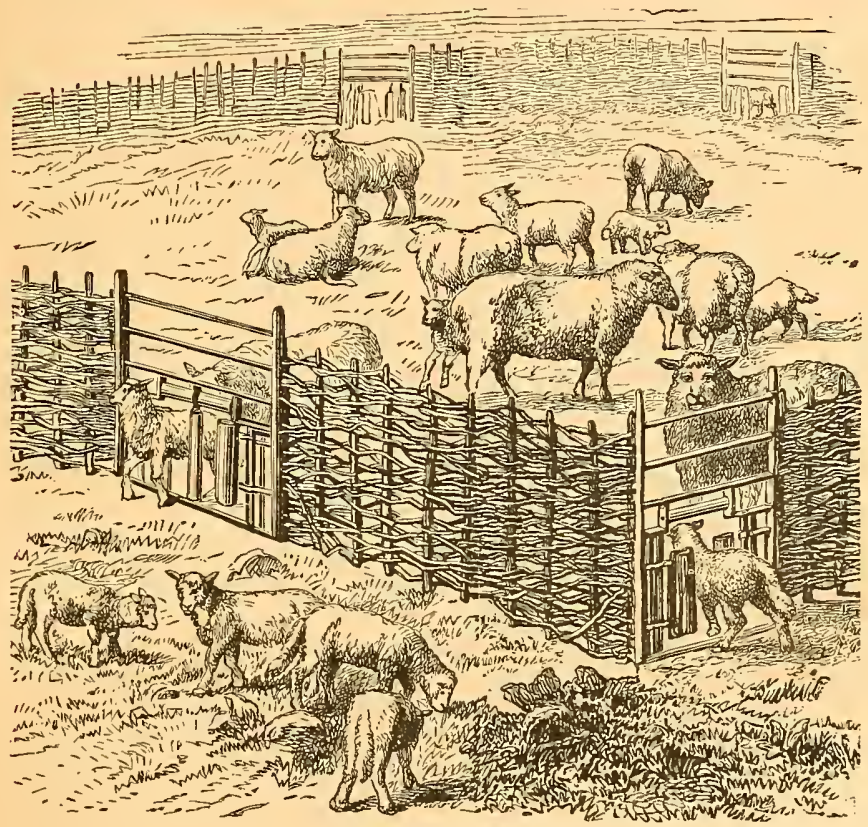

Fig. 15.-LAMB CREeP.

food should be gradually increased, unless they can be remored to a good pasture of short, tender grass. In this case even a small allowance at night on their return to the fold will be beneficial. The weaning should be very gradually done. The sudden removal of the lambs from their dams is injurious to both. It too abruptly deprives the lambs of their most easily digested and most agreeable food. It forces them to load the stomach with food for which it is hardly yet prepared, and st:ddenly arrests their growth 
both by a stinting of fool and by the nervous irritation consequent upon their suditen deprivation. The dams in full flow of milk, thus at once deprived of the means of relief, are subjected to the engorgement of the udder, with the consequent congestion of all the crgans connected therewith. This shock is very injurious, and frequently produces inflammatory disorders of the blond or garget. To avoid these ill effects of the sudden change, it is well to remove the lambs to a distant pasture, along with some dry ewes or wethers for company. The novel experience of a fresh pasture will cause them to forget their clams, and they will utter no complaints nor manifest any nneasiness. At night they should be turned into the fold with the ewes, whose full udders they will speedily relieve. By withdrawing any extra feed hitherto given to the ewes, somewhat gradnally, (in no case is it wise to make a sudden change in the management of sheep), their supply of milk will gralually decrease, and in two weeks the whole of the lambs may be weaned with perfect safety to themselves and the ewes.

After having been weaned, the lambs should have the first choice of pasture and the best and tenderest enttings of the fodder crops. Many farmers have found it advantageous in every way to turn newly weaned lambs into a field of corn in the month of August. The corn is too far growr to be injured, the suckers only will be nibbled by the lambs, and the weeds which grow up after the corn is laid by, will be eaten closely. The lambs also have the benefit of a cool shade, and where such a field can be conveniently applied to this purpose, there are several reasons why it might well be done.

The condition of the ewes must not be neglceted at this time. The chief danger is in regard to those that are heavy milkers. Such sheep should be closely watched, and the milk drawn by hand from those whose udders are not emptied by the lambs. The first approach to hardness or heat in the udder should be remedied by an immediate dose of an ounce of epsom salts dissolved in water, and mixed with a teaspoonful of ground ginger. The next two days 20 grains of saltpeter should be given each morning and evening, to increase the action of the kidneys. These remedies will generally relieve the udder, and will tend to greatly reduce the secretion of milk. If hay is given in place of grass, and the ewe confined in a cool darkenea pen, the drying up of the milk will be hastened.

As the improvement of the flock can be better made from within than by giving the sole attention to bringing new blood from 
without, it will be very important to select the best lambs, both of rams and ewes, for breeders. The selection should be mide chilefly in reference to the purposes for which the flock is kept, and strength of constitution, rapidity of growth, size, tendency to fat; fineness, length or quality of wool, and prolificness and certainty of breeding, in the parents as well as, so far as can be judged of, in the lambs themselves, should be made the tests by which the selection is determined. If the production of early lambs for market is the object, the produce of those ewes which bring single lambs of large size and quick growth will be chosen to increase the flock; if the production of mutton sheep, then those lambs from ewes which drop twins, and are good nurses, ought to be kept; and if wool of any particular kind is desired, then the selection should be made chiefly in reference to that. On no account should weakly lambs, or those ewes which are poor nurses, or fail to breed, or which exhibit tenderness of constitution, or are wanderers, or of uneasy, restless dispositions, be retained; but such unprofitable animals should be closely weeded out and fattenea for sale or for slaughter. The choice of ram lambs is of chief importance, for the inflnence of the ram runs through the flock, while that of the ewe is confined to her produce alone. To select a lamb for a stock ram is a matter requiring a knowledge of the principles of breeding, and some tact and experience. The latter qualifications cannot be acquired from books, but must be gained by practice; nevertheless, much as to the selection of lambs may be learned from a careful consideration of what will be found in the succeeding chapter, which is specially deroted in part to this important branch of the shepherd's knowledge.

The proper age for breeding differs with the class of sheep bred. The Merino is not mature enongh for breeding until fully two or three years old. Other breeds which mature more quickly are ripe for breeding as yearlings, but there is nothing gained by suffering any sheep less than a year old to reproduce. A young ram in its second year may be allowed to serve a few ewes, if he is vigorous and well grown. A ram at two years may serve 30 ewes iu a season, and after that from 50 to 60 or 70 , according to the manner in which the is kept, and if he is restricted to no more than one or two services of each ewe. The strength and vigor of the lamb certainly depends on that of the ram by which it is sired, as well as on the condition and character of the ewe. Ewe lambs of less than a year old should be kept in a separate flock by themselves where they may not be disturbed by the rams. The second year they are capable of breeding, and if they have been well 
cared for, will produce as large lambs and as many twius as older sheep. The young ewes having their first lambs are apt to be nervous, and need careful attention at yeaning time; it is then that the great convenience resulting from having a docile and friendly flock, well acquainted with, and confiding in, their shepherd, is manifest. The young ewes should not be put to the ram until the older ones are served, so that they will not drop their lambs until the spring is well advanced, and the pressure upon the sliepherd becomes lighter. As a rule they are poor nurses, and if the season is cold, will lose many lambs. If they are not allowed to have lambs until April or Mray, so much the better; it will then be necessary to keep them frum the ram until November and December. Dificulty in parturition is sometimes experienced with young ewes, and assistance is often needed. This should be given with the utmost gentleness and tenderness. When the presentation is all right aud natural, and the fore feet appear, but difficulty occurs in ejeeting the luead, a very slight and slow drawing upon the fect may lielp the ewe in expelling the lamb. Sometimes in her nervous struggles the head may be turned backwards, and does not appear when the fore legs have protruded. In this case the lamb should be gently forced backwards, and the hand or fingers, well oiled with linseed oil, and the finger nails being closely pared, are inserted, and the head gently brought inio position, when it will be expelled without further trouble. For more diffienlt and abnormal presentations, the services of an experienced shepherd will be needed, but such cases are very rare, and will very seldom occur if the flock has been carefully attended to, and has not been overdriven, or worried by dogs, or knocked about loy horned cattle. When a ewe loses her lamb it is best to make her adopt one of another ewe's twins. This may be clone by rubbing the skin of the live lamb with the dead one, removing the dead one and shutting up the ewe and live lamb together in a dark pen. When a lamb loses her dam, it may be given to a ewe that has lost lier lamb, or from which her lamb has been taken, or with care it may be brought up by hand without difficulty. In every considerable flock it will pay to have a fresh cow on hand at the lambing scason, to fill the place of foster mother to disowned or abandoned lambs, or to assist those whose dams for any reason are short of milk.

The question as to when a lamb becomes a sheep, although of no practical utility, lias sometimes been of sufficient importance to require a decisive reply. A legal decision was givell in an Engish court not long since, which is probably as reasonable as 
we may expect, and may be accepted as being authoritatire. The question arose out of the killing of some sheep on a railroad by a passing train, and it was denied that the complaint was properly made, the animals being lambs, and not sheep. The judge decided that lambs ceased to be lambs, and became sheep as soon as they had acquired their first pair of permanent teeth. This change of teeth generally occurs when the lamb is a year old. At this period the middle pair of the first teeth drop out, and a pair of the permanent incisors appear. At one year and nine months, two more of the first teeth are dropped and two more permanent incisors, one on each side of the former pair, appear. Nine months later, two more permanent incisors appear in a similar manner, and nine months later still, another pair are produced, so that at three years and a quarter the sheep has eight permanent incisors or nippers, and is then called a full-mouthed or perfect sheep. These periods of dentition are irregular, and in some of the early maturing breeds, the first pair of permanent teeth will appear before the end of the first year, and at 16 months, four permanent incisors may be found. The earlier maturity of the high bred and high fed races of sheep, such as the Leicester, Cotswold and Shropshire, sometimes amounts to a gain orer the common breeds of nearly a year in time, and full-mouthed sheep of no more than two years and a half old are net uncommonly met with.

The cliseases to which lambs are subject are but few, and those are mainly the rcsult of carelessness in their management. The lamb, which appears so delicate and tender an animal, is really hardy, and resists much ill treatment, else with so little consideration as they usually receive, the race would soon become almost extinct. Damp and cold are especially to be guarded against in the spring, and filthy yards at all seasons. With clean pens and dry, clean bedding, they will resist the severe dry colds of a northern January, and thrive and grow while snow storms rage, if only well sheltered. Sunshine has a remarkable effect upon lambs, and the warmth of the sun will often revive and strengtlen a weak lamb that appears past relief. Extremes of damp and inpure air in close pens, and bad drinking water, will produce diarrhea and paralysis, and these are the chiefly fatal disorders to which they are subject. Constipation is produced by want of proper laxative food, and permitting them to feed o. dry, withered herbage that has lost its nutritive qualities beneath the storms of a winter. If the directions as to their treatment heretofore given, are followed, there will rarely be any need of remedial measures, and prevention will be found better than any amount of cure. If, 
notwithstanding all possible care, some weakly lambs are found to require treatment, the simple purgatives already mentioned in this chapter, viz: a teaspoonful of castor or raw linseed oil will be found effective, after two or three closes, in remoring the troublesome matter from their intestines, and restoring the bowels to healthful action. If in any case, a stimulant seems to be needed, as when great weakness and prostration are present, the safest is a teaspoonful of gin, given in a little warm water with sugar. A still more gentle stimulant and anodyne, but one very effective in prolonged diarrhea, is prepared by adding to a pint of peppermint water, one ounse of prepared chalk, a teasponnful each of tincture of opium and of tincture of rhubarb; it is worthy of the name given to it by shepherds, viz: "lambs cordial," and at the lambing season no shepherd should be without a supply of it. The close is a teaspoonful for a lamb of a few days old, up to a tablespoonful for one of a month. Exposure to cold rains should be specially guarded against, and if by inadvertence a lamb is found chilled and rigid from such exposure, it may generally be restored by means of a bath of warm water and a teaspoonful of warm sweetened gin and water. After the bath the lamb should be gently dried, wrapped in a warm flannel, and placed near a fire or in a wooden box in a gently heated oven of a common stove. Where the flock is large, and the kitchen is not within reach, the shepherd should have the conveniences of a shed and an old cooking-stove in which he can keep a fire sufficient to heat a water bath, and provide a warm bed in the oven for any lamb that may need such attention; if the flock numbers several hundred head in all, there will seldom be a day in our changeable spring seasons when there will not be one or more patients to be treated. The specific cliseases to which lambs are subject will be found treated of at large in Chapter VII.

As the season progresses, and shearing time for the ewes has passed, the lambs will be found covered with ticks, unless care lias been exercised to free the flock from this tormerting pest. These ticks are wingless, broud, plump, dark red insects, about a quarter of an inch in length, and covered with a very tough and leathery integument. They are known scientifically as Melophagus ovinus, and produce a puparium which is nearly round in shape, red in colcr, and as large as a radish seed or duck shot. The iegs of the tick are short and stout, and it adheres with great tenacity to the wool. By means of a proboscis as long as its head, it pierces the skin and sucks the blood of its victim to such an excess that when numerous, they have been known to almost entirely empty the 
veins and deprive a lamb of life. The draft upon the vitality of lambs infested with ticks is very great, and sufficient to arrest their growth altogether. To rill the flock of these pests is therefore a necessary labor in the spring or early summer, and if need be, again in the autumn. The easiest remedy is to dip both sheep and lambs, as soon as the sheep are shorn, and again in August or September, in a decoction of tobacco mixed with sulphur. Coarse plug tobacco, or tobacco stems, which are cheaper than the leaves, and equally effective, are steeped in water at a boiling heat, but not boiling, at the rate of four pounds to twenty gallons of water.

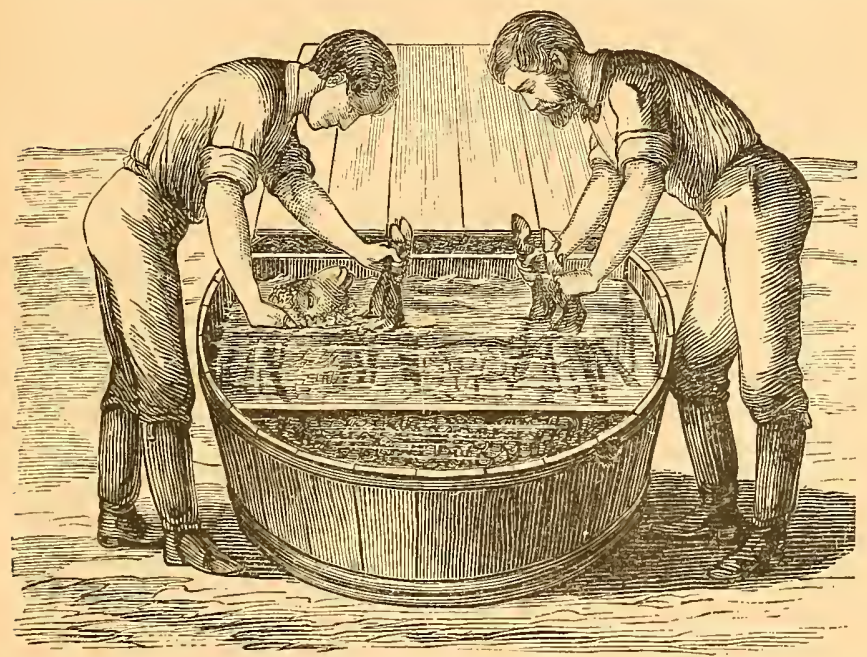

Fig. 16.-DIPPING SHEEP.

One pound of flowers of sulphur is then stirred in the liquid, which is brought to a temperature of 123 degrees, and kept so during the dipping by the addition of fresh hot liquor. During the dipping, the mixture is kept stirred to prevent the sulphur from subsiding. The dip may be conveniently placed in a trough or a tub large cnough to allow of the immersion of the sheep or the lamb, which is taken by the feet by two men and plunged into the bath at the temperature mentioned, where it is leeld for a minute or two until the wool is thoroughly saturated. The animal is then placed in a pen with a raised floor sloping on each side to a trough in the mirldle, along which the superabundant liquor escapes into a pail or tub placed to receive it. The method of dipping, (shown at 
figures 16 and 17), is calculated for small flocks, or for a few hundred lambs. For larger flocks, a larger tank is provided, 12 feet long, three feet wide, and four feet ceep. A fenced platform deads from a pen in which the sheep are gathered, up to the edge of the ciipping tank, and the sheep are taken one by one from the pen, led up the platform, and pushed into the tank in which the dip is sufficiently deep to cover them. As the sheep plunge into the dip, they are seized, and kept beneath it, except the head, which alone is suffered to emcrge above it. If in their struggles a little of the clip should enter their nostrils, no harm results, but the hot tobacco water is, on the contrary, often beneficial to those sheep which are affected by catarrh or grub in the head, and the violent sneezings which follow may help to free them from these troublesome parasites which often inlabit the nasal sinuscs. The shcep are rapidly passed from hand to hand along the tank until they reach the end, where there is a sloping plank upon which they can walk up to anotier platform. Here they are: allowed to remain while the excess of dip is squeezed from their wool. From this the

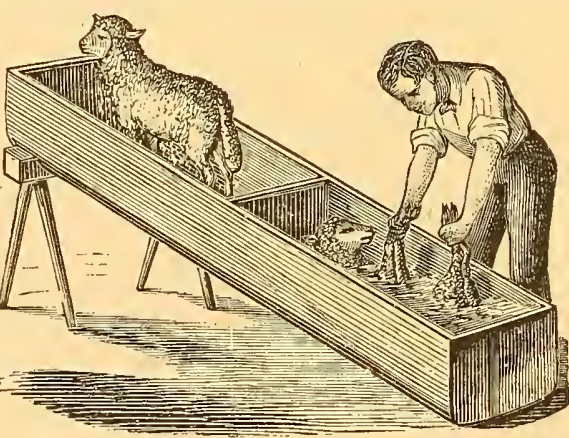

Fig. 17,-TROEGH FOR DIPPING LAMBS. liquid drains into tuks, and is carried to the boilcr to be reheated, and then returned to the tank for use again. The cost of dipping a large flock, numbering several thousands, in this manner twice in the season is five cents a head, and the improvement in the quality of the wool, which results from the cleansing of the skin from dust, grease, and the accumulated refuse of its scerctions, and its increase in quantity consequent upon the greatcr comfort of the sheep and their escape from the persccution of ticks and other parasites, is estimated at 20 cents per hear, so that the cost is repaid more than three-fold. The comforting knowledge to the humane shepherd that his flock is freed from a most annoying torment, is also something, which, although it does not enter into a pecuniary calculation, and is not measured by dollars and cents, yet is not on that account unworthy of consideration. 
There is no greater satisfaction to the owner of a flock, who cares for his sheep, and takes pleasure in their welfare, and in a measure loves the gentle kindly animals, and is interested in managing them so that they may enjoy all the comfort possible for them, than to know that, so far as any efforts of his are concerned, nothing is left undone that can add to their contentment, and that they are spared every discomfort and pain that it is possible to prevent.

\section{CHAPTER IV.}

\section{WINTER MANAGEMENT OF SHEEP.}

The change from green, succulent food, to that of a dry and concentrated character, is one that needs to be cautiously made. As the summer departs and the fall rains occur, succeeded in their turn by the more rigorous storms of winter, conditions arise which call for a complete change of management on the part of the shepherd who looks for profit from his flock. It may be a question with some if quality of feed or shelter is the more important consideration in the best management of sheep. Certainly abundant experience has shown that with the most careful and judicious feeding, sheep, which when well tended are in reality hardier than are generally supposed, have passed safely and thriftily through a winter's storms with no more shelter than that afforded by an open shed; and that they have of their own free will refused the shelter, and have chosen to rest upon the bare snow, at times when the air has been dry and clear. But no case has as yet ever occurred in the experience of any shepherd in which sheep have thrived without well selected, proper, and abundant food, and cases are always occurring in which sheep are greatly injured by excessive carefulness in this matter of shelter. To feed well and judiciously, may therefore be regarded as the first duty and interest of the sucpherd; and to shelter the flock only so far as to maintain it in healthful condition, avoiding exposure to unusual rigors of heat or storm, will be not exactly a second duty, but one that attaches to this first interest as being intimately associated with it rather than separated from it. Nevertheless, as before a flock can be fed, it is 
necessary to have a store of food and a feeding place, it may be well to consider first the subjects of shelters or barns, feed racks, and facilities for watering.

The first requisites for the comfort of sheep in their winter lodging are a dry clean floor, a tight roof, and abundant ventilation. The site of a sheep-house should therefore be well drained, and of such a character that it can be kept clean and free from filth. It should, if possible, be on high ground which slopes each way from it, but at any rate it should slope to the south or southeast. The house should be well roofed and provided with rain troughs and spouts to carry the water away from the fart into either a covered drain or a cistern. It should be open at the front, protected only by a projecting roof, and the walls, if of boards, need not be battened over the joints, as the air which will enter

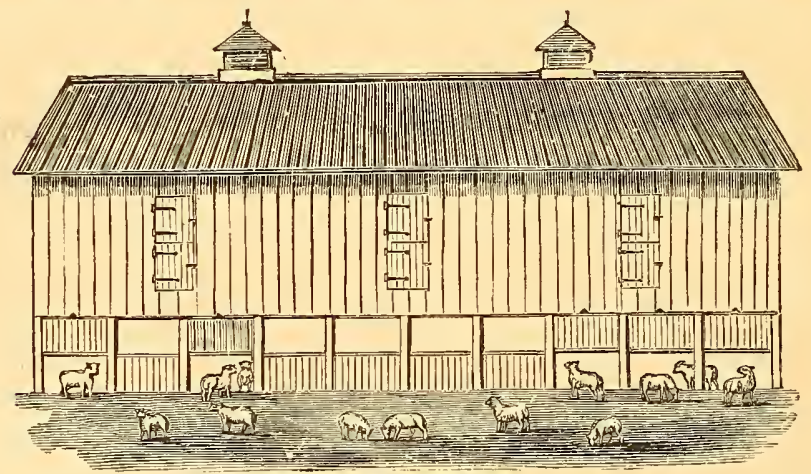

Hig. 13. - GHEEID BARN.

through these cracks will be no more than will be needed to keep that within fresh and pure. Some more carefully protected shelter must be provided for the use of yeaning ewes and young lambs, in a part of the house or in another building, but until the appearance of the lambs is looked for, this warmer shelter will not be reeded. The loft over the lower apartment will be used for storing hay or other fodder, and space for this purpose may be economized by having the upper floor only so far above the ground floor as will allow the shepherd a comfortable passage beneath it. A building which is well arranged and convenient is shown in figures $18,19,20$, and 21 . The following description with the illustrations are taken from the American Agriculturist. It consists of a barn, shown at fig. 18, about 20 feet wide, 16 feet high 
from basement to eares, and as long as desirable. This is intended to store the hay or fodder. The posts, sills, and plates are all 8 inches square, the girts and braces are 4 inches square, the beams $2 \times 10$, are placed 16 inches apart, and are cross-bridged with strips, 3 inches wide. The hay is piled inside, so that the feed passage below, over which there are trapdoors, is left uncorered. The hay is thrown down through these cloors, and falls upon a sloping shelf, which carries it into the feed racks below, (see fig. 19). The basement under the barn is 8 feet ligh, and is of stone on three sides; the front is supported by posts 8 inches square, and 8 feet apart. Between each pair of posts a door is hung upon pins, (fig. 20), which fit into grooves in the posts, so that the door may be raised and

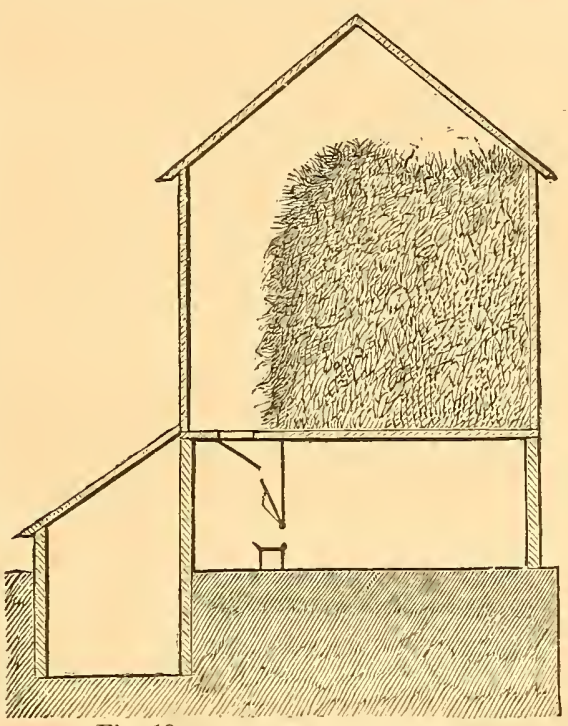

Fig. 19.-SECTION OE BUILDING. fastened, in such a manner, as to close the upper half of the space between the posts; or be held suspended half way, leaving the whole open; or be shut down and close the lower half; or be removed altogether. By this contrivance at least hali the front

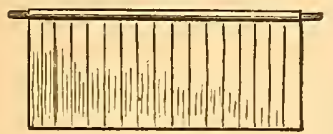

Fig. 20.-HANGING DOOR FOR BARN. of the basement must be left open, whether the sheep be shut in or out. The floor of the basement should be slightly sloping from rear to front, so that it will always be dry. Fig. 21 shows the plan of the bascment. The feedpassage is shown at $c$; the stairway to the ront-cellar at $b$, and the root-cellar at $a$. Fig. 19 gives a section of the whole barn. The hay-loft is above, and the passage-way and the doors, by which the hay is thrown down to the feed-racks below; as well as the sloping shelf by which the hay is carried into the feed-racks are shown. 
Below the feed-rack is the feed-trough for roots or meal. A door shuts off this trough from the sheep at the front, while the feed is being prepared, and when it is ready, the door is raised, and held up to the feed-rack by a strap or a hook. The feed-rack is closely

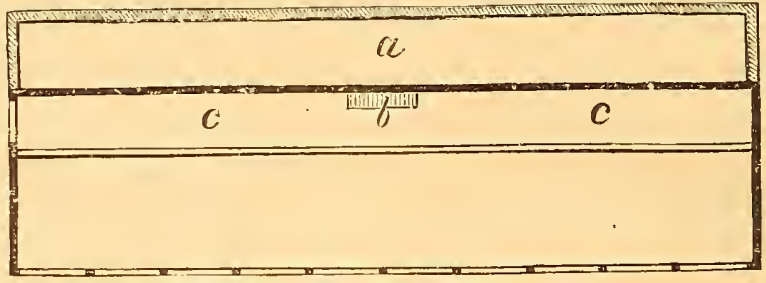

Fig. 21. -GROUND PLAN OF BARN.

boarded behind, and this back part, which is in the feed-passage, slopes forward to the front, so as to carry the hay forward to the bottom. The front of the rack is of upright slats, smoothly dressed, two inches wide, and placed three inches apart. The boards of the feed-trough are smoothly dressed and sand-papered, and all the edges are rounded, so that there is nothing by which the wool may be torn or rubbed off from the sheep's necks. It will be seen by this arrangement, that there is no dangerous thing

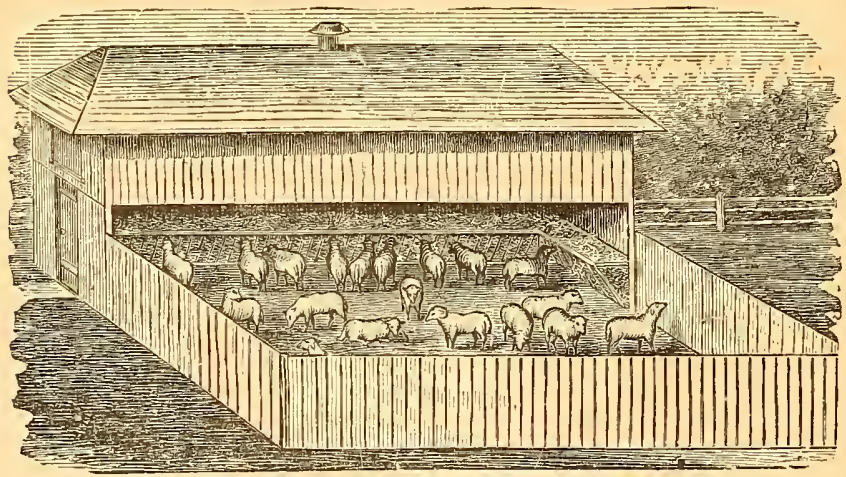

Fig. 22.-SHEEP SHED FOR A SMALL FARM.

by which a sheep or a lamb might be hurt, nor a place where it can get into mischief. The root-cellar is at the rear of the basement, and is reached by the stairs already mentioned. The cost of the barn here described, if built of pine or hemlock lumber, in 
BARNS AND SHEDS.

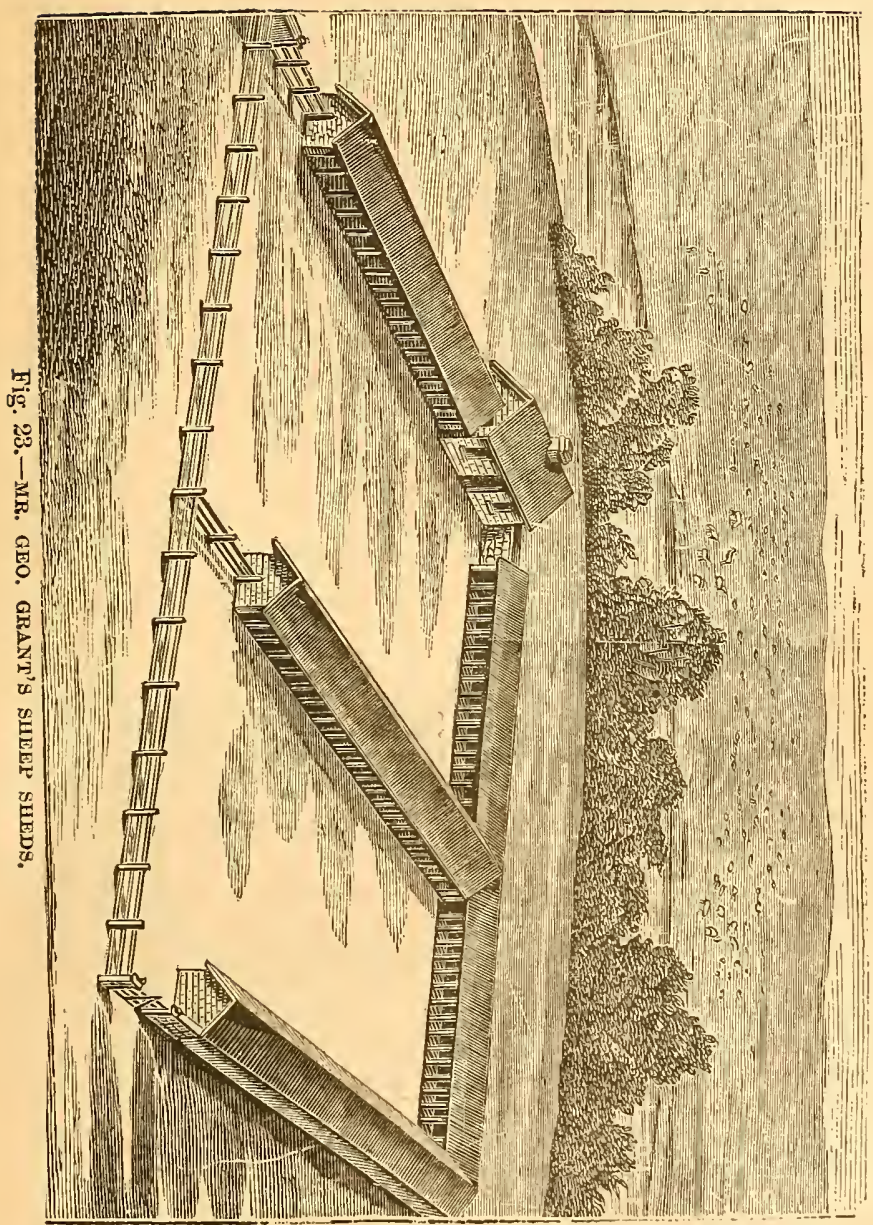


a plain manner, and of sufficient size to accommoüate 100 sheep, would be from $\$ 300$ to $\$ 500$.

Another sheep-house suitable for small farms, that is designed for small flocks, is shown at figure 22. It is altogether cpen in the front on the ground floor, and is intended to face to the south. This is a very cheap and convenient shed for a small flock; it has an enclosed yard attached to it. A shelter intencled for a large flock is shown at figure 23. This building was erected by $\mathrm{MIr}$. George Grant, of Victoria, Kansas, for his flock of 7,000 sheep. The walls are of stone, and the roof of boards. The main structure is $5 \% 0$ feet in length, and the three wings are each of equal Jength. The width of each of the sheds is 24 feet, and the hight of the walls 10 feet. At one corner of the "cor-

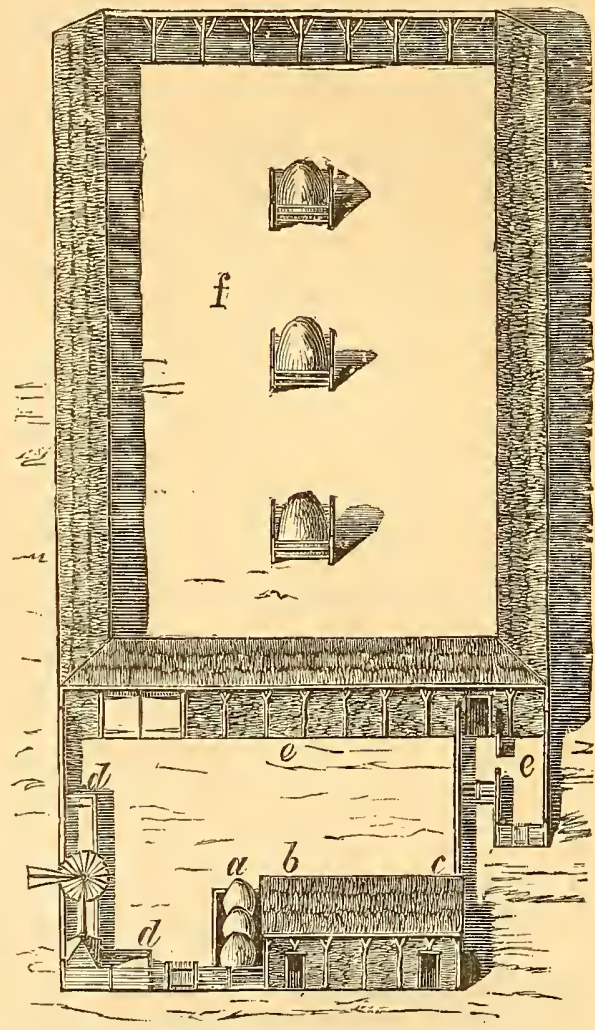

Fig. 21.-MT. SHAW'S SHEEP SHED. ral," which is the name given on the westcrn plains to such sheds as this and other enclosures, is the shepherd's house, in which he resides, and is at all times near his flock, and able to render immediate attention. A sher of this character is rather costly in its construction, and a small capitalist would find it beyond the limit 
of his resources. One of a cheaper construction and less permanent character, but nevertheless of equal value for shelter so long as it lasts, is shown in figure 24. This shed was built by Mr. Shaw, of Syracuse, Kansas, and was found to answer every purpose. It is made of posts set in the ground, which support a single sloping roof that is thatched with coarse hay from the river bot. toms adjacent to his location. The enclosure contains a windmill, watering trough, stack-yard, and feed-racks, and is intended to accommodate a flock of 200 to 300 sheep. The length of the enclosure is 200 feet, and the width 100 feet, making in all 600 feet of shed. Figure 25 represents the sheep-fold of Mr. Henry Nason, of Orange C. H., Virginia, in which his flock of 300 ewes is sheltered from the weather as well as from dogs and thieves by night. This flock is kept mainly for the production of carly lambs for market. Especial attention is given to the comfort and care of

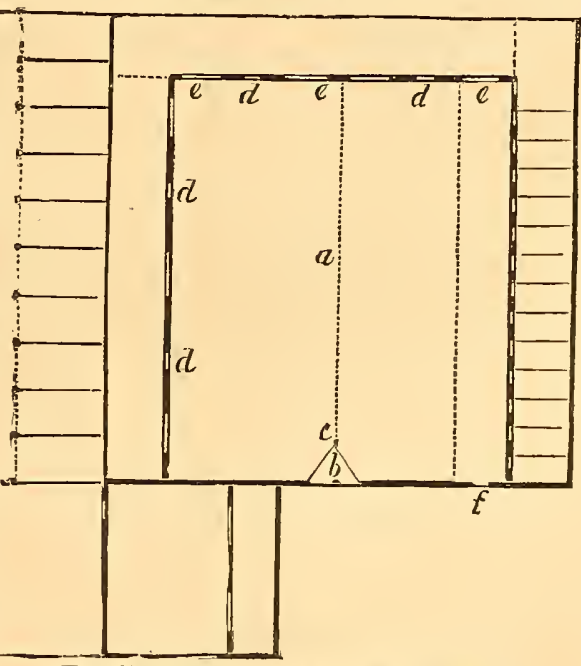

Fig. 25. - PLAN OF MR. NASON'S SHED. the ewes and the lambs, and warm separate pens are provided for them when they require them. The yard, $a$, is 100 feet square, divided by a hurdle fence, shown by the dotted lines, into as mauy portions as may be desired. The entrance is at $b$, where there is a gate hung upon a post, $c$, in such a way as to open or close each half of the yard. The yard is enclosed on three sides by a shed 10 feet high, with a roof sloping both ways. The ground floor, 7 feet high, is appropriated for sheep pens, and the three feet above for a hay loft. The shed is 12 feet wide, and has a row of separate pens 6 feet wide, upon the north side. On the other sides there are narrow doors for the sheep, seen at $d, d$, and slicling shutters, $e, e, 8$ feet long, and $3 \frac{1}{2}$ feet high, which are also used for entrances to the shed. The yard is closed at the front by 
a fence 10 feet high. There are no outside windows, and only two doors, and but one of these, that at $f$, is locked from the outside, so that the turning of one key secures the whole enclos. ure from trespassers. There is a second yard, 150 by 135 feet, upon the south side of the sheep yard, with an open shed facing the south, and divided into pens 9 feet deep, for cows or sheep, and a pig pen 35 fect square, at the south-east of the sheep yards. These sheds are made of inch boards, nailed up and down upon the frame work, and the roof is of boards, with a sufficient pitch to shed rain perfectly.

In estimating the size of the shede required for any given number of sheep it will be safe to allow 10 square feet of floor to each sheep, when a yard adjoining the shed is provided, and there is abundant ventilation in the shed; and $12 \frac{1}{2}$ square feet when there is no yard, but only the most ample ventilation by means of boards at the eaves, to be let down, and trap-doors in the roof to be opened. Space may be economized if thought desirable, and the expense of the sheds reduced, by having a second floor for the sheep which is reached by means of a sloping passage-way of planks upon which cleats are nailed crosswise to afford a foothold. Sheep will readily ascend a gang-way of this kind, and will choose the upper in preference to the ground flocr. The upper floor in this case must be made perfectly close and tight, of matched boards tarred at the joints, and ample dry bedding should be provided to absorb all the moisture. This floor should not be less than seven feet above the ground floor; this will secure sufficient ventilation if the lower doors are double, and the upper halves are kept open, and there are a sufficient number of open windows or ventilating boards or spaces. A shed 20 by 50 feet will comfortably contain 100 moderate-sized sheep; 75 large Cotswold or Leicester sheep have been accommodated in a lean-to shed of this size, with ventilating boards and traps in the roof. In this shed there was a ventilating board arranged near the bottom by partly opening which, a plenty of fresh air could be admitted. On the whole, the sheds with a half open front, that may be closed wholly or partly, with a yard adjoining, will be found preferable to those which are made to be entirely closed.

A convenient barn which furnishes space for shearing, room for the storage of wool, pens for lambs and ewes, and lofts for fodder and straw, with ample open sheds and a roomy yard, is shown at figure 26. It can be made larger or smaller, to suit the needs of a large or small flock. The main building, of which this is a representation, is raised four feet from the ground upon posts, and the 
space thus gained furnishes additional shelter. This barn has the advantage of being suitable for a cattle barn in case sheep-keeping is abandoned for a time, and is well adapted to either western or eastern sheep or stock farming. As perfect cleaniiness and pure air are necessary to the healthfulness of the flock, the matter of litter in the sheds and yards, as well as the drainage of the roof and floor, are to be well provided for. Eavestroughs, gutters and waste-pipes should be provided and made to discharge into a drain, which will carry the rain water beneath the ground, away from the yard. The litter should be dry, plentiful, and of a lriud that is absorbent. If plentifully given, and if the right kind, it may be allowed to accumulate for the whole winter without removal, and in so doing there will he less odlor in the shed than if it were cleaned ont weckly. The litter and the droppings are trod-

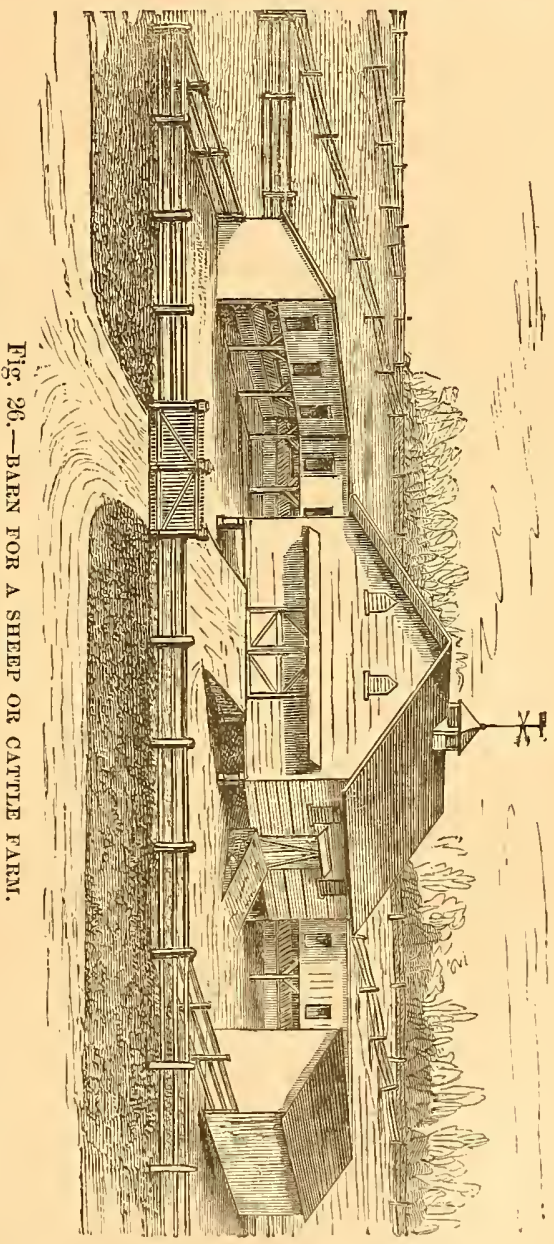
den down very compactly, and the mass being thus kept from the access of air, only a very slow decomposition occurs which gives off no more smell or vapor than can be absurbed by the fresh 
litter daily thrown down in the shed. Hardwood sawdust, dry seasoned peat or swamp muck, forest leaves, dried spent tanbark, long or cut straw, chaff, or even sand, make very good litter aud absorbents. If a supply of these materials cau be procured, sufficient for daily use in a crowded pen or yard, the straw, which would otherwise be needed for this purpose, may with great economy be reserved for fodder. If straw or corn-fodder cut into small pieces, is fed in the racks once a day, there will be a certain portion pulled out on to the flow which will add to the litter. If straw is used for litter, it should be cut into chafi, which will milch facilitate the removal of the manure in the spring. This is especially convenient if pea straw is used, for when a quantity of pea straw and manure is trodden together, they form such a tangled mass that it is a most tiresome labor to fork it up and remove it. Corn-stalks should not be thrown under foot for the same reason. If it is thought proper to remove the litter and dung periodically, every week for instance, then the floor should afterwards receive a heavy coating of dry litter. In case the manure is removed, it should not on any account be heaped in the yari. It will undergo an active fermentation and become hot, giving forth clouds of vapor in damp weather, and at all times pungent gases. Some of the sheep will choose the manure heap to lie upon at nights, and every one that is suffered to do this will inevitably sicken, and become affected with catarrh or pneumonia, or lose its wool in patches. Either the litter should not be cleaned out at all, or it should be removed to a distance from the yards. It is easy to manage matters either way, so that the air of the shed will be pure and free from offensive smell, if proper attention is given, and the shepherd is watchful and careful of the condition of the floors of the shed.

The feed-racks should be so made that the sheep can procure their feed without tearing the wool from their necks or filling their fleeces with dust, chaff, or hay-seed. The floor of the loft should be made close and tight, using either matched boards or double boards laid so as to break joints, and prevent the dropping of dust from above. A rack for hay or straw should be made in the manner shown at figure 27 ; it should be $3 \frac{1}{2}$ feet high at the front. The bars are only three inches apart. They should be made of ash, chestnut, or oak strips, dressed and smoothly sandpapered, and an inch thick by one and a quarter wide. The front of the rack should slope backwards at the top 3 or 4 inches. This prevents hay or clover dust from falling out upon the sheeps' heads. At the rear of the rack sloping boards are fitted, so that 
as part of the liay is eaten, the rest falls down to the front where the sheep can reach it. The end of the rack should be closed with bars in the same way as the front, so that young lambs cannot creep in and get lost. For want of this precaution a fine lively young lamb will sometimes get into a tight place, where it may become chilled and die. This rack may be made of any length, and should extend all round the shed in order to give the greatest possible extent of feeding room. The form of this rack prevents the she ep from thrusting their heads between the bars and wearing the wool from their necks, or from strangling themselves by getting their heads fast be-

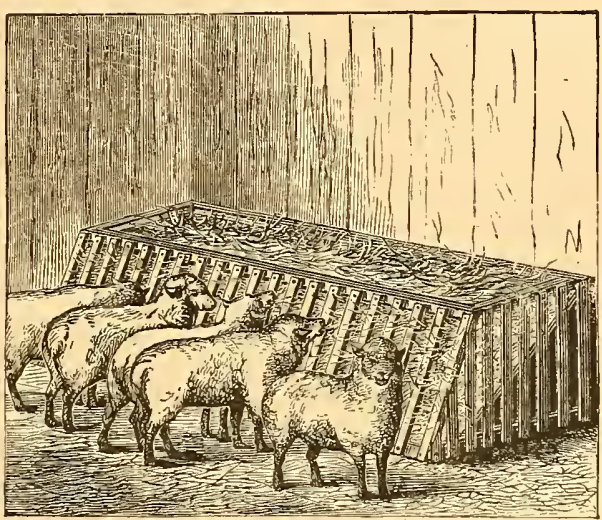

Fig. 27.-FEED-RACE. tween the bars, which they will do with many of the racks in common use, of which the bars are frequently too far apart.

For feeding cut or pulped roots, or fine feed, such as bran-meal or grain, a rack made on the plau of that shown at figure 8 on page 31 , will be useful. The rack there figured is a portable one intended for use in the field or yard, but a fixed rack similar to it may be macie in the shed if desired. The bars placed over the rack prevent the stronger sheep from crowding the weaker ones from their feed, and getting more than their share, and also prevent the more active ones from leaping into the trough in their eagerness to procure an undue portion of food.

The variety of foods suitable for the winter feeding is extensive. Hay, straw, pea and bean haulm, corn-fodder, roots of various kinds, corn, oats, peas, rye, buckwheat, cotton-seed and linseed oil-cake-meal, and bran, furnish a variety of food from which a proper choice can readily be made. The relative feeding values of these varions substances used as food, will determine their relative money values, and as these differ and fluctuate from time to time, it is often necessary, to secure the most profit on the feeding, 
to choose the food that is most economical in use, although it may be the highest in price. Clover hay is the most valuable single food for winter use, if it has been cut when in blossom, cured so as to preserve all its good qualities, and kept free from damp and mold. Where the main object in view is the production of market lambs, clover hay should furnish the chief subsistence of the ewes. It will also be found preferable as the staple and cheapest fodder when skeep are purchased for feeding for market, and the most rapid growth of flesh is desirable. Well cured pea straw will be chosen by sheep next to clover hay and before timothy or any other hay. Oat straw is readily eaten by sheep, and is a healthful food, especially if harvested before the oats were dead ripe. Bar. ley, wheat, and rye straw will lielp to keep life in a flock, but are not sufficiently nutritive to contribute much to the growth of flesh or wool, and should be used only as adjuncts to roots and grain, or oil-cake-meal. Rye straw is apt to be sprinkled with dust of ergot, a fungus which is frequently found growing on the heads of rye, and which has a highly injurious effect upon pregnant ewes, producing abortion or premature birtlss of the lambs. Rye straw is also frequently the cause of great inflammation of the stomachs and intestines of sheep, from the penetration of the mucous coats by the sharp awns or beards of the heads. Cases have occurred in which the stomachs of sheep fed on rye or bearded wheat straw, have been found after death thickly studcled with the bearòs, which caused inflammation of the coats of the stomachs and consequent deatb. Such straw should be avoicled as food, and used only for litter. The haulm of beans when well cured and saved, is both palatable and nutritious, and the leaves of corn-stalks furnish a food which is useful as a change of fodder, but is not nutritious enough of itself to support sheep in good condition. The relative values of the various dry fodders above mentioned may be estimated from the following tables, in which their composition and the proportion of actual nutritive matter contained are given.

COMPOSITION OF HAT, STRAW, AND CORN-FODDER.

\begin{tabular}{|c|c|c|c|c|c|c|}
\hline IN 100 PARTS OF & Water. & Ash & $\begin{array}{l}\text { Organic } \\
\text { Matter. }\end{array}$ & $\begin{array}{l}\text { Flesh } \\
\text { Form- } \\
\text { ers. }\end{array}$ & $\begin{array}{l}\text { Fat, } \\
\text { Starch, } \\
\text { \& Gum. }\end{array}$ & $\begin{array}{l}\text { Crude } \\
\text { fiber. }\end{array}$ \\
\hline Meadow IIay. & 14.3 & 6.2 & 79.5 & 8.2 & 41.3 & 30.0 \\
\hline Red Clover Ḧay. & 16.7 & 6 & 77.1 & 13.4 & 29.9 & 35.8 \\
\hline Pea Straw...... & 14. & 4.0 & si. & 6.5 & 35.2 & 40.0 \\
\hline Bean Straw. & 17.3 & 5.0 & 77.7 & 10.2 & 33.5 & 34.0 \\
\hline Wheat Straw.. & 14.3 & 5.5 & 80.0 & 2.0 & 30.2 & 48.0 \\
\hline Rye Straw.... & 14.2 & 3. & 82. & 1.5 & 27.0 & 54.0 \\
\hline Barley Straw.... & 14.3 & 7.0 & 78.7 & 3.0 & 32.7 & 43.0 \\
\hline Oat Straw.............. & 14.3 & 5.0 & 80.7 & 25 & 38.2 & 40.0 \\
\hline Corn Fodder... & 14.0 & 4.0 & 82.0 & 3.0 & 39.0 & 40.0 \\
\hline
\end{tabular}


The composition of clover hay here given is of that cut when in blossom. If cut when ripe, this hay has 4 per cent less of fleshforming material, 9 per cent less of fat, starch, sugar, and gum, or material for forming fat and sustaining respiration, and over 12 per per cent more of crude fiber or indigestible matter.

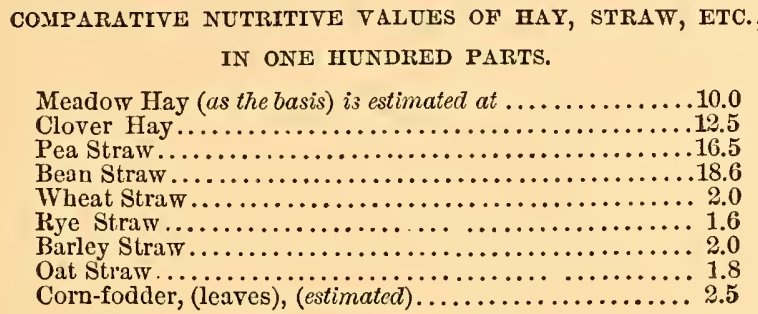

The different quantities of these several fodders which would have to be fed to produce equal nutritive effects, may be tabulated as follows, each quantity given being equivalent to 10 pounds of common meadow hay of mixed grasses of standard quality.

QUANTITIES OF VARIOUS FODDERS EQUAL TO 10 POUNDS OF HAY IN FEEDING VALUE.

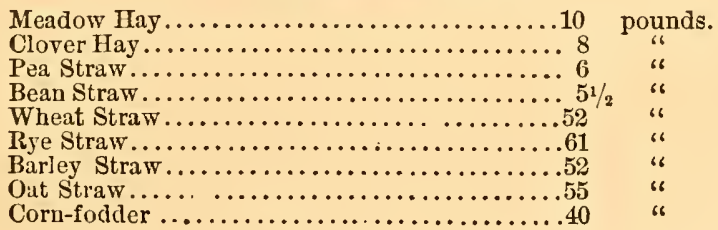

The last two tables must be taken with some qualifications. The values of these different articies of fodder are subject to very great variations, arising out of the conditions of their growth and the time and manner of harvesting, curing and preserving them. With the single exception of corn-fodder, however, the estimates here given will approach very nearly the actual feeding values as found in practice; the coln-fodder will be found of somewhat higher value than indicated by the above figures, estimated from a comparison of its constituents with those of oat 
straw. Generally, those who have fed this material largely, and who have taken pains to harvest it when the corn is just glazed, and before the frost has stricken it, and to cure and bouse it carefully, will agree that it at least more nearly approaches in value to good meadow hay than to oat straw, while some careful, intelligent, and observant feeders will insist that is very nearly, if not quite equal as fodder, to ordinary meadow hay. The inpossibility of subsisting sheep upon straw will be manifest when its value is compared with that of hay; for if 3 pounds of hay would sup. ply a sheep of $100 \mathrm{lbs}$. live weight with sufficient nutriment to maintain it in a thriving condition, as it should do, 17 to $20 \mathrm{lbs}$. of straw would be required as an equivalent, which is a quantity that no sheep could possibly be made to consume. Therefore, when sheep are wintered in the straw yard, unless they have a sufficient supply of grain along with the small quantity of straw they can be made to consume, they must live in a state of semi-starvation, a condition in which unfortunately not a few flocks are expected to exist. Roots furnish a staple food of the greatest value for winter feeding of sheep. When fed in proper quantities, their laxative effect healthfully opposes the tendency of dry hay or straw to produce costiveness, and in addition they supply a considerable proportion of needed phosphates and sulphur for the growing animal and its fleece. But if fed in excess, the large quantity of water they contain, and their large bulk, especially when they are fed in the winter, reduce the temperature of the animal too much, and gradually act unfarorably on the health. When ewes in lamb are fed roots in any but very small quantities, abortion is frequcutly produced, and this ill effect has been noticed more conspicuously when the roots have been manured heavily with superphosphate of lime. This has been noticed by some extensive feeders and breeders in England, where that fertilizer is largely used in root culture, and their experience should serve as a warning to ns. The reason assigned for the loss of lambs by abortion when many turnips are fed, is not only that the fœtus is affected by the presence of a mass of very colcl matter in the stomach of the ewe, but that there is an irritation produced in the intestines by this unacceptable food, which causes the death and expulsion of the fœtus. Nothing of the kind has occurred in flocks that have been largely fed on cooked roots, supplied at such a temperature that would prevent a chill to the animal. It may, therefore, be understood that it is the low temperature, generally near freezing, and often below it, at which the roots are given, and nothing in the roots themselves that act thus iujuriously. 
Knowing this, the ill effect likely to be produced, may easily be avoided.

The roots that are generally fed to sheep are sugar beets, mangels, ruta-bagas, yellow turnips, and white or cow-horn turnips, and are to be preferred in the order in which they are here enumerated. Their comparative nutritive value may be gathered from the following table, the estimates in which are from analyscs by Drs. Voelcker and Lankester :

TABLE OF THE NUTRITIVE ELEMENTS OF ROOTS.

\begin{tabular}{|c|c|c|c|c|c|}
\hline IN 100 PARTS OF & 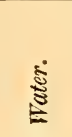 & $\begin{array}{l}\text { हैं } \\
\text { हैं } \\
\text { हू } \\
\text { हू }\end{array}$ & हैं & 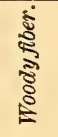 & ఖั \\
\hline 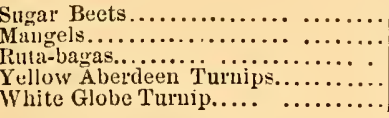 & $\begin{array}{l}81.5 \\
87.78 \\
89.40 \\
90.57 \\
90.43\end{array}$ & $\begin{array}{l}1.00 \\
1.54 \\
1.44 \\
1.80 \\
1.14\end{array}$ & $\begin{array}{r}15.40 \\
8.60 \\
5.93 \\
4.64 \\
2.96\end{array}$ & $\begin{array}{l}1.3 \\
1.12 \\
2.54 \\
2.34 \\
2.00\end{array}$ & $\begin{array}{r}.80 \\
.96 \\
.62 \\
.65 \\
1.02\end{array}$ \\
\hline
\end{tabular}

Considering the large quantity of water contained in them, roots may be considered as highly nutritious food, and when fed in conjunction with dry fodder, and in proper proportions, are greatly conducive to the health and growth of the sheep. Their effect upon the quality of the wool, especially the lustrous wool of some of the long-wool sheep, is very favorable. The proper quantity of roots to be given depends upon the kind of sheep. As a safe guide, it may be estimated that one bushel of roots will be a sufficient daily allowance for 10 sheep weighing $150 \mathrm{lbs}$. ench, live weight, if along with the roots, $1 \frac{1}{2} \mathrm{lb}$. of hay and $\frac{1}{2} \mathrm{lb}$. of meal or bran per head be given. The question of food rations will, however, be considered at length in another place.

Grain, or preparations of grain of various kir Js, furnish the concentrated foods, which are found needful to maintain shcep in a healthful condition, or to induce rapid growth and fattening for market. These foods exist in abundant variety, but no one alone can be fed with the greatest benefit for any length of time. $\Lambda$ change of food is both acceptable to, and healthful for sheep, and the difference in the money value of these articles of food, which cxists at nearly all times, makes it necessary to exercise a judicious choice in this respect, in order to secure the greatest profit. The feeding value of these various substances used as winter feed for shcep, raries greatly, as may be seen from the following table: 
COMPARATIVE NUTRITIVE VALUES OF GRAINS AND GRAIN PRODUCTS.

\begin{tabular}{|c|c|c|c|c|c|}
\hline IN 100 PARTS OF & 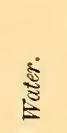 & $\begin{array}{l}\text { हैं } \\
\text { हैं } \\
\text { हैं } \\
\text { हैं }\end{array}$ & : & 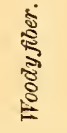 & चूँ \\
\hline Corn......... & 14.4 & 10.0 & 68.5 & 5.5 & 2.1 \\
\hline Oats ....... & 14.3 & 12.0 & 60.9 & 10.3 & 3.0 \\
\hline Barley .. & 14.3 & 9.0 & 65.9 & 8.5 & 2.5 \\
\hline Peas ... & 14.3 & 22.4 & 52.3 & 9.2 & 2.5 \\
\hline Rye............... & 14.3 & 11.0 & 69.2 & 3.5 & 20 \\
\hline Beans.... & 14.5 & 25.5 & 45.5 & 11.5 & 3.5 \\
\hline Buckwheat... & 14.0 & 9.0 & 59.6 & 15.0 & 2.4 \\
\hline Cotton-seed-cake without husks..... & 8.3 & 41.0 & $* 33.4$ & 9.0 & 5.3 \\
\hline Peanut Cake..................... & 11.0 & 40.00 & +38.5 & 4.5 & 6.0 \\
\hline Linseed Cake....... & 11.5 & 28.3 & 41.3 & 11.0 & 7.9 \\
\hline Bran, (Wheat)....... & 13.1 & 14.0 & 50.0 & 17.8 & 5.1 \\
\hline Bran, (Rye).. ...... & 12.5 & 14.5 & 58.5 & 15.0 & 4.5 \\
\hline Shorts, (Wheat) .................. & 11.65 & 11.75 & 61.42 & 8.29 & 4.2 \\
\hline Malt Sprouts....... & 8.0 & 23.0 & 44.7 & 17.5 & 6.8 \\
\hline Malt ............. & 4.2 & 8.8 & 76.3 & 8.0 & 2.7 \\
\hline
\end{tabular}

* Of this 16 per cent consists of oil. + Of this 11 per cent consists of fat and oil.

The analyses here given, however, are but an obscure guide as regards the comparative values of the different substances for producing fat. It is very important to arrive at a clear idea of this in feeding sheep, because the quality of the wool depends greatly upon the secretion of a requisite amount of yolk which consists in great part of oil and a matter approaching in character to wax, to say nothing of the desirability of rapidly producing fat. The fat-forming elements in any article of food consist of starch, sugar, gum, oil, and fat, all carbonaceous matters, or matters rich in carbon, with the addition of certain proportions of hydrogen and oxygen. The chemical composition of these elements is very similar, and in some of them is nearly identical. Thus an animal fed upon starch or sugar, may become fat, and it is well known that bees fed upon sugar are able to produce either honey or wax from this food. In the processes of digestion and assimilation, starch, sugar, and gum, are changed to fat. This fat is either consumed in the process of respiration, or is stored up in the tissues of the body, and increases the weight of the carcass. But in the consumption of food rich in starch, a much larger portion is necessary to produce a given weight of fat, or a given result in the process of respiration, than is required of a food rich in fat or oil. The relative values of fat or oil, and starch, as nutritive elements, is as one of the former to two and a half, nearly, of the latter, or exact$1 y$, as 10 is to 24 ; that is, $10 \mathrm{lbs}$. of oil or fat will go as far in producing fat or in maintaining respiration, and the natural heat of 
the body, in which process carbon is used up, as $24 \mathrm{lbs}$. of starch or sugar. Thus any food that contains 10 per cent of fat is of equal value to another which contains 24 per cent of starch. On reference to the table it will be found that corn contains 68.8 per cent of fat formers, while cotton-seed-cake contains only 33 per cent. But corn contains 5 per cent of fat, and cotton-seed-cake 16 per cent. The relative values of the two substances will therefore be as follows:

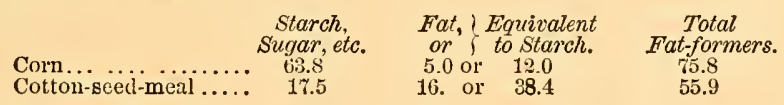

If the quantities of flesh-forming elements of each are added to the above totals, it will be seen that cotton-seed-cake having four times as much flesh-formers as corn, is the cheaper food of the two. Again, whole flax-seed contains 55 per cent of fat-forming elements, but as 37 per cent of these consists of oil, which is equivalent to 88.8 per cent of starch, the total fat-forming power of flax-seed is therefore equal relatively to $106.8 \mathrm{per}$ cent in pure starch. Cotton-seed free from the husk, and flax-seed, are therefore the most nutritive articles of feed for fattening. It is worth while here to call attention to the high value of the peanut after the oil is expressed, as food for stock animals we possess. As a substitute for oil-cake-meal where it cannot be procured conveniently, the following mixture has been suggested, viz:

Ground Linseed..........................40 lbs.

Wheat Bran..........................................

Flour of Bone............................... 4 " $-101 \mathrm{lbs}$.

The constituents of which per $100 \mathrm{lbs}$. are:

Flesh-formers, (albumen)...................

Fat-formers, (fat 11 per cent) $\ldots \ldots \ldots \ldots \ldots \ldots \ldots . . . . .51$ "

Ash or Saline Matter........................ \% " "

Water....................................15 " 100 lbs.

This makes a most valuable combination of feeding substances for a young growing animal, or a ewe giving milk. The greater nutritive value of fat is explained by physiologists from the fact that it is directly digested and assimilated, and enters into the circulation and nutrition of the animal without change, except a very fine mechanical division of its particles. On the other hand, starch and sugar undergo a series of chemical transformations in the course of which much of their volume and cffect are expended.

In choosing a variety of food then, for a special object, as for instance the feeding of a young growing animal; or the fattening of a mature animal and the sustenance of a sheep that produces a 
fleece rich in oil or yolk, as that of a pure-bred Merino, those foods which would furnish abundant flesh should be chosen for the one, and those rich in starch and oil for the others. By thus choosing judiciously and skillfully, there is an economy in the cost of the food, and the object sought is gained at the least expense.

Much may be gained by varying or mixing the food of an animal so as to stimulate the appetite; for a healthy animal will increase in weight in proportion to the food consumed solong as digestion and assimilation are perfect. If a sheep only eat $3 \mathrm{lbs}$. of hay per day, but will eat and digest in addition $6 \mathrm{lbs}$. of sliced turnips or beets, with a pound of bran sprinkled upon them, a manifest advantage is gained. If changing the hay for straw, 10 lbs. of turnips and $1 \mathrm{lb}$. of bran or oil-cake-meal can be consumed, the money value of the food may be reduced, and the sheep be equally well fed.

In estimating the amount of a sheep's food, it is necessary to take into consideration the age and condition of the animal. Whether it be in a growing state or in a state of maturity, its weight, and also the drain upon its vitality, as in the case of a ram serving a number of ewes daily; or a ewe in lamb, or suckling a lamb or a pair of them. On this account it is absolutely necessary to grade the flock and provide different quarters for those which need special feeding or care. As a guide for the estimation of a proper quantity of food, and for a judicious selection of the kinds which may be fed, it will be useful to consider the following instances.

In an experiment recently made by Dr. Voelcker, the chemist of the Royal Agricultural Society of England, four sheep were fed for seven weeks upon $196 \mathrm{lbs}$. of clover hay, $49 \mathrm{lbs}$. of linseed-cake-meal, and $3,743 \mathrm{lbs}$. of mangels; equal to a daily ration for each of $1 \mathrm{lb}$. of clover hay, 4 ounces of linseed-cake-meal, and $19 \frac{1}{2} \mathrm{lbs}$. of mangels.

The nutritive elements contained in this daily ration were equivalent to $4 \frac{1}{8}$ ounces of flesh formers, $53 \frac{1}{2}$ ounces of fat formers, and $4 \frac{8}{4}$ ounces of mineral matter.

Upon this mixed diet the sheep thrived and gained weight as follows :

\begin{tabular}{|c|c|c|c|}
\hline & $\begin{array}{l}\text { Weight at } \\
\text { commencement. }\end{array}$ & $\begin{array}{c}\text { Weight at } \\
\text { end of } 7 \text { weeks. }\end{array}$ & $\begin{array}{l}\text { Gain in } \\
\text { weight. }\end{array}$ \\
\hline No. $1 \ldots$ & $153 \mathrm{lbs}$. & $170^{1} / 4 \mathrm{lbs}$. & $171 / 4 \mathrm{lbs}$. \\
\hline No. 2... & $334 " 6$ & $1511 / 4$ & $171^{1 / 4}$ \\
\hline $0.3 \ldots \ldots$ & $170 " 6$ & 187 & 1766 \\
\hline No. $4 \ldots . . .$. & 135 “ & 155 & 20 \\
\hline
\end{tabular}


The gain on the average was equal to one pound in three days; or an increase in weight of one pound for every $56 \mathrm{lbs}$. of food fed ; or for every 62 onnces of dry matter contained in the foocl. This is a very good instance of a typical fattening food for an orclinary sheep of this size. The results of a large number of experiments made in feeding roots to sheep, go to show that $150 \mathrm{lbs}$. of ruta-bagas, or mangels, fed in open yards, or $100 \mathrm{lbs}$. fed in yards with sheds for protection, may be expected to produce one pound of increase in live weight. When $1 \frac{1}{2}$ lbs. of a mixed feed of oilcake and peas were given daily, along with $18 \frac{1}{2} \mathrm{lbs}$. of ruta-bagas, fed under shelter, the gain was equal to $2 \mathrm{lbs}$. for every $100 \mathrm{lbs}$. of roots, and $4 \frac{1}{2}$ ibs. of mixed peas and oil-cale; showing that $4 \frac{1}{2} \mathrm{lbs}$. of peas and oil-cake produced an increase of one pound in the live weight. A number of experiments in feeding clover hay with linseed-oil-cake-meal, have established the fact that, allowing $6 \mathrm{lbs}$. of oil-cake-meal for one pound of increased live weight, it required 11 to 13 lbs. of hay to make an equal gain. In feeding peas and beans with roots and hay, $8 \mathrm{lbs}$. of the mixed grain was found to produce an increase in weight of one pound. When oats were fed with the roots, there was one pound of increased weight for $7 \mathrm{lbs}$. of the grain. When barley was substitnted, 6 lbs. of the grain prolueed a gain of one pound. Thes interesting experiments are recorded in the Journal of the Royal Agricultural Society, Vol. I, p. 169; Vol. VII, p. 295; Vol. VIII, pp. 27, 28, and 256; Vol. $\mathrm{X}, \mathrm{p} .358$, and the Highland Society's Transactions; and are substantiated by exporiments made by Messrs. Lawes an 1 Gilbert, of Rothamsteal, in which they found that $272 \frac{1}{2}$ lbs. oil-cake, $252 \frac{1}{2}$ lbs. clover hay, and 3,753 lbs. ruta-bagas, fed together, produced $100 \mathrm{lbs}$. of increase. These results must of course be accepted as subject to variations in the quality of the various feeds, the kind and condition of the sheep, the state of comfort and repose in which they are kept, and the care and attention given to them. But making every allowance for contingencies, it may be safe to estimate from these results, that the relative quantities of the different feeds required to produce one pound of flesh, are as follows

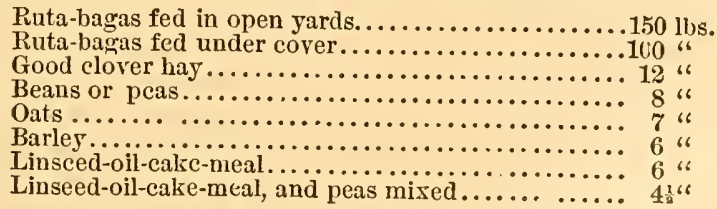

The last quantity mentioned, curiously enough corroborates the 
personal experience of many shepherds, and the remark heretofore made to the effect that much is often gained by varying or mixing the diet of sheep. In this instance the same effect is gained by the use of three-fourths the quantity of the mixed feed, as by the whole quantity when given separately. The actual money cost of the feed may thus be estimated nearly enough for all practical purposes. In estimating the values of the kinds of food more commonly used in the United States and Canada, there are but few really trustworthy data to depend upon, as the careful experimental feeding of animals for scientific information, has rarely been attempted. We have nevertheless amongst the current agricultural literature of the day, many recorded results contributed by careful and eminentiy capable and trustworthy men. From amongst these the following have been selected as being practical and to the purpose. In an article communicated to the Country Gentleman, by the Hon. George Geddes, of Fairmount, N. Y., in May, 1875, are given, the cost of feeding, and the gain in weight of 290 sheep fed by Mr. O. M. Watkins, of Onondaga County, during the previous winter, and particularly the cost, etc., during the month of January. The flock consisted of 100 grades, being half Merino and half Cotswold; another 100 that were Merinos, and 90 were called full-blooded Cotswolds, (probably high grades). All these sheep were fed alike, each having one pound of corn daily -half of it fed early in the morning, the other half at sunset. Straw and chaff were fed during the day, and one feeding of hay at night. The corn was worth 80 cents for 60 pounds, the hay $\$ 10$ a ton. The quantity of hay fed was reported as equal to 1.3 pounds to each sheep per day-making 40 pounds for the month, worth 20 cents. The corn for the same time was worth 41 cents, making the cost of corn and hay for each sheep for the month, 61 cents.

The 100 Merino and Cotswold grades increased from $117 \frac{1}{2} \mathrm{lbs}$. each to $128 \frac{1}{4}$ pounds, this being a gain for each sheep of 10 pounds, and making the cost of each pound 5.67 cents. The 100 Merinos weighed Jan. 1, $94 \frac{1}{4}$ pounds each, and Feb. 1, 101 $\frac{1}{2}$ pounds-gaining $7 \frac{1}{4}$ pounds each, at a cost of 8.4 cents. The 100 so-called full-blooded Cotswolds weighed 118 pounds each Jan. 1, and Feb. 1, 1231 -gaining only $5 \frac{1}{4}$ pounds each, at a cost of 11.6 cents per pound. Upon these facts, Mr. Geddes comments as follows: "The manure made during the time by these sheep, I consider worth more than the manure that wonld have been made by the same number of pounds of beef cattle. Thirty-two steers, each weighing 1,000 pounds, would almost cxactly equal the total number of pounds of these 
three flocks of sheep when they were weighed in the yards on the 1st day of January. All the labor involved in feeding and taking care of the sheep, would not equal that of cleaning the stables for the steers. MIr. Watkins purchased the 290 sheep well, and sold them well, and he reports his winter's doings with them as follows:

Cost of 290 sheep, (nearly 4c. per Ib.), ....\$1,260 61

do. 435 bushels of corn, at $80 \mathrm{c} . . . . . . . . .34300$

do. 13 tons of hay, $\$ 10 \ldots \ldots \ldots \ldots \ldots \ldots .613000 \quad \$ 1,73861$

Feb. 28th, sold 270 at $\$ 8$ each........... 2,160 00

do. do. 18 culls, $\$ 4$ each............ 7200

Two sheep got cast; sold pelts for \$2 each. $\quad 400 \quad 2,22600$

Profit.............................. $\$ \frac{\$ 49739}{}$

"This pays over $\$ 1.71$ for the trouble of buying and selling and risk on each sheep, if we call the manure pay for the labor of caring for the sheep. The price of hay is here very low this season, but corn is very high. Straw and chaff we consider as of but little value for manure, unless worked over by the feet of some animal, and used as an absorbent for their manure. For this reason we credit the sheep with the work of converting a large quantity of straw and chaff into available food for plants.

"I do not give Mr. Watkins" experience as an average, for it is far better than auy average that he can make for a series of years. Nor do I think it is by any means conclusive as between the breeds of sheep that he fed. The grade Merino and Cotswold I sold him the 21st day of last December. They were all ewes, 2 and 3 years old, and were a very even, and in all respects a clesirable lot. The other flocks I did not see, but I suppose, from information, that they were not so eren or desirable; and sleep here usually called full-blooded Cotswolds, come from Canada or the border, and are not very good, perhaps they are mostly the culls of the flocks they came from. After all reasonable allowances have been made, the lesson of this winter's work of Mr. Watkins is certainly that sheep are rnuch more profitable makers of meat than steers, such as can be bought in Buffalo in the fall of the year, and they are still better manufacturers of straw and other coarse forage into manure."

Both the facts here given, and the relator's comments, are very ' valuable. From the statement as to feed and gain in weight, the following deductions as to the value of the corn fed for producing increase of weight, may be made. Taking the three flocks, we have the following results for each, accepting the feeding value of hay as previously given, as a basis for a portion of the increase: 
GRADE MERINO AND COTSWOLD, AVERAGE GAIN, 103 LBS.

Feed consumed. Gain in weight. Ibs. of feed for $1 \mathrm{lb}$. of gain.

$\begin{array}{llr}40 \mathrm{lbs} \text {. of liay. } & 31 / 4 \mathrm{lbs} . & 12 \mathrm{lbs} . \\ 30 \mathrm{lbs} \text {. of corn. } & \boldsymbol{\gamma}^{1 / 2} \mathrm{lbs} . & 4 \mathrm{lbs} .\end{array}$

MERINOS, AVERAGE GAIN, $\% 1 / 4$ LES.

Ferd consumed. Gain in weight. lbs. of feed for 1 lb. of gain.

40 lbs. hay.

30 lbs. corn.

$$
\begin{aligned}
& 3^{1 / 4} \mathrm{lbs} \text {. } \\
& 4 \text { lbs. }
\end{aligned}
$$

COTSWOLDS, AVERAGE GAIN, 51/4 LBS.

Feed consumed. Gain in weight. tbs. of feed for 1 lb. of gain.

$\begin{array}{lll}40 \mathrm{lbs} \text {. hay. } & \hat{i}^{1 / 4 \mathrm{lbs} .} & 12 \mathrm{lbs} . \\ 30 \mathrm{lbs} \text {. corn. } & 2 \mathrm{lbs} . & 15 \mathrm{lbs} .\end{array}$

These different floc'zs were evidently uneven in quality, and as Mr. Geddes, who sold the first flock to Mr. Watkins, is an excellent and experienced farmer and stock feeder, it may easily be supposed that the sheep were in excellent condition and well prepared for fattening. The productive value of corn, in the case of this flock, may well be considered as exaggerated, as in the other instances it would be diminished by reason of the poorer quality of the sheep. A mean may therefore be taken, and the gain resulting from feeding the corn estimated as between the two gains of 4 and $7 \frac{1}{2}$, thus giving an average of about $6 \mathrm{lbs}$, , and bringing corn to an equality of value with barley or linseed cake, if not showing it to be superior to either. If the result of feeding the first flock be taken as the basis for the estimate, it would certainly show corn to be a feed of the highest value for fattening sheep; but one result can hardly serve as a basis upon which to found such a rule. Mr. R. J. Swan, of Genera, N. Y., in a communication in the Third Vol. of Rural Affairs, stated his plan of winter feeding; he gives to each hundred fattening sheep, two bushels, (126 lbs.), of corn, or the same quantity of oil-cake-meal per day, with wheat straw in racks three times a day, up to the 1st day of March ; afterwards feeding hay instead of straw, and reducing the corn or oil-cake-meal one-half. The lambs are fed hay three times a day, with three pecks of oil-cake-meal, or corn-meal, per 100. It is to be presumed that hay is fed ad libitum, although this account would have been more satisfactory had the quantity fed been stated. In a prize essay by Mr. Jurian Winne, of Albany County, $\mathrm{N}$. Y., the following hints for the winter feeding of sheep are given: "By feeding liberally with roots, and not too much grain, during the first week at least, the change from green feed to dry will be less apt to affect the sheep. In feeding, unless a person can do it himself, which is very seldom the case, the feeder should 
be instructed with great care, how much grain is to go to each yard or stable according to the animals it contains. An over-feed at the commencement is almost sure to bring on the scours, and after the sheep are over it, it will take at least two wecks' good feeding to put them where they started from. My mode, to avoid mistakes, is to number my yards and stables, and count the sheep in each yard and stable-allowing to each sheep one-half pint of grain per day to start with, unless they have been fed grain previously, when I allow a little more. I then make out a schedule thus: No. 1-60 sheep at one-half pint per day is 15 quarts, which divided into two feeds, is $\tau_{\frac{1}{2}}$ quarts to a feed; so I write on the schedule, 'No. 1-60 sheep must have $7 \frac{1}{2}$ quarts at a feed morning and night,-No. 2 at the same rate according to number, and so on until I get them all. This paper is tacked up in the place where the feed is kept, and by going with the feeder a few times to show him and see that he makes no mistakes, if he is a good man he can do it as well as the farmer himself. As soon as the feed is to be increased, a new schedule is made out accordingly, and so on, until the sheep are fed one quari each per day, when I consider them on full feed, especially if the feed is corn, beans, or oil-meal, or a mixture of either. If oats or buckwheat compose part of their feed, they should lave a little more. Regularity of hours is very important. Sheep should not be fed one morning at five o'clock, the next at six, and the third at seven. Our rule is this : Grain and oil-meal are fed at half-past five A.Mr. As soon as the grain is finished, hay is given-no more than the sheep will eat clean. The different yards and stables are carefully fed each day in the same order, which is important to avoid confusion and mistakes-beginning with No. 1, and so on through the list. After breakfast, water is given, going around twice to see that all are well supplied. The roots are next cut, (ruta-bagas, which I consider best), and of these to my present stock of abont 350 sheep, I am now feeding 10 bushels a day. At eleven o'clock straw is fed. Twelre is the dinner hour, and immediately after dinner the roots are fed. The troughs and tubs are now all examined, and replenished with water if necessary-also salt, salt and ashes, browse, litter, and anything else that may be needed, is supplied. The evening and next morning's feeds of grain and oil-meal are next prepared, and hay got ready for both night and morning. At 4 P.x. feeding the grain is again commenced, followed as before by hay, after which the water tubs and trouglis are emptied and urned over, and the work is finished for the night."

The value of roots for winter feeding is very inadequately esti- 
mated in the United States, but it may be well questioned if a flock of sheep can be profitably or successfully kept without them. A certain portion of water must be taken with the food every day. The more intimately this is mixed with the food, the better for the digestive process. In feeding 12 lbs. of roots to a sheep 80 to 90 per cent, or $4 \frac{1}{2}$ to 5 qts. of water are given in them. By the process of mastication the water is intimately mixed with the solid matter, and a semi-liquid pulp is formed exactly fitted for the ruminative and digestive processes of the stomach. By cutting or pulping the roots, and sprinkling or mixing the ration of meal, bran, or grain, upon or with them, the whole food reaches the stomach in the most appropriate condition possible. Digestion proceeds uniformly, the stomach does not need to be supplied with a large quantity of water at any time, and its solventjuices are not diluted and weakened. The bowels aet regularly, and constipation, one of the most tronblesome disorders of the flock when on dry food, is avoided and prevented. But the daily ration of roots must be apportioned with care and judgment. For lambs 5 to 6 lbs. daily will be sufficient; for two-year-olds and mature sheep, 10 to 15 lbs. will be an ample allowance ; the smaller quantity being enough for a Southdown, and the larger for a full grown Cotswold, Leicester, or Lincoln. For a Merino a much less quantity should be apportioned, as this breed cannot produce a fleece of good quality, or great weight, without being supplied with enough oily matter to secrete the large amount of yolk which their fleece contains.

Of all the roots usually grown, the sugar-beet is the best for sheep, being the most palatable, and containing the greatest proportion of solid nutritious matter. For every 100 sheep to be fed with roots at the rate of ten pounds per head per clay, cluring the feeding season of 5 months, about 4 acres clevoted to this crop will be required, yielding about 18 tons, or 550 to 600 bushels per acre. This is a small estimate, and only half the yield of a good or a possible crop, but is near that of onr average crops. The amount of food necessary to keep a sheep in good thrifty condition has been determined to be 15 pounds of actually dry substance per week for each $100 \mathrm{lbs}$. of live weight. As grain and hay contain about 14 per cent of water, this allowance will be equal to about 18 lbs. of hay or grain, or nearly 3 lbs. per day. But as for the perfect digestion of the food, a certain bulk is requisite, the mixed daily ration should be composed of such proportions of bulky and concentrated food, that 7 to 9 pounds are required to produce ar. increase of one pound in live weight. From the data previously 
given, it will not be dificult for the intelligent reader and shepherd to arrive at a correct judgment, and conform his plan of feeding to the peculiar circumstances of his flock, and with a view to the greatest profit.

\section{EARLY MARKET LAMBS.}

There are some special objects in the winter feeding of sheep which require particular methods of management to ensure success. In regard to feeding store sheep, and when the chief object. is the increase of the flock, and the healthful growth of the fleece, nothing need be said beyoud what has been given in the preceding pages. But special management is needed for the production of early market lambs, and for the fattening of sheep purchased to ensure profit both in money and manure; in regard to these cases some special explanation may be pertinent. The production of market lambs, if rightly wanaged, may be made rery profitable. This business may be followed on a suitable farm anywhere within 150 miles of a good market. The markets for lambs are found chicfly in the large eities, Washington, New Fork, Boston, Philadelphia, Baltimore, and Albany being the chief eastern markets, and St. Louis, Cincinnati, and Chicago, the chief western ones. Some few of the southern cities offer good markets for lambs early in the spring. April, May, and June are the months when the prices are the most remunerative; after. June the prices per pound for lambs are but little more than those for sheep. In A pril and May, a lamb weighing 40 pounds will often sell for $\$ 10$. Those farmers who make the raising of early lambs a special business, follow one of two methods. In one ease they kecp a permanent flock of ewes, sclected for their good character as nurses and milkers, quict in disposition, docile, and easily managed, and ready to act as foster mothers to other lambs whose mothers have been sent away. The other plan is to purchase, late in the summer, a flock of ewes, as well seleeted as may be, from which to raise a crop of spring lambs; the ewes are then shorv, and afterwards fattened and sent to market before the year is complete. Which of these two methods would be the best to adopt depends upon circumstances. The first plan needs for its successful operation a farm suitable for pasturing sheep, or which has at least sufficient suitable summer pasture for the flock. For the second plan little or no pasture is required; a rongh field in which the ewes may run while being fed for market, or a run upon the elover sod to be plowed for corn in May, being all that is required. A 
stock of ruta-bagas, which keep in excellent condition until June, if needed so long, is provided as a substitute for grass while the ewes are being fattened. This latter plan is well suited as an additional inchstry upon grain or dairy farms, in which some edditional capital may be turned over with a prospect of its being returned in less than a year with a gain of 100 per cent in money, besides a valnable adcition to the manure heap.

The selection of ewes and a ram from which to raise market lambs, is the chief point for consideration, the wool being a secondary object. The form of the sheep and their temperament are the first points to be regarded in their selection; but if the flock is to be kept permanently, it is best to procure sheep which will yield a good fleece as well as a good lamb, as this will add to the profit. Single lambs of good size, are more profitable than twins, which will generally be of smaller growth. It matters little about the breed, as this is not a point with the marketmen, although a black-faced Southdown is most in favor with them, because of its usual plumpness and fatness. A lamb from a grade Merino ewe, and a Southdown or Shropshire ram, is fat at any age, and is soon ripe for market, and will sell better than a larger lamb that is more bony and less plump. A cross from a grade Merino ewe and a Cotswold ram, is the next best lamb, if not altogether as good a one. A large bodied, short-legged, broad backed, native ewe, with some Merino and Southdown blood in her composition, is, perhaps, all things considered, the best sheep that can be chosen for a dam. A pure bred Southdown, Shropshire, or Cotswold ram, makes the best sire, the preference to be given in the order in which they are here named. Ewes that produce twins should be weeded ont of the flock, and those which bring a large lamb, and have plenty of milk, and are gentle and kind to their lambs, should be kept as long as they will breed. Ewes have been kept until 13 years old that have yearly brought and raised a lamb to maturity for market, without missing a season, or losing a lamb. One ewe of this kind may be made to pay the interest on $\$ 100$ cach year, and $i t$ would be well to raise the ewe lambs of such choice dains to replenish the flack. Some ewes will raise twins, and by skillful manarement, a ewe whose lamb has been sold may be made to foster another lamb, or at least be foreed to help feed it. If the cre shows any reluctance to adopt the strange lamb, she should be confined in a small pen, at stated times, and the lungry lamb turned in to her. The lamb will generally succeed in getting all the milk from her. If she is more than usually reluctant, she should be held while the lamb sucks, or be confined in stanchions 
(as described in a prerious chapter), for a time, until she becomes reconciled. The ewes thus made to serve as foster mothers will, after two or three seasons, accept the situation, and readily adopt the second lamb. In some flocks a lamb has cecasionally sucked three ewes, and in some cases, some enterprising lambs will forage around and get a meal from any ewe that will permit it to suek. It will be necessary to curb the enterprise of such lambs occasionally, lest they rob the others. When a flock of ewes is purchased each year, in August or early in September, they must necessarily be picked up in the most convenient manner, either from passing droves, or some well known drover may be engaged to procure them. Fairly good ewes may generally be procured by either of these methods for about $\$ 3$ per head. In selecting ewes from a drove, care should be taken to examine the teeth to ascertain their age, and none less than three or four years old, or what are called "full mouthed" eres, should be chosen. The ram should be chosen in this case as in the previons one. Whatever breed may be selected, compactness of form and vigor should be looked for, rather than size; a moderate sized ram, with a large roomy ewe, will produce a better lamb than a pair of the opposite characters. High condition in the ram is not desirable; a merely fair condition is more conducive to certainty in getting lambs; nor in this business is it best to confine the ram; the exercise with the flock being better for the animal's health than confinement. If the flock is too large for the one ram, it should be divided and separated, or two rams used, each being shut up on alternate days; no more than 50 erres can be served by one ram in the time during which the scrvice is required-or at most 40 to 60 days-for this is the time during which the season for selling lambs continues. The ram should not be less than three jears of age. As erres go fire monthis, or about 150 days with young, those ewes that are serred in the latter part of Angust will have lambs in January, and these lambs, withont any forcing, can be made marketable in April. All of the lambs should be dropped before the middle of March, and it will be found advisable and convenient to so apportion the ewes to be sarved, that the dropping of the lambs may be spread orer the whole of this period as regularly as possible. The presence of dogs about a flook of this charaeter should not be permitted. They are not only entirely useless, but are really an annoyance and an injury. After the lamb is a few days old, if thought necessary, it may be taught to suck some warmed, sweetened cow's milk, and any help to its growth, in the shape of extral food, will be useful. There is danger, however, of over-fceding a young lamb, which 
may be worse than under-feeding it, and caution is to be exercised in this respect; no more should be attempted than to encourage a healthy, thrifty growth. After the lamb is four weeks old, it may be taught to lick some fine bran, with a little salt mixed with it, or a little sifted oatmeal. As a rule, it will be safer to depend on increasing and exriching the ewe's milk, rather than to foree the lamb to swallow food which its stomach is not as yet able to completely digest. It is highly important to prevent the lambs from being annoyed and depleted of their blood by ticks or other vermin. To this end the ewes should be dipped in the fali to rid them of : ticks, and if a few should appear in the spring upon the lambs, they should be freed from the insect pests by careful nand-picking,

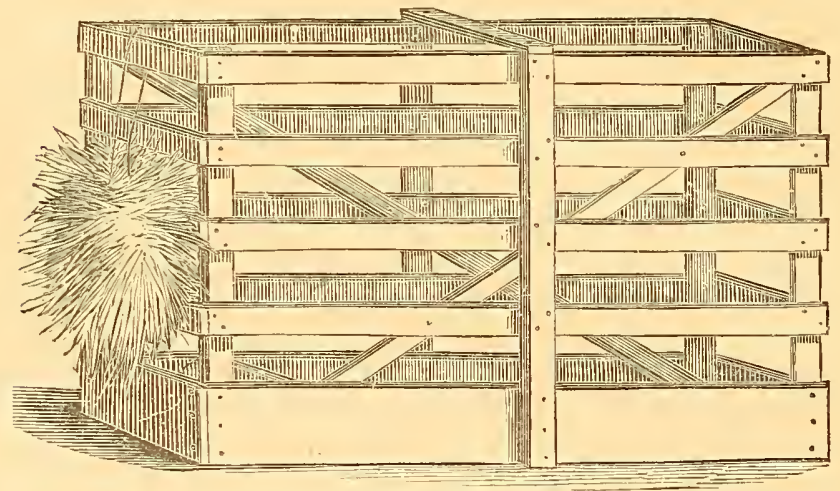

Fig. 28.-PACKING BOI FOR LAMBS.

repented if necessary. In case the ticks should be too numerous for hand-picking, the lambs may be dipped. This will be absolutely necessary if they are to be kept until after the ewes are shorn, as then the ticks will leave the ewes on which they are unsheltered, and seek refuge in the closer fleeces of the lambs. When this happens, the growth of the lambs is suddenly stopped, and it is often the case that some of them are tormented until they finally die.

The marketing of the lambs is one of the most important parts of the business so far as profits are concerned. As has been said, the early lambs bring the highest prices, but it may be that the later lambs will be found the most profitable, as being less cosily and troublesome to rear. When the proper market has been found, 
and a trustrorthy commission agent to whom they can be sent for sale has been selected, the method of packing for shipment should be well considered. A roomy bor, in which the lamb can stand or lie, but cannot turn round, should be procured for each lamb. Figure 28 represents a crate in which the author has shipped many lambs to market without a single case of accicient from any cause. The size is 36 inches long, 24 inches high, and 18 inches wide. It is made of lath 2 inches wide by 3 quarters thick. The best fastening for the top was found to be four pieces of soft tristed tarred hempen cord of the kind known as lath twine, and used for tying bundles of laths, at the saw mills. This form of box is also suitable for shipping stock lambs; these have been safely sent in them from New York to Charleston, S. C., and also as far as Denver, Col. In case of shipping to a distance, a bag of feed is tied to one of the upper corners of the box, containing sufficient to last through the journey, and a feed trough is fixed at each end of the bor, so that in case the lamb is carelessly put in wrong end foremost, or happeas to tura around, a trough is ready for use where it is wanted. On the shipping card should be plainly printed directions to the express agent to give half a pint of feed and water twice a day to the lamb. Shipments for short distances should always be made by express, so that there may be no delays. The time of shipment shonld be so arranged that the commission agent may be on hand to attend to the lambs on their arrival. For distances of not over 100 miles, the time of travel is so short that no feed or water is needed on the way, but the lambs may be fed lightly and watered before they are placed in the boxes. In this way the lambs travel with so little inconvenience that no loss of weight occurs, a matter which, when the price is 25 cents a pound, is worth consideration. The business of marketing lambs is extensively carried on in the neighborhood of large cities in the east, and thousands of ewes are yearly purchased in Ohio and western parts of New York and Pennsylvania by drovers from New Jersey, and eastern $\mathrm{Nem}$ York, and Pennsylvania, in the early fall, for selling to farmers who keep them orer winter, raise lambs the next spring, and scll lamb's fleeces, and the fattened sheep within twelve months, and repeat the operation yearly with great profit. $\Lambda \mathrm{s}$ an illustration of what may be clone in this way, the following may be cited: "Fifty-five ewes were purchased at \$3 per head, and unitil winter were pastured in a rough field at the rear of the farm, where they more than earned their keep and care, by the service they performed in destroying weeds. The account for one year, opened and kept expressly for this flock, is as follows: 
Dr.

Cost of 55 sheep .....................\$165.00

Value of hay, turnips, bran, meal, and oil-cake, fed. 205.81

Freight and charges on 24 lambs............... 7.92

Balance of profit and loss................... 145.64

$\$ 524.40$

CR.

21 early lambs sold at from $\$ \gamma @ \$ 10$ each............ \$192.00

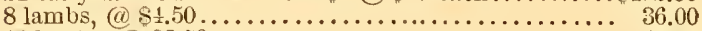

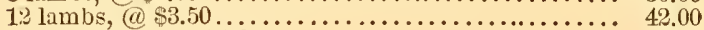

8 lambs kept,@\$4.00...................... 32.00

9 los. pulled wool, @30c....................... 2.70

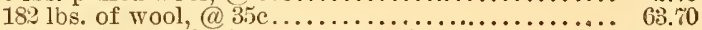

5 . sheep on hand ( 3 killed by dogs).............. 156.00

$\$ 5 \Re 4.40$

This leaves a profit of nearly 100 per cent. on the original cost of the sheep, and in addition a large pile of valuable manure, of which no account was kept."

\section{FATTENING SHEEP FOR MARKET.}

Where the clistance from market prevents profitable shipments, and the home market furnishes insufficient encouragement to breed early lambs, the purchase of sheep for fattening may be made a special business with great advantage. In this business the proper choice of sheep and shrewdness in purchasing are as necessary to success as are skill in feeding and choice of proper food. Where grades of Leicester or Cotswold sheep, such as are known in the American markets as Canada sheep, can be secured, those are the most profitable to purchase. The next best sheep are grade Sonthdowns; but little profit is to be made out of our native sheep in feeding them for mutton. They are poor feeders, and difficult to clothe with flesh or fat, and the farmer who would purchase sheep to feed for profit, should avoid them. He had better keep such sheep for breeding, crossing them with a thoroughbred Cotswold ram and feeding the produce.

A statement given by Mr. Jurian Winne, of Albany Co., N, Y.; in the Annual Register of Rural Affairs for $186 \%-8-9$, will be found of interest. In this case two lots of sheep from a large flock were set apart for feeding; they consisted of 60 grade Leicesters from Canada, and 61 Merinos; they were weighed Feb. 10th, and a careful account was kept of the food consumed during 46 days, up to March 28th, when they were weighed and sent to market. The selection was simply made as a test, and to aroid the trouble 
of keeping an accurate account of the whole flock, which were treated in exactly the same manner as these. The following figures give the result:

Feb. 20, c0 grade Leieesters weighed......... 8,8\%0 lbs. March :8, 60 grade Leicesters weighed.......... 9,878 lbs.

Gain in weight .................... $\overline{1,008}$ lbs.

Feb. 20, 61 Merinos weighed............... 6,909 lbs.

March : 8,61 Merinos weighed................ 7,389 lbs.

Gain in weight .................... 480 lbs.

Cost of feed for the first lot................\$174.43

Cost of feed for the second lot.................. 141.78

Against the cost of feed there are the gain in weight at $10 \frac{3}{4}$ and $10 \frac{1}{2}$ cents a pound respectively, the advance in price upon the whole weight, consequent upon the improved condition of the sheep, and the manure left. On the whole, there was a profit upon the first lot and a loss on the second one. Experience teaches that the proper selection of the breed of sheep is a very important consideration. It would be wise for such as have not had experienee, and who do not understand how to choose sheep for feeding, as well as how to feed and market them judiciously, to avoid the business, until by small ventures, they have learned how to succeed with larger ones. To buy judiciously is the great point, for "a flock well bought is half sold."

VALUE of MaNure.-The manure of sheep is naturally rich; their mastieation and digestion are so perfect that seeds of weeds are utterly destroyed in the passage through their intestines, and additional value is readily given to the manure by feeding a portion of concentrated food, sueh as oil-cakes, corn-meal, or bran. The urine and dung of the sheep are both very rich in fertilizing: elements. The urine contains 28 parts in 1,000 of urea, which is a highly nitrogenized substance, and 12 parts in 1,000 of salts, rich in phosphoric acid; the remainder is water. The fresh dung contains:

Of water....................... 68.0 per cent. $\Lambda$ nimal and vegetable matter............. 19.3 per cent. Saline matter or ash................ 12.7 per eent.

100.00 per cent.

The organic matter is rich in nitrogen, so much so, that 36 parts of the dung contains as much nitrogen as 54 parts of horse dung, 63 parts of pig's dung, 125 parts of cow's dung, and 100 parts of mixel barn-yard manure. The manure yielded is dry, and contains less water than that of other farm animals; thus for $100 \mathrm{ibs}$. 
of dry fodlder, the horse or cow yields $216 \mathrm{lbs}$. of fresh manureequal to $46 \mathrm{lbs}$. dry-while the sheep gires but $128 \mathrm{lbs}$. of moist manure-equal to 43 lbs. dry. It ferments rery quickly, and needs therefore to be kept solidly packed under foot, and free from access of air, or to be turned frequently when heaped in the yard. When the manure, made in the ordinary course of feeding, possesses this high relative value, it may readily be believed that when fattening sheep are bighly fed with stimulating food rich in albnmen and phosphates, the starch and oil only being assimilated in the production of fat, and the others being used only in parttheir dung forms a very rich and valuable manure. This is thoroughly well understood by English farmers, who practise the feeding of sheep more with a view to the value of their manure than for profit in other ways, and it is unfortunate for us that we do not so thoroughly appreciate this as to practise it ourselves. The following quotation from a paper upon this subject, read by an English farmer at a meeting of a farmers' club, and reported in an English agricultural journal, very clearly sets forth this vicw :

"The manurial value of oil-cake, when used regularly on a farm, can scarcely be over-estimated, the dung made in the stalls being so vastly enriched as to enable it to be spread over an extended acreage, with better results than could possibly be obtained from the same bulk alone, whatever the area to which it might be applied, and the effect is discernible on the color and quality of the pasture for a much longer period. The improvement effected on grass-land by cake-fed stock is an example of the utility and value of this excellent food which every one can understand, its action in this way being quicker, and so distinet as to be unmistakable. With sheep the improvement is peculiarly striking when netted [confined by nets or hurdies] over a pasture field and largely cakefed, the droppings, both liquid and solid, being so regularly distributed over the surface, that every rootlet is reached and nourished, and the herbage is accordingly forced into extraordinary luxuriance."

Another special branch of sheep keeping, which offers advantages to farmers favorably situated for it, is the raising of a good class of sheep to meet the demands of those who purchase for the purpose of raising lambs, or for winter feeding and fattening. Where markets are too cistant to enable these branches of sheep husbandry to be profitably followed, a good class of stockers or drover's sheep might be raiserl. Half-bred, long-wool mutton sheep could be raised in every western state and shipped to the great central markets of Kansas City, Chicago, St. Louis, Buffalo, and else- 
where, to be disposed of to drovers, or to farmers themselves who are seeking a supply of store sheep. This would give an opportunity of increasing the supply of long wool, so much needed, and of decreasing that of fine wool now too plentiful to maintain prices satisfactory to fine wool grower's. The season for marketing these sheep would be in August and September, the time in which they are most in demand, and one in which the western pastures generally fail. It may be that in a few years, at some or all of these points, and many others, there may yet be seen great sheep markets at stated periods, something like those of Ireland, Scotland,-or England, at which 40,000 to 80,000 sheep are offered for sale, and bought and paid for in a couple of days. When sheep breeding becomes fully developed in Aruerica, these markets will probably have been found needful, and bave grown and developed from necessity, as has been the case elsewhere, and such an economical and convenient clivision of labor as this may become a regular and systcmatic part of the business of sheep farming.

\section{$\rightarrow+\infty$ \\ CHAPTER T.}

\section{BREEDING AND BREEDS OF SHERP.}

The strength and vigor that results from the fixity of type, which is so marked a characteristic of wild races of animals, come through what is called the natural selection of parents. It is the natural force and strength of the most vigorous in perpetuating their kind, together with the hardening influences of exposure, which give them their strong constitution and great power to resist misfortune. The race is perpetuated only by the strongest, because weaker members perish from the hardships necessarily borne by a wild race, or are driven off or destroyed in the desperate conflicts which oceur between the males at the breeding season. To gain strength and vigor, the most skillful breeder conld follow no more effectire course than the one here indicated. The matural power possessed by the thoroughbred male animal to transmit his qualities, which power is recognized amongst breeders by the term "prepotency," fixes the type of the race which through this influence becomes homogeneous; every member presenting exactly the same character in form and habit. But when a race of ani- 
mals becomes domesticated, necessities arise which call for something more than mere vigor of constitution, although this should always remain a vital point in the breeders estimation. The sole aim of the stock breeder is profit, and this lies not so much in a long life as in early maturity. The total result of six or ten years of the life of a wild animal is crowded into two or four years of a domesticated one. The capacity for consumption of food, and the abiiity to turn a larger cuantity of food into flesh or wool in a shorter time are gained by the slill of the breeder, and in c $u$ urse of time the quality of the product is refined and improved until hardly a semblance of the original stock remains in the highly-brecl, improved animal. The rapidity with which these effects have been prodnced by some of the most skillful sheep-breeders is wonderful, and the names of Bakewell and Webb will be remembered, and their successes perseveringly emulated for many years to come. No animal is more easily improved in character, and none yields more readily to the breeder's art, than the sheep. But the reverse is also true, for if on the one hand success rapidly rewards the successful breeder, failure as rapidly warns the unsnccessful one that he has maje a mistake, and must immediately retrace his steps.

The management and selection of any existing breed of sheep, or of the production of any new breed or variety, must be a question of profit. The point for the farmer to consider is, what kind of sheep will pay him best to keep, taking into consideration his locality, his soil, the crops he can conveniently raise with which to sustain them, and his markets for disposing of his wool and his animals, whether as lambs or as store sheep, or fat sheep fit for the butcher. For want of thorough acquaintance with the habits, characteristics, and peculiarities of the various breeds, many a farmer has made a fatal mistake, and failed, when otherwise he might easily hare been successful. The results of these mistakes in selection, and errors of management, have led to much disappointment and disgust. One of the most serious errors of our breeders and farmers, is the endeavor to maintain up to a certain standard of excellence in this country, in spite of all the differences of climate and varieties of food, the highly bred races of English sheep, which have been imported from time to time. Nearly every flock of all the pure races has failed to keep up to the original standard, although new importations bave been added to them. The farmer who has purchased a few sheep from such flocks, being without the requisite knowledge as to their management, or not possessing the fitting food for them, has found them 
to dwindle away from day to day until only a sorry remnant has been left which has been finally absorbed into a flock of hardier natives, or has disappeared altogether. Had these farmers judiciously purchased male animals only, and used them, under proper restrictions, for the improvement of their uative sheep, they would in time have possessed flocks which they could have managed successfully and profitably, and have secured a permanent type suited to their locality and circumstances. But the improvement of a flock by breeding requires much patience and perseverance, and a fixed idea of some result to be gained. In breeding, good results rarely come by hap-hazard or accident. There must be a distinct end in view, and there must be appropriate and painstaking efforts made to reach that end. The breeder must lave a clear idea, not only of what he wants to gain, but of what he wishes to get rid of, and he must know the character of his flock intimately. One who knows all this can so accurately describe the kind of ram he needs to improve his flock, that a conscientious breeder from whom he may purchase the needed animal, can choose him as well, if not better, than he can himself.

In breeching to improve a flock, the qualities of both parents must be considered, remembering that the male exercises the greater influence in determining the character of the offspring. A pure-bred Cotswold ram, crossed upon a Merino ewe, for instance, will produce an offspring that much more resembles himself than it does the dam. This principle is well recognized amongst breeders. Nevertheless, the very best of the females should be chosen, and the faulty lambs culled out each year, until the finest only remain. During this time it would be pructent for the farmer to retain no males of his own breeding, but to secure by purchase or hire from some capable professional breeder, such changes of males as may be necessary. 1Tuch good may be done by unselfish breeders in the way of letting pure-bred rams for a fair consideration to neighboring farmers who may not have the means to purchase one outright. By changing rams occasionally, two farmers may rery profitably help each other without expending a dollar for the necessary new hlood.

The points sought for in rams, with which to improve a flock, are those which directly ard to the value of the sheep, or those which are evidence of the possession of valuable qualities. Thus the abundance of yolk, or the fineness of the wool, or its curl, or the depth or form of carcass, upon which depenels the quality and the quantity of the fleece, are esteemed in the Merinos; in the Southdown, the small head and leg, and small bones, with the 
black muzzle and legs are highly regarded, as these denote quick fattening properties, and hardiness of constitution. The breadth of shoulder, the straightness and levelness of the back, the breatth. of loin, and the spring of the ribs and rotundity of the frame of the Cotswold, Leicester, and other heavy-bodied sheep, indicate capacity for feeding and digestion, and laying on of flesh, and are therefore regarded as valuable points. Large bones are an unfavorable point, as they denote an abstraction of nutriment which shonld otherwise go to the formation of flesh and the greater value of the carcass. The absence of horns, for the same reason, is desirable in sheep bred for mutton. A soft, mellow feeling of skin and the tissue underneath, and a softness of the fleece, are indicative of a tendency to the rapid formation of fat. A round frame and broad loin iudicate the existence of abundant flesh, where it is the most valuable, and a general squareness of the outline of the figure proves the existence of large muscular development and consequently heary quarters. In short, for sheep which are not kept solely for the production of wool, what is wanted is, all the flesh possible with no more bone than can carry it, and that the flesh should be where it will be the most valuable, viz: on those parts which bring the highest prices on the butchers' stalls-the loins and quarters. Where wool is the sole object, weight and fineness of fleece alone need to be considered. Where wool and mutton are each equally sought for, the matter becomes complicated by many considerations, each of which should be studied with a view to give the preponderance to those which have the greatest special or local importance.

In crossing breeds, we seek to increase the size, improve the shape, or hasten the maturity of the sheep; or improve the length, quality, or closeness of the fleece. But it will not do to select at random any ram which may happen to possess the qualities desired, withont regard to some affinity of character with the ewes, lest lambs should be produced that are weak in constitution, or shapeless mongrels, through too wide a disparity between the parents. Experience has shown that the Leicester ram has made a greater improvement with long-历ool sheep than with the shortwool breeds, and that the Southdown has made a more successful first cross upon the latter. The Cotswoid has been rery successfully crossed mpon the Merino, the Hanpshire-down, the Southdown, and other races, and as the parent of cross-bred races, this most valuable breed has gained the highest reputation. As a rule, the first cross between a superior and high-bred race, and an inferior one, produces the best sheep for breeding together; further 
crosses often produce animals which deteriorate in breeding, the progeny regaining more of the character of its inferior parentage, and losing that of the superior one. Judgment and cantion are needed in selecting those results which hure been successful, and in rejecting those which are unfavorable, also in continuing the interbreeding for a sufficient length of time to eliminate all the defects which may reappear at times in the progeny. It is only after several generations that animals can be produced, which may be permitted safely to perpetuate their lind without further careful selection. During the intervening period, very close watchfulness is necessary; the form of the animal, the preponderance of the desired points, as well as those that are not desirable, the character of the fleece, and the soundness of the animal's constitution, should all be patiently studied. Great contrasts between breeding animals should be avoided, as being dangerous to uniformity, and a gradual approach to a desired end by several steps will be found more certainly effective than to endeavor to attain it by one or two violent efforts.

The selection of rams for breeding is a matter of the greatest importance. Not only the character of the flock, but the number of the lambs, to some extent, depend upon this. For general purposes, the ram should be chosen for lis perfection of shape and fleece, rather than for his size or weight. For mutton sheep, whether long wool or medium wool, a round barrel, broad loin, fine bone, short legs, close wool, especially upon the back and loins, swall head, full fore arms and thighs, and a mellowness of flesh within the fore legs upon the ribs, where a poor sheep never carries any fat, and in general an evenness of excellence, rather than any special single point of superiority, whether of size of bocly, or length, or weight of fleece, should be sought. A very heary, large-bodied ram, will probably prodnce very irregular lambs, which will disappoint the breeder; while a well knit, more even, smoother but smaller ram, will produce lambs of great uniformity and resemblance to himself, and rery frequently, and especially so if out of well selected ewes, greatly surpassing him in size of carcass at maturity. In breeding from a large ram upon small bodied ewes, unless there is some special reason against it, a ram with a small head should be chosen, and the ewes selected should be wide across the loins, with a broad rump and wide pelvis. From a disregard of this it is sometimes the case that severe labor or death in parturition occurs amongst the ewes. In the first coupling of the young ewes, the greatest care should be cxercised in selecting the ram, for its influence may 
and sometimes will extend beyond his own immediate progeny, and molify that of future sires upon the same dams. While this influence of the first male is not so general as to afford a basis for a rule, yet observation has shown it to be of sufficient force to entitle it to the consideration of careful breeciers. The influence of the ram upou the sex of the progeny, is something equally worth considering, although it is as yet somewhat undetermined. In theory it is supposed to be exerted through a natural provision by which the fecundity of a race increases along with the better opportunities it enjoys for its subsistence. Thus it is reasoned, when animals are well fed and cared for, and are not allowed to breed early, their produce will be in greater part females, permitting a more rapid increase, in consistence with their more favorable opportunities for development. On the contrary, when animals are sparely fed or exhaustively used, and allowed to breed early, the tendency of nature is to restrict the production by the birth ehicfly of males. This theory receives confirmation through the tendency of the early breeding and exhaustively producing Jersey cow to have male calves, and through some observed facts in sheep breeding.

One of the facts directly pertinent to this matter is recorded in the Annales de l'Agriculture Française, as follows. It was proposed at a meeting of the Agricultural Society of Severac, to divide a flock of ewes into two parts, that an experiment might be made to test the question of breeding for sex. One flock of ewes was put into an abundant pasture, and was served by very young rains. The other flock was put into a pocrer pasture, and was served by rams not less than four years old. The result is given in the tables which follow; the flock from which the excess of female lambs was expected, being served by rams 15 months to 18 months old, produced three twin births, and the flock expected to yield the most male lambs, and which was served by rams over 4 years old, produced not one double birth.

Flock for female lambs served by rams under 18 months old. Sex of the Lambs.

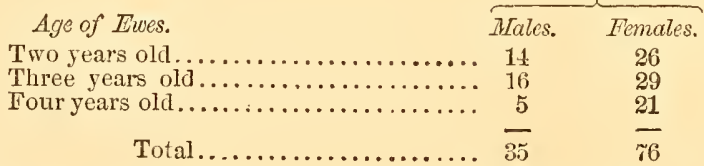

The excess of female lambs in this flock is very remarkable, as is also the excess of male lambs shown in the next table. 
Flock for male lambs served by rams over 4 years old:

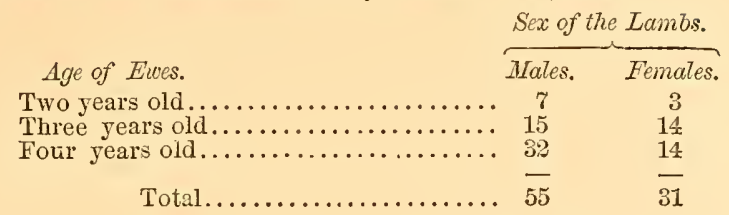

The result certainly justified the expectation, but it can scarcely be held to be anything more than suggestive for further research or experiment, rather than conclusive for the founding of a rule. The following well considered remarks made by the Hon. A. M. Garland, editor in charge of the sheep and wool department of the National Live-Stock Journal, at a meeting of the Madison Co., (Ill.) Farmers' Club, Hay 8th, 1875, are suffieiently valuable and pertinent to be recorded here: "One essential to successful breeding is a persistent encleavor to attain the standard that has been fixed upon by the breeder as his idea of the perfect animal. While the sheep will be found to conform more readily than any other animal, except perhaps the dog, to certain well understood physiological laws, the attainment of all the desired characteristics, and their incorporation into the life and constitution so as to insure transmission with the desired force and certainty, is a labor involving not alone judgment and taste, but patience as well. Mythology tells us of the goddess who leaped full-armed from the head of Jove; but the aitainment of perfect encls without the employment of patient and laborious means, is not among the blessings that surround the business man in this material age. He who expects to accomplish in a year what others have only completed in a lifetime of labor, is pretty surely doomed to gather the bitter fruit of disappointment, and the chances are largely in favor of pecuniary loss as well. It required over fifty years of labor, and care, and study, to bring the nine-pound flecee rams imported by Humphrey and others, up to the 25 and 30 pound shearers that head a number of the flocks of the present day. The highest types of the Cotswold and Southdown are the result of an expenditure of time, and money, and study, equal to that bestowed upon the Merino in the United States in the last half a century. Such facts as these afford small encouragement for those young men who see risions, and those older ones who dream dreams, of a speedy fortune and an assured fame by the establishment of an intermediate breed of sheep-one that will combine in a single animal the good curalities of all the breeds and the weak points of none. Any of the estab- 
lished types will improve what is known as our common native sheep, sufficiently to justify the payment of a fair price for a choice ram. Grades from these flocks of common sheep, bred towards the long wools, the Downs or the Merinos, will be found profitable stock to the average farmer. Care shonld be had to breed all the time in the same direction-that is, always using the best rams of their kind within reach, having due regard to prudence in making the purchases. The first cross will usually show a greater change from the standard of the coarse-wooled mother than subsequent ones, though an occasional cropping out of her less desirable characteristics may be expected, but should not discourage the effort at-improvement as persistent crossing by pure-bred rams will bring its reward in a sightly flock of grades, that can be depended upon to reproduce their characteristics with reasonable certainty."

"In and in" breeding, or breeding between near relatives, is a subject which has given rise to much discussion, and to much diversity of opinion. The truth seems to be that close breeding up to a certain point is necessary to secure a fixed type, and when judiciously done, it may be the means of securing most valuable results. The English sheep breeders who have become most noted for their successes, have bred very closely, a most conspicuous example being Mr. Bakewell with his improved Leicesters. Probably no race of animals were so closely interbred as this. But it is questioned by some breeders if the limit of safety in this respect has not been overstepped, for no race so strongly exhibits in their defects the evil resuits which follow from too close breeding for any considerable length of time. The small light bone, the baldhead, the prominent glassy eyes, the thin, delicate skin, the tendency to tuberculous diseases, and other scrofulous affections, all of which are characteristic of some classes of the Leicesters, are the very evils which are known to follow from too close sexual affinities. Safety certainly lies in the avoidance of this sort of breeding to any great extent, and as a general rule for ordinary breeders, it may perhaps be laid down, that to breed a ram to his own lambs may be permitted, but to breed to the second generation of offspring should be avoided. To change the ram the second year wonld be to act on the side of safety, and except in rare instances, and for the attainment of clearly apprehended results, this should be the limit of close breeding. To breed a ram to his own ewe lambs is regarded as safer, and not so close breeding as breeding full brother and sister together, and yet to attain certain desired ends, this is and has been done, and will often be done by breeders. 
It may be questionable, however, if the results sought might not be as certainly and more securely gained by using less closely related animals. Mr. Edwin Hammond, a noted breeder of American Merinos, who has done much to develop this breed, seldom used rams with which to make his crosses that were not of his own flock. His famous ram Sweepstakes, came from a closely in-and-in bred family; but because the most skillful breeders have succeeded in producing conspicuously favorable effects, it must not be concluded that other less capable breeders or farners who know but little of the science of breeding, can hope to achieve any satisfactory measure of success. Besicles, it should be considered that we only hear of the successes of these breeders. Their failures are at once put out of the way, and no record is made of them; in fact a portion of their skill, and not an inconsiderable portion either, consists in instantly recognizing their failures, and in summarily disposing of them.

In summing up these few general remarks upon breeding, the following may be accepted as maxims for guidance to those as yet not familiar with the principles of the art. Breed for some well un. derstood object. Learn and know the character of every ewe and ram in the flock. Remember that the male gives his impress upon the progeny most strongly. Purity of blood in the male is an absolute necessity. It is cheaper to pay a fair price for good rams to a capable breeder, who makes the production of breeding animals his business, than to attempt to raise one's own breeding stock. Animals that are not pure-bred, when coupled, tend toward reversion to the inferior stock rather than to progression towards the superior. Animals, as sheep, that are easily impressed favorably, as easily retrograde; the rule works both ways. To feed well, is the co-efficient of, to breed well; without good fceding good breeding is of no avail. Breeding lays the foundation, feeding builds on that. The first cross is the most effective, the next is but half as effective, and so on until, as in the increasing fraction $1 / 2,3 / 4,7 / 8$, ${ }^{15} / 16,31 / 32,63 / 64$, etc., etc., unity is approached by diminishing quantities, and is thus never reached; so the higher we breed the less adrance is made in proportion. That a type so fixed that the breeders care in selection can ever be relaxed will never be reached.

NATIVE BREEDS OF SHEEP.

The Mexican Sheep.-Since the first discovery of America by Europeans, more than four centuries ago, there bave been numerous importations of sheep into both South and North Imerica. The first of these importations consisted doubtless of the common 
native sheep of Spain, designated by Dr. L. T. Fitzinger, the author of a paper upon the races of domestic sheep of Europe, (presented to the Imperial Academy of Science in Viemma, in 1860), as the landschaf, or common rustic sheep, (Ovis aries). This sheep bore a very meager fleece of coarse wool. It is probable that all that part of the American continent which became subject to its Spanish discoverers, including the islands of the West Inclies, was stocked with this common rase. At that period the Spanish government very jealously guarded the Merino sheep, and forbade their exportation, even to their own American colonies. It is known, however, that a few Merinos were occasionally smuggled into Peru, and that to these was due the superior character of the wool of that country, which exists up to the present century. Elsewhere, however, the character of the dominant race of sheep was very inferior, and it now so remains; the imports of wool from South America into the United States being coarse in quality, and rating only as among the third class. Of a similar character to this is the race of sheep known in our western territories as "Mexicau." Their origin is clearly the same as that of the native South American slreep, and their appearance is identical with that of the sheep represented in ancient Spanish paintings as the ordinary race of the country, the property of the peasantry. It may be concluded as most probable, if not certain, that this race, one of the ten primitive or distinct original races which inhalited Europe, as determined by Dr. Fitzinger, (whose classification is confirmed by other scientific men), unaltered by more than three centuries of acclimatization, is now represented by the bulk of the flocks which roam over Mexico, Texas, New Mexico, Arizona, parts of Califoruia, and more recently Colorado. These sheep are hard 5 , wiry animals, weighing about 40 pounds, and yielding when unmixed with any Merino blood, a fleece of about two pounds of coarse wool. Of late this inferior race has been improved to some extent by crossing with pure Merinos from Vermont and other eastern states, and is found to make an excellent basis whereon to build up an improved and useful race. These sheep are of but little value, and in flocks are sold and bought at about $\$ 1.50$ per head. The business of shipping rams westward to supply this demand, from almost every state where Merinos are kept, has already reached respectable dimersions, and is rapidly increasing. The result cannot fail to build up, in course of time, a valuable class of native sheep well suited to these localities. These improved sheep produce a fleece weighing about 4 pounds of grade Merino wool, which will supply to a very great extent local manu- 
factories of such woolen goods as are in demand in the western country, and thus render the far western states independent, so far as regards their supply of woolen manufactures, of the eastern factories.

The Virginia Sheep.-A native race of greater pretensions, and far greater value than the preceding, sprung from the first importation of English sheep in Jamestown, Va., in 1609. The original settlers of this new Dominion were in part men of wealth and position. The stock they imported would naturally be of the best that could be obtained, and the favorable climate of the country for sheep-raising, would tend to preserve the sheep from degradation. Repeated importations of excellent sheep were made during the succeeding two centuries, by prominent Virginians, amongst whom were the Washingtons, and various members of the Custis family. Thus was founded a class of more than usually good, heavy bodied, long-wool sheep, which still exists and is famed for producing excellent early market lambs. Of late years considerable Leicester, Cotswold, and Southdown blood has been mingled with the old stock. Although the Virginia sheep can hardly claim to be considered as a distinct breed, yet they certainly furnish a very good basis upon which, by careful selection and interbreeding, to found a breed thoroughly well adapted to the locality, as they are already acclimated and possess established qualities.

The Improved Kentucky Sheep.-An account of the efforts which have been made to produce native varicties of sheep, would not be complete without the mention of what has been called the "Improved Kentucky Sheep." This breed or race originated with Mr. Robert Scott, of Frankfort, Kentucky, who crnssed the common native sheep of the locality, with Herino, Leicester, Southdown, Cotswold, and Oxford-down rams. This was begun about 40 years ago, by selecting 30 natire ewes, which were bred to a selected Merino ram. The yearling ewes of this cross were bred to an imported Leicester ram. The ewes of this cross were served by an imported ram of the Southdown breed. The produce of this cross were then bred to a ram of mixed blood, threefourths Cotswold and one-fourth Southdown. The next two crosses were made by Cotswold rams, and the next by an Oxforddown ram. The produce of the last cross were bred to Cotswcld rams again. This brought the flock up to 1855 , when a mixed Corswold, Oxford, Leicester, and Southdown ram was brought into service. After this the rams produced by this very mixed 
breeding were used. In $186 \mathrm{Y} \mathrm{Mr}$. Scott furnished an account of his sheep for the annual report of the Department of Agriculture for 1866 , in which he gave some very flattering testimonials which he had received from various parties, to whom he had sold his sheep, with pictures of rams and ewes of his flock. At that time his flock consisted of about 200 ewes and 50 yearling rams. Since then the breed has been quietly working its way into favor in Kentucky and the Southern States, aud has gained many friends. Its character has been gradually fixed by careful breeding by Mr. Scott, and it is now a heary-bodied long-wool sheep, which produces a heavy fleece, good mutton, and a heavy market lamb. The fleece consists of a long lustrous combing wool, in quality midway between the Leicester and the Cotswold. Some skins, and rugs made from the cured skins, were exhibited at the Centennial, and received a prize for their excellence. In a private letter to the author, Mr. Scott states that his sheep have been received with so much favor, and have become so popular, that it is with diffculty that he can keep up the working numbers of his flock. This example of successful cross-breeding is an instance of what a careful and skilful breeder may accomplish, rather than a result to be confidently hoped for by any tyro in the art, or any person who may have an ambition to found a new or improved breed of sheep.

The American Merino.-One of the most successful instances of the fortuitous results of sheep breeding, exists in the establishment of the American Merino. In a Treatise upon the Australian Merino, by J. R. Graham, superintendent of an extensive sheep station on the Murray River, (published in Melbourne, in 1870), the following testimony is given: "Of all imported sheep, those of our first cousins, the Americans, are the best. The best rans imported into Melbourne of late years were some American rams." This coming from so capable a judge, and in competition with the best selections of Merino sheep to be procured elsewhere in the world, may be taken without question as proof that the American IIeriuo is the best sheep of its class in the world. It is therefore interesting to trace the course through which this breed has been brought to its present excellence, which enables it to stand alone on its own merits, beyond any capability of further improvement by any variety of Merino sheep now existing in any part of the world.

The history of the American Merino commences with the present century, and with importations of choice sheep from Spain. The honor of the first importation seems to belong to Mr. William Foster, of Boston, who managed, "with much difficulty 
and risk," to bring with him from Cadiz, two ewes and one ram. Uufortunately his enterprise came to naught, for presenting these valuable and costly sheep to a friend, this friend made them into mutton and ate them. This same friend afterwards paid $\$ 1,000$ for a Merino ram. One ram was imported in 1801, and was used on the farm of a Freuch gentleman, Mr. Delessert, near Kingston, $\mathrm{N}$. Y. This animal weighed $138 \mathrm{lbs}$, and his fleece, well washed in cold water, weighed 8 lbs. $8 \mathrm{ozs}$. He was a very fine ram, and finally fcunded a valuable flock on the farm of E. J. Dupont, near Wilmington, Del. Later in the same year, Mr. Seth Adams, of Zanesville, Ohio, imported a pair of Spanish Merinos, which received a premium at the fair of the Massachusetts Agricultural Society the next year. In $1802 \mathrm{Mr}$. Livingston, the American Minister to France, sent two pairs of French Merinos home to his farm on the Hudson River. In 1507, Mr. Livingston imported some choice Spanish ewes from France, and in 1808, his flock began to acquire a wide reputation, his rams selling for $\$ 150$ each, and half-blood ewes and rams for $\$ 12$ each. In 1802, Colonel Humplreys, the American Minister to Spain, sent 25 rams and 75 ewes, selected from the choicest flocks in Spain, to Derby, Connecticut. From what particuiar family of Merinos these sheep were selected, does not appear, the evidence, however, seems to point to the fact that they were Infantados, or sheep from the flock of the Duke of Infantado, one of the chief grandees of Spain at that perind. This flock was bred and inproved by Col. Humphreys, with much success. At the death of this gentleman, in 1818, his flock was scattered, and only two or three then obscure farmers had the lnck, or precantion, to preserve them pure and clistinct. On the rise of the Merinos into their future high reputation, these fortunate persons were brought into notice as the possessors of flocks of pure Merino sheep. But the most extensive and noteworthy importation, and that which gave form and cliaracter to the American Merinos, was that of the Hon. Wm. Jarvis, the American Consul at Lisbon, in 1809 and 1810. This consisted of 3,850 sheep of the flocks of Paulars, Negrettis, Aqueirres, and Montarcos of Spain. These flocks, consisting of nearly 50,000 head, had been, for political reasons, confiscated and sold by the Spanish goremment, with other property of the four grandecs who had owned them.

Of the imported shcep, 1,500 came to New York, 1,000 to Boston, and the remainder to Philadelphia, Baltinsore, Alesandria, Norfolk, Richmond, Portland, Wiscasset, and Portsmouth. Another shipment of 2,500 followed in 1810 , and were distributed 
between New Fork and Boston. These sheep were of the prime flocks of Spain, and Spain's loss was our gain. Mr. Jarris re. served 350 of the sheep for his own isse. A few other minor im. portations of Spanish sheep were made by other parties in 1810 and 1811. The knuwledge that we had thus obtained the very best sheep in the world, started a speculative ferer, which ras increased by the war with England in 1812, when Merino wool sold for $\$ 2.50$ a pound. Imported rams were eagerly purchased for $\$ 1,000$ to $\$ 1,500$ each, and ewes sold for $\$ 1,000$ a head. Many flocks of pure or grade sheep were started in all parts of the country, and much care was taken in the breeding of them. This lasted until the peace of 1815 , when sheep that were valued at $\$ 1,000$ a head, in 1809 , sold for $\$ 1.00$, and of cotrse all interest in breeding then ceased. Afterwards, under the stimulus of various protective tariffs, the business revived, and fine wool-growing again attracted attention.

In 1821, 7 Saxon Merino sheep were imported by G. \& 'T. Searle, of Boston, and this was followed by several other importations by the same parties. By bad management much loss resulied to the importers, and in consequence of the poor quality of the sheep, the whole business was a failure for all concerned, inclucling the purchasers. The inferiority of the Sason breed was manifest, and these sheep, which yielded a fleece of but $2 \frac{1}{2}$ to 3 lbs. per head, could not compete with the Spanish sheep, which produced 4. Ibs. of well washed wool per head, of nearly equal value, although not quite so fine as the Saxon wool. The Saron sheep have all disappeared since 1846. Then the American Merino came into general faror. This class of sheep, in 1840 to 1845 , consisted of sereral families of distinctly marked rarieties, due chiefly to the various courses of breeding followed by their several owners. The distinguishing peculiarities of these families consisted mainly in their size and hight of carcass, length and fineness of wool, the pendulous dewlaps and skinfolds of the rams, and the amount of yolk in the fleece, and its consequent greater weight and darker color. Up to the period in question, the choicest flocks were to be found in New England, on account of the greater care there taken in breeding. Some of the Connecticut and Termont breeders had taken great pains to improve their flocks, and much emulation existed amongst trem in this respect. Gradually, differences became merged and blended by the continued purchase of rams by the owners of defective flocks, from the more careful breeders, and finally only the two families, the Paulars and the Infontados continued to be bred as distinct in all parts of the 
country. Since then these separate families, their crosses, and those between them and other pure flocks, here been greatly improved. The carcass has become larger and heavier, and the fleece has been increased in weight. This is shown by the following table, taken from a more extensive one published about 70 years ago by Petri, who visited Spain for the express purpose of examining the Spanish sheep, and from some measurements made by the Hon. H. S. Randall, of Cortland, N. Y., and published in his valuable work on "Fine Wool Sheep Husbandry," as well as from numberless well authenticated weights of fleeces. The table is as follows:

\begin{tabular}{|c|c|c|c|c|c|c|c|c|c|}
\hline NAMES OF FLOCKS. & 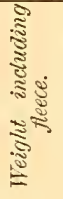 & 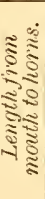 & 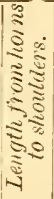 & 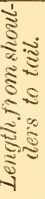 & 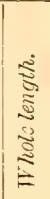 & 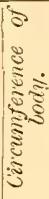 & 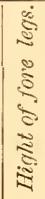 & 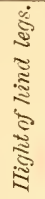 & 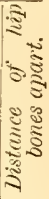 \\
\hline Tegretti Ram & $\begin{array}{c}b s . \\
97\end{array}$ & $\begin{array}{l}\text { in. } \\
9^{\circ}, 4\end{array}$ & $\begin{array}{l}\text { in. } \\
19\end{array}$ & $\begin{array}{l}i n \\
26\end{array}$ & $i n$. & $\begin{array}{l}i n . \\
19^{1}\end{array}$ & $\begin{array}{l}i n . \\
15\end{array}$ & $\begin{array}{l}\text { in. } \\
10\end{array}$ & $\begin{array}{l}\text { in. } \\
6\end{array}$ \\
\hline$\because$ Ewe. & 67 & $81 \%$ & 17 & 25 & 5012 & $191 \%$ & 13 & $91 / 4$ & $41 / 2$ \\
\hline Infantado Ram.... ....... . & $1001 / 2$ & 10 & 18 & 27 & .55 & 50 & 12 & 9 & 6 \\
\hline Gwe... & 70 & 9 & $\begin{array}{l}171 / 2 \\
18\end{array}$ & $\begin{array}{l}25 \\
26\end{array}$ & $511 / 6$ & $\begin{array}{l}47 \\
5316\end{array}$ & 12 & $\begin{array}{l}81^{1} \\
8\end{array}$ & 6 \\
\hline Eire. & $69^{3}$ & 9 & 14 & 25 & 17 & 45 & $101 / 2$ & $i^{1} \cdot{ }_{4}$ & 4 \\
\hline Estantes of Sierra de Somo Ran & $96 \frac{1}{2}$ & $91 / 2$ & 18 & 24 & $51 \frac{1}{2}$ & $50 \frac{1 / 3}{3}$ & 12 & $8^{7}$ & 6 \\
\hline " $"$ " " " $" \mathrm{E}_{1}$ & $621 \frac{1}{2}$ & 9 & 1. & 25 & & & 11 & 7 & 5 \\
\hline 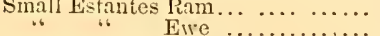 & $\begin{array}{l}49 \\
30\end{array}$ & $71 / 3$ & 12 & 21 & $\begin{array}{l}\text { 1:31/6 } \\
38\end{array}$ & & $\begin{array}{r}10 \\
8\end{array}$ & $6 \frac{1}{6}$ & 3 \\
\hline merican Merino Ra & 102 & 9 & 10 & & & כ2 & 11 & 9 & 9 \\
\hline Ei & 114 & $9 \frac{1}{2}$ & 1 & 2 & $17 \frac{1}{2}$ & 4932 & 11 & 9 & 8 \\
\hline 131 & $1:$ & $?$ & it & & 10 & & 0 & 9 & 0 \\
\hline Ew & 100 & 9 & 1. & 27 & & $-183 / 1$ & $81 / 2$ & 8 & 8 \\
\hline
\end{tabular}

These differences, it will be observed, occur in those respects which add greatiy to the value of the animal, the heavier weights of carcass, the shorter neck, the shorter legs, and the very greatly increased width of loin. All these points of improvement tend to show an animal of excellent physical vigor and constitution.

As to the fleece: in 1800 to 1813 , the imported Merinos yielded $3 \frac{1}{2}$ to 4 lbs. of brook-wasled wool, in the ewe, and 6 to $7 \mathrm{lbs}$. in the ram. The heaviest fleeced ram imported, that of Mr. Dupont, produced 81 lbs. of brook-washed wool. In 1845 the product had increased to $5 \mathrm{lbs}$. for some small flocks, and $9 \mathrm{lbs}$. for rams. IIr. Stephen Atwood, of Vermont, reported in this year that his heaviest ew's fleece was 6 lbs. 6 oz., and his heariest ram's fleece, 12 lbs. 4 oz. In 1849 , a ram, belonging to $\mathrm{Mr}$. Randall, produced 13 lbs. $3 \mathrm{oz}$ of weil washed wool. Up to this period the Merinos had been under a heary cloud, and improvement had not oceured so rapidly as it has done since then. The weights of the fleeces of 
those early days of the American Merinos are far surpassed now, and the arerage of some small flocks reaches over 10 pounds of washed wool. Many remarkable reports of recent shearings might be selected from various agricultural journals, which go to show a greatly increased production of wool per head, and the reports may doubtless be accepted as in the main correct. In the Ohio Furmer of June 19th, 1875, are reported weights of some fleeces of pure-bred American Merinos, viz : of a flock of 44, an aged ram's fleece weighed 20 pounds; 34 yearling ewes' fleeces reighed 410 lbs. $3 \mathrm{oz}$, an average of over 12 pounds, and 9 aged ewes' feeces, 108 lbs. 7 oz., an average of 12 pounds. The wool was 3 inches long, of a clear white color, and therefore free from excessive Folk. Also of a flock of $80 ; 19 \mathrm{ram}$ lambs, average age $13 \frac{1}{3}$ moiths, sheared $325 \mathrm{lbs}$, average $17 \mathrm{lbs} .2 \mathrm{oz}$. per fleece; 13 rams, 2 to 6 jears old, sheared $225 \frac{1}{1}$, or 17 los. 5 oz. per fleece; 48 ewes prodticed 668 lbs. 6 oz., or 14 lbs. nearly per Heece. The extreme weights of the ram lambs' fleeces were from $14 \mathrm{lbs}$. to 20 lbs.; of the rams, 14 lbs. to $24 \mathrm{lbs} .4 \mathrm{oz}$, and of the ewes, $12 \mathrm{lbs}$. to 18 lbs. These fieeces, being doubtless unwashed, would shrink one-third in washing. In the Michigan Farmer of July, -, 18r5, the weight of 16 fleeces is reported at 168\% lbs. of washed wool, an average of $10 \frac{1}{2} \mathrm{lbs}$. each; 10 ewes yie\}ded $91 \mathrm{lbs}$; 3 yearling rams produced $45_{2}^{1} \mathrm{lbs}$, and three yearling ewes $32 \mathrm{lbs}$. The Detroit Tribune, about the same time, reports a flock of 43 ewes and wethers which produced 399 lbs., an average of about $91 \mathrm{lbs}$. of washed wool. Seven yearling rams sheared 100 lbs., being 13 months' growth of wool; one oi these fleeces weighed $15 \mathrm{lbs}$., and the sheep after shearing weighed $49 \mathrm{lbs}$. One 6-year ram sheared 19 lbs. mnwashed wool. Another flock of 33 ewes produced 318 lbs. of wool, washed on the sheeps' backs 9 days previously. These reports are selected at haphazard, upon casually glancing over a few of the papers which are in the habit of publishing news of this character, sent by known correspondents. In all these cases the names and addresses are given with the reports, but are withheld here, as they are in no way exceptional, or surpass the reports of the flocks of numberless other farmers or breeders. Indeed, many thoroughly trustworthy reports are constantly being given of greater weights of fleece than any of these. The following reports of the reights of the premium fleeces sheared at the annual meeting of the Ameriean WoolGrower's' Association of 1875 , may be given as finally conclusive of the fact under consideration, viz : the gradual improvement and present high value of the American Merino in the hands of Ameri- 
can breeders, until it has now no superior in the world as a wool bearer, or as an improver of inferior races of sheep.

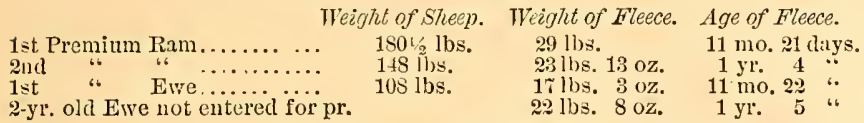

It is impossible, in the limited space that can be here devoted to this breed, to rehearse the means by which these sheep have been gradually brought to this excellence. For these details the reader who would study the subject of fine-wool sheep breeding, is referred to the excellent work of $\mathrm{Yr}$. Randall before referred to, in which it is treated of at length. The portrait on the next page gives a remarkably accurate general view of a first class American Merino ram. It represents the ram "Golden Fleece," bred and owned by E. S. Stowell, Cornwall, Vermont

The clescription of a high bred American Merino, of such excellence as may be readily found in numerous flocks at the present time, may be summed up as follows, giving prominence to the several most important characteristics, viz:

The Carcass should be plump, medium size, round, deep, not long in proportion to roundness, the head and neck short and thick; the back should be straight and broad, the breast and buttock full ; the legs short, well apart, and strong, with heavy forearm and full twist. This compact figure indicates a hardy constitution, ease of keeping, and good feeding properties.

Skin.-The skin should be of a deep rich rose-color, thin, mellow, loose, and elastic on the body. This indicates a healthy, well conditioned animal. A pale or tawny skin indicates impurity of blood, or at least weakness of constitution, and is therefore objectionable.

Folds and Wrinkles.-These are permissibl s to a certain extent. The fashion in this regard has doubtless passed beyond the bounds of wisdom, and excessive wrinkling or folding of the skin is unsightly and useless, if not worse. In shearing, it causes a waste of time, and gives no adequate return in wool. A deep, soft, plaited dewlap on both ewes and rams, and some slight wrinkles on the neck of the ram, satisfied the early breeders in this respect. While heavy neck-folds on the ram, and short ones back of the elbow and on the rump, are tolerated by breeders at the present time, jet it is simply fashion, and adds nothing to the value of the animal, but on the contrary is dearly paid for in the increased cost of shearing. An exception to this may be taken in respect of rams 


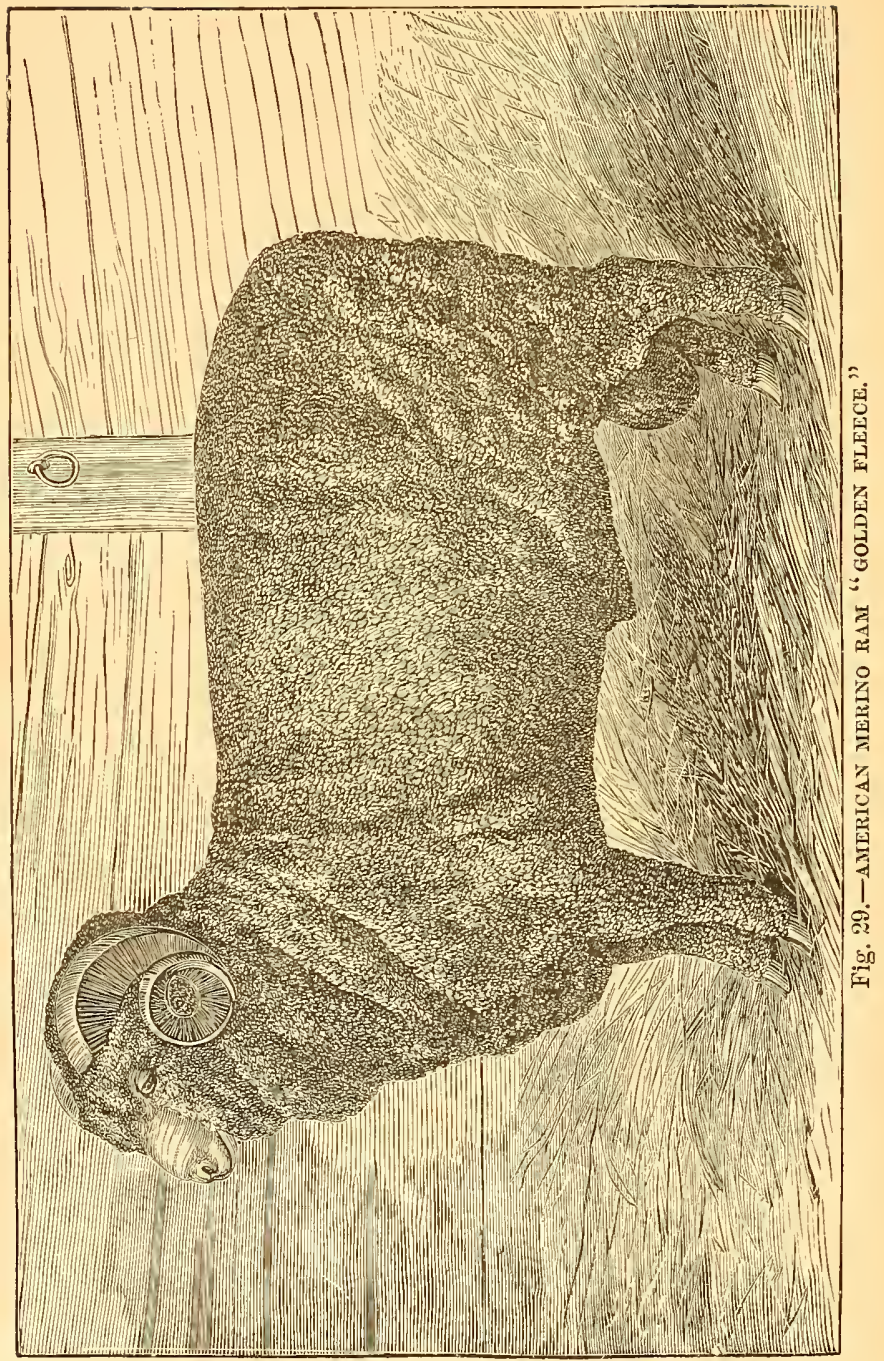


to be used in improving the poor, smooth-skinned native race common on the western plains, in which case a heavy yolked and much wrinkled ram may be found desirable.

The Fleece.-A sheep bred exclusively, or chiefly, for wool, must necessarily be valued in proportion to the value of the fleece. The wool of a pure-bred Merino of any value, should stand at right

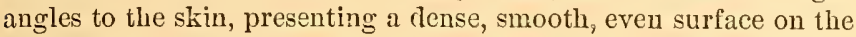
exterior, opening nowhere but in those natural cracks or divisions which separate the fleece into masses. These masses should not be small in size, or they indicate excessive fineness of flecee; a quarter of an inch is the limit in this respect; nor too large, lest the wool be coarse and harsh. The length should be such as, coms. bined with thickness of staple, will give the greatest weight of fleece. Medrum wool is generally in greater demand than fine wool, and it is more profitably produced. Two to three inches is probably the most desirable length of fleece for profit. A change, however, is taking place in this respect, since the practice of combing Merino nool has become general, and three inches and over is a frequently desired length of fiber. It is not desirable to have the face covered with wool long enough to fold up in the fleece. If the eyes are corered with such wool, the sheep is either blinded, or the wool must be kept clipped close. The ears should be small, with a coat of soft mossy hair about half way to the roots, and for the remainder, covered with wool. A naked ear is very ohjectionable. Evenness in quality in erery part of the sheep is very desirable. Hair growing up through the wool on the thighs, the neck-folds, or scattered through the fleece here and there, is not to be allowed. The wool should be sound, that is, of even strength from end to end of the fiber. It should be highly elastic and wrinkled, curved or wavy. The number of these curls, or waves, to the inch, is rot so much a test of excellence as their regularity and beauty of curvature. A folding back of the fiber upon itself is not so desirable as a gentler curve. (See Chapter on Wool).

Pliancy and Softness to the feeling in handling, is an excellent test of quality, so much prized by manufacturers, that practiced buyers will sometimes form an accurate julgmeut of a fleece by handling it in the dark with gloved hands.

Yolk:-To what extent the yolk shonid exist in the wool of the Merino, is a matter of dispute, and in some demree a matter of taste. A certain portion of yolk is absolutely necessary to the existence of a good fleece, and beyond this it is questionable if any 
excess of yolk answers any good purpose. This is considered at some length in the Chapter on Wool, where it naturally belongs. When it is in such excessive quantity as in a fleece which weighed $19 \frac{1}{2}$ lbs. before washing, and only 4 lbs. aftermards, it is decidedly objectionable, except in the case of a ram chosen to impart greater yolkiness to a flock which is deficient in this respect. In general, as wool is the object sought, no more yolk is necessary than the quantity required to promote the growth of the fleece anc to keep it in good condition, soft, pliant, and thoroughly well lubricated.

\section{FOREIGN BREEDS.-LONG-WOOL SHEEP.}

Long-wool sheep are properly natives of the rich low-lands of England, which are productive of abundant, succulent, nutritions pasture. But there have been great improvements in agriculture cluring the past century, which have enabled farmers to produce enormons crops of clover, artificial grasses, and roots, and to purchase large supplies of rich concentrated foods, snch as the various oil-cakes. As one result of this improved agriculture, the longwool sheep have been taken from the alluvial lands where they originated, to the uplands, where they have greatly increased in number, and also improved in character. The fact that these large bodied, heavy fleeced sheep have been found far more profitable than the lighter short- rool sheep, has been the all-sufficient canse of this adaptation of the race to new conditions, for profit is the moving power in every industry, and what is, is simply because it is profitable, and for no otber reason in this day of eager search for increased comfort and wealth. The profit of long-wool sheep consists not only in their weight of meat and fleece, but in their rapid gromth and early maturity. In the change of locality alluded to, and from circumstances of feed and management, some of the ancient breeds bave disappeared altogether, and other breeds have been much changed by extensive crossing with the most popular and highly bred of them. The long-wool sheep of the present time may be divided into two classes; one of which still remains localized in low rich alluvial soils, and drained marshes of certain parts of England; this, includes the Lincoln and the Romney Marslı breeds. The other class belongs to dry arable plains, or farms devoted to grain, grass, and root crops, and other specialties of mixed farming. This class includes the Leicester, Cotswold, and Oxford-down breeds.

The Lixcoln is the heaviest bodied sheep in existence. In 1826 a three-shear sheep of this breed, (40 months old, or about 


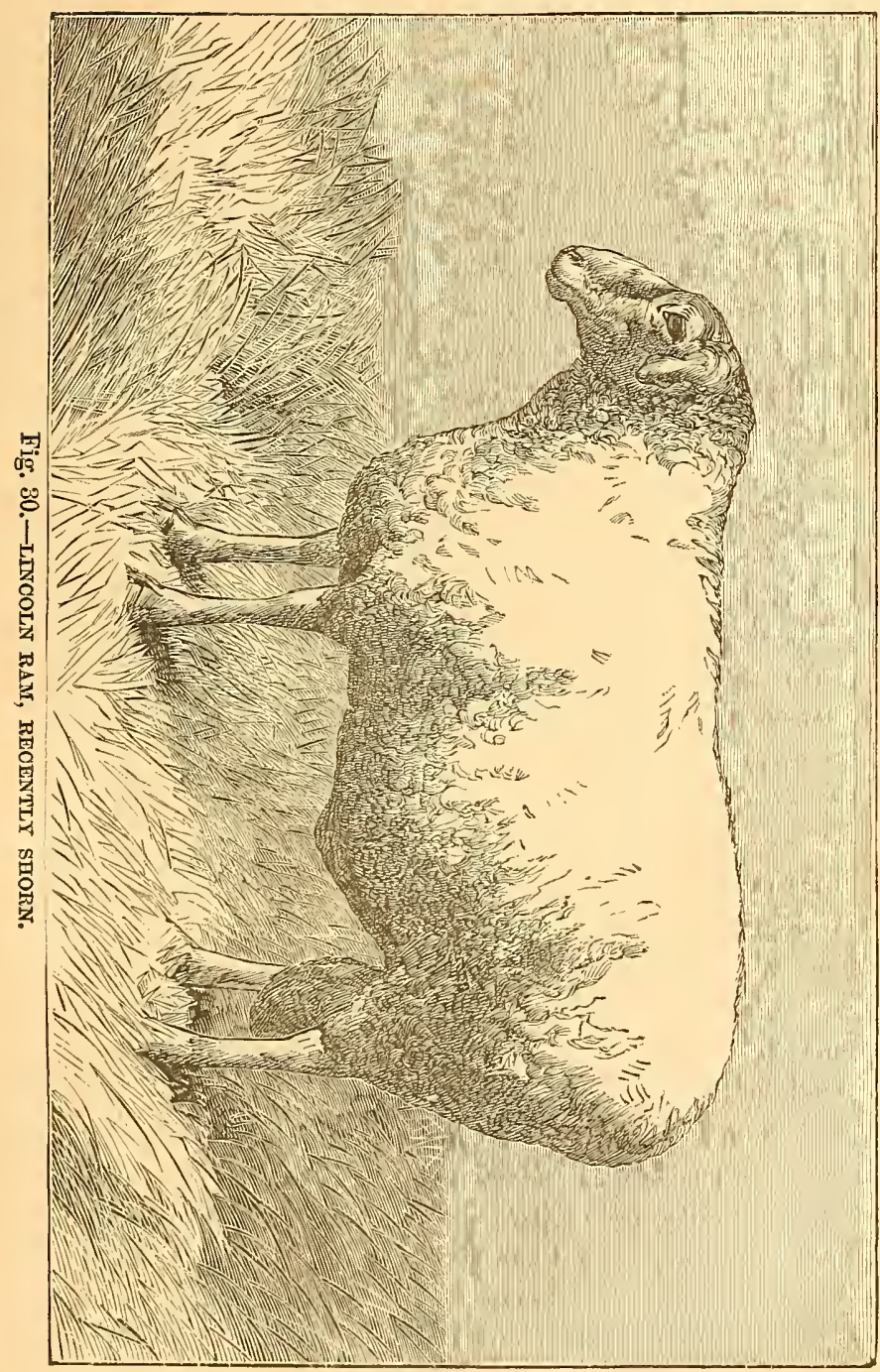


that age), was slaughtered in England, which dressed $96 \frac{1}{2}$ lks. the quarter; a two-shear sheep dressed $91 \mathrm{lbs}$. per quarter, and a yearling dressed 71 lbs. per quarter. In a report on Lincoln sheep, it is stated that thirty 14-months-old wether lambs, slaughtered at Lincoln Fair, averaged $140 \mathrm{lbs}$. each, dressed weight, and 100 together of the lambs clipped $14 \mathrm{lbs}$. of washed wool apiece. The usual practice of the Lincolnshire breeders is to feed the sheep until about two years old, when they will have yielded a second fleece weighing 10 to 14 pounds, and will dress 120 to 160 lbs. dead weight for the butcher. The wool of this breed is very long and lustrous, measuring nine inches and over. The origin of the present highly improved breed, was a race of heavy-bodied sheep which in its pure state is now practically extinct. It inhabited the low alluvial flats of Lincolnshire, and the adjoining localities, on the eastern coasts of England. These sheep were large and coarse, with a long, ragged, oily fleece, which nearly swept the ground. They fed slowly, but made much inward fat, and their meat was well flavored, fine grained, juicy, and not too much overlaid with fat on the outside. A century ago this was the established character of these sheep. When the improved Leicesters of Mr. Bakewell came into notoriety, the intelligent Lincolnshire breeders obtained some of his rams, and by admixture of their blood, in time established a distinctly new breed. In connection with a system of farming, in which heavy crops of roots and green fodder were the chief productions, this improved breed became fixed in its character as the heaviest producers of mutton and wool in the world. In one instance $26 \frac{1}{2} \mathrm{lbs}$. of wool was taken from a 14 montlus old lamb. From 1862 to $18 \%$, the majority of prizes for long-wool sheep at English fairs, were taken by the Lincolns, but it was not until the former date, that the breed was given a distinct place as a separate class at these shows. Since then it has achieved great prominence, and become very popular for crossing upon other breeds, for the production of feeding sheep, and for its yield of long, lustrous, and worsted wools. The Lincoln requires the best and richest soils, and succulent herbage, and can only thrive under the best management and very high farming. At present it is questionable if we in this country have any place in our agriculture which this sheep can profitably fill, unless it be in a very few instances, where the highest skill of the breeder is exercised under peculiarly favorable conditions of soil and climate. A fine flock of these sheep was imported by Mr. Richard Gibson, of London, Canada, and has been carefully and successfully cultivated by him. A portion of Mr. Gibson's flock has been recently 


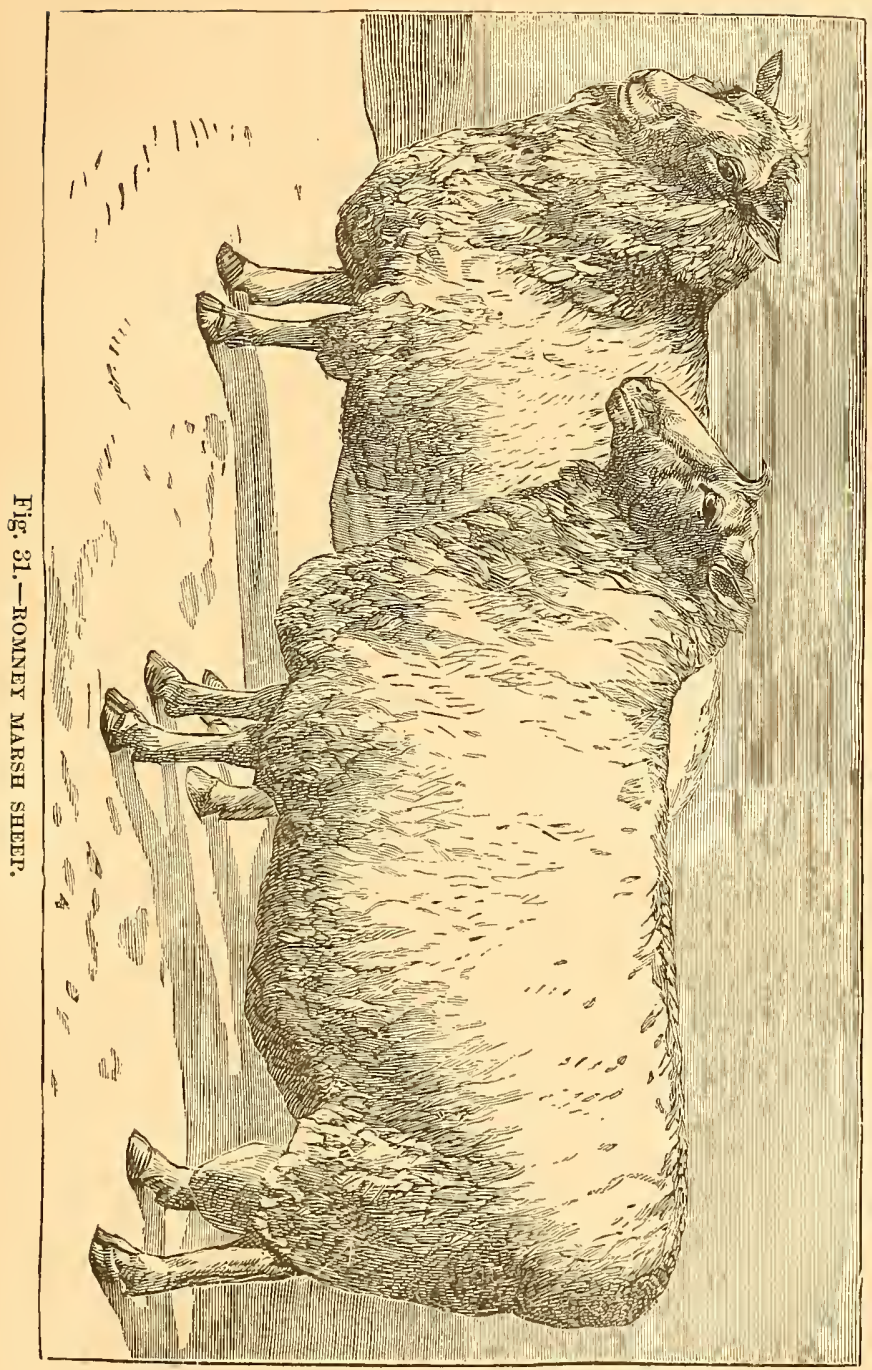


purchased by Mr. William A. King, of Minneapolis, Minn. Mr. George Grant, of Kansas, also has a flock. Their adaptability to our climate is therefore in a fair way of being thoroughly tested.

The Romney Mansn Srreep.-This breed is also an inhabitant of low, alluvial lands. Its home is in south-eastern England, in the extensive marshes of the county of Kent, which are ditched and diked in the same manner as those of Holland. It has existed there from time immemorial, and has fed on the rich clay lands which are so productive of herbage as to be capable of carrying 14 sheep to the acre. This breed has also been much improved by crossing with Leicester rams. It is hardier than the Lincoln, and survives much neglect. It is rarely sheltered, even in severe weather, and the lambs are generally pastured during the winter in the stubbles upon the adjoining uplands, where they undergo many privations. It is not improbable that this hitherto neglected, but valuable and hardy sheep, could find suitable homes upon onr eastern coasts, and rich river flats, where it would serve a better purpose than the more highly bred and delicate Leicester, in improving, or displacing, our less valuable native sheep. The characteristics of the Romney Marsh sheep are: a thick, broad head and neck, long carcass, flat sides, broad loin, full and broad thigh, neither heavy nor full fore-quarter, thick, strong legs and broad feet; wool long, somewhat coarse, and coarsest on the thighs; much inside fat, and a favorite animal with the butcher. There is a tuft of wool on the forehead. The fleece weighs from 7 to 10 pounds, is of long staple, sound quality, and bright and glossy; it is in demand by French and Dutch manufacturers for a sort of mohair fabric known as "cloth of gold," (Drap d'or). At three years old the wethers dress from 100 to 120 lbs., and the ewes from 70 to $90 \mathrm{lbs}$. After a moderate amount of crossing with the Leicester, it was found that to persevere further in this direction tended to make these sheep less hardy, and the cross was at once abandoned. Inter-breeding amongst the cross-bred sheep maintained the improvement without sacrificing the hardiness and vigor of constitution, which renders this breed so well adapted to its bleak and wind-swept pastures.

The Leicester.-It was more than a bundred years ago that the old Leicester sheep fell into the hands of Mr. Robert Bakewell. They were then large, heavy, coarse animals, having meat of a poor flavor, a long and thin carcass with flat sides, large bones, and thick, rough legs. They were poor feeders, and at two or three years old made 100 to $120 \mathrm{lbs}$. of mutton. The wool was long and 


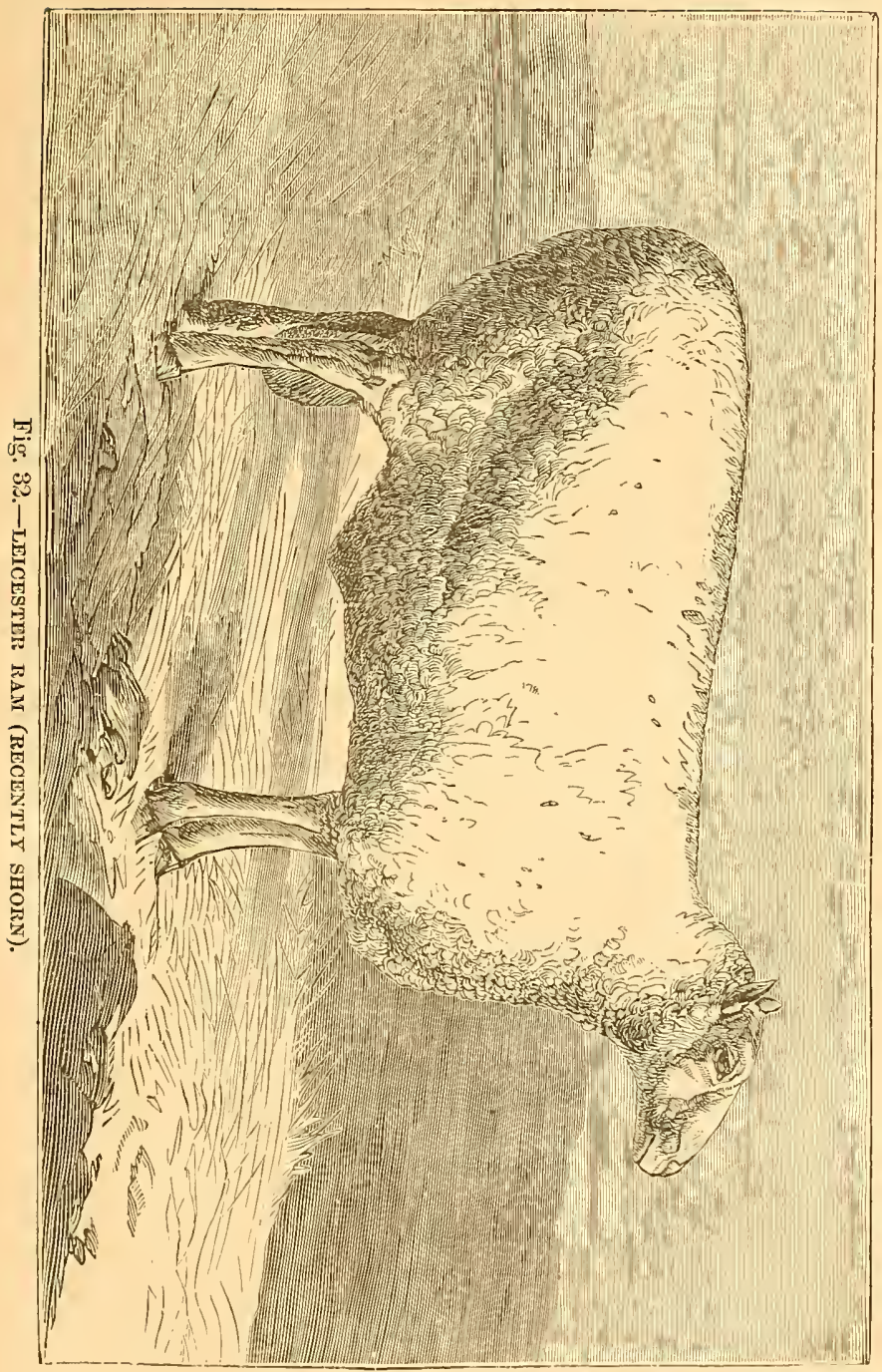


coarse, and of only moderate value. By a course of breeding, about which he was very reticent even to his friends, and which he kept secret from other breeders, Mr. Bakevell totally changed the character of these sheep, and built up for himself a reputation as a successful breeder, which is second to that of no other in the world. Of his system of breeding, the most that is known is, that he commenced with the inferior, old Leicesters, selecting the best of them he could find. He apparently used any animal whatever, without reference to breed or color, nor did he regard relationship, if he considered those coupled together would be most likely to produce the results that he wished to attain in the offspring. His object was to produce an animal that wonld yield in the shortest time, and with the least consumption of feed, the largest amount of flesh and fat, mean while not neglecting the fleece. His ideal sheep was to him precisely what the desired Short-horn was to the Culley Brothers, Mr. Bates, or Mr. Booth; and all these breeders gave their whole soul to the attainment of their one single object. The Culley Brothers were pupils of Mr. Bakewell, and it is but just to give him some share of the honor attained by these originators of the Short-horn. Each of these breeders bred in-and-in, both frequently and closely, and each of them went outside of the breed he was building up and improving for foreign blood, when anything was to be gained by it. It is stated of Mr. Bakewell that he used sheep of six or seven different breeds, and one visitor to his establishment, reported that, in going about the stables alone, early one morning, before Mr. Bakewell had risen, he saw a black ram, but a very magnificent animal, hidden away in a pen. In course of time his success was recognized by the best test-that of the market value of his sheep. He began in 1755 ; in 1760 his rams were let for an annual sum of about $\$ 4$ each. In 1780 he received $\$ 50$ for the season's use of a ram. In 1784 the price was raised to $\$ 525$. In 1786 one ram was let for $\$ 1,575$. In 1789 he received $\$ 6,300$ for the use of three rams, all born at one birth ; $\$ 10,500$ for seven others; and $\$ 15,750$ for the use of the remainder of his flock. Twenty-two hundred dollars was paid by each of two breeders for the use of one ram for their flocks alone, he reserving one-third of his use for himself, making the yearly value of this one ram equal to $\$ 6,600$. After his death, Bakewell's system of close breeding was followed by his successors, but with the effect of reducing the value of the breed to the farmer. The sheep became delicate, and weakened in constitution, reduced in size, less prolific, and less careful of thcir lambs. New blood, chiefly of the hardier Cotswold, has been of late years introduced 
with the effect of restoring their lost qualities. The modern improved Leicsster is without horns; with white face and legs, a small, fine head, bare on the poll; a large, bright, and very promine-t eye; square and deep neck and shoulders; straight, flat, broad back; deep body; hind quarters tapering somewhat to the tail, and not so square as in the Cotstrold; clean legs, and fine bone. The flesh is good, but overloaded with outside fat. The fleece is fine, glnssy, silky, white, and of but moderate length, a veraging 7 to 8 pounds in weight. The skin is thin, soft, and elastic, and of a very delicate pinkish tinge, when the animal is in full health. The Leicester cannot by any means be called a hardy sheep, as it requires good keep, careful shelter, and skillful treatment to maintain it in thriving condition. When ailing it gives way at once, and declines rapidly. It matures rapidly and early, and at twelve months old when well fed, will dress 100 pounds, and at two years reaches a weight of 150 pounds. A four-year-old ram in prime condition has weighed 380 pounds live weight. For use in this country, tiue Leicester cannot compete with the Cotswold, nor is it fitted in any way to become the farmer's sheep, excepting in rery rare cases, when its services might be desired to refine a Cotswold cross in the hands of a breeder who thoroughly understands his business.

The Cotswold. - This breed has become so common in America, and has been bred so extensively without fresh importations of new blood, that it may well be adopted as a native sheep. Many excellent flocks are now self-sustaining, and under their American nativity, lose nothing of their original excellence. The IIaple Shade flock, originally the property of Mr. John D. Wing, of Dutchess County, N. Y., but some years ago divided, and now owned by other parties, is one of many instances of the successful acclimatization of this most valuable sheep. The Cotswold has an ancient history. It is said to have been introduced into England from Spain, by Eleanora, Queen of Henry II, of England, in the twelfth century. Althongh there is nothing more than tridition to support this, yet there is some corroboration of it in the fact that in Spain there has long existed, and is now, a breed of coarse, long wool sheep not unlike the original Cotswold in some respects. It is known, however, that in fifty years after this early date, the wool of the Cotswold sheep was a source of material wealth, and was jealously guarded by law. Three eenturies after this, (in 1467), permission was granted by the English king, Elward IV, as a royal favor, to export some of these sheep to Spain. They were originally very coarse animals, with thick, heary fleece, well allapted to their home upon the bleak exposed Cots- 


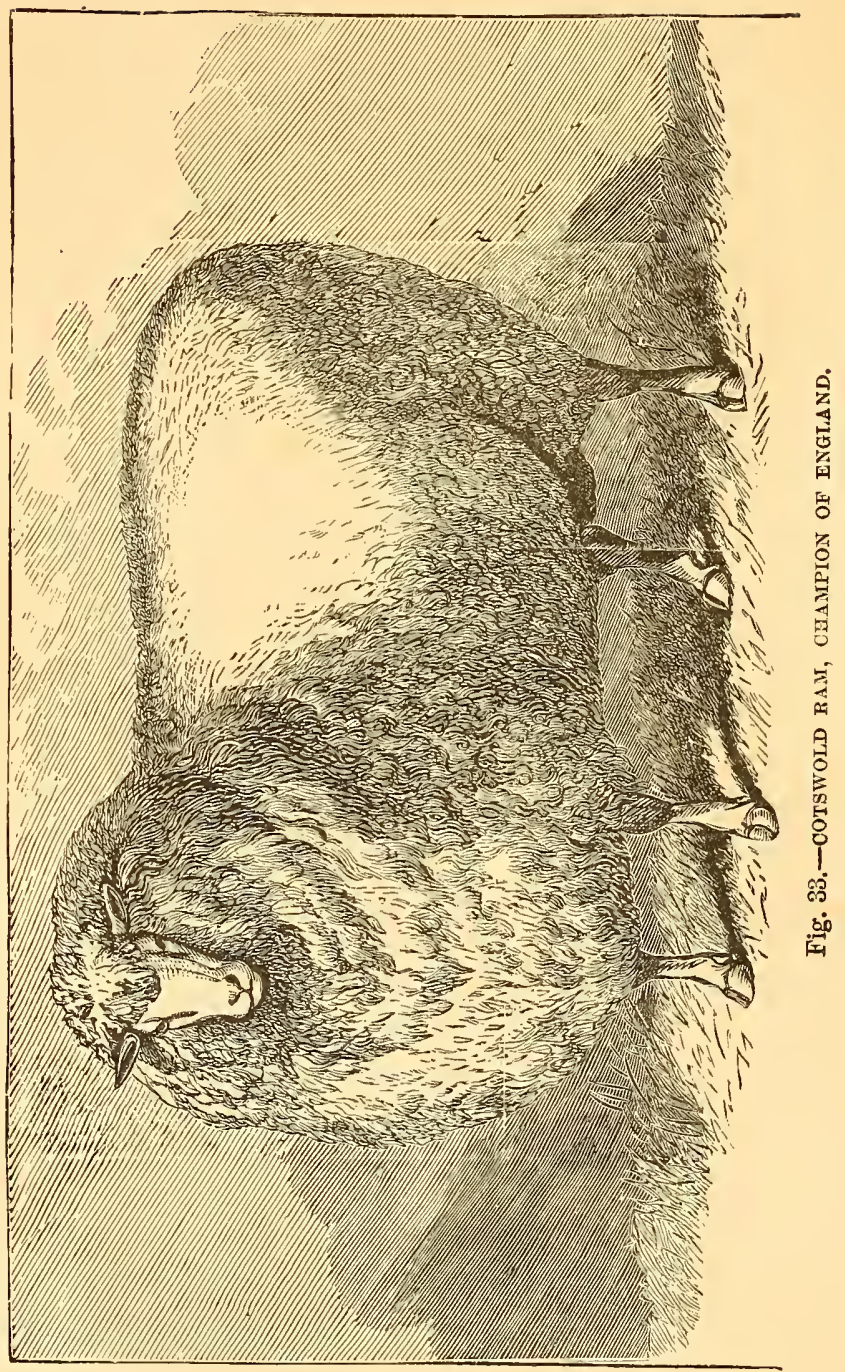


wold hil!s. So valuable and staple a breed could not long remain witbout improvement. Naturally, the srveat nutritious herbaga of the limestone soil covering these hills, favored this improvement, and as the pastures became enclosed, and agriculture improved in character, the flocks improved with it. When the Leicester became the most popular sheep of England, it was made to assist in this course of improvement of the Cotswolds. It gave to the breed a better quality, a smoothness and refinement, and a greater aptitude to fatten, while it did not lessen its ancient hardiness of constitution. The modern Cotswold is still capable of enduring hardship and exposure, and is at home on all sorts of soils. It produces a large carcass of excellent mutton, and a heary fleece of valuable combing wool, adapted by its peculiar character for a class of goods of wide consumption, it being in demand for various manufactures from the small matters, such as worsted dress braids, up to various kinds of cloths for men's and women's garments. Moreover the breed matures at an early age. It is not unusual to find sheep of $120 \mathrm{lbs}$. and over, at a year old. A full-grown sheep, exhibited at a Christmas cattle market in Lingland, dressed 344 pounds, or 86 lbs. per quirter. The weight of the fleece should average 8 lbs. for a flock of all kinds, and some of our naturalized flocks surpass this weight of fleece. Many erves have shorn $11 \mathrm{lbs}$. each. The fleece of "Champion of Eugland," whose portrait is given on the opposite page, weighed 18 lbs., and the fleeces of the ewes of the same flock, weighed from 11 to 16 lbs. The description of a well bred Cotswold is as follows: The face and legs are white, but scmetimes dashes of brown or gray derived from the original stock, may be found on both face and forelegs. The head is strong and massive, with sometimes a Roman nose, without horns, and having a thick forelock of wool upon the forehead. The neck and forequarters are not so square and heary, nor the brisket so prominent, as in the best Leicesters, but the hind quarters are square, full, and broad, and the thigh solid and heary. The back is straight and broad, and the ribs well sprung, giving a round body; the flanks are deep; the legs are clean, of moderate length, but the bone is not so fine as in the Leicester. The general style and appearance is good and attractive, and indicative of a vigorous, active, and hardy animal, and a prime mutton shcep. They are active and well fitted for gathering a living upon a pasture in which a Leicester wonld hardly thrive. The lawbs are active and hardy, and the ewes are good mothers. The fleece is closer upon the back than that of the Leicester, and only in aged rams exposes the skin along 
the middle. The wool sometimes reaches a length of 9 inches, and although coarse, is soft and mellow. In some of these sheep, the fleece is beautifully waved. No breed is more valuable for crossing than this. It has helped to establish several permanent cross breeds; the Oxford-downs and the Shropshires in England; a Cotswold-Merino in Germany, and another of this cross, which is well under way in this country, and last, but not least, a very promising cross breed, originated on the Beacon Farm, Long Island, by Mr. William Crozier, and called the Beacon-downs. It has, moreover, been used to produce many cross-bred market sheep in various parts of England, and is extensively used by our sheep-raisers in the production of market lambs. Being capable of adaptation to almost any locality, and producing a wool which, hoth in its pure state and in its grades, is of wide availability in the woolen manufacture, it may justly claim to be the most valua. ble sheep we have acquired, and to promise a more extended usefulness than any other we at this time possess, or can probably procure.

The OxFORD-DOwns.-This is one of the newly established cross-breeds, which has made a favorable reputation, and promises to become permanent. It has already been introduced here, and has made its appearance on several farms, the owners of which possess more than usual enterprise. It is classed among the longwool sheep, but it is only since 1862 that it has gained the honor, or has been awarded the justice of a separate class at the English fairs. It has rapidly extended its domain in England, and as a wool and mutton producer; firmly bolds all it gains. It originated in a cross of a Cotswold ram upon a Hampshire-down ewe, made in or about the year 1830 , by Mr. Twynham and several other farmers, of Hampshire, England. The produce was a sheep heavier than the dam, and resembling the Cotswold in size and fleece. The wool, however, was finer and firmer than that of the Cotswold, and from five to seven inches in length. The first cross rams and ewes were bred together, no further cross being made. By continued care the best points have been preserved, and the constitution and character of the first cross have been maintained. The result is, a sheep that is found profitable to feed on a mixed farm; hardy, producing at 14 months old a carcass of 80 to $88 \mathrm{lbs}$., and a fleece of 8 or $9 \mathrm{lbs}$. of wool, which is in great demand in the worsted manufacture. By good feeding these weights are much increased. At the Smithfield, (London), fat cattle show of 1873 , a pen of three 22 -months-old shearlings weighed alive $895 \mathrm{lbs}$, or an arerage of $298 \mathrm{lbs}$. each. Rams have been known to shear 20 


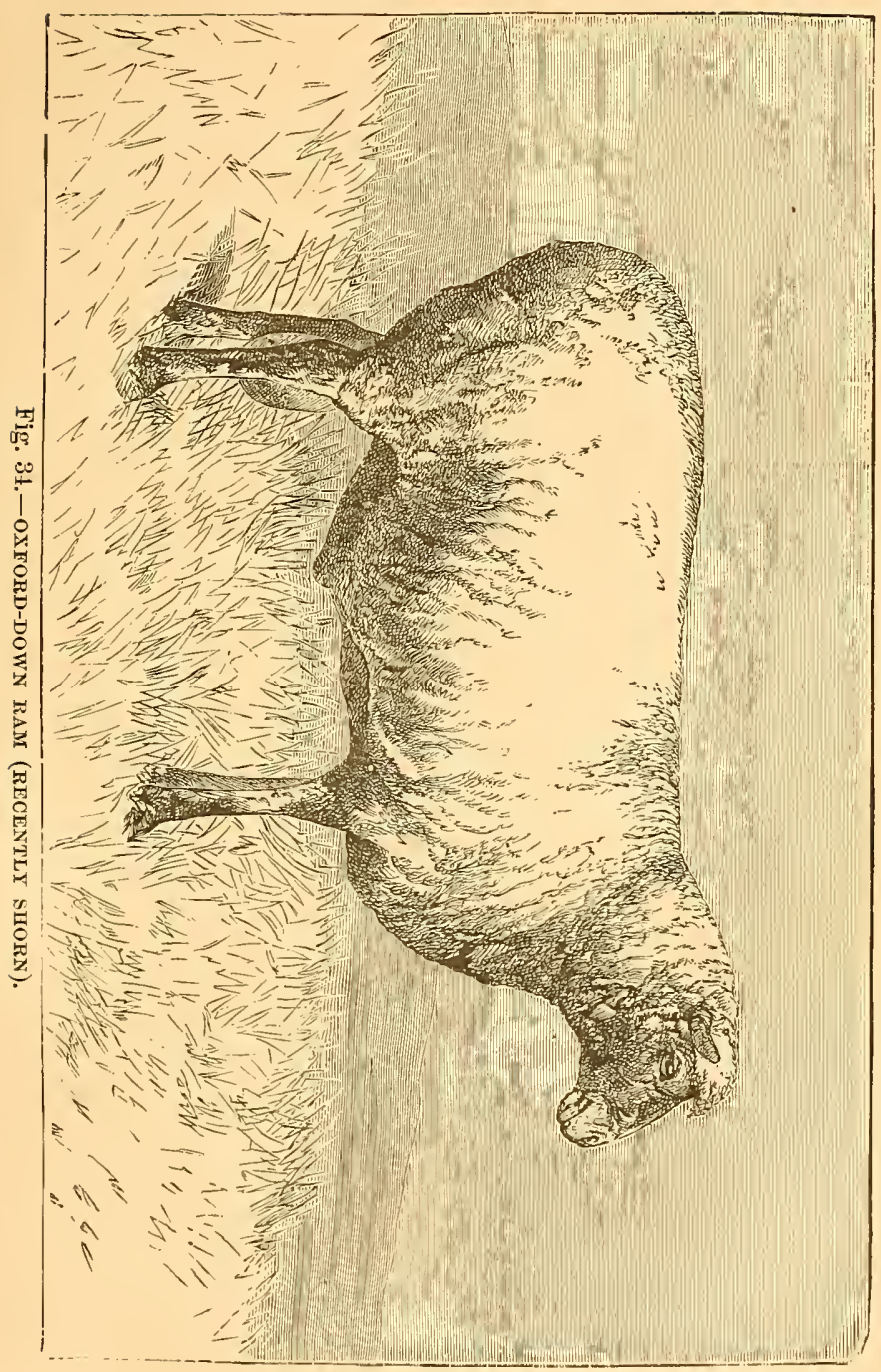


1bs. of wool for their first fleece. The Oxford-down has a head much like a Cotswold, with a tuft on the forehead, but with dark face and legs, which are derived from its other parent, the Hampshire-down; a thick set somewhat curly fleece, a round barrel on short legs, and yields, when less than two years old, a mutton considered by its friends as superior to the Southdow of the same age, but inferior to it when older than two years. Its native locality is a district at the foot of the Cotswold hills, an area of mixed soils, abounding in springs, and requiring much draining. At particular seasons in the winter, neither the Cotswold nor the Southdown could be made to thrive upon these wet soils, but the cross-bred sheep have successfully withstood the inconvenience without being affected with the usual disease of the district, such as giddiness, or water on the brain. They have been found very profitable feeders, requiring but little purchased food, and standing the exposure incident to folding upon green crops in the winter, without difficulty. Good rams of this breed bring about $\$ 60$ per head at the ram sales.

\section{MEDIUM AND SHORT-WOOL SHEEP.}

The Shropshire Sheep.-The Shropshire is one of the crossbrcd sheep that owes its origin in part to the Cotswold, the other parent being an original breed of sheep common to the district, and known as the "Morfe Common" sheep. This word "common" does not express quality, but is used here as referring to an unenclosed tract of land known as "cornmon land," or public property; such tracts formerly existed in many localities in England, and to a considerable extent in the early settlements in New England. These shcep of Morfe Common, (which was a tract of 600,000 acres of land), were the original stock upon which crosses of Cotswold, and afterwards of Leicester and Soutlıdown, were made at various periods. This course of improvement appears to have been begnn about 1792. From the unequal admixture of blood, the Shropshires vary somewhat in character, sometimes possessing the character of a short-wool, and sometimes that of a medium-wool sheep. The original sheep was horned, black or brown faced, hardy, and free from disease, producing 44 to $56 \mathrm{lbs}$. of mutton to the carcass, and a fleece of $2 \mathrm{lbs}$. of moderately fine wool, which was used in the cloth manufacture. Aft $\mathrm{r}$ threequarters of a century of cultivation, they are now without horns, with faces and legs of a dark or spotted gray color ; thick, meaty neck; weH shaped, rat'ier small and fine head; neat ears well set 


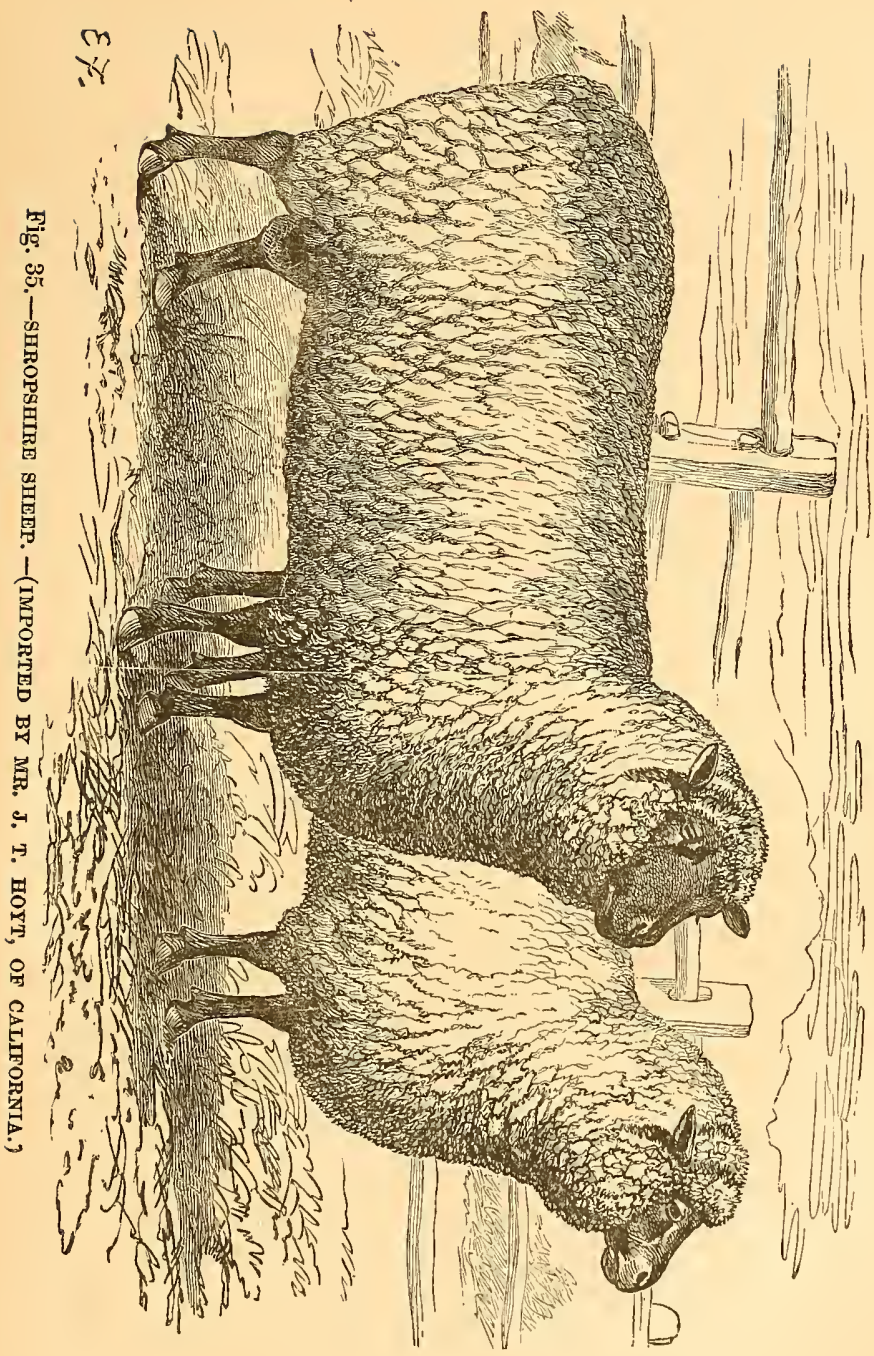


on the head; broad, deep breast; straiglit bacts; a good, round barrel; and clean legs with strong bone. They are very hardy, thrive well on moderate keep, are quickly fattened, and produce at two years old, 80 to $100 \mathrm{lbs}$., or even $120 \mathrm{lbs}$. of excellent meat, which brings the highest price from the butcher. The ewes are prolific and good mothers. The fleece is heavier than that of the Southdown, being longer and more glossy, and weighs on the average about 7 lbs. of marketable wool. The portraits on the preceding page are of some members of a flock imported from England in 1874 , by $\mathrm{I}_{\mathrm{i}}$. J. T. Hoyt, of Suisun City, California. This sheep possesses many valuable qualities for our uses, and promises to make a satisfactory farmer's sheep in localities where medium wool and choice mutton are profitable, and where the flocks have to depend upon pasture for the greater part of their support. Its close, well set fleece, and hardy constitution, will also belp to carry it throngh considerable exposure and variable weather, without injury. Prize rams have sold in England for $\$ 500$ each, but at the annual ram sales, the prices run from $\$ 50$ to $\$ 150$. There are several flocks of this breed kept in different parts of the United States and Canada, which promise to become sources of supply.

TIIE Southdown.-The modern improved Southdown descended from an old established breed of sheep, which have inhabited the hilly portions of England from the most ancient periods of known history of that country. In the southern part of the country, and in the counties of Sussex, Kent, Hampshire, and Dorsetshire, there is a range of low hills, unclerlaid with chalk, which descend gradually on the south to the sea coast, and on the north merge into rich eultivated lands. These low hiils or "Downs," have a dry suil, and are covered with a rich, sweet, short, dense herbage. Upon this farorable soil the ancient breed throve without special care, and when skillful breeders, emulating the success of Mr. Bakewell with the Leicesters, commenced to improve it, they speedily raised its character. At first the Sussex or Sonthdown sheep were small, and with few good points; long and thin in the neck, narrow in the forequarters, high in the shoulders, low behind, sharp on the back, and with flat ribs; their only good points being a good leg. Their mutton, however, chiefly from the excellent character of their pasture, was of the bcst flavor, and highly valued. By the careful attention of Mr. Ellman, of Glynde, the defects were weeded out, and after 50 years of constant selection of breeding animals, he brought his sheep into repute and favor, as the first of the short-wool breeds. Mr. Jonas Webb, of Suffolk, continued the course of improvement from 1822 , 


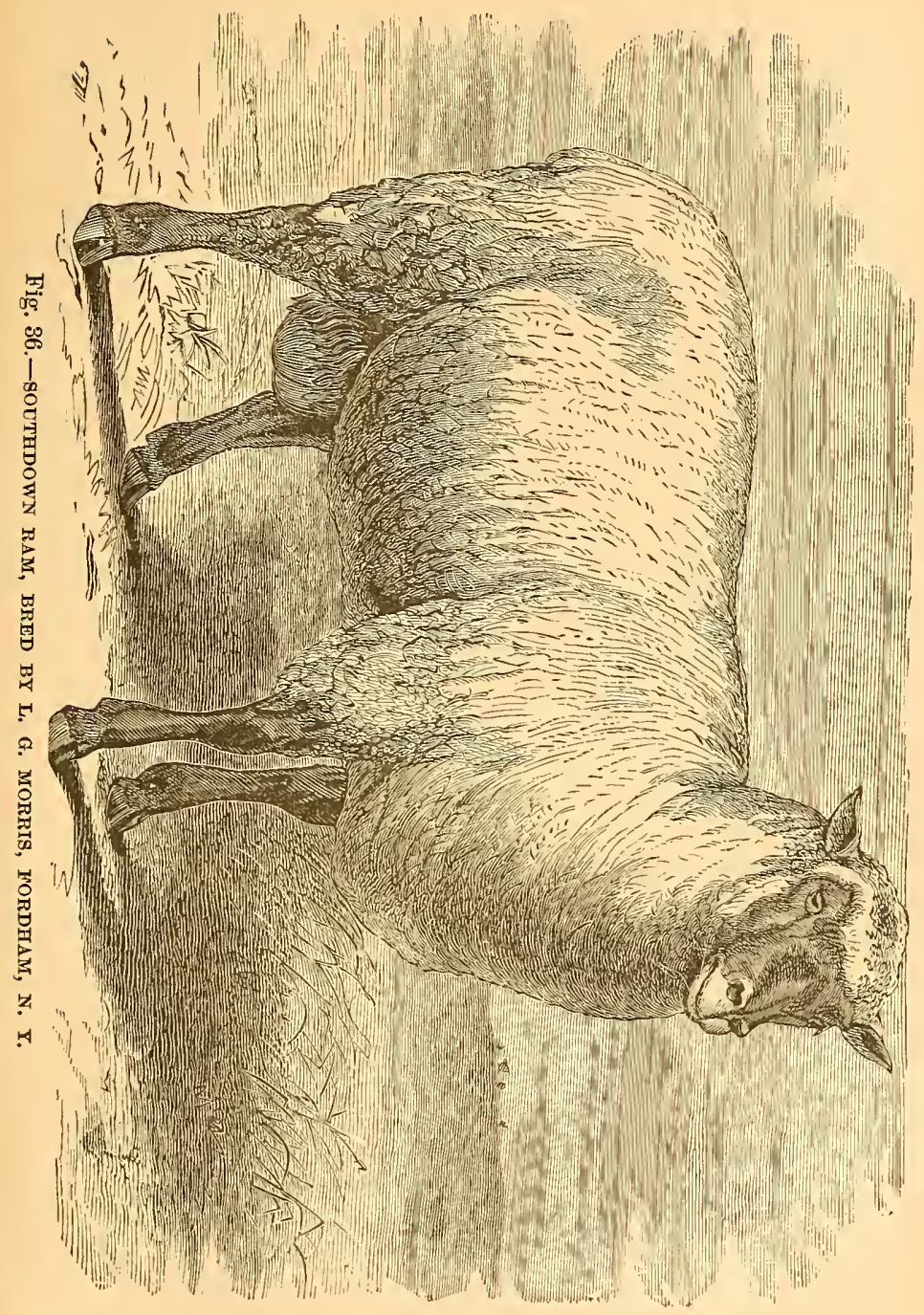


but it was only in 1840 that he gained a premium for his stock at an exhibition. After this he took a prize at excry exhibition of his sheep, and in 1843 the Highland Society paid him the compliment of having portraits of his prize sheep taken for the museum at Edinburgh. In 1855 Webb's Southdowns were exhibited at the Paris exhibition, and a ram, for which $\$ 2,600$ had been refused, was presented to the Emperor Napoleon. Since Mr. Webb's death, many breeders have made a wide reputation with the Southdowns, and at the present time they hold the position of being decidedly the best mutton sheep in the world. As yearlings they yield 75 to $80 \mathrm{lbs}$. in dressed weight, of the choicest meat in the market, and a flock of high character will produce an average of $6 \mathrm{lbs}$. to the fleece of a wool in demand for flannels and soft goods. The ewes are prolific breeders and excellent mothers. These sheep, as they are now bred, are without horns and with dark brown or black faces and legs. The size is medium; the body round and deep; the forequarters are wide and deep, and the breast is broad. The back is broad and level; the rump square and full, and the thigh full, and massive. The legs are short with fine bone. The form is smooth, even, fine, and symmetrical, without coarseness or angularity in any part. The habits of these sheep are active, and they are docile and contented. They are able to azcommodate themselves to any district, or style of farming, where moderately good pasturage is to be had, and are well suited as gleaners upon an arable farm. Mr. Webb's farm was mostly all under tillage. For the improvement of our native sheep in a particular clirection, they are not to be surpassed, and in this respect they rival the Cotswold. Indeed, there is scarcely a cross-bred race of sheep in England, or Europe, but has been indebted to the Southdown for some of its smoothness, rotundity, hardiness of constitution, and excellence of flesh. It is an excellent feeder, its lambs are active and hardy, and as the producer of market lambs from grade or pure Merino ewes, the Southdown ram has no superior, or equal, if the favor with which the dark faces and legs of the lambs are received by butchers is considiered There are no fatter lambs come to market than those of a cross of Southdown and Merino. The Southdown has become thoroughly naturalized in America, and its dark face and compact fleece, impervious to the heaviest rains, have left their mark upon a large proportion of our natives, ranking in this respect next to the MLerino.

The Hampshire-Downs.-The Hampshire-downs have of late rapidly risen in favor. Previous to our late war, many of them were imported into the southern states under the impression that 


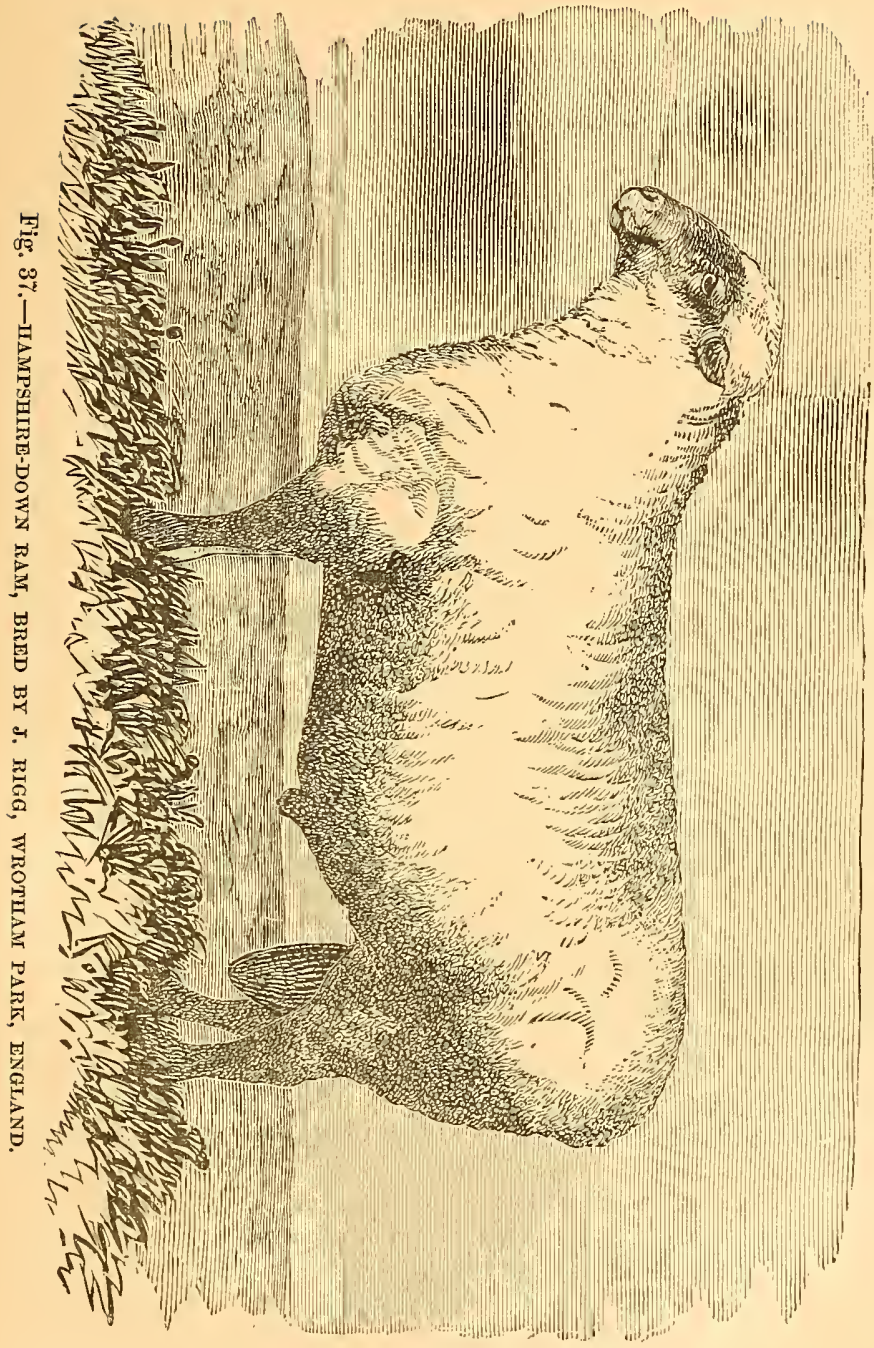


they surpassed their rivals and progenitors, the Southdowns, in adaptation to the climate. Amidst the vicissitudes of a state of war, no stock so rapidly suffers and disappears as sheep, and as Spain lost her Merinos in the French war of last century, so it is probable that the south has lost her Hampshire-downs. It is a valuable race of sheep, occupying a place where a larger animal than the Southdown is required. It originated in a cross made about 70 year's ago between a native, white-faced, horned sheep of the district, and the pure Southdown. The prepotency, or natural vigor and force of the Southdown ram, entirely changed the character of the breed in a few generations. The horns disappeared, the face became black, the frame was made more compact, the back broader and straighter, the barrel rounder, the legs shorter, and the quality of the flesin superior. The cross retained its ancient hardiness, its Roman nose, and massive head, and large size. It beeame, in fact, a larger Soutlıdown, maturing at an early age, and faiting rapidly. The large size of the lambs of this breed make it specially valuable under certain circumstances; at a year old they weigh 80 to $100 \mathrm{lbs}$. The fleece reaches a weight of 6 to 7 lbs. of wool suitable for combing, being longer than that of the Southdown, and not so fine. The mutton of the Hampshire-downs is not overloaded with fat, and has a good proportion of juicy, well flavored, lean meat. This breed is occasionally crossed with the Cotswoll, when it produces a wool more valuable for the worsted manufactures than that of the pure Cotswold.

THe Donsex Sheep.-Th1s is a breed which inhabits a district in the south of England, where it bas been preserved intact for a long period. It has some very valuable characteristics, one of the chief of which is its fecundity, and its ability to breed at an early season. The Dorset ewes take the ram in April, yean in September, and the lambs are fit for market at Christmas. A large proportion of the erves produce and rasse twins or triplets. A flock is mentioned owned by Mr Pitfield, of Bridport, Dorset, Eng., consisting of 400 ewes, which raised 555 lambs in one season. The ewes are ready for the ram immediately after yeaning, and may thus produce two crops of lambs in a year. Where market lambs can be disposed of, this peculiarity may be turned to good account, and with great profit. Both rams and ewes are horned. They have white legrs; white, broad, and Iong faces, with a tuft of wool on the forehead; black nose and lips; low, but broad shoulders; straight back and deep, ful bristset; the loins are broad and deep; the legs are rather long, but light in the bone. A related and neighboring breed known as "Pink-noscd Somersets," have pink 


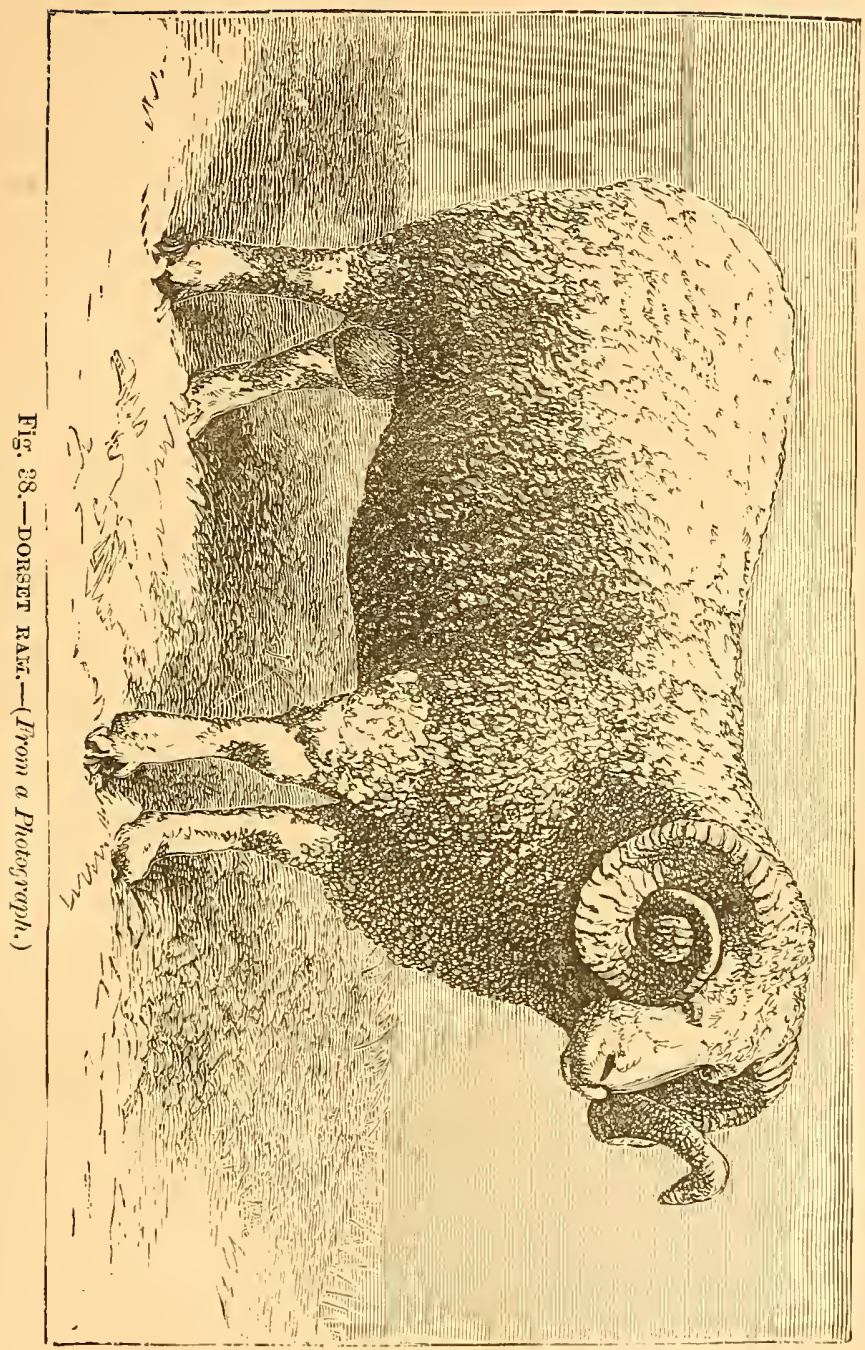


noses, and are not so valuable. The Dorsets are hardy, very quiet and docile, and submit to any reasonable management with facility, adapting themselyes readily to changes. They mature early, weigh 100 ibs. dead weight, at two years old, when folded upon turnips alone, for which kind of feeding they are well suited. The fleece is close and heavy, yielding $6 \mathrm{lbs}$. of white, soft, clean wool adapted to combing purposes. The lambs are sheared for thcir fleeces of "lambs wool." When crossed with the Southdown, the Dorset ewes produce mostly single lambs, which, when shorn, yield

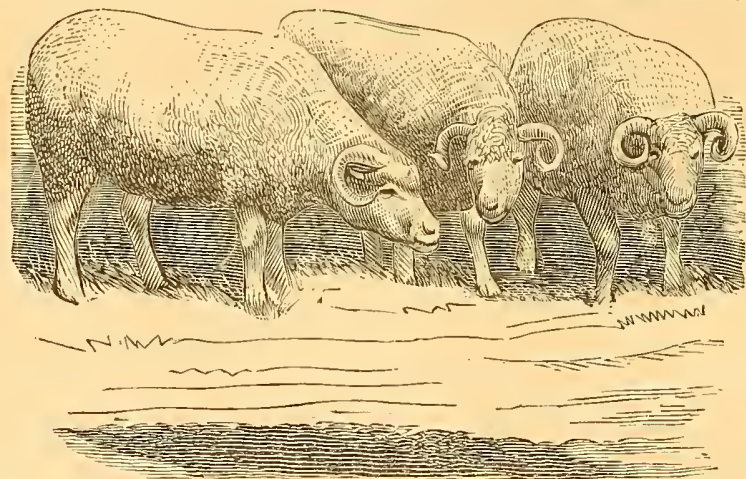

Fig. 33.-DORSET EWES OF MR. PITFIELD's FLOCK.-(From a Photograph.)

about 2 lbs. each of valuable wool, and make, when mature, a larger and better feeding sheep, with a heavier and fincr flecee than the dams. A few Dorsets have been introduced into Virginia, but have attracted no notice beyond the simple fact of their existence there. They certainly possess some valuable points for our use which should make them good subjects for experiment.

The Cheviot.-The Cheviot hills traverse the boundary between England and Scotland. These hills have given their name to a very hardy breed of sheep, the origin of which is perhaps somewhat fancifully dated back to the attempted invasion of England by the Spanish Armada. When this formidable and dreaded fleet was wrecked upon the stormy British coasts, it is said that some of the sheep with which the ships were provided, swam ashore and escaped to these hills, where they bred and multiplied. They were originally small, light-boned, hardy sheep, and were spread over most of the hilly part of the Scottish lowlands. A hundred years ago the attention of breeders was drawn to the Cheviots, and they were greatly improved in size and value. It is said that a 


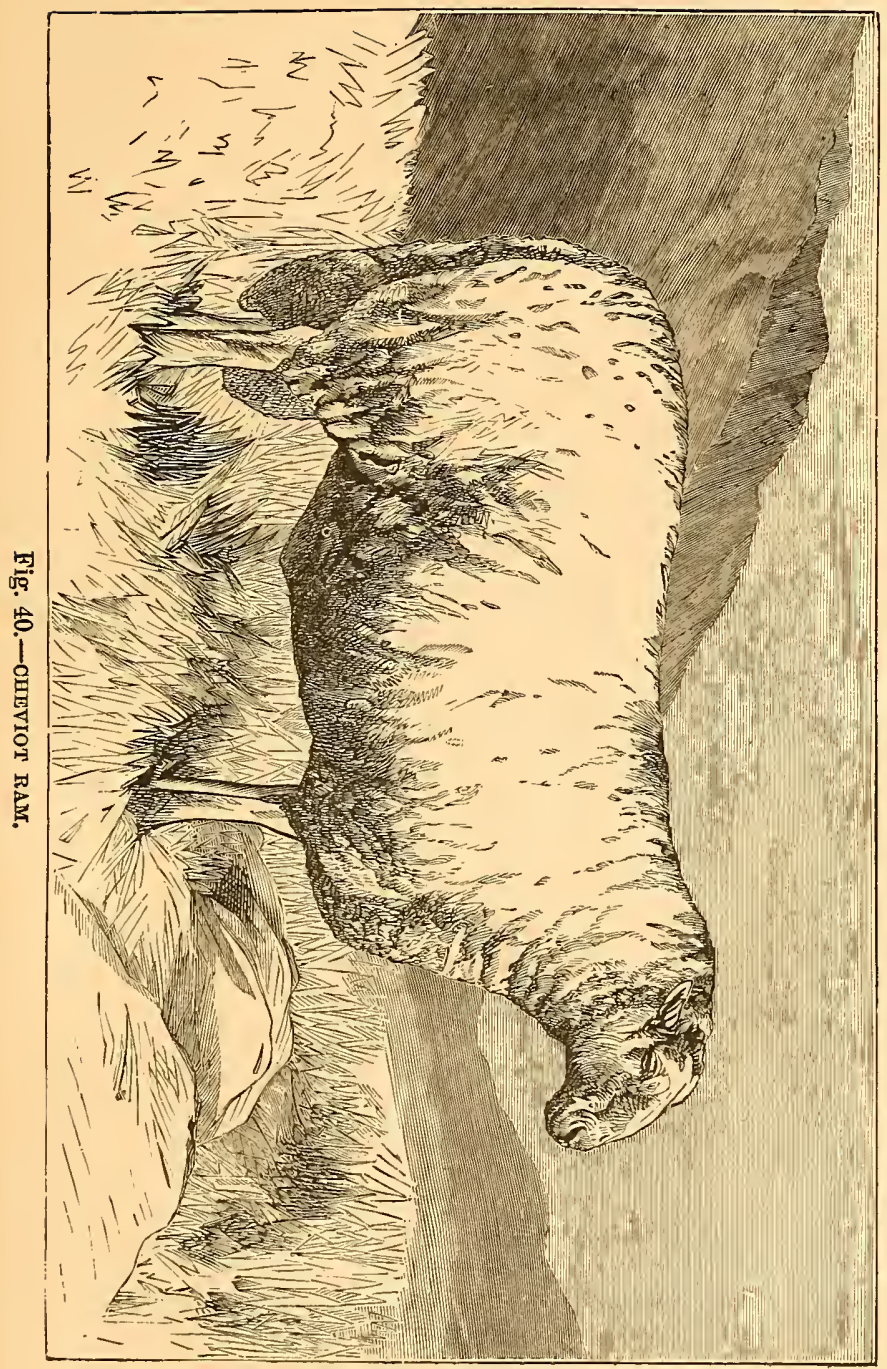


Lincolnshire cross was used for this purpose, and that a Leicester cross was tried and failed. It is now a most useful breed, and when fed upon sweet, dry herbage, produces a very choice mutton, much sought after by the epicure. It is without horns, the head and legs white, but sometimes, though rarely, dun or speckled, the face good, but strong featured and massive; the eyes lively; the body long, set upon clean, fine legs; the hindquarter and saddle full and heavy; the forequarter light, as in all mountain breeds, and in habit they are quiet, docile, and submissive to restraint. As a mountain breed they stand first in every respect, and yet are very useful lowland sheep. They fatten quickly on turnips, after pasture, without grain, and make a dressed weight of $80 \mathrm{lbs}$. at 3 years old. The ewes are good mothers, and the lambs are very hardy, spending the whole season on the hills without shelter, except in drifting storms of snow, when, without protection, they would be in danger of being buried in the drifts. The final clisposition of the Cheviots, when full grown, is to be sold to southern farmers, who raise a crop of cross-bred lambs by a Leicester ram, and fattening the ewes when the lambs are weaned, sell both to the butchers, turning over their capital with interest within one year. Upon good pasture the fleece becomes fine, and sells for a higher price than when they are fed upon coarse grass. The fleece yie:ds about 5 lbs. of medium wool, which furnishes the material for the useful and fashionable Scotch tweeds and Cheviot cloths. No wool is in greater or steadier demand than this class of clothing wool.

The Black-Faced Scotcm Shemp.-This breed is without doubt the oldest in Scotland. The story of its origin is obscured by tradition. It is known, however, to have existed, much as it now is, for several centuries, having disputed possession of the hills whereon Norval's "father fed his flock," with the wolves and foxes of the semi-civilized period, which preceded the last political settlement of Scotland with England. Since the union of the two countries, great improvements have taken place in Scotch agriculture, and the Black-faced sheep have gained with it. They are a horned breed, the horns of the ram being massive, and spirally curved. The face is black, with a thick muzzle; the eye is bright and wild; the body square and compact, with good quarters and a broad saddle. They are very muscular and active, and remarkably hardy, able to endure the privations incident to a life of continual exposure upon bleak and storm-beaten mountains. Only the heaviest snow-drifts, followed by thawing, freezing, and crusting of the snow, overcome them. They instinctively herd together 


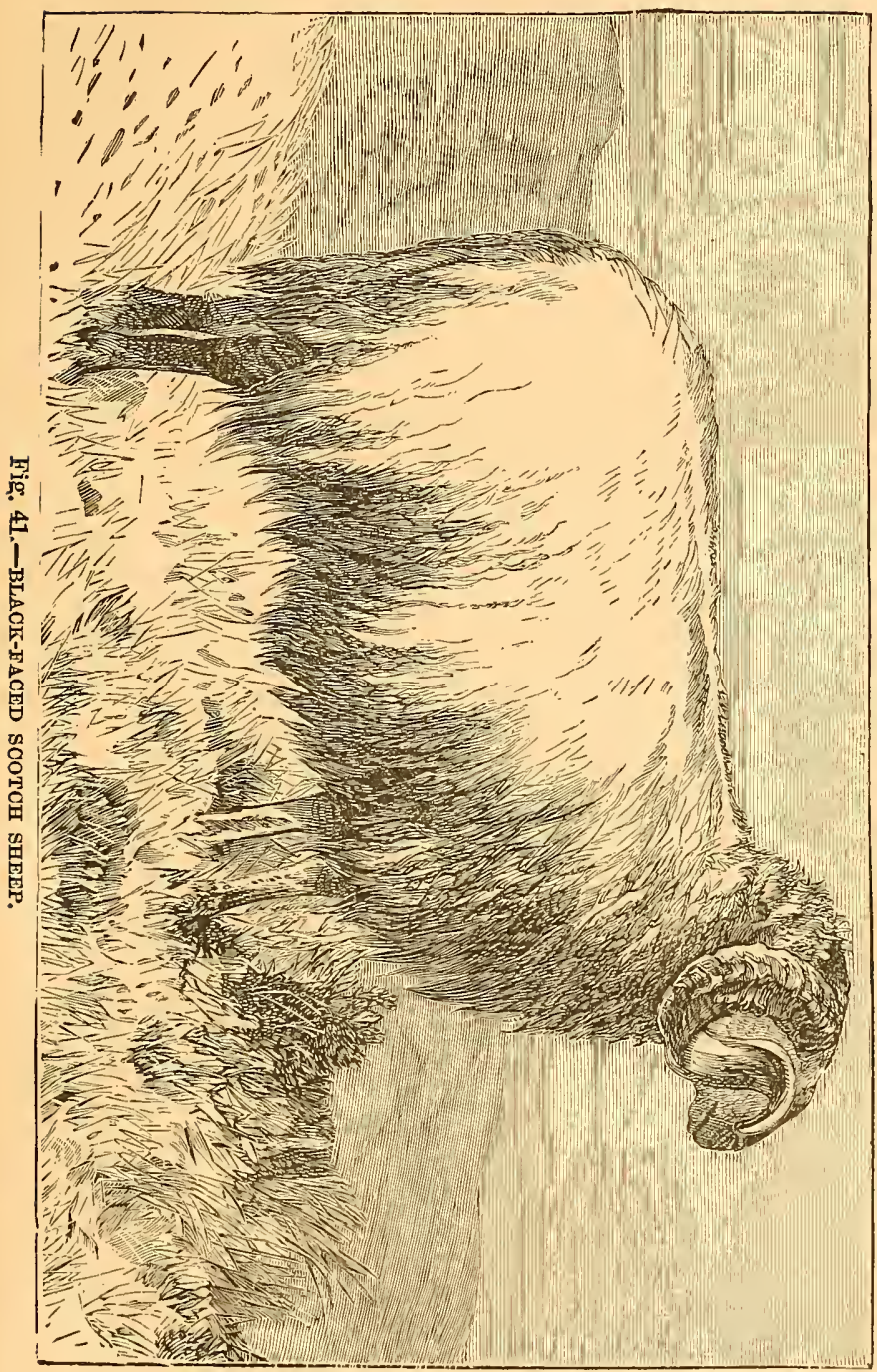


in storms, and although completely buricd in a snow-drift will manage to push the snow from their bodies and form a cave over them, in which they will live upon what scanty herbage may be within their reach, until help comes. Thus buried, these sheep have lived for two or three weeks before they have been found and extricated. After every storm the shepherd's first duty is to explore the drifts and release the imprisoned sheep and lambs. This hardiness fits them for their roving life upon their rocky heather-covered pastures, the heather in part furnishing their subsistence. They dig the heather from beneath the snow, or feed upon it when all else is covered. They are docile, and easily handled with the help of the sagacious Colley dogs, and are generally sufficiently able to help themselves in emergencies. Their activity is such that the $\mathrm{dog}$ is sometimes unable to head off a straying flock, or even to get abreast of it when instinctively bound to change their abode. Three clays before a storm they are on the alert, and seek lower ground and shelter. At lambing time, the ewes find retired spots, and year after year return to the same locality to rear their lambs. When removed from their native haunts, they have been known to journey night and day a distance of 60 miles, and to swim a large river, to return to their old pasture grounds. As an instance of the sagacity and activity of the sheep, it is recorded that a small flock which were thus on the way to a former pasture ground, were obstructed by a canal which had to be crossed. As they could not easily pass this obstacle, the flock, headed by an old wether, traveleci along the bank until they overtook a canal boat which was passing along in the center of the canal. The cunning wether sprang on to the boat and thence to the opposite bank, the whole flock following in Indian file. These sheep are kept in large flocks, sometimes of several thousand, and frequently of one to four thousand. The lambs will survive a surprising amount of cold and hunger, and are on their feet almost at the moment of birth. The ewes take the greatest care of their lambs, and will remain with them for several days, even after accidental or untimely death.

The mutton of this breed is of peculiarly fine flavor, and the saddles are in great request. The carcass weighs about $65 \mathrm{lbs}$., and the fleece averages about $3 \mathrm{lbs}$. of washed wool. The breed improves easily under the care of a judicious breeder, but the natural qualities of this sheep are such that it is fitted for a place where no others would profitajly thrive, and a change in its character that would eause it to lose this quality would unfit it for its position, and deprive it of its chief value. How vast the room in our 
exposed mountain localities, or on our unsheltered northern plains, for such a sheep as this; a race hardy and self-dependent, and that would produce choice mutton, and a fleece rrell adapted for rural manufactures of coarse cloths, carpets, blankets, and rugs.

The Welsh Mountain Sheep.-This breed is said to be one of the indigenous races of Britain. Formerly, it probably roamed over hill and lowland of the whole of Wales and adjoining parts of England. Of late, more profitable breeds have usurped its place in the cultivated lowlands, and have driven it into the remotest pastures or stretches of barren moor, bearing only gorse and heather, upon the sides and summits of the Welsh mountains. Here it has so far found a resting place, furnishing those very small, but highly appreciated legs and hind quarters, which are valued on the tables of wealthy Englishmen as the rarest delicacies. These legs weigh about 4 lbs., and the whole hind quarters from 7 to $10 \mathrm{lbs}$, and are sold at the confectioner's and fancy grocer's shops, at two or three times the price of ordinary mutton. A recollection of the tender sweetness of one of these Welsh legs is apt to give a higher appreciation of these small sheep than might be profitable for a farmer to entertain, yet it is a question if there are not many localities amongst our mountain ranges, where flocks of these small hardy sheep could be kept with profit. As might be expected, these sheep are hardy and good nurses to their lambs, rarely producing more than one, except when crossed with improved breeds. The rams are horned, but ewes rarely so; their faces are white, rusty brown, speckled, or gray. The head is small and is carried high; the neck long; the shoulders low; the rump high; the chest narrow; the sides flat; and the girth small. The average fleece yields about $2 \mathrm{lbs}$. of wool, the best of which furnishes the material for the valued Welsh flannel, which never shrinks in washing, and of which sheets and blankets are made that last a lifetime. The Welsh wool is all home-spun, and is woven at home into all sorts of clothing and domestic goods; the farmers and their families being wholly clothed in wcolen. The cloths are home dyed, either black, blue, or red. The red cloth furnishes the material for the women's cloaks, which are universally worn, and which when a French army landed on the Welsh coast, in 1797 , were mistaken by them for the red coats of British soldiers, and led to their immediate and unconditional surrender before the mistake was discovered. This race of sheep, comparatively so puny, is a source of much comfort and wealth to the Welsh pcople, and attempts to supplant it by the Chevict and Black-faced sheep, have so far failed. No other sheep can com- 


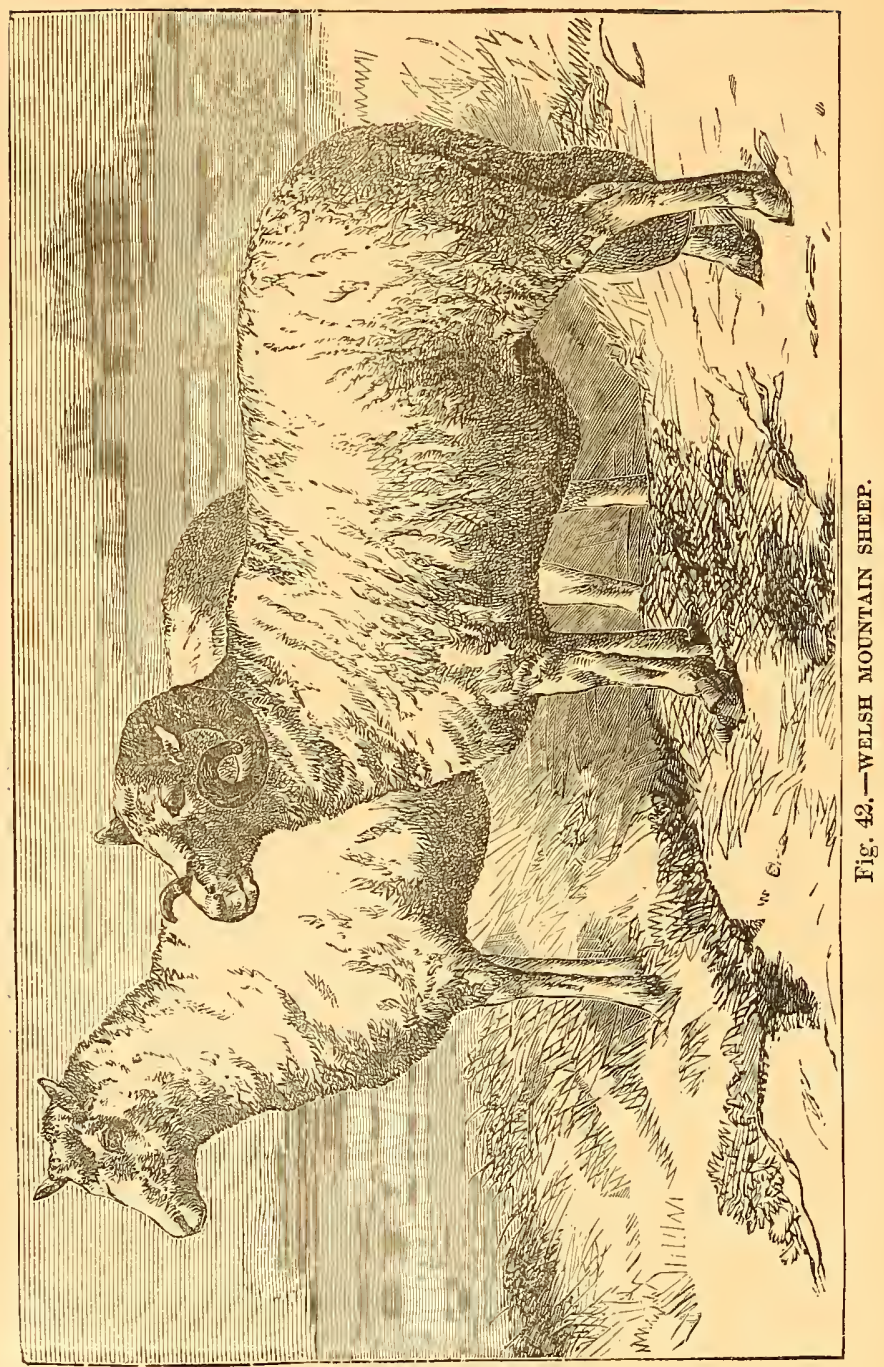


pete with them on their native mountain tops, and none are more profitable on the lowland pastures, than a cross upon them of small pure-bred Southdowns, Cotswolds, or Leicesters. The flocks usually kept number from 50 to 500 head.

The Spanish, French, and German Mernos.-The Merinos of Spain, France, and Germany, although they now possess different characters and habits, have the same origin. The French, Saxon, and Silesian flocks, were all originally from Spain. The Spanish Merino existed as a distinct race 2,000 years ago, and the fine robes of the Roman Emperors were made from the wool of the Spanish flocks. There is no history or tradition as to their origin which can be accepted as reasonable by any practical shepherd. It is probable, however, that the fine wooled sheep, which we read of in the ancient histories, were rather the natural product of very favorable conditions of soil and climate by which inferior races were greatly improved, than of any direct efforts to breed them up to a desired standard. Yet luxurious Romans may undoubtedly have created a demand for fine wools, which Spanish shepherds knew how to produce by coupling suitable animals, for the art of breeding was well understood in those ancient days, and many of the maxims of modern breeders are simply reproductions of those in vogue as long ago as the early Christian era. The finest sheep of Spain, when they first attracted notice, were found widely scattered over that country, divided into varieties occupying distinct provinces, and those varieties, again, were subdivided into large flocks, owned by wealthy proprietors, each of which flocks possessed such marked characters as would entitle it to be considered as a distinct family or sub-variety. The system of culture by which these various families became possessed of their special characteristics, are well described in an essay by Dr. R. R. Livingston, which was presented to the Society for the Promotion of Useful Arts, of New York, in the year 1809. It is unnecessary here to clo more than to refer to this work. It is sufficient to record the fact that, at a very early period of modern history, Spain possessed the only valuable flock of fine wool sheep in the world, and that all other naturalized races of Merino, our own included, have been derived from that country. It may be added, that to a great extent, if not altogether, Spain has lost her pre-eminence, and breeders do not now resort thither for fresh importations. The Spanish sheep are estimated to number ten millions, in which are included Merinos of the two now remaining families, the Infantado or Negretti, and the Escurial, and various other fine and coarse wool shecp. The 
Negretti sheep are of more interest to us than any other of the Spanish sheep, as it is of this breed alone that any are now brought to this country. The Escurial sheep are of little value to us, either for breeding or crossing with our own. They are represented here by the Saxon and Silesian Merino, which have descended from them, as will be hereafter explained. The Merino cannot thrive in a moist climate. A wide range of dry, upland pasture is necessary for them, and they do not require a very nutritious herbage. Wet pastures are very unhealthful for them, and the liver rot and diseases of the lungs carry them off from a large flock by thousands, in unfavorable seasons. On this account, the Merino has not thriven in England, and it now exists and thrives in those countries only where the climate is dry and warm, or even hot.

The French Merino.-As this variety has been imported to some extent into the United States, and possesses some value for crossing upon our native Merinos, or other sheep, it is important to notice its character and peculiarities. It originated from an importation of a flock of over 300 Spanish sheep, selected from the finest flocks of Spain in 1786. This flock was placed upon a public farm, for the improvement of stock, at Rambouillet, near Paris. In the selection from various sources, it appears that the flock was of a mixed character, but by careful breeding, through a course of years, the differences became merged into a breed of sheep, which surpassed its ancestors, in the opinion of its French owners. It was in increased size of carcass and weight of fleece, that the improvement was chiefly, if not wholly, made. In 1825 they became the largest pure JJerinos in existence, with remarkably loose skin, and immense neck-folds. In 1842 there were flocks of these sheep in France, whose fleeces weighed $14 \mathrm{lbs}$. for ewes, and 20 to $24 \mathrm{lbs}$. for rams. At this time a flock was imported into this country by Mr. D. C. Collins, of Hartford, Ct. The wool of these sheep was considered by a competent judge as equal to the best Spanish Merino wool. It was of a brilliant, creamy color, on a rich, soft, pink skin, which was loose and wrinkled. Their form was fine, their constitution excellent, and in size they were much larger than the American Merino. In 1846, Mr. Taintor, also of Hartford, commenced to import these sheep. His rams sheared from 18 to $24 \mathrm{lbs}$. of unwashed wool, and ewes from 15 to 20 lbs. The ewes weighed alive from 130 to 200 pounds, and the rams from 180 to 300 pounds. There was much less yolk or gum in the fleeces than in those of the Spanish sheep, and there was consequently less loss in washing the wool. 
The French Merino soon spread through the northern states, but many breeders became clissatisfied with their tenderness, as compared with the Spanish breeds, and they rapidly fell into disfavor. They were not fitted for our rough farming, and required more care than American farmers are inclined to give to their stock. The best of these animals were found, with proper care, to be profitable, but the inferior ones were entirely worthless. Uncler such circumstances it is not surprising that they should fall out of the race in competition with naturalized Spanish Merinos, which, even when inferior, were still valuable, in proportion to the good qualities they retained. In France the Merinos

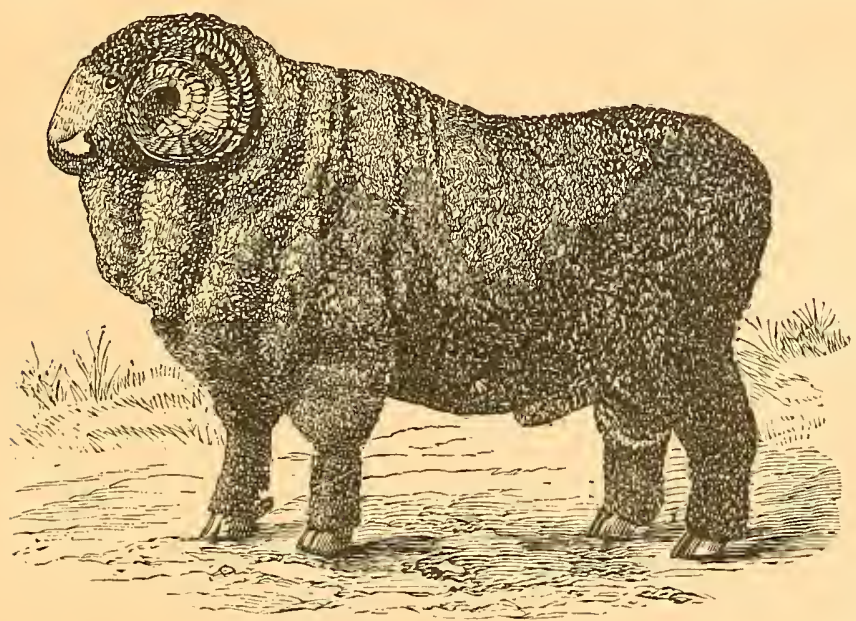

Fig. 43.-FRENoH MERINO.

have favorably competed with the English breeds as mutton sheep, and it is only recently that the French agricultural jourmals are beginning to compare the profits from the Southdowns with those from the Merinos.

At the Vienna International Exhibition in 1873, the Frencl Merinos were largely represented, and were very favorably noticed. The specimens there exhibited were large and well formed, the skin was free from large folds or wrinkles, and the wool was long, fine, strong, and thickly set on the skin. The best of them, however, came from Germany. The ram, whose portrait is here given, was exhibited by Herr Kannenberg, of Gerbin, near 
Kosternitz, in Pomerania. Its wool was 3 inches in length, very thick upon the skin, very equal in quality, of fair strength, and covered the legs and eirs. The sire of this ram clipped $27 \mathrm{lbs}$. of unwashed wool, which, when washed in hot water, yielded $17 \mathrm{lbs}$. of clean wool. Ferdinand Schwartz, of Lappenhagen, exhibited a French, (Rambouillet), Merino ram, whose fleece weighed, unwashed, $31 \frac{1}{4} \mathrm{lbs}$., equal to $15 \frac{1}{2} \mathrm{lbs}$. of washed wool. This animal had three neck-folds, but no "rose" or rump fold. His wool was $2{ }^{3}$ inches long, and thickly set upon the skin.

Prince Schaumberg-Lippe, of Post Stalitz, Bohemia, exhibited some combing or delaine wool Merinos, of French blood, whose fleeces were of the extraordinary length of 5 to 7 inches. The yield of the whole flock, of more than 800 , is said to average $14 \frac{1}{2}$ lbs. per head of unwashed wool, which shrank in scouring in the factory, 58 per cent. It is impossible to consider the excellent points and intrinsic merits of the well bred French Merino, and its poor success, so far, in this country, without being forcibly reminded of the lack of wisclom of a course frequently and periodically pursued by American breeders and farmers, and nowhere more strikingly shown than in the past experience of our sheep husbandry with its sudden and excessive vicissitudes. The "ups and downs" of this industry, every few years, is one of the strangest manifestations of unsteacliness ever recorded in any pursuit. It is unfortunate for us that we can hardly restrain ourselves from over sanguine expectations on the one hand, or on the other hand, when results do not meet our anticipations, from the ntmost depression. Being too ready to form opinions, and to act in obedience rather to our sudden impressions than to our mature judgments, we enter into new enterprises without consideration, and abandon them in a panic. Thus a thing excellent in itself, and of inherent value to $\mathrm{ns}$, is extolled to the skies without justice at the outset, and then with equal want of justice, is condemned and sacrificed as utterly valueless, because it has failed to turn all it touched into gold. This is the history of all our agricultural manias. And the French Merino has been made the subject of just such exalted expectations, and of just such deep denunciatioas. Yet there is a place for this breed in our agriculture which it will hold and keep at some period in the future in spite of past adverse experiences.

The Saxon Merrno.-In 1765 the King of Spain, on the application of his brother-in-law, Prince Xavier, sent 300 Merinos of the Escurial family in to Saxony. These sheep, naturally the finest wooled and the least hardy of the Spanish flocks, were so bred as to still further increase the fineness of the fleece, and to diminish 
their strength of constitution. The ewes yielded from a pound and a half to two pounds of washed wool, and the rams from two to three pounds. The wool was almost free from yolk, and remained clean and white; the staple was from one inch to an inch and a half in length. The body of this sheep was thin, the legs long, the neck long and thin, the skin pale, and the constitution weak. Yet the beauty and extreme fineness of the wool were such (a fiber, not of the finest, measuring $1 / 8_{40}$ of an inch in diameter) that it overbore the objections to the defects of the sheep. While this is the general character of the Saxon sheep, there are a few breeder's who have striven with success to give them more size and greater compactness of form.

The management of the noted Saxon flock of Baron Sternberg, from which most of our recent importations of these sheep bave been made, is worthy of note here. This flock consists of 1,200 head : 600 ewes, 100 rams, 250 lambs, and the rest wethers and yearlings. They are kept in one large brick stable, 330 fect long, 63 feet wide, and 30 feet high; this is well ventilated, and made to be closed in severe weather. The ewes, rams, etc., are kept in divisions separated by hurdles, supported by stakes driven into the floor. In these are placed fodder-racks and feed troughs. Above the stable are hay and straw lofts, floored with boards, which are covered with several inches of beaten clay. The litter and manure remain in the stable six months at a time, until it is in a compact, solid mass, three or four feet thick. The sheep are stabled here from November to April, and foddered on straw, hay, turnips, and brewers' grains. In summer they are taken out to graze from 9 to 12 in the forenoon, and from 3 in the afternoon until sunset. Great care is taken in coupling the ewes; those rams being selected that are needed to cover defects or improve weak points in the ewes. Mere fineness of wool is not aimed at. The greatest possible size of carcass compatible with tine elothing wool, and a fleece at least $2 \frac{1}{2} \mathrm{lbs}$. in weight, are the desired objects. The weak and inferior lambs are killed off when young, and the flock is rigoronsly weeded of all but healthy animals. The value of the land upon which this flock is kept with profit is $\$ 200$ to $\$ 300$ an acre. The importation of Saxon Merinos into the United States have shown that this breed cannot, under ordinary circumstances, profitably compete with other varieties of Merinos, on account of the cost of the shelter and extra care needed for its proper management, and the smallness of the fleece. The supcrior fineness of the wool does not bring a sufliciently bigh price to make up for the deficiency in weight. In competition with the 
American or French Merino, the Saxon has been found unprofitable for the production of wool in the present condition of the woolen manufacture, yet there may occur cases in which it can be made useful at some future time, when the demand for very fine wool may return under the influence of the changes of fashion.

The Silesian Merino.-The Silesian Merinos have become already a successfully acclimated breed in the United States. This breed became established through importations from Saxony as well as from Spain. The flock out of which the only importation into America was made, became naturalized in Silesia by an importation of Infantado and Negretti Merinos, in 1811, by Ferdinand Fischer, of Wirchenblatt. Mr. F:scher personally selected 100 Infantado ewes and 4 Negretti rams, and these sheep have bcen interbred without admixture from that date to the present. So careful has been the breeding, that since its commencement over 60 years ago, the pedigree of every sheep of the flock has been recorded. This purity of blood is one of the most valuable characteristics of the flock in question, in which, having acquired an offshoot from it, we are especially interested. Perfect purity of blood gives force, or, to use the breeders' phraseology, prepotency to the breed used in crossing on other races, and insures uniformity of improvement. If this general opinion of breeders is founded on fact, as must be admitted, then the value of the flock to be referred to, can hardly be questioned, and it might truly be designated as pure Spanish, instead of, by reason of its acciclental location, Silesian. As it is, however, generally known as Silesian, and is as well entitled to that name as are the French Merinos to theirs, it is convenient to continue its use. The American Silesian Merinos were imported from the flock of Mr. Fischer, by the late Mr. Wm. Chamberlin, of Dutchess Co., N. Y., from 1851 to 1856 . In all, 212 ewes and 34 rams were importcd. The ewes shear from 8 to 11 pounds of unwashed wool, the rams from 12 to 16 pounds. The wool is from two inches and a half to three inches long, dark on the outside, without gum, but with plenty of oil of a white and free, but not sticky, character. The ewes weigh, alive, from 110 to 130 lbs., and rams from 145 to 155 lbs. They are hardy, good breeders, and the ewes are good nurses. After some years' experience with them, Mr. Chamberlin has stated that they do not deteriorate, but that the wool grows finer, without losing in the weight of the fleece. They mature slowly, and do not reach their full size until four years old; after eight or nine years they become lighter in weight. The mature shcep are as large as the ordinary American Merino. The Silesian is simply 
a very high-bred Spanish sheep, resulting from the union of two of the best families, and bred for more than half a century for a particular purpose by one breeder, or what is really equivalent to that, a father and son. The fleece is superior in fineness to that of any other Merino we possess, and for a really fine wool, is unrivalled. It is fortunate that the Silesian Merino begins its career in America under such favorable auspices, and that the shepherd in charge of the flock, Mr. Carl Heyne, so thoroughly understands its requirements and management. It is to be hoped that the conservative and judicious management of this flock will help to establish it successfully, and to launch it on a long course of usefulness. Rams and ewes of this flock are already being distributed by sale throughout the country, and the original flock now numbers over 800 head. One peculiarity in Mr. Heyne's management, is especially noteworthy; the lambs are yeaned very early in the winter. This is of course a matter of choice on the part of the shepherd, but it involves the greatest excellence of management, and the provision of roots for the maintenance of the nursing ewes, along with a perfect arrangement for shelter and warmth during the winter season. It is obvious that few American breeders, and still fewer farmers, would find it possible or profitable to incur the necessary expense of this sort of management for the amount of proft realized from the wool alone.

Cross-Bred SheEP.-It is a somewhat suggestive fact that just now the most profitable sheep in Europe are cross-bred. The cross-bred races in England are what the English farmers pertinently designate the "rent-paying sheep," that is, that there is more money in them than in any others. The cross is made between the strictly mutton sheep and the strictly wool-bearing sheep. The sheep raised chiefly for wool are of slow growth and late in maturing. The high-bred mutton sheep are high feeders, and require the most careful treatment. They have been refined so highly that they no longer possess the requisite constitution, nor are they so prolific as to satisfy the wants of farmers who depend, not upon the high prices obtained by breeders for their stock, but upon those offered by the purchasers of meat and wool, who can only give what the inexorable necessities of the markets enable them to pay. The eross-bred sheep are of quick growth and early maturity ; their mutton is acceptable in the markets; their fleeces are of wide adaptation to woolen manufactures, and they are ensily fed and make a greater weight of marketable meat with a comparatively small consumption of food. In MIr. Lawes' experiments, related in the Royal Agricultural Journal, it was found that 
the cross-bred sheep could be fed more cheaply, for the same weight of flesh, than the pure breeds, with but one exception, that being the Cotswolit. The same necessity to make the most profit on the least expenditure, exists with American as with the English, French, and German farmers, and we are discovering, as they have done, that the cross-bred sheep bring the most money to their owner's. In England, through the operation of this fact, there has been established for some years past a system of ram sales, at which breeders of pure blood sheep offer their surplus rams for sale or for hire by the year. By this means farmers are enabled to select for themselves such breeding animals as they may need. These sales are attended by purchasers from all parts of Enrope, Australia, and South America, and also by a few of the more enterprising breeders of the United States and Canada, or their agents. At the Vienna Exposition of 1873, where there were exhibited several cross-breeds of sheep which were highlly satisfactory, the favorable resuits of this system were prominently set forth. The most conspicuous of these was

The Cotswold-Merino. - These are fine examples of sheep. They are without horns, with bare faces resembling the Cotswolds, but with the pink noses of the Merino; the ears are slightly drooping, and the top-knot shorter and less abundant than in the Cotswold. The wool is much finer than in the Cotswold, very bright, with good curl, thickly set on the skin, and well filled with liquid yellow oil, but free from solid yolk or gum. The fleece is better closed than that of the Cotswold, and is easily kept free from dirt and dust. The flesh is firmer than that of the Cotswold, and thicker than in the Merino, both back and ribs being well covered. The girth taken over the wool averages 5 feet 8 inches. The wool is scant below the knee and hock. This is the character of the first cross. When interbred without further crossing, this character has been well maintained. The cross-bred animals and their produce are of strong constitution, mature quickly, becoming prime íat at 12 to 14 months old, and weigh alive at that age 140 to 148 pounds. The flock from which some of the specimens exhibited at Vienna were taken, numbered 340 head, and was bred by the Moravian Sugar Factory Company, of Keltschan, Austria. The sheep are fed upon waste beet pulp from the factory, a small quantity of oats, hay, and oil-cake, in addition to clover pasture and mangels, which completes the round of the year's feeding. The mutton is held in high esteem, and brings the extreme price of 8 conts per pound, live weight, after the fleece is sheared. 
There are many other flocks similarly bred in Austria and Hun. gary, and all are reported as heing equally satisfactory. In reference to these sheep, a German agi icultural journal published in Vienna, in its issue of June 2, 1873, remarks as follows: "Wo cannot sympathize with the complaints of the admirers of high, fine wool, looking as we do upon the farmer as a merchant who must keep up with the times, and supply the wants of the market. As the public have ceased to ask for the very fine cloth which was so highly valued 50 years ago for its beauty and durability, no one can complain that the manufacturer turns his attention to cloths of coarser quality, suitable to the present public taste. When the manufacturer no longer requires so much of the high, fne wool, the price falls, and the farmer ceases to produce an article that is no longer profitable." There could certainly be nothing more pertinent to our own case than this. The same need has found its same remedy here, and the Cotswcld-Merino is largely bred for the production of market lambs, and some of our best breeders are giving their attention to the establishment of permanent flocks of this cross, with promising results.

The Soutmown-MERINo.-This cross has been tried with success in Germany upon a middle quality of land, not sufficiently productive to support the heavier bodied Cotswold-Merinos. The first cross-bred sheep possess goou feeding qualities, and when bred together without further crossing, lieep well up to the standard of the parents. The Arch Duke Albrecht has a flock of 1,400 of this cross, of which some specimens were exhibited at Viemna. The wool is rated as middle fine, weighing $3 \frac{1}{4} \mathrm{lbs}$. to the fleece in the shearlings, and $3 \mathrm{lbs}$. in the two shearlings. This cross made upon grade Merinos, is very common in the United States, where carly market lambs are produced, there being no fatter, better, or mo:e desirable lambs to the butcher, although there are heavier, than those from this cross. As in the Cotswold-Merinos, the first cross is the best for interbreeding.

The Leicester-Merino.-This cross is a somewhat unusual one, and does not appear to have been made with a view to the permanent cstabishment of a new race of sheep, except in rare instances where the possession of a suitable breed of Merinos and the taste of the proprietor have been coincident. In one case only has the effort to establish this cross been reported in any publication of wide circulation. The history of a flock of about 500 Leicester-Merinos, bred by M. E. Pluchet, of Trappes, France, given to the Central Agricultural Society, of France, in January, 1875, is 


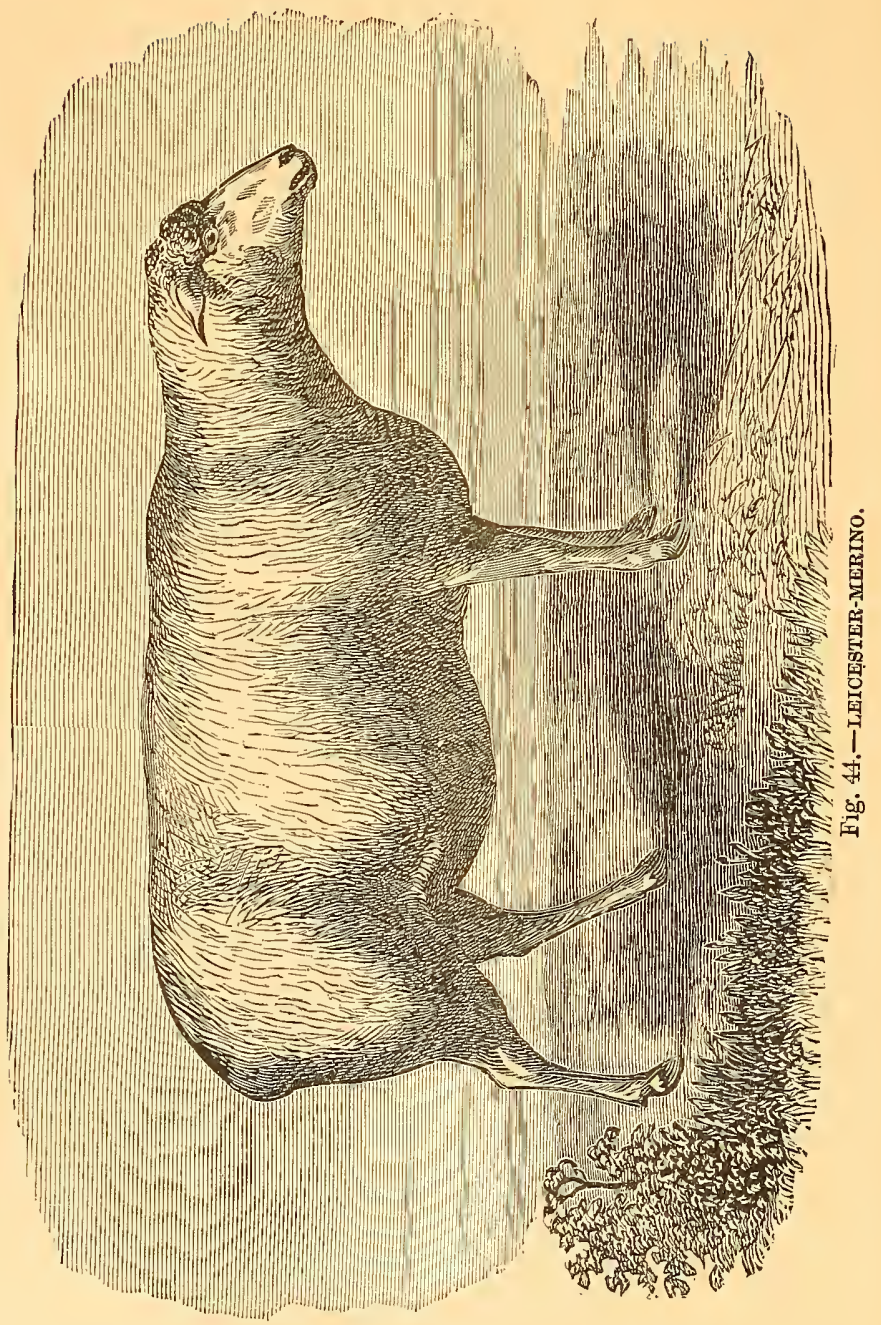


published by Eugene Gayot, the well known writer upon live stock, in the Journal d' Agriculture Pratique, of the 27th of May following, with a portrait of one of these sheep which is reproduced here. The course followed by Mons. Pluchet during the 36 years of his persevering effort is very suggestive and instructive. $\mathrm{He}$ commenced in 1839 by coupling his Rambouillet Merino ewes, weighing about 68 pounds when dressed for the butcher at 3 years old, with a pure Leicester ram of moderate size. The effort to produce what he wanted, by one cross only, failed. At first the lambs were too small, and the fleece was too light. Greater success was made by crossing the half-blood ewes with rams of quarter Leicester blood. The produce, containing three-eighths Leicester, and and five-eighths Merino blood, were much improved, giving a much longer and better fleece than the half or quarter, bloods. After continuing a course of breeding the produce of this cross together, up to 1856 , a new type of animal, entirely different from its ancestors, resulted. The carcass was much larger than in the Merino, the wool was not so long as that of the Leicester, but finer and softer; the face was free from wool, and the head was square, with large, prominent eyes. The bone was remarkably fine; the flesh solid, and the ewes were prolific and remarkably good nurses; but neither the carcass nor the fleece were sufficiently heavy to be profitalle. The ciwes of this cross were coupled with a pure Leicester ram, and the produce being eleven-sixteenths Leicester, were again crossed with rams of threeeighths Leicester, or of the previous cross. The sheep thus procured were $8 \frac{1}{2}$ sixteenths Leicester and $7 \frac{1}{2}$-sixteeuths Merino, or nearly half bloods. The close in-and-in-breeding of this cross gave a race of sheep that, when fed on the same pastures as the original Merinos, produced exactly the same dead weight of meat of superior quality at 24 months, that the Merinos gave at 36 months, and a fleece weighing $9 \frac{1}{4} \mathrm{lbs}$. in the yolk, which sold at a higher price per pound than the Merino fleece. Under the circumstances in which Mons. Plachet was placed, the result was very profitable, and the new race he originated occupies a place which neither of the original parents was able to fill. Uncler a system of close breeding, without fresh admixture, the quality and character of this flock are maintained, and the ewes continue to be both prolific of lambs and milk, and are excellent nurses.

Cotswold-LEICEsTER.-A very handsome cross-bred is produced by the union of the Cotswold ram with the Leicester ewe. 'The flecce of this cross is of a silky fiber, beautifully waved and curled. The wool partakes of the fineness and luster of the Lei- 
cester, and the strength and weight of the Cotswold. It is in great request for the manufacture of fine dress braids, and is sought by the manufacturers chiefly in Canada, where the cress is most common. The cross is hardier than the pure Leicester, and yiclds a fine mutton, but when bred together, the produce is very apt to deteriorate. The portrait given on page 139 represents a ewe bred by Mr. Burdett Loomis, of Winclsor Locks, Ct., and very much resembles one bred by the author.

Cotswold-Southdown.-The Southdown is pxr excellence the mutton sheep of the world. But mutton alone is not profitable; there must be a fleece as well as the carcass, to repay the cost of feed and care. The Cotswold is a profitable wool bearer, but its mutton is not so desirable as that of the Southdown, nor is its fleece adapted to a wide variety of uses in manufacture. If the excellencies of the two breeds could be combined, and better mutton than the Cotswold, and a better fleece than either be produced by amalgamating the different bloods, a desirable result would be reached. In this lies the whole secret of the desire to produce cross breeds. In the effort to reach this result, all the cross breeds have been obtained. It cannot be supposed that sheep breeders have yet reached the limit of profitable crossing. The constant change in the public taste for cloths, dress goods, and fabrics, and the new-found needs and capabilities of various and peculiar localities, will ever operatc to cause new crosses and combinations of breeds, and to furnish opportunities for the skillful exercise of the breeder's art. The Cotswold and the Scuthdown bloods flow together in more than one firmly established cross breed, but with other admixtures. Efforts to combine these two breeds alone, and to produce a new race which shall be more profitable than either alone, have been made of late both in this country and in Germany. In the latter country the Moravian Sugar Factory Company, previously mentioned in this chapter, have formed a fluck of cross-bred sheep which successfully answers the purpose of producing mutton and a wool which, for certain manufactures, is desirable and profitable.

In the United States, Mr. William Crozier, of Beacon Farm, near Northport, Long Island, has commenced to breed a flock / and found a race which he calls the Beacon-downs. His success so far has been encouraging. A description of this sheep with the portrait, from which it is here reproduced, appeared in the American Agriculturist of June, 1875. The flock was commenced six years ago by crossing Southdown ewes with a Cotswold ram, and the first cross, being very satisfactory, was interbred. 


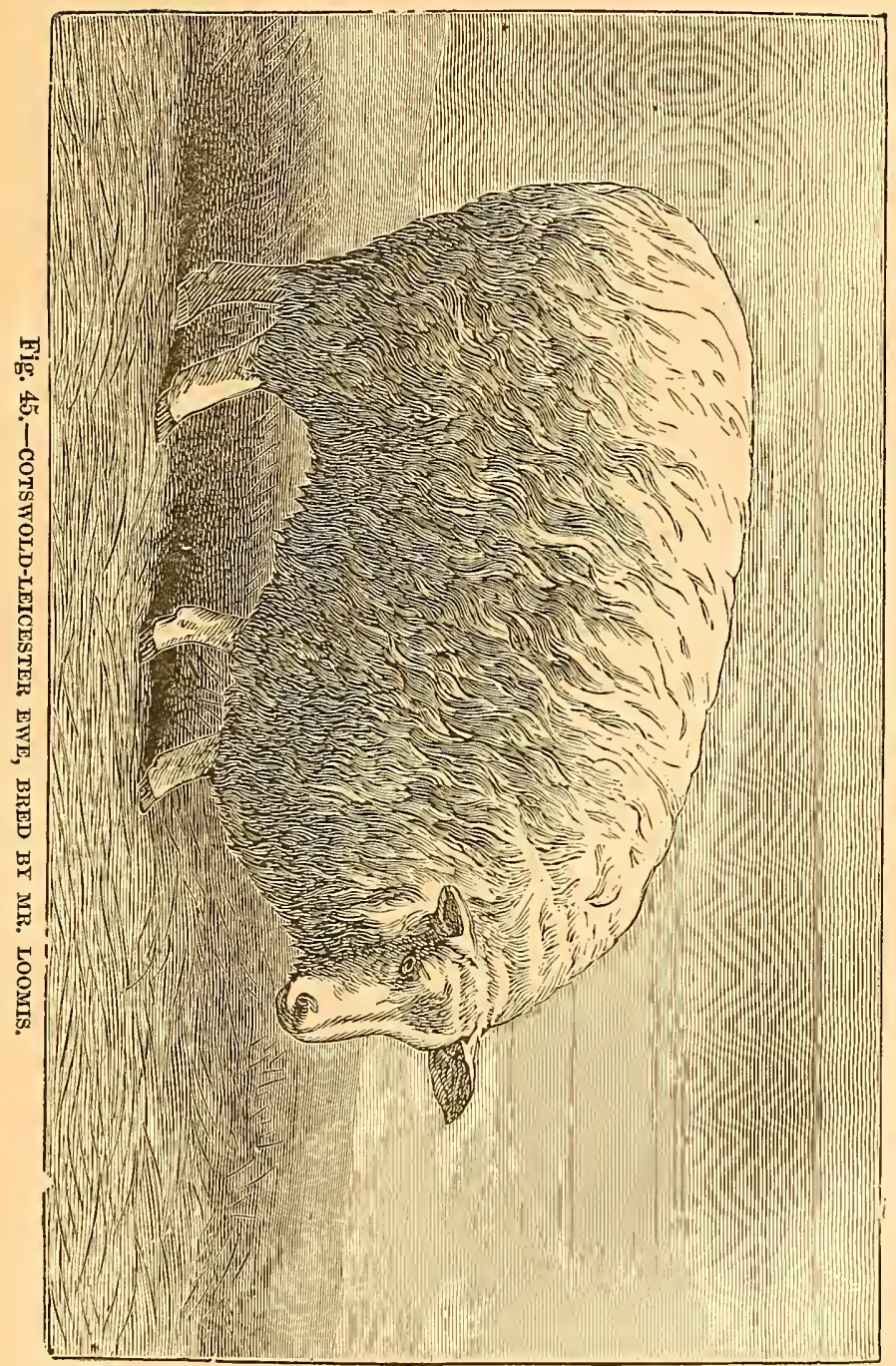


It was found to maintain its original character perfectly, producing a sheep which yielded a fleece of wool closer and finer than that of the Cotswold, but not so long, weighing from 11 to $13 \mathrm{lbs}$, and a much heavier carcass of mutton of a quality equal to that of the Southdown which weighed, at three years old, 150 lbs. The ewes are prolific, the lambs strong, healthy, and maturing quickly, reaching a live weight of 140 to $160 \mathrm{lbs}$. at twelve months. They are found to be equally suitable to the light pastures of Long Island, with either the pure Southdown or the pure Cotswold, and are perfectly at home beneatl the hot summer suns of our climate. It is a coineidence which is not at all remarkable, being founded on common necessities, that in producing this and other crosses, the Germans and ourselves have taken up the same materials to work with. The climates of both the United States and southern Germany are similar; the summers are hot and dry, and the winters compel the use of preserved and dry food for a considerable length of time. The breeds which would be suitable to the mild, moist, and even climate of England, are not exactly adapted to Germany or the United States, and we must hesitate to follow, or must follow with great caution, the lead of the English breeders. But the example or success of the Germans may be made more safely applicable to our circumstances, inasmuch as the conditions in both cases are similar. This coincidence is a proof of the fact. that in working out these changes, breeders and farmers are forced to follow certain natural laws, and that as they work in conformity thereto, they succeed, but when they oppose these laws, they must necessarily fail. It is in exact accordance with this fact that we find it difficult or impossible to preserve, for any length of time, the condition of sheep imported from England, more especially of thie more highly refined breeds; but that we can easily acclimate their produce, or build up cross breeds which will be more profitable and convenient for us to keep. With our wonderful diversity of elimate, soil, and surface, and with the varied demand for staples for manufactured fabrics, there is opened a field for the exercise of the breeder's skill in producing new races to accommodate these conditions, and to meet these demands, which is hitherto unexampled in the history of agriculture. This is no mere matter of conjecture. It has been clearly demonstrated by experience and practice. Wool of the cross between the Cotswold or Leicester rams on Merino ewes has been imported into New York from New Zealand and Australia, for some years past, to meet the demands of the manufacturers of delaines and other staple goods. Our wool-bnyers have been in the habit of going to 


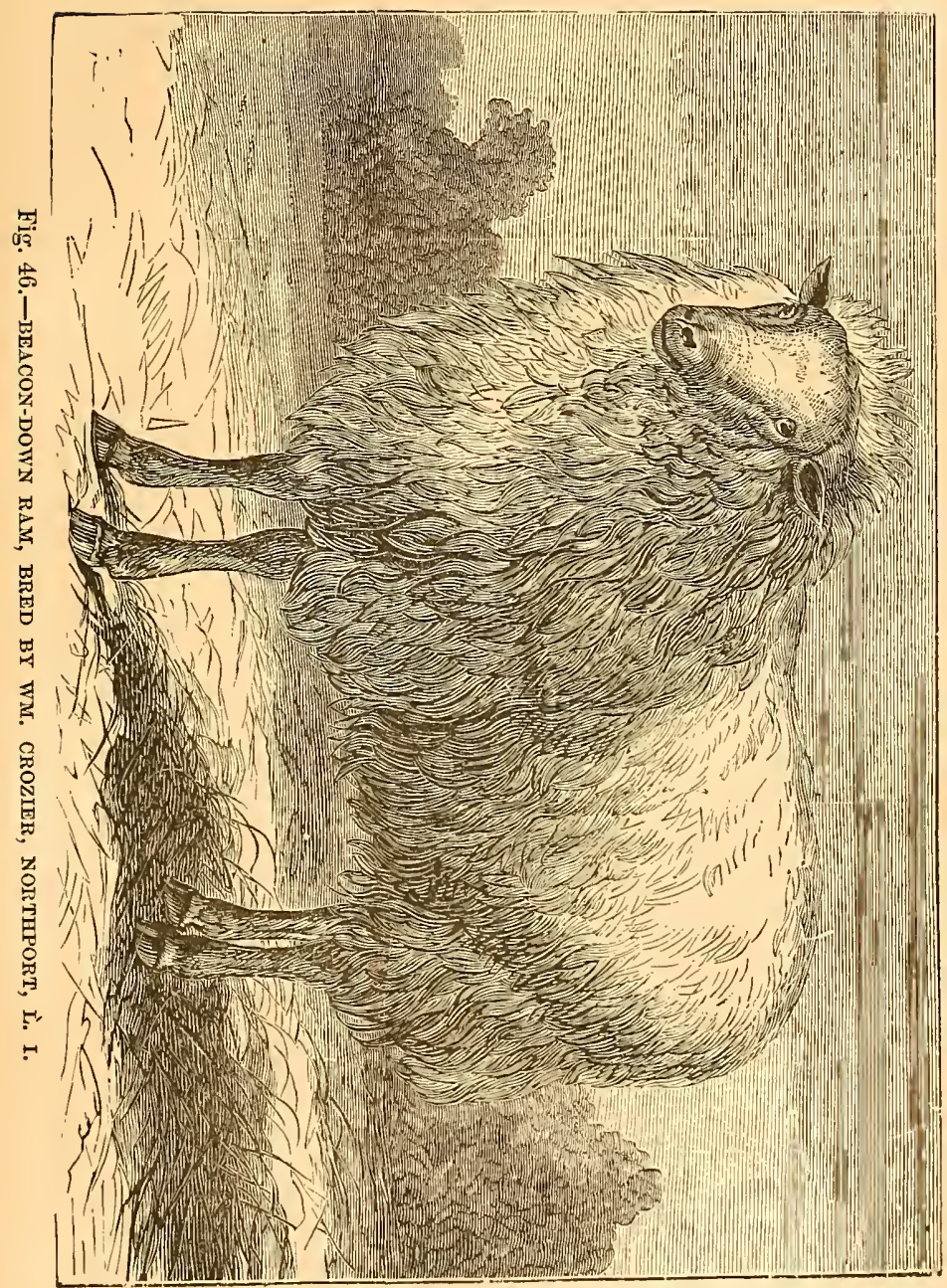


those distant countries to select wools suitable for their needs which they cannot procure at home. The heavy expenses involved act as a protection to this industry here, not to speak of the present import duty levied on foreign wools. Large quantities of this cross-bred wool are also used in England, where it camnot be produced so cheaply as here. It would be strange indeed if we cannot, with our vast territory, equally favorable in climate and soil with those distant regions of the southern hemisphere, at least compete on equal terms with the shepherds of those countries, more especially as we enjoy an immense advantage, which they do not, in having a market at our very doors for the mutton which these sheep so profitably produce. In short, the production of American cross-bred sheep offers a most enticing field for experiment and labor both to the skillful breeder and the enterprising farmer. For the first in keeping up a supply of pure bred rams, and in improving their quality so as to meet the demand of the farmer; and for the latter in seeking out, selecting, and using these pure rams on our native sheep with proper knowledge, judgment, and skill, so as to supply the demands of our own manufacturers at least, if not those of other countries. To do this there must be an actual contact and interchange of ideas and experiences between the woolen manufacturer and the breeder and farmer, by means of which the needs of the one and the opportunities and duties of the others, may be mutually explained and made known. Neither branch of our native wool industry can flourish as it should and might without this interchange of views and the recognition of an identity of interest.

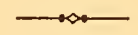

\section{CHAPTER VI.}

\section{WOOL-ITS STRUCTURE AND USES.}

Wool in its character and structure in no respect differs from hair. When hair is soft, pliable, and of a spiral or wavy form, it is what we call wool. Wool, like hair, is the outer covering of some species of animals, and is a growth from the skin. The skin of an animal is a composite structure consisting of two portions, the outer and insensible layer called the epidermis, and a highly sensitive, vascular and nervous layer beneath this, called the 
derma. It is in the Cerma that the Lair is rooted, and from it that it is nourished. The hair, (or wool), consists of two portions, the shaft, or that which pierces through the epidermis and forms the outer coat or fleece, and the bulb or root which is imbedded in the derma. The bulb of the hair is rooted in a gland called the hair follicle, and from this it derives the cells which form the outer surface of the hair. These cells are converted into flat scales, inclosing the interior fibrous structure of the hair, and as they are successively produced, they overlap like slingles on a roof, or the scales of a pine cone, forming the imbricated coat of the hair to be hereafter described at length. Rising into the hair bulb is the hair germ, which furnishes the hair with nutrition, and the elements of its growth. On each sicle of the hair follicle is a gland which secretes a viscid fluid. These glands, known as the sebaceous glands, open by small canals into the sheath of the hair. Other

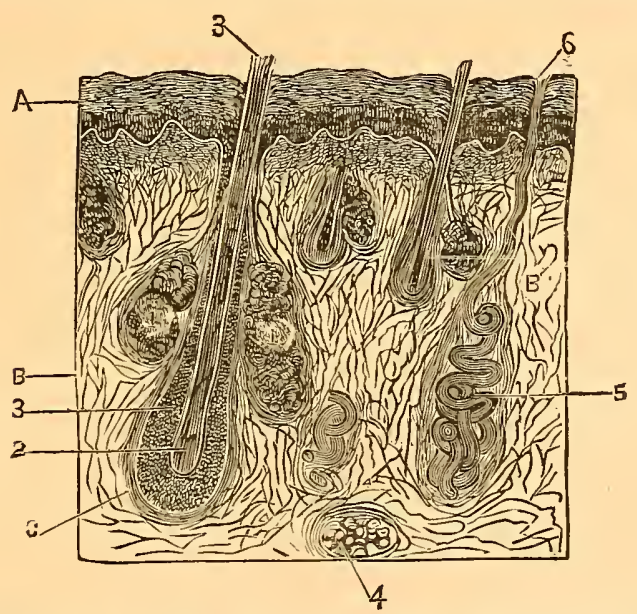

Fig. 47.-SECTION OF SKIN HIGHLT MAGNIFIED, SHOWING THE GROWTH OF THE HATR.

sebaceous glands open independently upon the surface of the epidermis. They secrete a fluid which serves to lubricate the skin, and in the sheep supplies the oil and rolk that fill that purpose for the fleece and prevent any injury to the wool by continued rubbing, or "cotting," or felting, in consequence of the wearing and friction, while upon the sheep's back. In a hcalthy skin this secretion with those of other glands, (called the suclori- 
parous glands), which are situated in the derma, amount to a total quantity which surpasses that of the evacuations from boith the bowels and kidneys.

In fig. 47 is shown the structure both of the skin and the hair, the engraving, (from Chauveau's Comparative Anatomy of the Domestic Animals), representing a section of the skin highly magnified. The epidermis is shown at $A$, the derma at $B$, the hair follicle at $c$, the sebaceous glands at 1 , the bulb or root of the hair at 2 , the hair at 3 , a fat cell at 4 , a sudoriparous or sweat gland at 5 , and at 6 the excretory duct of this gland, or pore of the skin.

Hair or wool is composed of three layers. The onter one, the epidermis, is very thin, consisting of the flattened cells or scales overlapping as previously mentioned. In wool these imbricated scales are highly developed, and fill a most important office, giving
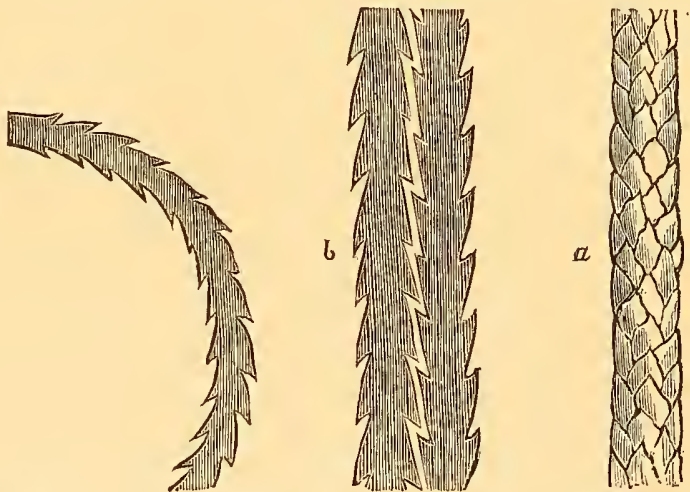

Fig. 48.-APPEARANCE OF WOOL WHEN HIGHLY MAGNIFIED.

to it much of its value as a material for the manufacture of cloth. When examined by a microscope of high power, a fiber of wool presents the appearance shown in fig. 48. The discovery of the serrated surface of wool which is generally attributed to Mr. Youatt, was previously announced by M. Monge, in Annales de Chimie, in-1795. This serrated or toothed surface confers upon wool its felting property. When wool is carded it is torn to pieces and mixed and twisted in every direction. The waved or curved structure of the fiber of some qualities of wool aids in this twisting and entangling of the fibers, (see fig. 49), and the points of the scales projecting as so many minute hooks hold the entangled mass together closely and firmly. Pressing, rolling, or beating 
the wool together, causes it to adhere in a compact mass, in other words causes it to felt firmly together, and the more firmly, the more it is rolled, beaten, or worked. These scales are very minute and numerous; in the length of one inch of a fiber of fine Saxony wool, there are no less than 2,720 of them; in Southdown wool there are over 2,000, and in the Leicester wool there are over 1,800 of them to every inch. Upon the whole surface of a fiber of Merino wool one inch long and $1 / 750$ of an inch in diameter, there are over 23,000 of these points. The more numerous they are, and the more waved or curled the wool, the better its felting quality.

The second layer, the cortical substance, is the thickest portion of the fiber. It also contains the coloring matter. It is fibrous and striped lengthways. The central portion of the fiber consists of the medullary substance, or marrow, and occupies a narrow, irregular

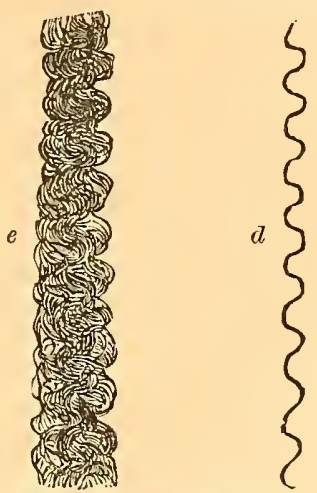

Fig. 49.-FIBERS OF wOOL. cavity. Fiair or wool is not hollow or tubular, as is frequently supposed, but solid, and consists of these three portions. The fiber grows from the root, and increases by addition of cells contiunously formed in the follicle. It is thus seen that the growth and perfection of the wool depends in the most intimate mamner upon the mutrition and perfect health of the animal. $\Lambda$ n interesting and valuable addition to the natural history of wool and hair has recently been made through some investigation ordered by the Secretary of the Treasury of the United States, for the purpose of identifying the presence of sheeps' wool in manufactured goods, the materials of which are ostensibly the hair of the cow and calf. The investigations were made by Professors John L. LeConte and J. J. Woodward, of Washington, D. C., with the help of a microscope magnifying nearly 100,000 times, (310 diameters). The full report of these investigations is published in the Bulletin of the National Association of Wool Manufacturers, Vol. V, No. 7, 1875, (Boston), a publication of the greatest value to intelligent woolgrowers as to all woolen manufacturers. After describing the well known structure of hair and wool, the report proceeds: "But not= withstanding this similarity of structure, most of the iudividual 
hairs of the cow and calf are so unlike the majority of those of the wool-bearing animals in their size and shape, that it might seem easy to make the distinction. They are much shorter, much thicker at their base, taper rapidly towardis the point ; the medulla occupies a larger proportional part of the whole hair, and the free edges of the scales of the cuticle, which are so disposed as to form from twenty to forty imbrications to the $1 / 100$ tli of an inch, lie quite smoothly upon the surface of the hairs, so that their contours, as seen under the microscope, closely approximate continuous lines. These characters are so well marked that the coarser hairs of the cow and calf can readily be distinguished from the woolly hairs of any of the wool-bearing animals. On the other hand, howerer, the majority of the woolly hairs of the sheep offer a combination of characters which are never found in the hairs of the cow and calf; namely, each of these hairs extends from balf an inch to several inches in length without any medulla, and without perceptible taper. They present at frequent but irregular intervals, well-marked, one-sided, more or less spirally arranged thickenings of the cortical substance, which give to the wool its curly character. The mean diameter of each hair varies from $1 / 500$ th to the $1 / 1000$ th of an iuch, or even less; and the scales of the cuticle are so arranged that their free edges project somewhat, forming well-marked imbrications, of which usually from fifteen to thirty can be counted in the $1 / 100$ th of an inch. The fine hairs of the goat and kid, from the $1 / 1000$ th to the $1 / 2000$ th of an inch or less in diameter, also run from half an inch to an inch or more, without perceptible taper, without medulla, and are clothed with a cuticle resembling that of sheep's wool, but are almost, or alto. gether, devoid of the irregular thickenings of the cortical substance which characterizes the latter. Similar hairs are found in certain deer, and some other animals, but never on the cow or calf." The report is accompanied by bighly finished heliotype illustrations of samples of different kinds of hair and wool.

The chemical composition of pure, dry wool, is as follows:

COMPOSITION OF PURE WOOL.

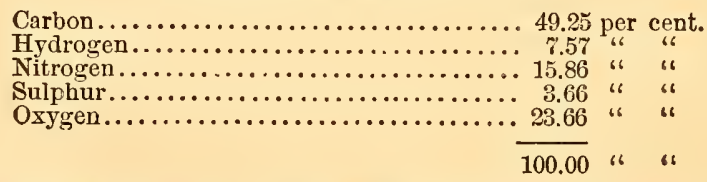

The fibers of fine wool are very closely seated upon the skin. The pure Merino has from 40,000 to 48,000 fibers on a single 
square inch; the original coarse wooled breeds have from 5,000 to 6,000 fibers on an inch. The twentieth cross of a pure Merino ram upon a coarse wool race had no more than 25,000 fiber's to the square inch; this fact shows very forcibly how long a period it may take to remove the effects of one cross, for if this statement be true, the presence of only $1 / 1,048,687$, (less than one millionth part), of impure blood is sufficient to reduce the fineness of the fleece nearly one-half. The yolk which is secreted from the glands of the skin is an alkaline substance, partaking of the character of a soap. At its seczetion it is liquid, and in some breeds of sheep it remains in this state, moistening and softening the fleece; in other breeds, particularly some families of the Merinos, the yolk thickens or dries into a sort of gum or wax of an orange yellow color, which adheres to the wool in scales, and greatly adds to its weight. The yolk or "suint" has been found by Dr. Voelcker to consist of a combination of fatty acids with potash, forming a putash soap which is soluble in water. When dried, the yolk contains $59 \mathrm{per}$ cent of fatty compounds, with some uitrogen, and 41 per cent of mineral matter, of which from 60 to 84 per cent is potash. In some places this potash is profitably recovered from the refuse liquid of wool washings. In November, 1865, Maumené and Rogelet communicated to the Chemical Society of Paris, the details of their experiments on the nature of suint, which led them to take out a patent for the manufacture of potash salts from this source. They showed that suint is made up of neutral fatty stlts containing much potash, but not more than traces of soda, and rarely even that; that the soluble portion yields on evaporation and calcination a mixture consisting mainly of carbonate of potassium, with chloride, sulphate, phosphate, and alumino-silicate of potassium in smaller quantities, also a little lime, magnesia, and oxide of iron and manganese, the arerage composition being

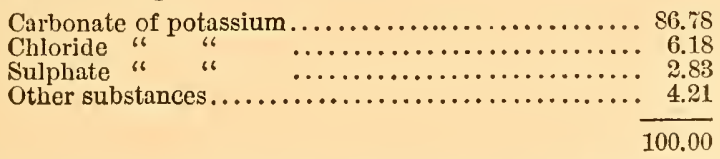

The yolk soluble in water forms from 20 to 22 per cent of the weight of the fleece, and besides this, the fleece contains from 7 to 10 per cent of oil, which is not removed in ordinary brook washing unless it be in part dissolved by the action of the superabundant potash of the soapy yolk. When the oil and yolk are removed by washing, the wool becomes harsh and dry to 
the touch. The presence of a considerable amount of yolk in the fleece is justly supposed to indicate a superior quality in the wool, and while excessive yolk is undesirable, it is a disputed point just when that excess begins. A fleece of Merino wool that loses onehalf in washing, can scarcely be said to have an excess of yolk. Many breeders do not hesitate to go beyond this, and insist that no amount of yolk can be called excessive. In this view they are supported by the high authority of Mr. Youat, who has said: "farmers never bestow a thought on yolk, and neither understand nor care about it; this question withont doubt will some day be regarded as one of the very cardinal and essential points of the sheep." Mr. Randall, our highest authority on fine wool, in his work previously referred to, does not favor the production of yolk to an excessive extent. He very justly remarks that when manufacturers cease to pay tha same price for excessively yolky wools as for those which are only moderately yolky, the breeding of sheep that produce four pounds of yolk for one pound of wool, must go out of fashion. Perhaps this matter may safely be left in the hands of the manufacturers, who are not apt to pay for what they do not want; and while they continue to buy excessively yolky wool, it will be most profitable for the farmer to produce it.

\section{CLASSIFICATION OF WOOLS.}

Wool is generally classed as short and long. It is also graded as superfine, fine, medium, and coarse. The terms carding and combing wools are no longer sufficiently distinctive, as many kinds of wool are now combed that were formerly carded, and the continued improvement of combing machinery gradually adds to the list of combing wools. Merino wools of less than three inches in length are now combed, as are the short wools of the Southdown grades. It is very important for wool-growers to know exactly the wishes and needs of the wool manufacturers, and to seek this knowledge should be their constant aim. At present, and for some time past, the coarse and medium wools have, in many parts of the country, borne the same price as the finest Merino wools; in some markets fleeces of one-quarter and half-blood Merinos have sold for more than those from full-blood animals. The quotations of wool in the New York Mercantile Journal of July 29th, 18\%5, were as follows :

NEW YORK, MICHIGAN, AND INDIANA WOOLS.

Super Saxony fleece...................50c.@52 c.

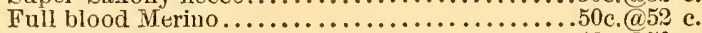

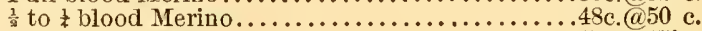

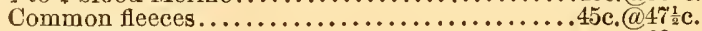

Combing wool......................... 60 c. 
OHIO AND PENNSTLVANA WOOLS.

Choice Saxony fleece XX................50e.@53 c. Full blood Merino X.....................45c.@50 c.

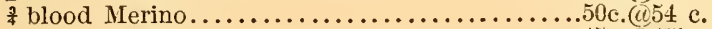

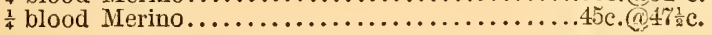

ILLINOIS, WISCONSIN, AND IOWA WOOLS.

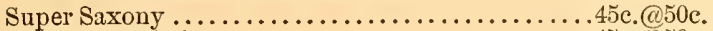

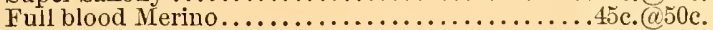

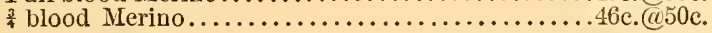

The demand of manufacturers is clearly for medium mools, the yroduce of half-bloods or grade MIerinos, or of crosses of Merinos with Southdowns. The chief difficulty in wool-groming is the tendency on the part of farmers to run in a crowd upon the same variety and quality; at one period it will be fine wool, at another combing wool, and often they are led to breed without knowledge or judgment. A great variety of wools is needed to meet the demands of manufacturers, and when a farmer has become possessed of a flock of the right sort, his best course is to keep to it, and not change because a temporary decline in his class of wool discourages him for a season. In addition to these grade Merino wools, there is a constant and increasing demand for combing wools for worsted and coarse fabrics.

Combing wools are those fitted for a prozess known as combing, which consists in ärawing out the fibers so that they are straight and parallel, the shorter portions of the wool called "noils" being removed by the operation. The fibers are then spun into worsted yarns; the ends of the fibers being covered in the spinning, these yarns are smooth and lustrous. In carding, the fibcrs are placed in every possible position with regard to each other; the ends projecting from the yarn, form a nap in the woven fabric which covers and hides the threads. Carding wool must therefore be short and full of curls; combing wool, on the contrary, needs to be long and free from curls and of a bright and lustrous surface. Long Merino wools, although they are combed for making fine cloths without nap, and for delaines, cashmeres, coburgs, and other dress goods, are not designated combing wools, but as delaine wools. Common flannels require in their manufacture the coarsest common native wools up to medium Merino wools. For fine flannels, fine to the finest wools are used; for blankets, the most ordinary native wools, " noils," medium Merino wools and Southdown and grade Southdown wools are used. For shawls, all grades of Merino wools, up to picklock, are nsed; some fleecy varieties are made of worsted combing wools ; felted cloth slirts and other goods are made of the lowest grades of wool, but the 
finer kinds, as piano and table covers, are made of medium Merino wools. Kinitted goods, such as underslirts, vests, drawers, hose, etc., require a great variety of wools from the lowest qualities up to the high grades of Merino; certain fancy varieties requiring the finer kinds of combing wools. Fancy cassimeres, meltons, beaver cloths, and overcoatings, require chiefly medium grades of Merino wool, a small quantity only of the finer grades being required for the best qualities. For mixing with shoddy, which is an extensive manufacture, the finest and longest Merino wools are found the most profitable, as such wool carries the grcatest quan- 1 tity of the short fiber of the substitute. Ladies' cloths, cloakings, and thim dress goods require fine long Merino wool; the finest and longest Merino wool is used for men's fine worsted coatings. Serges, moreens, alpacas, lastings, mohair lusters, furuiture damask, reps, bunting for flags, webbings of all kinds, sashes, picture cords, tassels, and soft goods, such as nubias and shawls, braids and bindings, are all made of the long combing wool of the Lincolns, Leicesters, and Cotswolds, or their grades. For various carpets, coarse Texan or Mexican and California wools are used, and similar grades of foreign wool known as Chili and Cordora carpet wools. This enumeration indicates as closely as need be, what kinds of wool the American farmer may grow with safety and without risk of wanting a market. Considering that the imports of wool of many of the grades mentioned, and of

the recapitulated woolen goods, amount every year to fifty millions of dollars or over, there would certainly seem to be no danger that the farmer will lack a profitable market for any kind of wool he may find it convenient to grow.

\section{PURE AND GRADE MERINO WOOL.}

It will be noticed how large a proportion of the foregoing manufactures derive their material from the Merino, either directly in its pure state, or indirectly as grades or cross breeds. Some information as to the character of the Merino wool, and the tests by which superior breeding animals may be known and selected for the improvement of native sheep, will therefore not be out of place. The character of a Merino fleece may be judged by the following tests, viz:

Strength of Fiber. - This is indicated by the amount of grease in the wool, abundance of oil or yolk indicating a healthy condition of the animal. The first sign of clisease is a change in the character of the secretions, and the skin being the chief secreting organ of the body, it is there that the change may be somest noticed. 
The moment the health of the sineep fails, the growth of the wool is arrested, along with the secretion of the oil or yolk, and the continuity of the strength of the fiber is destroyed to the great reduction of its value.

Fineness.-In a perfect fleece, the wool should be equally fine over the whole body; coarser wool may be looked for, if anywhere, on the top of the shoulders and the rump, and a weaker quality on the breast and belly. The finest wool is but $1 / 1200$ of an inch in thickness, ordinary wools $1 / 750$ to $1 / 850$ of an inch in dianieter.

Curl.-The curl of the wool is very important. This is the waved or erimped cliaracter of the fiber which in the perfect wool consists of minute bends or crimps. There should be a perfect regularily in these waves, which ought not to be so abrupt as to appear as folds. In very fine wool there should be at least 30 of these waves to the incl in length. (See $d, e$, fig. 49.)

Thickness.-This quality refers to the closeness of the fibers upon the skin. A pure Merino should have from 40,000 to 48,000 fibers upon every square inch of its skin. The weight of a fleece must necessarily depend on this characteristic.

Closure of the Flece.-The closure of the fleece on its outer surface is of great importance, for the reason that a well closed

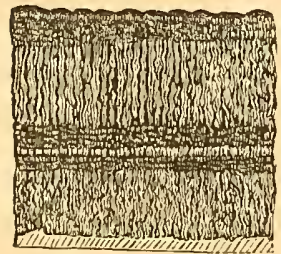

Fig. 50. fleece is impervious to dust and dirt which would otherwisefind its way into the wool and in jure its quality. The closure is effreted by the abundance of yolk which gathers at the ends of the wool, and mats the fibers together. The viscid gum gathers dust, that

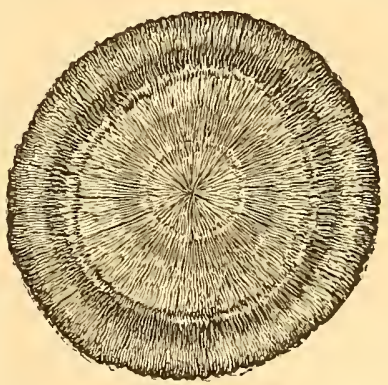

Fig. 51. coats the fleece with a black surface, which feels to the hand as a firm crust. When the crust is pressed the elasticity of the fleece is at once perceived. Upon parting the fleece to inspect the wool, the experience or ignorance of the operator is at once perceptible. He should grasp the fleece at the points of the fibers with the fingers and thumbs of both hands, and part the surface 
gently, exposing the wool to the skin. The wool, on opening the fleece, should appear beautifully white and glossy, or rich yellow or orange colored, according to the style of the sheep. The fleece is then closed carefully without allowing any dust to fall down into the opening. The appearance of the open fleece should be banded with varying colors of light and darker yellow or orange,

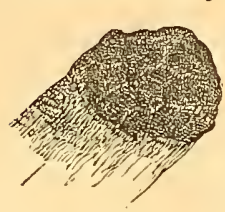

Fig. 52. as in fig. 50, or when opened, as a cup in fig. 51. A well closed flecee will exhibit a surface as shown at fig. 52, and a badly closed one will appear as at fig. 53. The well closed fleece is divided into small sections, which are tabular or flat and smooth

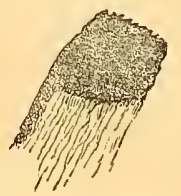

Fig. 53.

upon the surface; when the fleece is uneven in length, it cannot close well, and a few fibers only are matted togethen; the surface is then dotted and not smooth; this forms the defect known as "toppiness." The defects in wool may be cnumerated as follows:

"Stripy" or Watery Wool, generally shows itself in inferior animals on or near the shoulder, where the best wool ought to be. The wool subject to this defect is devoid of those beautiful natural curves or waves which are characteristic of really good wool. When compressed in the hand, it has no elasticity, and handles in a dead and lifeless manner, more like flax than wool. Such wool is only fit for making inferior goods. This defect is a sure proof of impure blood, and no sheep exhibiting it should be bred from.

Toppiness is not of much importance as affecting the quality of the wool, but it indicates a defect in the breeding of the sheep. It has already been described. When this defect, however, extends to a matting together of the wool at the ends of the points, a quantity of noils are made in working the wool, and there is a waste. When toppiness is found in the fleece of old sheep, it becomes a more serious objection, as it is quite possible that a lamb's fleece may be toppy by reason of uneven growth in its early life, and after having once been shorn, the defect may not reappear.

Broad-topped Wool is seriously defective, and very decidedly reduced in value; no animal having this defect should be kept in a flock having any pretentions to character for excellence. It consists in an interlacing of the ends of the fibers which are split from the top downwards. The fleece appears in good condition superficially, with a good even top, but the surface is divided into 
broad masses or "tops," and when one endearors to part these to examine the wool, the mass is found to be almost felted together, and must he torn apart. This matted wool is dead, and breaks off in the process of manufacture, causing very great loss of material.

Feity Wool is that which has a tendency to felt togethex on the sheep's back. The defect is caused by an absence of yolk, and in highly yolked sheep, by a continued wet season, which washes the yolk from the fleece. It is a direct result of low condition from poor feed, or of chronic ill health. Some sheep are constitutionally subject to "felty wool," and should be weeded onit of the flock.

Cloudy Wool is that which adheres together from the bottom of the fleece upwards, but not in so great a degree as in felty wool. A flossy appearance is discovered at the bottom of the staple, which is removed by the comb. In clothing wools this is not so objectionable as in combing wools; in the latter the floss is thrown out and becomes waste. This is also a constitutional defect, and sheep so affected should be weeded out of au otherwise good flock.

Kemp is very easily detected, and although it may be found in but a few spots at first sight, it indicates that it exists all through the fleece. It consists of coarse, white hairs, projecting from the surface of the flece, on the face, the forearm, the insicle of the flank, and in rams on the scrotum also. Whenever it is apparent in these places, it will invariably be found through the greater part of the fleece, chiefly on the whole of the belly, half-way up the sides, on the rump, thighs, and shoulder. In these places, short white hairs will be found in the staple, at the roots of the wool; and as these hairs will not take any dye, they injure the flece for the manufacture of dress goods or fine cloths. Kemp lessens the value of the wool nearly or quite one-balf, and should make a breeding animal worth no more than its weight as mutton. On some heavily wrinkled Merino sheep, these kempy hairs may be seen on the edges of the wrinkles, and ou the back of the head, but nowhere else. But it is even then a fatal objection to such sheep as breeders, for this is kemp, and may appear in all the produce of such sheep, and there can be no certainty but some of the produce may be badly affected.

Break in wool renders the fleece absolutely worthless for any combing purpose, and however fine the staple, or otherwise good in quality, it can only then be manufactured into a class of goods for which inferior wool is used. It is exactly what its name implies. When a breachy staple is taken and stretched, it parts with 
great ease at the middle or some portion of its leagth. There is a weak spot, and if the fiber is examined with a microscope, it will be found very mach attenuated at that spot, and of a dull, dead appearance. From what has been already said about the structure and growth of wool, it will be easily understood that when by bad management, neglect, starvation, orerfeeding, irregularity in feeding, want of water, or any other evil which affects the condition or health of the sheep, the growth of the wool is temporarily stopped, етеn for a day, this suspension of growth must inevitably be marked by a weakness in the fiber, which can never be remedied. As the wool grows, this weak spot is carried forward, and if the evil is soon removed and the sheep recovers quickly, it is still there and there it remains. No defect is so frequent as this; to aroid it, the flock must be kept with perfect regularity, and must receive no check for however short a time it may be. This involves the most skillful and carcful management, which is unfortunately too rare. Regular poor feed may make an inferior staple, but one worth more than a breachy staple, which may result from one single neglect in the course of a season. Want of water causes more break in wool then any other evil to which sheep are subjected by careless owners or ignorant shepherds.

Uniformity in the fleece covers many minor defects, and to determine the evenness or uniformity of the fleece, the shoulder is first examined. Here the finest and best wool should be found. Taking this as the standard, the wool from the ribs, thigh, rump, and breech, is compared with it; the nearer the latter approaches this in quality, the better. If it is all equal in fineness, the fleece will be "even" in regard to fineness. If the wool on all the parts mentioned is reasonably regular in length, and near to the standard in this respect, the fleece is "even" as regards length of staple. The density is then tested. The hand is closed upon a portion of the rump and on the loin, and if the fleece is found to be as dense and elastic or springy on those parts as it is at the shoulder, the fleece is "even" as regards density. A perfect fleece will be found of nearly equal fineness from the shoulder to the thigh; of nearly equal length at the shonlder, rib, thigh, and back; of equal density on the shoulder and across the loins, and free from any of the defects before mentioned.

Most of the points here indicated, both as regards defects and good qualities, refer to other wools as well as to that of the Merino; those points which depend on the peculiar character of Mrerino wool and its excessive yolkiness will be readily understood as necessarily applying to that alone, and those which depend on 
the organic structure of wool and the condition of the sheep, to all sorts of wool alike.

Wool in its natural condition contains many impurities, dirt of all kinds, sand, dung, and the usual secretions of the skin, and before it can become fitted for the uses of the manufacturer, it must be freed from these impurities. The wool-buyer, who generally comes between the farmer and the manufacturer, does not demand that the wool should be thoroughly cleanse i, but only freed from its grosser impurities. No washing that the farmer could give his fleeces would be sufficient for the purpose of the manufacturer, who scours the wool in hot soapsuds before he can cleanse it sufficiently. But nevertheless, the buyer prefers the fleeces to be partly cleansed, and this partial cleansing is what is generally known as "brook washing."

WASHING THE WooL on the sheep's bac's is the usual practice. There are several methods of doing this. Where a brook or river can be used for the purpose, all that is needed is to choose a place where the water is waist deep, and the bottom is gravelly. A muddy or sanciy bottom is to be avoided, as it will be impossible to prevent some of the bottom from being stirred up and mingling with the fleece. Cases have been known in which such a bottom has been chosen for this purpose with the special object of adding to the weight of the fleece by the admixture of sand. It is hardly necessary to say that this mode of cheating can never be profitable; if one lot of fleeces thus aduiterated be paimed off upon the bnyer, his remedy may be a severe one, and at the best the cheat will not be forgotten. Generally, however, buyers are not to be imposed upon, but look sharply enough after their own interests to discover all attempts at dishonesty, and to make the perpetrator pay soundly for his error. In washing and making up wool, the most thorough honesty will be found to pay well in the long run, and a reputation for fair dealing will often be found to have a direct money value, especially when the market happens to be against the seller.

Soft water is to be preferred for washing wool. Hard water leaves the wool harsh and dry to the hand, and detracts from its appearance in the market. Soft water leaves the wool soft and mellow, and it more rapidly recovers it: tone and elasticity when washed in water free from lime. The ground having been chosen, the sheep should be closely penned upon the bank of the stream; the side of the pen next the stream should be narrow, with a passage-way leading to the water. A plank platform, projecting over the bank, from which the sheep can be plunged directly into the 
water, is very convenient. The washers enter the stream and receive the sheep from the hands of the drivers, plunging them bodily beneath the surface, two or three times. In catching the sheep and handling them in the water, the assistants should avoid pulling the wool. If a sheep is hauled around by the wool, the skin is bruised, and the wool is injured and weakened at the bruised spots. To catch a sheep it should be seized with the right hand by the hind leg above the hock, firmly with the whole hand, yet without unnecessary violence. The pressure upon the sinew above the hock joint paralyses the leg for a moment, and the sheep will rarely struggle. The left hand is then slipped around the breast, and the shepherd has perfect control of the heaviest sheep, without pulling in the least upon the wool. A crook, fig. 54, is a convenient implement with which to catch wild or unruly sheep. It is quietly passed in front of the leg, which is seized and held while the shepherd secures the sheep in the way described. After the sheep is thoroughly soaked, the animal's head is held above water, while the fleece is shaken and squeezed, so as to free it from dirt. As many as possible of the tags and matted locks around the breech should be opened and cleansed. When this has been done, the sheep is passed to another washer, who finishes the

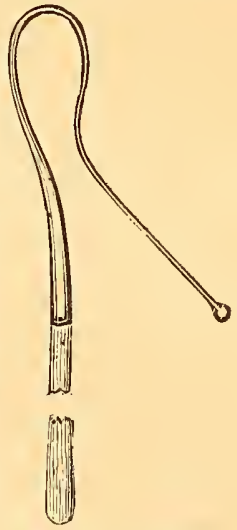

Fig. 54. - CROOK. washing, and directs the sheep to the bank, squeezing the water from its fleece as it emerges from the stream. A clean, grassy bank should be chosen. Some long wool sheep, with heavy fleeces, which hold a great quantity of water, may need some help to get upon their feet as they reach the bank. Ewes that have not lambed shonld be handled carefully in the washing, although it is rarely, in well managed flocks, that ewes are allowed to be in lamb at this time.

This method of washing is often very disagreeable and injurious to those who practice it. Where ague is prevalent, or where rheumatism is feared, it is better to choose some other plan. A rough dam may be made in a small stream, and a spout placed in the dam, beneath which the sheep may be washed. A sparred roadway may be laid across the stream, through which the water will escape. By wearing rubber thigh boots, and a rubber apron, the washers may be kept dry, and avoid the danger of long con- 
tinued exposure to chilly water. In fig. 55 is an illustration of this method of washing. For a large flock, the spout may be made to extend across the whole dam, so that several sheep may be washed at the same time, each sheep being passed from hand

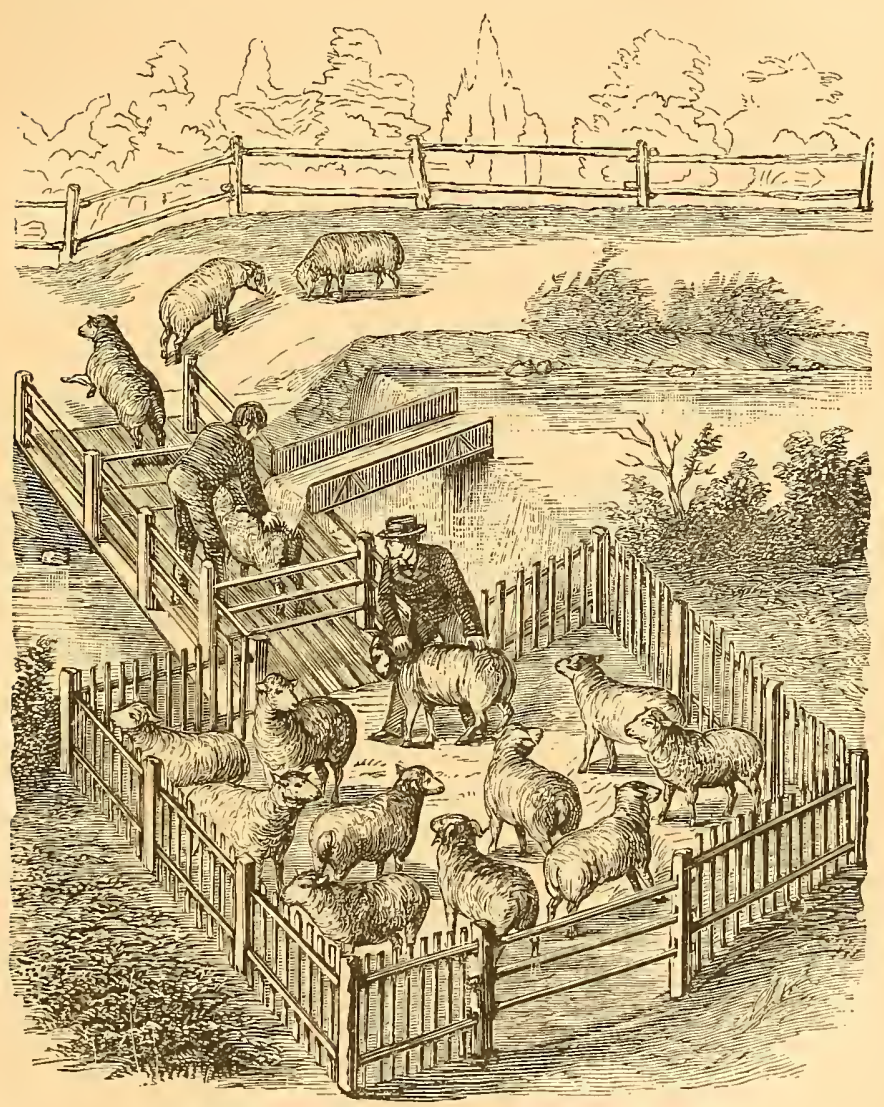

Fïg. 50̃.-ARRANGEMent For WASHING SHEEP.

to hand, until finished by the last one. With sufficient help, one sheep per minute may easily be washed by this method. After the sheep are washed, they should be kept in a clean field, and in a clean yard at night, for the week at least before shearingr, to per- 
mit the fleece to dry and to regain sufficientyolk to recover a soft and mellow handling.

Thgging axd Triming the Feet.-If the sheep are very dirty, and have not been kept trimmed about the tail, it is advisable that they should be tagged before they are washed. The ccarse soiled tag-locks about the hinder parts, and the belly of the rams and wethers, may be clipped off in the spring and thrown into a basket or barrel to be soaked and washed by themselves. The same time will be the most convenient to trim the feet, which is a more necessary thing to do than is generally supposed. The toes of old sheep, upon soft pastures, will grow long and turn up, and cause lameness, or the soles and edges of the hoof will become ragged and worn, the horn turning under at the edges. In this condition the feet gather filth or small stones and gravel, which work into the hoof and cause disease. Foot-rot is in many cases thus engendered. The feet should then be trimmed at washing time, if not oftener. A sharp knife may be used to pare the ragged edges of the hoof and the sole, and toe nippers to shorten the toes. A pair of common wire-workers' cutting nippers may be used for the latter purpose. The edge of the nippers should be filed sharp, with the berel on the inside, and brought to a smooth edge with a piece of oil-stone.

SHEARING.-Sheep should not be shorn until the weather has become warm and settled. May is the usual time for shearing in the northern states. The tools of the shearer are a pair of shears, and if desired, a shearing-bench upon which sheep may be placed to aroid the necessity of his stooping so much as is required when the sheep are laid upon the floor. The common shears with a thumb piece upon one side, and an easy spring no stronger than will be sufficient to make the shears open freely when released from pressure, is the best tool for the shearer. Sereral new and patented shears have been introduced, which the inventors claim may be used even by inexperienced persons without danger of cutting the sheep's skin. A trial of these shears does not support this claim, and the common shears are not yet superseded by any of these so-called improvements. The shears should be brought to a fine, sharp edge upon a fine oil-stone. The berel of the cutting edge should be about 35 degrees, or scmewhat more than that of a common pair of scissors, and less than that of a plane iron.

The floor of the shearing room should be kept perfectly free from straw, chaff, or litter, and if a boy is kept constantly at work with a broom in his hand removing dirt, tags, and rubbish, his 
time will be well employed. The shearer has better control over the sheep when cn the floor than on the bench, and the handling is not the same under both circumstances. In shearing on a bench the shearer catches the sheep by the left hind leg, backs it towards the bench, and rolls it over upon it. He then sets the sheep on its rump, and standing with his left foot upon the bench, lays the sheep's neck across his left knee, with its right side against his body. The two forelegs are then taken under the left arm, and the fleece is opened up and down along the center of the belly by small short clips with the shears. The left side of the belly and brisket are then sheared. The tags are clipped from the inside of the hind legs and about the brcech, and thrown upon the floor. They should be swept up at once and gathered into a basket, and by no meaus allowed to mingle with the fleece wool. The breech is then shorn as far as can be reached. The wool from the point of the shoulder is then clipped as far as the but of the ear. The wool is shorm around the carcass and neck to the foretop, procceding down the side, taking the foreleg and going as far over the back as possible, which will be two or three inches past the back bone. When the joint of the thigh, (the stifle), is reached, the shears are inserted at the inside of the bock and the wool shorn around the leg back to the thigh joint. The wool over the rump is then shorn past the tail. The sheep is now completely shorn on one side, and two or three inches over on the other side, along the back from neck to tail. It is then taken by the left hind leg, and swung around with the back to the shearer, leaving some wool beneath the left hip, which will ease the position of the animal, and keep it more quiet. The wool is then shorn from the head and neck down the right side, taking the legs and brisket on the way. The fleece is now separated. The job is completed by clipping the tags and loose locks from the legs.

To shear on the floor, the sheep is set upon its rump, with the head thrown back beneath the left arm of the shearer, and its back toward him. The wool is then opened at the neck, and clipped downwards in regular lines on the right side from belly to back, and over the spine as far as possible on the other side in much the same manner as has already been described. The sheep is then laid on its shorn side, and the shearer, kneeling on the left knee, and straddling the sheep, with the left foot laid over the sheep's neck, remores the fleece from the left side, and finishes by removing tag locks from the legs and scrotum. In bad shearing, the greatest injury to the fleece takes place on the back, and is caused by the operator not raising his hand, so as to keep the 
points of the shears close down to the skin. This is known as "cutting through ;" it takes place when the sheep is being shorn on one side; and, in shearing over the back, the points of the shears cut nearly or quite through the fleece, from the inside to the out; then, when the animal is being shorn on the other, or "turning-out" side, the shears are again pointed upwards, and the cuts on the first and last side overlap each other, causing the fleece to part in two halves all along the back. No good shearer makes second cuts; the fact that wool has been left by the first cut proves that the shears have not been held properly; and the wool remored by a second cut being perfectly useless, entails a severe loss on the manufacturer, and greatly lowers the repute of the brand in the markets. Cutting through, and a habit of continually making second cuts, are the most objectionable characteristics of the unskillful shearer. A sheep may be shorn so close as to satisfy the most exacting employer, and yet it may be shorn very barlly; and the only conclusive test of good shearing, or the reverse, is io be found not on the outside of the animal, but on the inside of the fleece.

When the sheep's skin has been unavoidably cut in shearing, each cut should be smeared with tar, which will prevent flesh flies from depositing their eggs in the wound, and probably avoid after trouble.

It is said to be a fact that newly shorn rams are incapable of breeding until their fleeces have recovered considerable growth. Some evidence in support of this assertion is given in a pamphlet published in Australia, in which the author, Mr. J. R. Graham, the superintendent of an extensive sheep "station" on the Murray River, states that in a flock of 4,000 ewes and 100 rams newly shorn, he had but 165 lambs, and on another occasion a flock of 100 ewes, which were drafted with 4 rams, newly shorn, produced only 9 lambs. On another station when the ewes were coupled with newly shorn rams, there were not 5 per cent of lambs. This, if a fact, is more curious than important in this country, where, except in California, sheep are not shorn near the breeding season. If wool were not shorn, it would be shed annually, or its grow th would be rendered uneven, and its fiber weakened at the season when the coat of an animal covered with hair is usually shed. A fleece that is suffered to grow for two seasons, shows very distinctly the division between the growth of each year. This, however, occurs only in those countries where the winter and summer climates differ considerably, and where the transition from one to the other is sudden. Where the climate is nearly eren throughout 
the year, as in California or Australia, the fleece will continue to grow on, without change. At least th's is the case with the Merino, whose fleece has been known to grow to a length of 22 inches in a continuous period of six years in Australia. In California a fleece was shorn in 1874 , which weighed 52 pounds; this was doubtless the result of two or three years' growth. The retention of the fleece for an indefinite period is a peculiarity of the Merino, which is not known to appertain to any other variety of sheep.

Packing the Fleece. - The manner in which the fleeces are made up has no little influence upon the price at which the wool will sell. Wool buyers prefer to have the fleece loose, light to

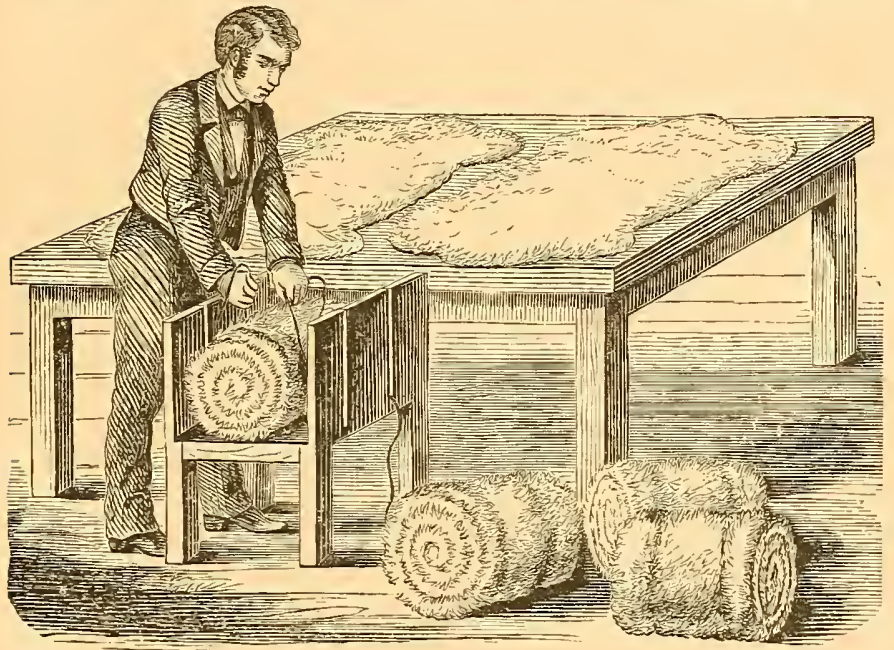

Fig. 56. - TABLE FOR TYING WOOL.

handle, and elastic; and tied up so that it can be easily opened if need be. The method of packing in Ohio and Western Pennsylvania, is to lay the fleece upon a table, turn in the head and tail, then the flanks, and roll it up in a neat roll, tying it with a string at each end. This method is shown in figure 56. Sometimes the fleece is tied with one more string across the ends, but this is rarely necessary, excepting when the wool is very short. A fleece thus tied is light, easily handled, shows the quality of the wool, and can be felt all through. The efiect of the manner of putting up the fleece is seen in the following quotations taken from the wool market report of Coates Bros., Philadelphia, of Juiy 1st, $18 \% 5$. 
Ohio, Pennsylvania, and W. Va. fleece..........50c.@52c.

New York, Michigan, and Wisconsin fleece, XX..46e.@Sc.

Illinois, Iowa, and Missouri fleece, XX.........45c.@4tic.

The difference of 4 to 5 cents per pound is the value of the extra care in making up the fleeces. The difierence is even greater than this, for New York, Michigan, andW isconsin wools of better qual-

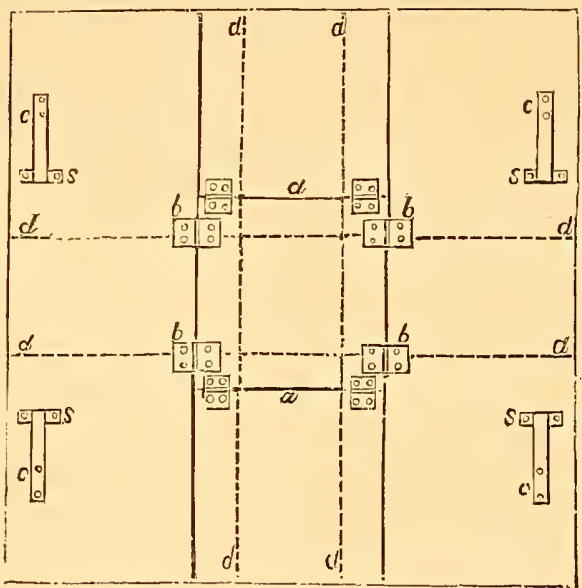

Fig. 57.-PLAN OF WOOL TABLE. ity than some Ohio wools, are bought at the regular rates quoted, simply because the Ohio fleeces come to market in better shape. This is 10 unreasonable cistinction, as will be seen when the manner of sorting wool is explained further on.

There are various kinds of wool tables for packing the fleece other than that shown in figure 56. One in common

use in New York is thus described in the American Agriculturist of May, 18\%2, with the accompanying engravings, to which the letters refer. It is made of three boards one inch thick, and twelve inches wide. The center one, fig. $5 \%$, is divided at equal distances at $a, a$, and connected with hinges opening upwards. The two outside boards are joined to the center square by hinges at $b, b, b, b$,

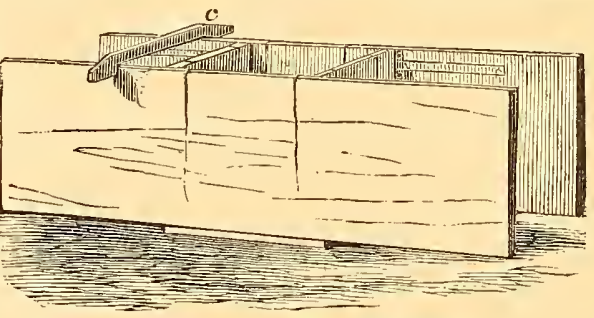

Fig. 58.-WOOL TABLE CLOSED. also opening upwards. At $c, c, c, c$, screw on the springs, cutting away the wood underneath so that they may lie flush with the boards when pressed down. At $d, d, d, d$, make a cut one inch deep 
with a thin saw, to hold the ends of the strings. A hook is made, (e, fig. 58), of hard wood, one inch thick and fourteen inches between the jaws, and the box is done.

To use it, first fix the strings from the cuts $d, d, d, d$, in the direction of the dotled lines on fig. 58. Lay the fleece with the

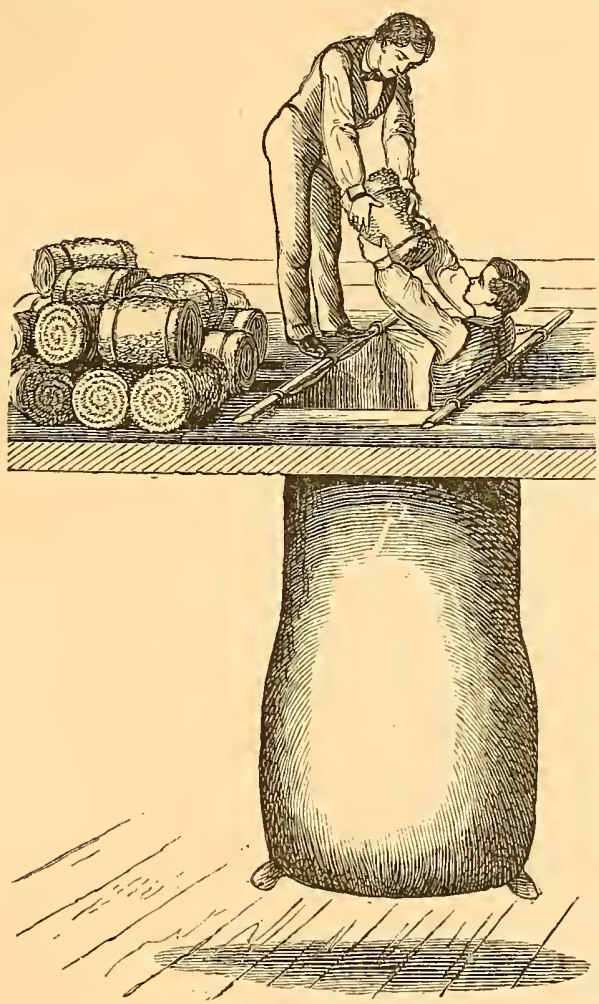

Fig. 59.-PACK1NG WOOL. clipped side downwards on the boards, bring up the sides, which secure by placing across them the hook, as in fig. 58; then close the ends, which the springs will keep in their places; tie the ends of each string tightly over the wool; then remove the hook, and the box will fall back, leaving the fleece tightly packed and tied.

Nothing should be tied up in the fleece, nor should coarse twine nor too much twine be used. All tags and waste wool should be scrupulously kept out of the fleece, as it should not only look good, but should be good. This observing of little things is one of the ways in which wool growing is made a profitable business. Tag locks and dirty wool should be washed in a tub with soft soap and cold water and sold by itself. The soft soap tends to give tubwashed wool a mellow handling free from harshness.

When the grower ships his wool to a distant market, he necessarily packs the fleeces in bales. The bale should be solidly packed 
both for economy in freight, which in light bulky articles, is charged according to bulk and not by weight, and for the better condition of the fleeces on their arrival at their destination. A convenient method of baling the fleeces, is to hang the sack from a trap-door in the wool loft, as shown in figure 59. The fleeces are handed or thrown to the packer, who places them in the sack, pressing them down close with his bare feet, and, as he reaches the top, with his knees; a handful of tags is put in each corner of the sack and tied tightly to make a handle by which the package can be hauled about in its transportation to market. When filled, the bale should be plainly marked with the exact weight, tare, and net weight, upon one of its sides.

Sorting. - When the wool reaclies the dealer, it undergoes a process of sorting. The same fleece contains wool of various degrees of fineness, and it must be prepared for the manufacturer, who purchases only exactly what he needs for his particular use. The fleece is unrolled, and the sorter selects the fine locks from the coarse ones; the neck, shoulder, and side wool from the thigh, and haunch wool; and this from the belly and breech wool. Each fleece is sorted into from six to ten dificrent qualities, which are selected by the sorter wilh surprising quickness and certainty. A well rolled fleece is much more quickly handled than one made up disorderly, and the saving of the time of a highly paid workman, is of itself sufficient to enhance the value of a well packed fleece over that of an opposite character several cents a pound.

The final disposition of the wool, after it has reached the manufacturer, is not within the limits of this book, although the various processes of scouring, dyeing, oiling, plucking, carding, combing, breaking, drawing, roving, spinning, reeling, and weaving, are all of the greatest interest to the wool grower, as relating very intimately to his share of the general industry, and showing how far the best management of his flock goes to ease the labors, and facilitate the operations, of the numerous artisaus concerned in all these various branches of the manufacture, and consequently adding to the value of his raw product. The perfection of the various processes cannot be better illustrated than by the facts that in only ordinary spinning, a pound of wool is made to extend three-fourths of a mile; in superfine spinning, it stretches to a distance of 22 miles; and that the very finest woolen yarn hitherto spun, will reach a distance of 95 miles for every pound. Fifteen hundred fibers of the finest wool laid side by side will cover only one inch of space, and 2,225,000 of them placed compactly together, will make a bundle only one inch square. How much evil 
then may the ignorance or carelessness of the shepherd or the wool-grower, work to the possible benefit to the world through this industry, by reducing the value of a staple upon which so much of the labor of mankind is expended.

The wool production of the whole world is estimated by $\mathrm{Mr}$. H. C. Carey, at 1,800,000,000 lbs. This estimate is rendered probable by comparison with the estimates of the production of those countries of which we have more or less accurate knowledge through official reports. An estimate of the number of sheep and pounds of wool produced in the following countries in 1866, made by the London Statistical Society, and published in their journal, here reproduced. To this is added in the last column the number of sheep mentioned as existing in those countries in the official reports of their governments published since that datc:

TABLE OF SHEEP AND WOOL PRODUCTIONS OF THE FOLLOWING COUNTRIES IN 1866.

\begin{tabular}{|c|c|c|c|c|}
\hline COUNTRIES. & $\begin{array}{l}\text { Mallions } \\
\text { Sheep and } \\
\text { Lambs. }\end{array}$ & $\begin{array}{l}\text { Millions } \\
\text { lbs. Wool } \\
\text { Produced. }\end{array}$ & Fears. & $\begin{array}{l}\text { Mllions } \\
\text { Shlieep and } \\
\text { Lambs. }\end{array}$ \\
\hline 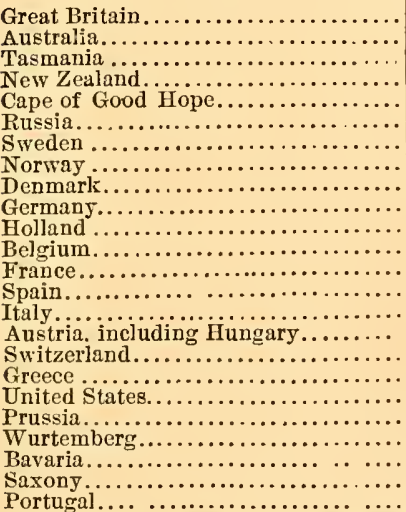 & $\begin{array}{r}34.1 \\
37.4 \\
1.7 \\
8.4 \\
10.0 \\
45.3 \\
1.6 \\
1.7 \\
1.9 \\
25.3 \\
1.0 \\
0.6 \\
30.4 \\
22.1 \\
11.0 \\
16.6 \\
0.4 \\
2.5 \\
32.8\end{array}$ & $\begin{array}{r}160.0 \\
152.2 \\
6.1 \\
28.8 \\
38.0 \\
90.8 \\
6.1 \\
6.4 \\
7.0 \\
52.1 \\
6.2 \\
3.5 \\
91.2 \\
74.4 \\
24.8 \\
31.1 \\
1.3 \\
7.6 \\
117.6\end{array}$ & $\begin{array}{l}1873 \\
1874 \\
1874 \\
1874 \\
1865 \\
1863 \\
1871 \\
1865 \\
1871 \\
1871 \\
1866 \\
1872 \\
1865 \\
1867 \\
1871 \\
1867 \\
1873 \\
1874 \\
1872 \\
1872 \\
18663 \\
186 \% \\
18 \% 2\end{array}$ & $\begin{array}{r}29.4 \\
45.0 \\
1.5 \\
11.6 \\
9.8 \\
45.1 \\
1.6 \\
1.7 \\
1.8 \\
.8 \\
.5 \\
24.0 \\
22.0 \\
11.0 \\
20.0 \\
0.4 \\
2.5 \\
* 34.0 \\
1.5 \\
.5 \\
2.0 \\
.3 \\
2.4\end{array}$ \\
\hline
\end{tabular}

* Lambs not included.

It will be noticed that this list is unfortunately very imperfect, and that those countries only are mentioned whose product enters into commerce, and which is published in government reports, and is therefore more ensily figured up by the statistician than that of such countrics as the states of Northern Africa, Asia, and South 
America. The average weight of fleece, the relative value of the wool per pound (in American dollars and cents), and the yearly income from each sheep, in wool, is giren in the following table:

TABLE OF THE PRODUCE AND PRICE OF WOOL AND YEARLY VALUE OF THE FLEECE IN THE FOLLOWING COUNTRIES IN 1866.

\begin{tabular}{|c|c|c|c|}
\hline COUNTRIES. & $\begin{array}{c}\text { Pounds } \\
\text { Wool } \\
\text { per Sheep. }\end{array}$ & $\begin{array}{l}\text { Price per } \\
\text { pound of } \\
\text { wool. }\end{array}$ & $\begin{array}{c}\text { Annual } \\
\text { Revenue } \\
\text { per sheep. }\end{array}$ \\
\hline 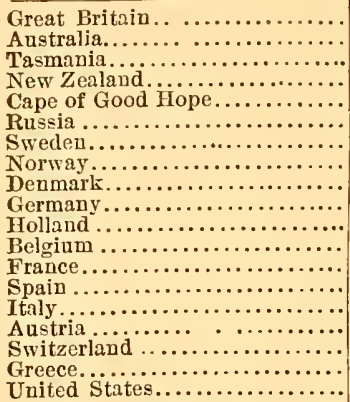 & $\begin{array}{l}4.7 \\
4.1 \\
3.5 \\
3.4 \\
3.2 \\
2.0 \\
3.7 \\
3.7 \\
3.7 \\
2.1 \\
6.0 \\
6.0 \\
3.0 \\
3.5 \\
2.2 \\
1.9 \\
3.0 \\
3.0 \\
5.4\end{array}$ & $\begin{array}{l}.25 \\
.37 \\
.38 \\
.27 \\
.33 \\
.21 \\
.19 \\
.17 \\
.23 \\
.41 \\
.19 \\
.18 \\
.18 \\
.41 \\
.21 \\
.38 \\
.18 \\
.14 \\
.40\end{array}$ & $\begin{array}{r}1.17 \\
1.51 \\
1.33 \\
.90 \\
1.05 \\
.42 \\
.68 \\
.62 \\
.85 \\
.85 \\
1.14 \\
1.08 \\
.54 \\
1.45 \\
.46 \\
.72 \\
.54 \\
.42 \\
2.16\end{array}$ \\
\hline General avera & 3.6 & .26 & .94 \\
\hline
\end{tabular}

The most striking item in the above comparison is the greatly larger annual revenue derived from each sheep in America than elsewhere. When we take into account along wilh this, the lower price of our lands, the American shepherd will be seen to have a far more profitable business than that of any other sheep owner in the world. Much of this advantage is doubtless due to the higher prices received by the wool-grower through the operation of the protective duties levied upon foreign wool. Some of it is certainly due to the greater weight of the fleece consequent upon the improvement which has been made in our sheep. With two exceptions the average weight of American fleeces is the highest in the list. But by far the greater advantage exists in the higher comparative price of wool, which is only exceeded very slightly in two instances, those of Spain and Germany, and in these countries the bulk of the wool is of the finer sorts which bear a high market value. The benefit accruing to wool-growers by the present tariff is unmistakable, and although this is not the place to discuss the question, it continuance would certainly seem to be very desirable.

The following table gives the number of sheep, (omitting lambs), enumerated in the decennial census reports of the Uniied States for the years named: 


\section{STATES AND TERRITORIES.}

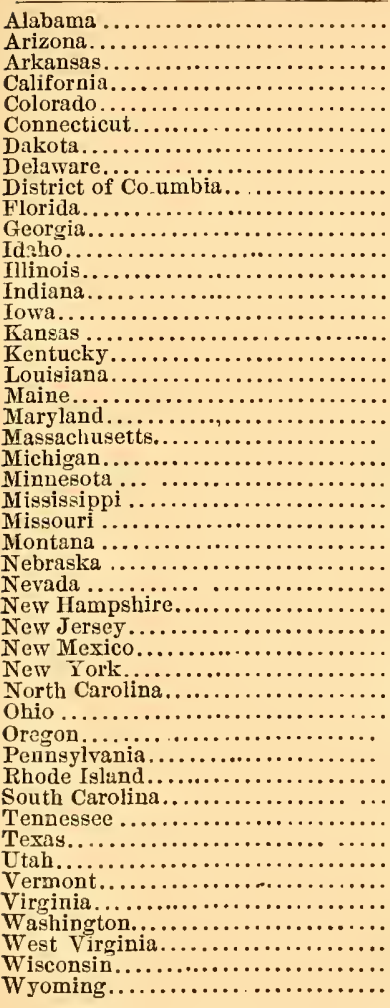

Total

\begin{tabular}{|r|}
1870. \\
Numbcr. \\
\hline 241,934 \\
803 \\
161,077 \\
$2,768,187$ \\
120,928 \\
83,894 \\
1,901 \\
22,714 \\
694 \\
26,599 \\
419,465 \\
1,021 \\
$1,568,286$ \\
$1,612,680$ \\
855,493 \\
109,088 \\
926,765 \\
118,602 \\
434,666 \\
129,697 \\
73,560 \\
$1,985,906$ \\
132,313 \\
232,732 \\
$1,352,001$ \\
2,024 \\
22,725 \\
11,018 \\
248,750 \\
120,067 \\
619,438 \\
$2,181,578$ \\
463,435 \\
$4,928,635$ \\
318,123 \\
$1,791,391$ \\
23,938 \\
124,594 \\
826,783 \\
714,351 \\
59,672 \\
580,347 \\
370,145 \\
43,063 \\
552,327 \\
$1,069,282$ \\
6,409 \\
\hline $28,477,951$ \\
\end{tabular}

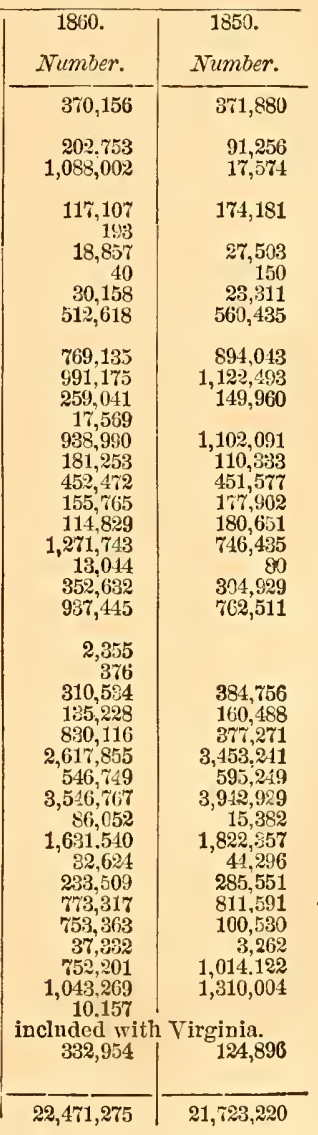

The increase since the last census, (1870), in the western states and territories, is very great. For instance, the estimated clip of wool in California, as reported by Messrs. E. Grisar \& Co., of San Francisco, for the three decennial periods named, and for 1875 , was as follows:

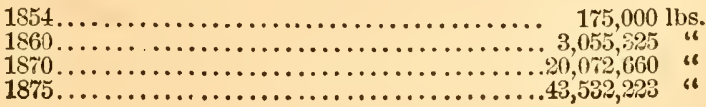


While some of this very great increase will result from the rapid improvement in the character of the sheep, yet there is nevertheless reason to suppose that the number of sheep in California now reaches at least $5,000,000$, which is nearly double the number of 1870.

In Colorado, persons engaged in the sheep industry, estimate the flocks to amount to abont one million; and in the neighboring territories of Da'zota, Wyoming, New Mexico, and Arizo$\mathrm{na}$, this industry has become so wonderfully developed during the past five years, that a reasonable estimate wonld give the whole present number of sheep pasturing upon those plains as at least $2,000,000$, where in 1870 there were little more than 120,000. The profitable character of the business of rearing sheep upon these magnificent and costless pastures, is tending to still further attract the attention of stock men and capitalists, who are establishing flocks in almost every available portion of these territories. A business in which capital used with care and skill returns a profit of 75 per cent, cannot fail to become developed with rapidity in so favorable a locality. What the limit of the productive capacity of these broad pastures may be, it would be hazardous to attempt to prognosticate.

\section{CHAPTER VII.}

\section{THE ANATOMY OF THE SHEEP; ITS DISEASES AND THEIR REMEDIES.}

GENERAL VIEW OF ITS ANATOMY.

The structure of the sheep more nearly resembles that of the ox than any other of the domestic animals. It possesses a less degree of nervous energy than the horse, ox, or pig, but it is capable of enduring greater extremes of heat and cold with less inconvenience, and possesses a more vigorous digestion than those animals. The most of its nervous energy is expended on its digcstive and assimilative functions, and the least proportion upon its sensitive and locomotive organs. None of our domestic animals so completely digests coarse fodder, or so thoroughly and profitably turns the most nutritious food into flesh and fat as the sheep. 
In this respect it is the most valuable and profitable feeder the farmer can make use of; at the same time no other animal is so feeble and defenseless, nor so soon succumbs to disease of a debilitating or exhausting character. Its circulatory system beirg weak, it is on the other hand comparatively free from inflammatory cliseases, to which the horse and ox are especially subject.

This peculiarity of the character of the sheep may be inferred from a view of its skeleton, fig. 60 , in which the small space occu-

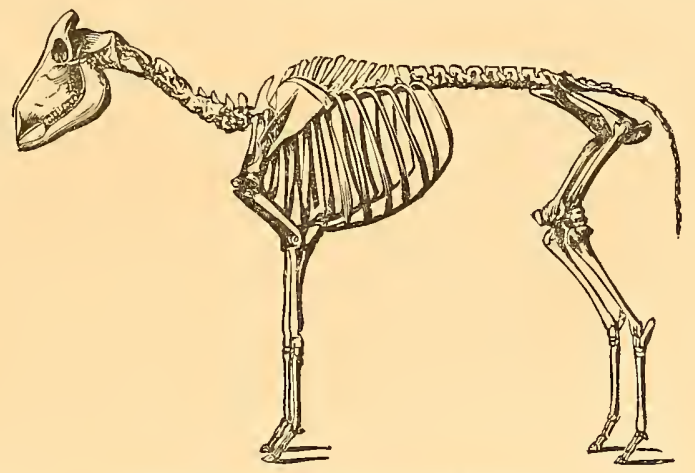

Fig. 60.-SKELETON OF THE SHEEP.

pied by the heart and lungs, is very marked in comparison with the large abdominal space which gives ample room for the digestive organs. The bones of the sheep number 226 , including 32 teeth. These bones are disposed as follows:

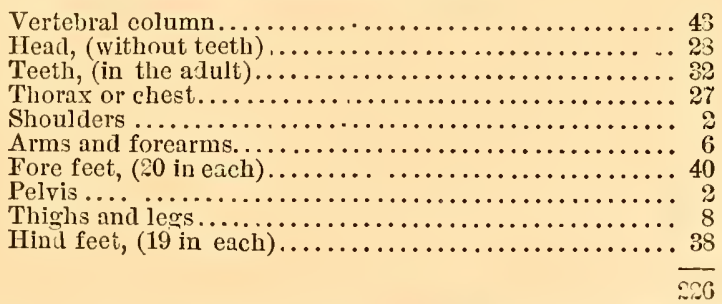

The structure of the head of the sheep is such as to secure great strength. In horned sheep, the upper portion of the skull is more strongly built than in the polled or hornless ones. This structure is necessary to protect the brain from the shocks consequent on the mode of warfare of the rams, which are pugnacious animals, 
and especially of those which are armed with heavy horns. The skull consists of two tables or plates, half an inch or more apart, the outer thick and tough, the inner hard and brittle. These plates are connected by ridges of bone, which divide the space between them into compartments called sinuses. This structure gives the skull exceeding strength and ability to resist blows and punctures by sharp substances. The bones of the head are joined together by sutures or dove-tails, which are also conducive to extreme strength. In this manner the brain is protected, and the horns are prov:ded with a solid and elastic foundation. The form of the head is shown in figure 61 , in which 1 is the occipital bone; 2 , parietal bone; 3 , core of right frontal bons; 4 , the left core covered by its horn; 5 , superciliary foramen; $5^{1}$, channel descending from it; 6 , lachrymal bores; 7 , zygoma ; 8 , nasal bones; 9 , supermaxiliary bones; 10 , premaxiliary bones; $10^{2}$, its internal process; 11 , incisive opening. The cavity which contains the brain is less than a third the size of the rest of the skull, the larger portion being devoted to the functions of eating and smelling. The space devoted to mastication is large, and the space occupied by the nostrils, which are the breathing passages, relatively small. Most of the bones of the face are hollow, and are divided into ser-

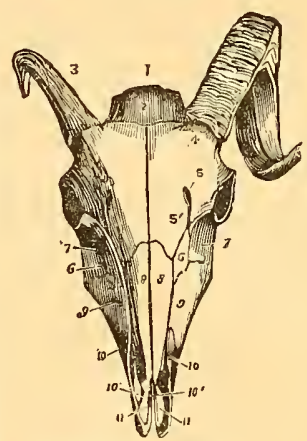

Fig. 61.-BoNes of A RAM'S HEAD. eral sinuses and cells by which the head is rendered light and strong. The sinuses and cells are lined with membranes which secrete mucus, and are therefore called mucous membranes. The inner cavity of the skull is lined with several membranes which still further add to its strength, and to the security of the brain. The teeth of the sheep consist of incisors or cutters, and molars or grinders. There are 8 of the former, all being upon the lower jaw, and 24 of the latter. Upon the upper jaw, in place of cutting teeth, the sheep has, in common with most of the ruminants, a cartilaginous plate or cushion, upon which the teeth of the lower jaw impinge when the mouth is closed. The sheep has no canine teeth or tusks. There is a long space of the jaws on each side between the incisors and molars, which is destitute of teeth. The milk teeth, or decidnous or temporary teeth of the sheep, are twenty in number; the eight incisors on the lower jaw, and three molar teeth on each side of both jaws or twelre in all. The two 
central front teeth appear either before or soon after birth, and in about three weeks after birth, the whole of the twenty temporary teeth appear. The first change in the teeth occurs at the age of three months, when the lamb cuts a permanent molar tooth. The next change also occurs at the back of the mouth, when at nine months old, another, the second permanent molar tooth appears. At one year old the lamb has but eight permanent teeth, or two at the back of each side of each jaw. The age of fourteen months is marked by the appearance of two permanent incisor teeth at the center of the front of the jaw. In judging of the age of a sheep, the condition of the molars may be studied with advantage. If a sheep is certified to be not exceeding one year old, and the fifth molar, (the second permanent one, and the last one on each jaw), is found to be sharp on the edges and but slightly worn, the age may be regarded to be properly stated, even though the central pair of front teeth have already appeared. But if these teeth are well up and the last molar is worn and smooth, and there is a space between this tooth and the angle of the jaw, the sheep is certainly over a year old. The sixth molar tooth is in its place at the age of eighteen months, and this is the only test of this age of the sicep. The second pair of front teeth, one on each side of the first pair, appear at twenty-one months of age, and at two years are fully grown and stand well up from the gum and level with the first pair. After the sixth molar is cut, the three forward and temporary molars are replaced by permanent tecth, which are fully grown at the age of twenty-seven months. At two years and a balf the third pair of front teeth have become fully grown, although in some forward sheep of the quickly maturing breeds, these teeth may appear at two years of age. Generally they indicate an age of two years and a half. At the age of three years, in the Cotswolds and other forward breeds, the fourth and last pair of front teeth appear; but in other breeds they are not present until three and a quarter or three and a half years. The sheep is then what is known as "full mouthed." The following table of the periods of dentition will be found useful in determining the age of a sheep:

At one month, 8 temporary front tecth and three temporary molars on each side of caeh jaw.

At three months, a permanent molar is added to these three.

At nine months, the seeond permancnt molar appears.

A fourteen months, two permanent incisors appear, (as $c, c$, fig. 62).

At eighteen months, the third permanent molar appears.

$\Delta \mathrm{t}$ twenty-one months, there are four permanent ineisors, ( $\sigma, \alpha, \mathrm{fig} .68)$. 
At twenty-seven months, the temporary molars are changed, and permanent ones appear.

At thirty months, there are six permanent incisors, ( $\alpha$, $a$, fig. $6 \frac{1}{1}$ ).

At thirty-six to forty-two months, there are eight permauent incisors, ( $a, a$, fig. 65).

It has been decided in an English court of law, that a lamb becomes a sheep when the first pair of permanent incisors have ap-

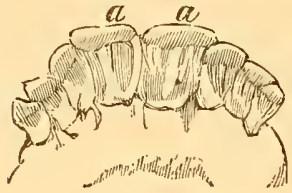

Fig. 62.

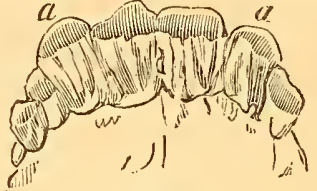

Fig. 63.

peared. When the mouth is full toothed, the sheep is considered as mature, or full grown, when the teeth begin to show signs of wear, the sheep is "agel."

The composition of the bones of the sheep and of the marrow contained in their cavities chifiers in no respect from that of the bones and marrow of other domestic animals. Bone consists of animal matter and earthy salts; usually in the following proportion, viz: phosphate of lime, 55 per cent; carbonate of lime, 4 per cent; phosphate of magnesia, 3 per cent; soda, potash, and com-

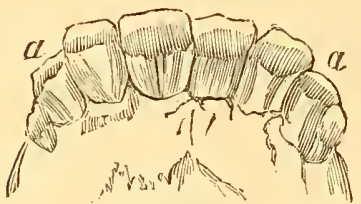

Fig, 64.

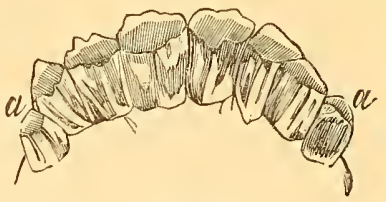

Fig. 65.

mon salt, (chloride of sodium), 3 per cent, and 35 per cent of gelatine. These proportions differ to some extent with the kind of bone, its solidity, and the age and condition of the animal from which it is taken. The bones of the skeleton are joined together by means of cartilages, or ligaments, which form what are known as articulations. Where the bones move one upon another, their ends, or the parts brought in contact, are covered with cartilage. Every bone is enveloped in a highly sensitive lining or membrane called the periostenm. Although the bones seem to be solid and insensible matter, chiefly composed of eartlyy salts, yet they are bighly sensitive, and are formed of tissue which is penetrated by 
an infinite number of minute canals known as the Haversian canals which are from $1 / 200$ to $1 / 2500$ th of an inch in cliaraeter. These canals are parallel to the length of the bone, and frequently communicate together, forming an intricate net-work, which may be seen when

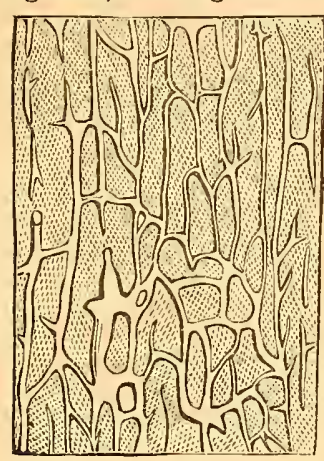

Fig. 66.-THE HAVERSIAN CANALS. a section of tỉe bone made lengthwise is highly magnified, as shown in figure 66. In a cross-section of the bone these canals appear as at fig. 67 , being surrounded by concentric layers, $a$, through which radiating tubes, $b$, of the minutest size, penetrate.

The periosteum is a highly vascular and nervous membrane which covers the entire bone, except the cartilaginous surfaces which move upon each other at the joints. It connects the outer surface of the bones with the tendons, ligaments, and muscles.

The marrow is a fatty, pulpy substance, which fills the central canals and the spongy tissue of the bones. It is pink in color, and contains merely a trace of fat in young animals, but as age advances, it becomes yellow and less solid, and contains $96 \mathrm{per}$ cent of fat. The bones are penetrated and lined within and without with numerous arteries, veins, and nerves. Some of these arteries penetrate the bones by appropriate openings, and divide into branches which form a network that lines the inner surface of the bones, and another that penetrates the substance of the marrow. Other arteries penetrate the spongy portions of the bones, and others form a net-work which belongs to the periosteum, and which enter the substance of the bones by means of the

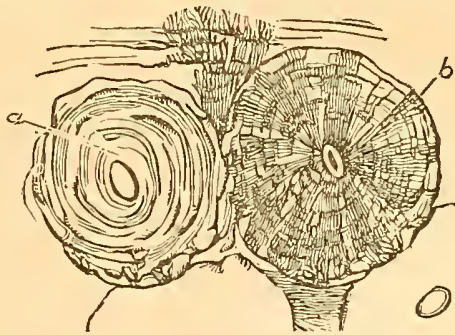

Fig. 6r.-CROSS-SECTION OF BONE. Haversian canals. Veins accompany these arteries, and are very numerous where the spongy tissue is abundant. Nerves are abundant in the marrow and the spongy tissue, but few in the compact tissne. Portions of the vertebrie are remarkable for the numerous nerres they contain. By means of the artcrics and 
veins, the bones receive nutriment and means of growth or repair, and by means of the nerves they become sensitive.

The skeleton or frame work is clothed with flesh or muscular tissue. The muscles consist of bundles of fibers which possess the power of contraction when excited by sensations communicated by the nerves. The muscles are very cliversifed in shape, some being spread out in fan shape, some being thick and bulky, and some long and thin. The fibers are intermingled with fat or with cellular membrane. It is in the abundance of the cells which contain the fat, and in the power to assimilate food to supply the fat, that a sheep of a good breed or character is distinguished from one of a poor or bad character. The abundance of fat cells both within and upon the surface of the muscles gives the soft mellow handling which distinguishes an excellent mutton sheep. The muscles are either directly connected by the ends of their fibers to the periosteum or corering membrane of the bone, as in the scapula or shoulder blade; or the ends are gathered together closely and interlaced with the stronger fibers of the tendons or ligaments which are attached to the bones. By the contraction of the fibers of the muscles and tendons, the movements of the joints are made. In the muscular portions of the sheep consists the whole value of the carcass to the butcher, and the whole art of the brceder and feeder of those heavy-bodied breeds, known as mutton sheep, is concentrated in the effort to increase the muscular development in those parts of the carcass, as the loins and legs, the meat of which is most highly valued. The muscles are enclosed in the skin which forms the covering of the animal. The protecting coat of the animal grows upon the sizin. This is either hair or wool, hoth being of similar construction and composition, differing only in form or degree of fineness and texture.

The brain occupies the cavity of the skull, and is the central seat of sensation and intelligence. From it proceeds the spinal marrow, which is a continuation of the brain, and which occupies a cavity through the center of the spine or backbone, from the head to the tail. The brain is largely supplied with blood by means of the carotid arteries, and the jugular veins serve to return the blood fr $\sim m$ the brain to the heart and lungs. In the sheep the brain is very small as compared with the size of the body, its average weight being but $4 \frac{1}{2}$ ounces, while that of the $\log$ is $6 \frac{1}{2}$ ounces. This difference in the development of brain reasonably accounts for the superior intelligence of the shepherd $\log$, one of which easily controls and gruides the movements of a thousand sheep.

The nerves proceed from the brain and spinal cord, and pen; 
trate in a net-work of the most astonishing fineness to the remotest portion of the body, every portion of which, howerer minute, being endowed by the nerves with the faculty of sensation. In the sheep there are forty pairs of nerves, ten of which proceed from the brain, and thirty from the spinal cord. Each of these has its plexus, or system of branches and net-work. The nerves consist of bundles of white filaments or threads. The different senses, sight, smell, hearing, taste, and touch, are supplied by the nerves, which proceed directly from the brain. Another important brain nerve is the par vagum, or pneumo-gastric nerve, which procecdis to the heart, lungs, stomach, liver, and the bronchial or breathing apparatus. It is this nerve which gives the breathing, circulating, and digestive organs their power of motion independent of the will. Any injury or disease of this nerve affects these vital functions, and its division or destruetion occasions instant death. The spinal nerves convey both sensation and motion. The spinal cord of the sheep weighs one ounce and three-quarters.

The vital functions of an animal are respiration, circulation, and digestion or nutrition. By the first the system is supplied with oxygen, which is one of the sources of animal heat and is the agent by which the blood is purified. By the second, the tissues or living structure of the animal are supplied with nutriment and relieved from dead and used up matter, and by the last the blood is replenished with fresh supplies of nutritive elements.

Respiration commences at the moment of birth and continues to the moment of death. It consists of an inspiration or in-drawing and an expiration or out-forcing of air. The motions necessary to these alternate actions are made by the diaphragm, a membrane which divides the chest from the abdomen. When this membrane is relaxed it is convex or rounded towards the chest. When its fibers contract, it is straightened or flattened, and of course enlarges the carity of the chest and causes a rush of air to fill the enlarged space. This alternate contraction and relaxing of the muscles of the diaphragm cause the motion of the chest, which is observed in breathing. A corresponding movement is also made in the abdomen, as may be noticed in the flauks of hard driven animals. The lungs occupy the largest portion of the cavity of the chest, and enfold the heart. They are two in number, the left and the right; the left lung is divided into two parts, eailed lobes; the riglit is divided into four lobes, of which one is curved around the heart. Fig. 68 shows this peculiarity, 1, 1, being the right lung ; 2,2 , the left: 3 , the trachea or windpipe; 4 , the heart; 5 , the carotid arteries; and 6 , the vena cava, or great vein which 
carries the blood which has circulated through the body to the heart, from which it is forced to the lungs for purification. The lungs are composed of a spongy, highly elastic mass of cells. When the cavity of the chest is enlarged by the contraction of the diaphragm, this elastic mass swells and fills the cavity. The cells enlarge, and vacuums are formed in them to fill which a stream of air is immediately cirected. The air rushes through the nostrils into the trachea or windpipe, and thence into the bronchial tubes, which penetrate the mass of the lungs in all directions, as the branches and twigs of a tree. By these bronchial tubes, air is carried into every portion of the lungs, where it meets the bluod brought thither from every extremity of the body by means of the rena cava through the lieart. In this contact the blood, loaded with impurities, and deprived of the oxygen which is needed for the support of the body, parts with its load of offensive matter, and takes up from the air whatever oxygen it requires to restore it to a state of purity, and to enable it to fulfill the functions of

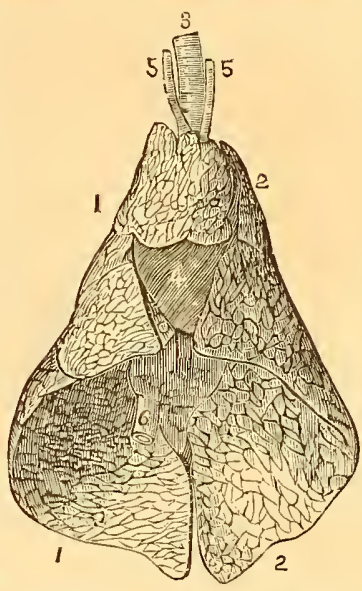

Fig. 63.-THE LUNGS ENVELOPING THE HEART. circulation once more. The air having performed this office, is expelled from the lungs by the relaxing of the muscles of the diaphragm, and is expired. The expired air is highly charged with carbonic acid and rapor of water, nearly the whole of its oxygen having been absorbed by the bloorl. It is also charged with other products of the constant decomposition or waste of the tissues of the body, or of unnecessary matters which have entered the circulation throngh the digestive organs.

Circulation consists in the constant motion of the blood from the heart through the arteries to the inner and outer surface of the body, and through every tissue of which the body is composed; thence back by the veins to the heart; thence to the lungs, where it is purified and fitted to again serve for the nutrition of the body ; it is then sent from the lungs to the heart to start again upon its round to the extremities.

The blood is the most important part in the system of an animal. It consists of a white fluid colored red by very small globules, 
called the blood corpuscles. From the blood the tissues of the body derive materials for their nutrition, growtl, or repair, and for their secretions. The blood is replenished with new matter from the digestive organs, which dissolve and prepare the food for this purpose. To carry on circulation, an apparatus is rovided which consists of the heart, the arteries, the capillaries which form the connecting link between the extremities of the smallest branches of the arteries and those of the veins; the veins; the arteries of the lungs; the lungs with their capillaries, and the veins of the lungs. There is thus a double circulation as it were, which may be readily understood by a reference to the diagram, fig. 69 ,

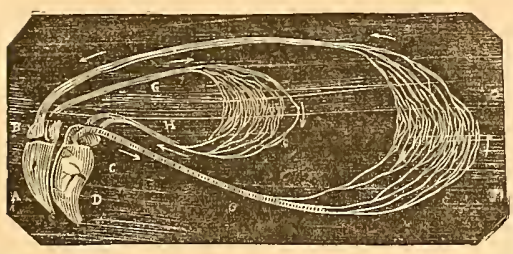

Fig. 63.-DIAGRAM OF teFE Circulatron. in which $C D$ represents the left auricle of the heart, which forces the blood through the arteries I, in the direction of the arrows to the fine network of the capillaries; then to the veins $F$, and thence to the right auricle of the heart, $A B$. From this it is foreed through the right ventricle which opens from the right auricle into the pulmonary artery $G$, still following the course indicated by the arrows, into the net-work of the capillaries of the lungs, from which it is conveyed by the pulmonary rein $F$, into the left ventricle, whence it passes to the left auricie, on the same course over again. The heart is a mass of very strong muscular fiber, having the four cavities just mentioned, and being supplict with valves which regulate the flow of the blood. The muscles of the heart contract and expand with regularity, performing what we usually term its " beats," four times or thereabouts for every inspiration of the lungs. In a young sheep the heart beats 80 to 90 times in a minute; a full grown one, 70 to 80 times, and in a very oll one, 55 to 60 times. At each contraction the blood is forced through the arteries and their branches to the capillaries. These capillaries are exceedingly small, being from $1 / 2000$ to $1 / 3500$ th purt of an inch in diametsr, and inosculate or join together again and again, fcrming a net-work of the closest character, so close that the finest needle cannot penetrate the skin or membranes anywhere withont wounding one or more of them, and causing an escape of blood. Whil z circulating in this net-work of capillaries, the blood gives up to the tissues amongst which it circulates, the materials needed for tucir growth and increase, ant also to sap- 
ply th? waste of matter caused by every mechanical movement of the animal; for every contraction of the fibers of the muscles causes a decomposition and destruction of some portion of their substance. Fience is explained the waste of matter or loss of weight caused by excessive exertion or insufficient food. Here the blood also absorbs the dead, used up matter created by this dec smposition and destruction of tissue, and carries it off from the system. This it does by means of the skin, the kidneys, and the lungs, through which the blood is filtered as it were of matters useless to the system by means of these capillaries; and the excretions of perspiration both sensible and insensible, that of the urine, with some others, are thus thrown off. In this manner the blood becomes depleted of its nutritive properties, and absorbs the wastes of the system in its intricate course through these infinitely small capillaries. It enters them from the arteries a bright red, and leaves them a dark, blackish purple fluid. It courses onwards through the veins loaded with impurities, to the Iungs, which it enters still a dark fluid; here it passes through a second set of capilharies much finer than the former, in which it is exposed to pure air contained in the cells of the lungs; the carbonaceous matters it contains come in contact with the oxygen of the air, and are decomposed, burned in fact, giving forth the heat needed for the continuance of life; when the blood thus rendered pure, leaves the lungs a bright red once more, again fitted to fulfill its functions. Before entering into the lungs, the blood receives a new supply of matter from the lymphatic vessels, called lymph, which is derived from the digested food. The vessel which conveys the lymph or chyle, is called the thoracic duct, and passes upwards into the cavity of the chest in close contact with the vertebræ or spine. The temperature of the blood of the healthy sheep is $100^{\circ}$. The blood is now believed to possess vitality; while its circulation exists it is fluid, and when it is dead it coagulates. The cause of the coagulation of the blood is not known, and there is a difference between its coagulation in and out of the body. If a part of the body be wounded, the blood which escapes from the divicied vessels, coagulates between the edges of the wound, forms a clot of organized material, throws out new vessels, and gradually restores the wounded parts. It is this coagulating property which saves the life of a wounded animal and directly leads to recovery; if the blood remained fluid, the least wound would cause a flow which would not stop until the vessels were empty and the animal dead. The constituents of the blood are exactly those of flesh.

Digestion is the proccss by which food is taken into the body, 
masticated, dissolved by the stomach and intestines, and renciered fit for absorption by the lacteals and lymphatics, and assimilation by the blood. The parts concerned in digestion are the lips, teeth, and tongue, the salivary glands, the gullet, the stomach, the intestines, the liver, the lacteals, and the thoracic duct which connects the digestive process with the direct function of circulation and nutrition. The lips are used by the sheep in gathering its food, very much as they are used by the horse, and to a much greater extent than by the ox. The sheep's lips are thin, and very active in their movement. The upper lip is divided by a groove, or fissure, so that each half can be moved independently of the other. The sheep possesses no muffle or broad space between the nostrils on the upper lip, which in health secretes a liquid which appears in small drops upon its surface, as in the ox. The teeth have been already described. Their office is well known. The tongue serves to convey the food to the teeth, and from the teeth to the gullet, and also the cud from the gullet to the teeth. The salivary glands secrete a fluid which moistens the food during mastication, and which also possesses some of the character of a solvent, or a pre: paratory digestive agent, in being able to convert starch into soluble dextrine ard sugar, and thus prepare it for digestion by the stomach. The glands are three in number, and are named the parotid, the submaxillary, and the sublingual. The first is situated at the outside of the angle of the lower jaw; the second is placed on the inside of the lower jaw, near the angle; and the third is bsneath the tongue. Ducts from these glands give ont the saliva naturally whenever the membranes of the mouth are excited by the presence of food; or unduly, as in some diseases which cause an excessive secretion of the fluid. The gullet conveys food or drink from the mouth to the stomach. The pharynx is the upper part of the gullet, by which it is connected with the mouth. It is separated from the larynx, the entrance into the windpipe or air passage, by a cartilaginous lid called the epiglottis, which, when food is swallowed, closes the larynx and allows the food to slide over it. The pharyns, gullet, stomach and intestines, together form what is termed the alimentary canal. The gullet, also called the œsophagus, is a very strong, muscular tube, lined with insensible white membrane. The fibers of the muscles run spirally around the tube, in opposite directions, and thus cross each other. By the contraction of these muscles, gradually extending downwards, food is carried into the stomach; while by their contraction in an upward direction, the fond is brought back to the mouth to be masticated the second time in the process of rumina- 
tion. The food taken up by the lips and teeth is ground and mixcl with saliva in the mouth, passed backwards by the action of the tongue to the gullet, and then forced into the stomach.

The stomach of the sheep consists of a large irregular sac or pouch, dirided into four compartments, generally referred to as distinet

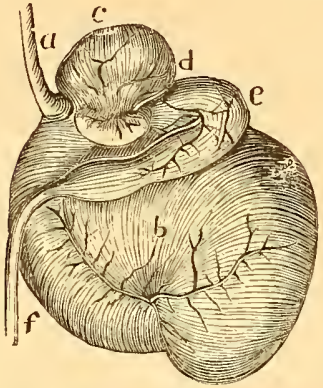

Fig. 70.-RIGHT SIDE OF THE STOMACH. stomachs, or the first, second, third, and fourth stomachs, (see figs. 70,71 , and 72), or the rumen or paunch, seen at $b$; the reticulum or honeycomb, $c$; the omasum cr manyplics, $d$; and the abomasum, or rennct, or true digestive stomach, $e$. The gullet is seen at $a$, and the duodenum at $f$. The functions of the stomachs of the ruminating animals are known only somewhat obscurely. Anatomy only teaches their form and character, and leaves all the rest in doubt, or to be dccided by experiment and observation. From the structure of the stomachs we are able to form a generally complete idea of the process of digestion which goes on within them; of some of the details there is nothing certain as yet to offer. The first two stomachs are placed parallel to cach other, and the gullet cucls almost equally in each, as seen at $a$ in fig. 72 , which shows the inside formation of the stomachs. The second stomach, $c$, communicates with the third by the œsophagean canal, $g$, which opens into the third stomach, (not seen in figs. 70 and 71 ), and ends there. The fourth stomach is connected with the third by a distinct opening. The paunch, $b$, is the largest compartment, being four times the capacity of the other three together. It is divided into four incomplete compartments by muscular

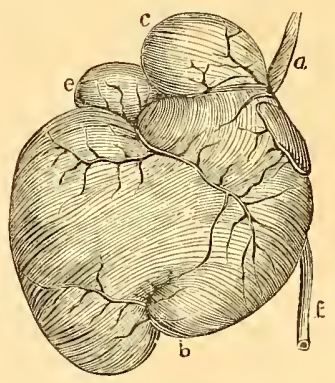

Fig. 71. - IEFT SIDE OF THE STOMACH.

walls, and is lined with a membrane covered by a multitude of soft pillars compressed closely together, which make an uneven surface. The second stomach, $c$, is lined with cells having fire or six sides from which it takes the common name, the honeycomb. These two comparimeats, or stomachs, are in reality oae, the latter being 
simply an appendlage of the former. The œsophagean canal which leads from the second stomach to the third, performs a very important function in the act of runination, or it is supposed with reason

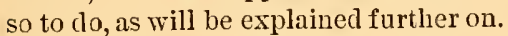
The third stomach or "manyplies," in the sheep the smallest of the stomachs, is lined with a number of leaves or folds, placed lengthwise, by which the surface is greatly increased. The fourth stomach joins the third, and communicates with it by an opening inmediately opposite to the œsophagean orifice. The fourth stomach is lined with a membrane which secretes the gastric juice, the true digestive

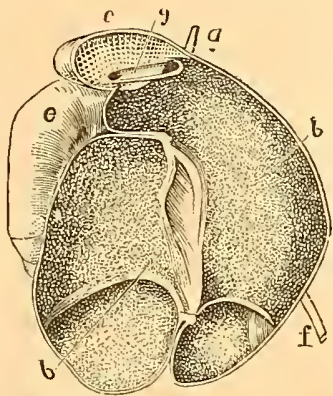

Fig. 72.-INTERIOR OF THE STOMACH. solvent. It opens directly into the duodenum or small intestine.

Rumination, or chewing the cud, is a process which distinguishes a class of animals, known as ruminants, from all others. For the performance of this process the complicated stomach above described is provided. To understand this important alimentary process, it is necessaiy to ascertain first, into which of the stomachs the food passas after its first mastication; second, in what manner and by what process the food is rejected by these stomaclis and returned to the mouth for a second mastication; third, to which of the stomachs is the food finally transmitted for complets digestion.

Some careful experiments, by the French physiologist, Flonrens, liave to a great extent determined these questions; and the comparative anatomist, Chauveau, has summed up the functions of the stomacls of ruminants as ascertained from every moderi source of information as follows:

1st. The rumen is a sac in which the food swallowed during feoling time is held in reserve, and is softened, and whence it is carried to the moutin during rumination.

2nd. The reticulum partakes of the functions of the rumen, to which it plays the part of an accessory or reservoir ; the food contained in it being always dilutel by a larger quantity of water.

3rd. The asophagean canal carries into the omasum the food swallowed the serond time, or after rumination, or even those port.ons of food which the animal suorllons in very sma'l quantity and in a fincly divided or softened condition the first time. 
4th. The omasum completes the maceration or reduction of the food to a sufficiently fine condition for digestion, by pressing it bectween its leaves.

5th. The abomasum is the true digestive stomach, and finally dissolves the food by its gastric secretion.

In these processes the csophagean canal performs a peculiar function. The ordinary food of the ruminating animal is coarse in texture, and when swallowed is bulky. When it enters into the stomach and meets the opening of the cesophagean canal, it forces open, by iis bulk, the muscular lips of which the opening is composec, and drops partly into the first, and partly into the second stomach. M. Flourens has satisfied himself, by careful experiments upon a living sheep, that when the animal ruminates, a portion of the food swallowed previously and now contained in the first and second stomachs-which are really one-is forced by a contraction of the stomash into the esophagean canal, and this then contracting, closes all the other openings except that of the gullet, and at the same time compresses the morsel of food into a pellet or ball, which is immediately forced by the upward muscular contraction of the gullet into the mouth. When it has been chewed and mingled with the copious secretion of saliva which takes place during rumination, it is again swallowed. Being now softened and in a semi-liquid condition, it passes over the lips of the opening of the canal, without forcing them apart, into the second stomach, and enters the third stomach; a small portion of it only escaping into the first and second stomachs. When fine or semiliquid food is first swallowed, it follows exactly the same course, the same being true of watcr when drank. Fiom the third stomach the food passes on to the fourth stomach to be finally ciisposed of. It has been found that the pellets of food, returned to the mouth for rumination, are of the precise size, shape, and form of the portion of the cesophagean canal between the first and third stomachs. Sheep have been dissected with these pellets ready formed in the canal for transmission to the month.

The intestines of the sheep are of great length, being twentyeight times longer than its body. In the duodenum, which is the upper portion of the intestines that directly communicates with the lower orifice of the stomach, the partially digested mass of food undergoes still further changes. As it passes from the stomach it is termed chyme. In the duodenum the chyme is mingled with the bile, which comes from the liver, and the pancreatic juice, a secretion of the pancreas, or "sweet-breacl," and becomes fitted 
for absorption by the lacteals which communicate with the intestines. It is now termed chyle, and is a white milky fluici which enters the thoracic duct and mingles with the blood as previously described. The refuse and insoluble portion of the food, with unused portions of the bile pass on through the lower intestincs, and is discharged by the rectum as dung.

The liver is a large organ with the appearance of which almost every person is familiar. It is called a gland, because its office is to secrete a fluid which is peculiar to it, and it is the largest gland in the body. Its secretion is called the bile. Its position in the body is below the diaphragm and adjacent to the stomachs, with the third of which it is in direct contact. It is enveloped in the peritoneum or membrane which covers and also encloses the whole of the contents of the abdomen, and forms as it were a sac or bag, onc-half of which is doubled into the other half. The liver in substance is granular, consisting of grains, or lobules, from one-tenth to one-twentieth of an inch in diameter. Its color is reddish brown. The lobules of which it is composed are closely packed, and are held together by fine tissue and a net-work of minute veins and ducts. Each lobule is connected with a blood vessel at its base, and another vessel comes from the center of the lobule and joins the former one at its base. Between these two is an exceedingly fine net-work of capillary vessels similar to those previously described. By means of arteries and reins called portal canals, which enter and ramify through the substance of the liver, the blood is carried into and throngh the substance of each lobule in streams of exceeding fineness. From the blood thus passing through the lobules, the gall or bile is secreted by small cells not exceeding $1 / 1000$ th of an inch in cliameter, and is collected iuto minute vessels called biliary ducts, from which it is gathered into larger ducts, which pour their contents into the great bile ducts. There is a receptacle in the liver of the sheep known as the gall-bladder, to which the gall is carried from the hepatic duct by another duct named the cystic duct. When the gall contained in the gall-bladder is required for use, it returns by the same duct into the hepatic duct, and thence into the great bile duct which ends in the duodenum, below the stomach.

The gall is an alkaline fluid of composite character, containing soda, two peculiar acids, (glycocholic and taurocholic, the lat ter of which contains sulphur); mucus; cholesterine; stearic, oleic, and lactic acids, with potash and ammonia, and a peculiar coloring matter. It is in fact a sort of liquid soap. The bile is ponred into the duodenum by the great bile duct. Near this duct is 
another from which flows the secretion of the pancreas or sweet-bread. This fluid is slightly alkaline and very similar to the saliva. Its office is supposed to be to change the undissolved starch in the chyme into sugar, and to form an emulsion with the oil or fat of the food, and prepare it for absorption directly into the blood or into the lacteals. The cfince of the gall is to nentralize the acidity of the chyme derived from the gastric juice, which is an acid fluid, to assist in the transforma ion of starch into sugar, and the absorption of oil or fat. It is the chief agent in changing the chyme of the stomach into the chyle, which is the perfected suuree of nutrition of the blood. The perfect action of the liver is therefore absolutely necessary to the sustenance and the life of the animal. The quantity of gall secreted by the liver of the sheep every twenty-four hours is from 3 to 5 pounds. The whole of this, however, is not destroyed in the performance of its office, but a large portion is taken into the system in the circulation, the surplus bcing regained from the blood by the secreting cells of the liver and again returnad for duty to the intestincs. Another offics of the liver is to prepare crude albuminous matter of the blood for final absorption into it. It is also able to form sugar from other carbonaceous matters conveyed to it in the chyie absorbed by the lacteal vessels. Thus the liver acts as a filter, in separating detrimental matters from the blood, besides supplying a necessary agent in digestion, as well as for respiration. Its importance in the animal functions cannot be over-estimated.

The lacteals are a series of small absorbent vessels which form a net-work in connection with the coats of the intestincs, and proceed to the thoracic duct, where they terminate. They exist much more numerously in connection with the small intestincs than with the lower ones. Their chief seat is the mesentery, which is the thin membrane which supports the small intestines. The lacteals enter the numernus glands of the mcsentery, and pass through them, uniting to form larger vessels and becoming fewer and fewer in number, being finally reduced to two or three ducts which end in the thoracic duct. The lacteals absorb the chyle, which is presented to them in the intestines, convey it to the glands in which it is enriched and perfected, and thence convey it to the vessels which terminate in the duct from which the new nutritive matter is poured into the large vein near its junction with the lyeart, to enter into the circulation.

The chyle is very similar in its composition to the blood, differing from it chiefly in the absence of coloring matter, or the red globules which give the color to the blood. It coarulates on 
being allowed to rest, although the clot is softer than that of the blood.

The thoracic duct extends from the loins to the neek, and its course is along the spine. It is the principal trunk of the absorbent system, and, as has been explained, is the connecting link between the digestive organs and the circulatory system, as the pulmonary artery and vein is the connecting link between the circulatory and respiratory system.

The spleen is another organ which is very important, as being the seat of a rather obscurely understood disease, known as splenic apoplexy. It consists of a spongy mass of tissue of a mottled blue or purplish gray color. It is suspended near the great curvature of the stomach, but of its functions nothing is precisely known. It is supposed to act as a reservoir of blood for the portal vein; it is also supposed to destroy the red globules of the blood, as it has been discovered to contain blood globules in a state of decomposition. It is, however, known that, in the course of researches to discover the uses of this gland, animals from which it has been remover have recovered from the operation, and have continued to live in apparent good health. The fact of its engorgement with blood in the disease of ruminents known as splenic fever or apoplexy, and its increase of volume in certain bilious disorders, wonld tend to show that its functions are in some way closely connected with the circulation, and perhaps with the digestive processes and nutrition.

The Urinary or Excretory Organs.-The urine is separated from the arterial blood by the kilneys. These organs, with the liver and the lungs, are employed in the purification of the blood. The liver separates compounds abounding in hydrogen, the lungs those which abound in carbon, and the kicheys those abounding in mitrogen. The nitrogen eliminated through the kidneys exists in the form of urea, a crystalline substance which readily decomposes and gives off its nitrogen in the form of ammonia. There are two kidneys, one each side of the spinal columu. The kidneys are attachel firmly to the loins; in the sheep they are shaped like a bean, and are imbedded in fat. They perform a donble office, or two separate functions, one being to discharge from the blood any excess of water that may accumulate in it; the other being to rid the blood of excess of saline matter and the products that result from the waste of the tissues. The blood enters the kidneys by arteries, and the urine, separated as by a filter, through a very complex system of capilaries, flows into two white ducts termed ureters, which pass it ouwards to the bladder. The urine of the 
sheep is not so copious as that of the cow in proportion to its size, but possesses a larger proportion of salts. The following is an analysis of sheep's urine:

Water.

Salts of potash, soda, lime, magnesia, silica, iron,

alumina, and manganese................... 1.2 " "

$\overline{100.00}$ ،

In fig. 73 is shown a section of the substance of the l:idney highly magnified, in which appear the uriniferous, (urine carrying) ducts or tubes, $(a, c)$, surrounded by the secreting glandular substance, $(b, b)$, which is enclosed in the net-work of the arteries, $(c, c)$, and the fibrous tissue, $(d, d)$.

The bladder is situated in the pelvic cavity, or the lower part of the abdomen. It is composed of two coats, the outer one being muscular, and capable of contracting so as to expel its contents. One half is enveloped in a third coat, and the other half in the

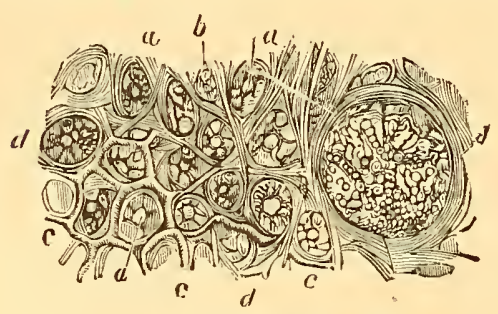

Fig. 73.-STRTCTURE OF THE KIDNEY. tissue of the pclvic region, and masses of fatty matter. The muscular coat consists of fiber placed in varicus directions, lengthwise, crosswise, oblique, and spiral, so that in the act of contraction the bladder is reduced in size evenly and in crery direction. A strong muscle encircles the opening, from which the urine is discharged, and which is called the neck of the bladder. The contraction of this muscle closes the neck and retains the contents, its relaxation opens the orifice and allows the contents to be expelled. From the neck of the bladder proceeds the urethra, by which the urine is discharged. In the ewe the urethra is very short, in the ram it is much longer, and passes down from the anus along the abdomen to the extremity of the penis. The functions of the bladder are very important. It serves as a reservoir for the urinal fluid which is constantly secreted by the kidneys and retains it until a considerable quantity has been accumulated, and thus spares the animal from otherwise coatinually dribbling away the urine as it is secreted.

The Reproductive Organs.-These are entirely different in the 
male and female. The female organs are more abundantly dereloped than those of the male, and have more intricate functions to fulfill. They consist of two secreting organs called ovaries, which are charged with the elaboration of the ovum or egg; the uterine tube through which the ovum passes on leaving the ovary; the uterus or womb in which it rests after its impregnation, and in which it remains until it is fully developed; and the vagina or canal through which the fœtus or young animal when perfected is discharged. In addition there are two mammæ or milk-producing glands enclosed in the skin, and attached to the lower part of the abdomen and inner parts of the thighs, each of which has a set of secreting glands and milk ducts flowing into a tube which has its orifice in the teat. These milk glands are called the udder. The ovum is a cell about $1 / 100$ th of an inch in diameter, which is contained in another cell or ovisac, of which the ovaries contain a certain number. At stated periods called the œstrum or condition of "heat," the ovaries become excited and distended, and discharge one (or more) of these ovisacs, which, partaking of the condition of the ovaries, becomes distended and bursts, releasing the ovum, which, when it is brought into contact with the impregnating fluid of the male in the uterine tube, undergoes a change, enters into the uterus, and in course of time becomes a living animal. When the female is not brought into connection with the male at the season of heat, the ovum undergoes no change, but passes on to the uterus, where it is absorbed. The impregnated ovum, when it reaches the uterus, becomes grafted upen its lining membrane and draws directly from the mother's blood the materials for its development.

In the male the reproductive organs consist of two glands, which in the ram are suspended in a sac between the thighs. This sac is called the scrotum. The glands, called the testicles or testes, are each enclosed in four envelopes, being separate and distinct from each other. One of these envelopes is a portion of the peritoneum or lining of the abdomen, which descends through an opening in the abdomen. This opening remains afterwards, and it is thus that in castrating the ram, the inflammation which often takes place, spreads into the abdomen and clestroys the animal. The glands are oval in shape, and consist of a grayish pulp. They are attached to the spermatic cord and artery, and their function is to secrete the spermatic or impregnating fluid, which is alkaline, and contains minute filaments not larger than $1 / 6000$ to $1 / 8000$ th of an incli in length. These filaments possess the power of independent movement for some days after their expulsion from the organs of 
the male. A canal or dust called the vas deferens, leads from the testes to the outward and exposed male organ. In the ram this organ has at its extremity a small spiral appendage called the vermiform, (or worm-like), appendage. This has a very narrow orifice, and is often on this account the seat of obstructions which are difficult to remove.

The testicles of the ram are very large in proportion to its size, and the whole reproductive powers are highly vigorous, enabling him, when well nourished, to serve effectively a hundred ewes in a season.

\section{OBSERVATIONS ON THE DISEASES OF THE SHEEP.}

In judging of the symptoms of disease in the sheep, it is necessary to take into account the nature, constitution, and labits of this animal. The diseases of the sheep are numcrous and more generally fatal than those of other domestic animals. The digestive organs of the sheep are largely and powerfully developed, and its capacity for the production of blood is very great. Yet its needs for this large supply of blood is not to support its nervous system, which is feebly developed, nor its inuscular exertion, of which it is incapable to any great extent, nor its circulation, which is only of inferior amount, but the surplus must necessarily go to the production of flesh, fat, and wool. In the sheep, therefore, the production of flesh, fat, and wool, is the chief of its functions, and the greater part of its vitality is expended in this way, leaving but a small amount to sustain the comparatively weak vascular system. The sheep is unable to sustain severe muscular labor; and slow movement, except for very limited periods, is all that it is capable of. From the small brain development of the sheep, its weak nervous and circulating system, it is to a great extent free from diseases of an inflammatory character. From the large exercise of its digestive powers, it is to be expected that diseases of the digestive organs should be frequent and serious, and this we find to be the case. From the same causes that render it comparatively free from diseases of an irritating character, it with more than usual readiness succumbs to those in which debility and the exhanstive effects of parasites are the chief features. Indeed it is to the attacks of parasites, both external and internal, that sheep owe their most troublesome and fatal disorders. Infectious or contagious diseases have greater scope for action amongst sheep than amongst other clomestic animals, by reason of their gathering together in large flocks, and thus being more exposed to unwhole- 
some influences than those animals which are usually kept singly, or which when kept in large numbers, naturally break up into small separate herds. The strueture of the foot, and the manner of the growth of the crust and sole are such as to subject it to disease in that organ from which other animals are free. In the management of a flock of sheep, it is necessary to bear in mind the peculiarities and habits, so that the watchful care of the shepherd may be given as far as possible to exercise precautions which may prevent disease. Fortunately our climate is so well adapted to these pecnliarities and habits, that our flocks suffer from far fewer diseases than those of other less favorable climates, and at present many disatses prevalent in other countries are unknown to ns except by report. Precautions to be effective must be intelligently exercised, and it is only by thoroughly understanding his flock that the shepherd can know what to avoid and what to do. The symptoms which indicate approaching disease should be instantly recognized, or the threatened danger cannot be averted. Then the timely remedy may be employed, which is rarely ineffective, while that which comes later is rarely serviceable or effective. The remedies to be administered must be consistent with the peculiarities of the sheep. Possessing but a weak rascular and nervous system, and a small supply of circulating blood, bleeding is rarely called for, and can be employed only with danger of doing harm in place of good. For the same reason tonic and stimulating medicines are more frequently needed, and may be given in larger doses. Purgatives, especially saline ones, for the same reason, always demand an accompanying stimulant.

Purgatives are frequently called for, as the digestive organs so abundantly developed and largely exercised, are readily diseased or disordered, and disturbance of the system rarely occurs without sympathetically or otherwise involving those organs. The veterinarian used to study the diseases of the horse, and to apply his reasoning to the peculiarities of that animal, is too apt to lose sight of the vast surface of the stomachs of the sheep, the insensibility of much of this surface, and the fact that medicine administered with the food or in solid form, will most probably fall into the rumen, where it will be ineffective. So too the shepherd, who consults veterinary works, will be misled to a great extent, and be induced to believe the too common idea that it is folly to physic a sheep, and the best treatment is to cut its throat at once. In treating sheep, purgatives are useful to reduce ferer, to lower inflammation, and to restore tone to the stomach and lirer. They should always be given in a liquid form. Of all the purgatives, 
Epsom Salts and Linseed Oil (always raw) are the most suitable and effective. The action of stimulants given along with a purgative is always beneficial.

Stimulants, of which Ginger, Gentian, Aniseed, and Pepper. mint-oil are the most usual and useful, restore the tone of the stomachs and excite them to action, thus aiding in the operation of the purgative, which might otherwise still further enfeeble them.

Bleeding, when it is necessary in the outset of inflammatory disorders or local excitements, should be performed by operating on the veins under the eye (see fig. 76 ) or the ear ; the inside of the fore arm is a convenient place; when a large quantity is to bo taken, the jugular vein of the neck may be opened by first cutting off some of the wool, pressing the rein with the finger, and cutting it lengthwise-never crosswise-with a sharp lancet. Never less than two ounces or a wine-glassful should be taken, and rarely more than half a pint.

In referring to the diseases hereinafter treated of, as far as possible, the canses to which they may generally be attributed, with the means of prevention, will be given. The remedies mentioned will be those to be given to a full-grown animal, for lambs, one-half or' less of the doses shoul? be given, and for very young lambs, still less should be given.

The most prolific causes of disease are over-feeding, under-fecding, irregularity of feeding, want of water, drinking impure water, impure air, clamp, and over-driving. If these were avoided there would be but little complaint of the frequent troubles, difficulties, and losses in keeping sheep. While they exist, medicine, at the best, is but a temporary expedient, effective only during the time in which extra care is used. When this care is allowed to relapse the trouble will infallibly recur.

\section{CAUSES, PREVENTION, AND TREATMENT, OF DISEASES COMMON TO SHEEP.}

\section{DISEASES OF THE RESPIRATORY ORGANS.}

Catarrh is very common during the fall, winter, and spring. It will be found on close observation to be rarely absent in any flock. In our dry climate, subject, however, to sudden changes of temperature, catarrh, or cold, is mostly due to exposure to damp in open yards, or to too high a temperature in sheds or pens, rather than to exposure to the weather in open fields. Flocks that are more care- 
fully tendied and housed than usual, are found to be more subject to it than others. Of two flocks equally well fed, but one of which is carefully shut up every night and protected (?) from every draft of fresh air, and another whose bed is the snow in an open, airy, dry yard, it will be the first that will be troubled with cough and discharge from the nose, while the latter will be free from it. Fresh air, ample ventilation in partly open sheds, dry gards and clean, dry bedding, and protection from chilling rain-storms in winter, with whatever protection may be needed immediately after shearing, should the weather be cold and rainy, will generally be amply sufficient to prevent any trouble from this complaint. Chasing by dogs and conscquent over-heating, and over-clriving, are certain causes, and these should be carefully avoided. The judgment of the shepherd should be exercised in exceptional cases, acting always under the general rule that dry cold is rarely hurtful to sheep, while they suffer from wet or damp cold, and that moist, warm, steamy, close atmosphere, especially when confined in sizbles, will inevitably produce cold or catarrh, which if not at once remedied will generally result in serious disorders of the lungs. This disease consists of inflammation of the lining membrane of the throat, windpipe, nostrils, and the sinuses of the had. It produces an increase of the secretion of mucus and consequent irritation and coughing. When long continued, the cough becomes dry and deep seated, showing that the lungs are involved.

The treatment consists in removal of the causes, good nursing, aclministering sliglitly warm mucilaginous drinks, as oat-meal grucl or linseed tea, along with a gentle stimulant, such as half a teaspoonful of ground ginger. The antiseptic effect of a small quantity of clean pine tar rubbed upon the sheep's nose, some of which the animal will lick off and swallow, will be beneficial. If there is fever, and the nose is dry and hot, the following may be given, viz:

Epsom Salts...............................1/2 ounee.

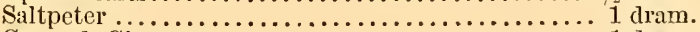

Ground Ginger................................ 1 dram.

This should be mixed with molasses and placed on the back part of the tongue witl a long, narrow bladed wooden knife or spatula. The animal's head should be held up until the whole is swallowed in repeated small quantities. Or the dose may be mixed with thin gruel and administered by means of a small horn.

Bronchitis is simply a deep-seated catarrh which affects the bronchial tubes or air passages in the body of the lungs. It is dangerous, inasmuch as the inflammation readily spreads and affects the lungs. In bronchitis the cough is more severe than in catarrh, 
t'se pulse and the respiration are both quickened, there is some fever, and the appetite fails. The treatment is the same as that prescribed for catarrh, but to be continued longer, changing the close to the following, to be administered for three or four days, reducing the quantity of saltpeter gradually one-half.

Linseed-oil...............................1 ounce.

Saltpeter.................................. 1 dram.

Powdered Gentian.............................

Bleeding must not be attempted in this disease. Quietness is incispensable, and a clean, airy, but solitary, pen should be provided, and a plenty of pure, fresh water supplied.

Pneumonia or Inflammation of the Lungs.-This is a more frequent disease than is generally suspected. Many sheep exhibit the peculiar symptoms of pneumonia, and are too far gone for recorery before their too careless owners are aware that they are affected. High bred imported sheep, the Leiccster more particularly, are very liable to this disease, which is generally fatal to them. It consists of inflammation of the substance of the lungs, and frequently follows neglected attacks of bronchitis, the inflammation easily and quickly passing from the lining membrane of the air-passages to the cellular tissue of the lungs. Washing in streams of cold spring water, or sudden chills from exposure to cold showers, quickly succeeding hot wcather, or when lieated with driving, or after shearing, or too close penning in warm stables in cold weather, are the usual causes. It is rarely that this disease develops fully without previously passing through the earlier stages, or without some serious mistake in the management of the sheep; and it is only by instant attention and proper treatment that its usually rapid and fatal course can be arrested.

The symptoms are a quick and labored breathing with painful heaving of the flanks; a painful cough; discharge of thick yellow mucus from the nostrils, high fever, and great thirst; hard, quick pulse; constant grinding of the teeth, together with loss of appetite and rumination. On examination after death, the lungs are found to be hard and gorged with blood, and if thrown into water they sink to the bottom. The disease usually terminates in death in from twenty-four to thirty-six hours.

Treatment is of no avail unless commenced immediately. Bleeding from the jugular vein, until the animal staggers, is the first and most effective remedy. If found necessary, this should be repeated in six hours. Two ounces of Epsom salts should be given immediately after the bleeding; if this does not cause free purging, one ounce more may be given in three hours. Copious purging is not 
to be dreaded in this disease with sheep as with the horse. Injections of thin oat-meal gruel, strained, should be given every two hours. After the bowels have been well evacuated, the following may be given twice a day in oat-meal or linseed gruel :

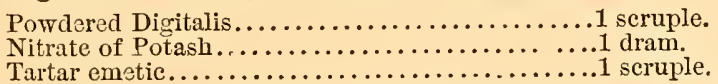

to be continued several days. As soon as the sheep improves and begins to move about, a pint of gruel may be given every three hours with half a dram of powdered Gentian. Warm drinks of dissolved gum Arabic, or linseed-meal tea, in which a little honey is dissolved, will be useful. The nostrils should be freed from accumulated mucus by washing or sponging with a mixture of equal parts vinegar and water, or of one ounce of acetic acid with a quart of water. Some of the acidulated water should be squeezed into the nostrils to clear them as far as possible.

One dram doses of tartar emetic alone hare been given with benefit in this disease. As it is in nearly every case avoidable by proper care and precaution, and is rarely cured when once well seated, it will be by far the best policy to prevent its occurrence.

Pleurisy, or inflammation of the membrane covering the lungs and the lining of the cavity of the chest, is produced by the same causes as pneumonia. It frequently accompanies this latter disease. It most frequently follows the careless washing of sheep or their exposure to cold winds with wet flecees, or from a serere chill after having been sheared. After an attack of this disease, and a seeming recovery, an adhesion of the lungs to the sides of the chest often takes place which prevents the sheep from thriving and keeps them in poor condition, from which they cannot be recovered. Wide-spread canses, chiefly those arising from the nnfavorable condition of the weather, sometimes affect the flocks of extensive districts, and lead to the supposition that the disease is epizootic or contagions. This, however, is not the case.

Prevention consists in watchful eare to protect the sheep from sudden change of the weather at a time when they are more than usually exposed to its ill effects; also from a too sudden change from housing to open pasturing in the spring. All sudden changes in the management of sheep should be made with cantion, a change, even from poor to rich foed, may produce this or other inflammatory diseases, and carc must be exercised in this respeet.

The symptoms are similar to those of inflammation of the Iungs; more pain is experienced, and the sheep exhibits more distress, sometimes moaniug in agony. After death, the cavity of the chest 
is found filled with fluid; the surface of the lungs is highly inflamed, and covered with livid patches, but their substance is not affected. Generally no trace of disease is found elsewhere.

The treatment consists in copious bleeding as for pneumonia, but more blood may be taken with benefit. The following may be given :

Powdered Digitalis.......................1 scruple.

Nitrate of Potash ............................ dram.

Nitrous Ether, (Spirits of Nitre)................ drams.

to be administered in linseed-meal or oat-meal gruel twice a day

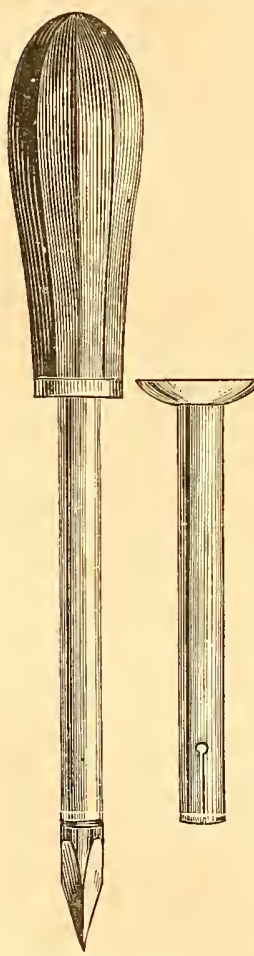

Fig. 74.-TROCHAR AND CANULA. for four or five days. When recovery begins, the following tonic may be substituted:

Sulphate of Iron................

Infusion of Quassia or Chamomile..1/4 pint.

Ground Ginger................

If the animal is valuable, it may sometimes be saved after the effusion of serum in the chest has occurred to a considerable extent, by tapping the cavity with a trochar and canula, (fig. 74), and drawing off the fluid. When this effusion has taken place, it may be discovered by tapping the sides of the chest, when a dull dead sound only is heard; also by a gurgling sound during expiration, which is painful and difficult. The trochar is inserted cantiously between the eighth and ninth ribs, and the cantla left in the opening through which the fluid flows. Generous feeding and great care are needed after tapping.

\section{DISEASES OF THE DIGESTIVE ORGANS.}

Choking.-Sheep are not often troubled with obstructions of the gullet, except when fed upon cut or sliced turnips, or permitted to consume the shells of turnips which have been scooped out by them in the field. When a sheep is thus choked, the head is held down, saliva flows from the mouth, breathing is difficult, and the stomach becomes distended with gas, or air swallowed in the efforts to dislodge the obstruction. When this vocurs, the sheep's head should be raised and held firmly between one man's legs, 
while another pours a teaspoonful of linseed oil or melted lard down the throat and endeavors by gently manipulating the gullet to work the obstruction downwards. If this is ineffectual, a probang should be used. This is a flexible thin rod, as the wash rod of a rifle, or a piece of light rattan or cther tough elastic material. A soft ball of tow, or of strips of linen cloth is securely fastened to the end of the rod. This is well soaked with sweet oil or lard, and gently inserted into the gullet until it meets the obstruction, when it is to be forced downwards without violence, a few gentle, but smart taps on the upper end with a light stick being generally more effective than continuous pressure. If the lining of the gullet is injured in the opcration, and the sheep refuses to eat, grucl or other liquid food should be given until the soreness disappears. If the obstruction cannot be removed in this way, the sheep had better be slaughtered. If it is a valuable animal, an effort which is frequently successful, may be made to save it by cutting open the skin and the gullet upon the obstruction, and removing it. The opening in the gullet is then closed by a stitch made with a surgeon's curved needle, and the wound in the skin closed separately in the same manner: The sheep should be securely held during this operation. Soft food should be given until the wound is healed. (See Treatment of Wounds).

Costiveness-Stretches.-This complaint is more frequently a symptom of disease than a disease itself. Yet it frequently occurs when changing the flock from pasture to dry food. The dung then becomes dry, hard, and scanty, and is discharged irregularly. The termination of the bowel is red and inflamed, and when roiding dung, the sheep grunts or moans as with pain. Care in changing the food is a preventive, and a few onnces of linseed-cake-meal daily will obviate the difficulty. Injections of warm soap and water, or of one ounce of linseed-oil, will relieve the bowels, and one ounce of linseed-oil given by the mouth will generally bring about a cure.

When the costiveness is of long contimance, from neglect, the sheep may be perceived stretching itself, spreading the feet apart, raising the head, curving the back, and extending the abtomen. This may also occur from obstruction of the bowels, which, however, is rare with sheep, but is most frequently caused by costiveness. A teaspoonful of Sublimed Sulphur, (Flowers of Sulphur), mixed with a small quantity of molasses or lard, may be placed on the tongue to be swellowed, once a day, for a reek. A regular allowance of a mixture of four ounces of Sulphur with one pound 
of salt, placed where the sheep can have access to it at will, is a sure preventive of costiveness.

Diarrhea or Scours.-A looseness of the bowels, without pain, fever, or other complications, frequently occur's when sheep are turned to pasture in the spring, or turned on to rich succulent green food, as clover, rape, or turnips. It is sometimes perceived when they are exposed to the hot sun in early spring without shelter. It is not dangerous of itself, but as the disease very quickly interferes with the process of nutrition, the blood is soon affected, and the more serious blood disorder, dysentery, supervenes. Diarrhea may generally be prevented by careful regulation of the food, and avoiding sudden changes, and the regular supply of salt. It is quickly subject to proper treatment, which consists of the administration of astringents and cordial preparations. The following mixture should always be kept on hand by the shepherd, ready for instant use:

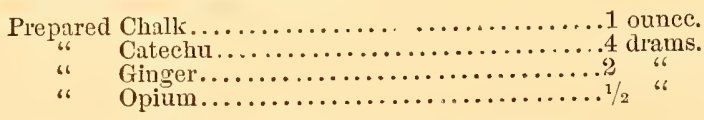

to be mixed with half a pint of peppermint water and bottled for use. Two large tablespoonfuls of this is given night and morning to a sheep, and half as much to a lamb, always previously shaking the mixture well. Cotton-seed-cake-meal is both an excellent preventive and remedy for this complaint, and a supply should be kept for use. Half a pound a day should be given to a sheep.

If any mueus or glutinous substance appars in the dung it is a proof of the existence of irritating matter in the intestines, and a laxative should be given previonsly to the above. This may be

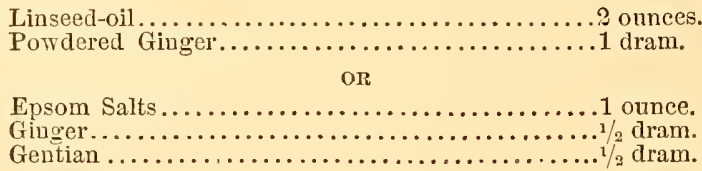

to be given in infusion of linseedi-meal.

Hoven, or distension of the rumen, is not uncommon in slieep. It consists in the formation of gas in the first stomach, or rumen, by which it is so much distended as to press injurinusly upon the diaphragm or membrane which encloses the chest. This preventing the contraction of the diaphragm interferes with the respiration. It appears as an enlargement of the left side of the abdomen, by which the skin is tightly drawn until in apparent danger of 
bursting. It is caused by the rapid fermentation in the stomach of very succulent green food, which has been greedily swallowed while wet with dew or rain. The stomach may at the time be disordered, and its digestive powers impaired; or the distension may be produced by other diseases of which it is an attendant or a symptom. In such a case it indicates a decrease or chemical change of the alkaline secretions of the rumen. The treatment should be immediate, lest suffocation ensue. An alkaline fluid poured into the rumen, frequently alleviates the symptoms and removes the trouble. This may be

Ammonia Water (Aqua Ammonixe) ......... 1 teaspoonful.

Water................................

to be administered through a horn. A hollow, flexible probang, which should be kept for this purpose may be inserted through the gullet into the rumen, by which a means of escape for the gas may be made. The alkaline liquid mentioned may be poured into the stomach through the tube of the probang, or an opening may be made through the flank into the rumen with the trochar and canula, (fig. 74), or by a small bladed knife. This opening should be cautiously made at the spot where the greatest swelling is found. In the latter case a quill should be inserted into the hole to allow the gas to escape. If the passage be stopped by solid matter, a wire may be put through the quill to restore the opening. The ammoniacal liquid previously mentioned, or a solution of a teaspoonful carbonate of soda in quarter of a pint of water may be injected through the quill with a common syringe. Afterwards the following may be giren with the horn:

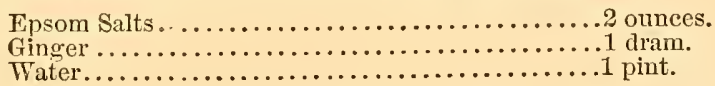

If the production of gas still continues, a dram of chloride of lime dissolved in water will tend to remove the gases generated by the now decomposing food.

Where none of these appliances are at hand, the following substitutes may be used, viz: Flour, lard, and salt, to form a bolus mixed with one dram of carbonate of ammonia, at the early stage, or one dram of chloride of lime at the later stage. Small boluses of this mixture to be placed on the root of the tongue or into the gullet, so that they may be swallowed. Sulphuric ether is sometimes given in doses of two drams each in cold water, it is a valuable stimulant and antispasmodic when the animal becomes rigid or convulsed. 
The after treatment should be tonic, and the food should be

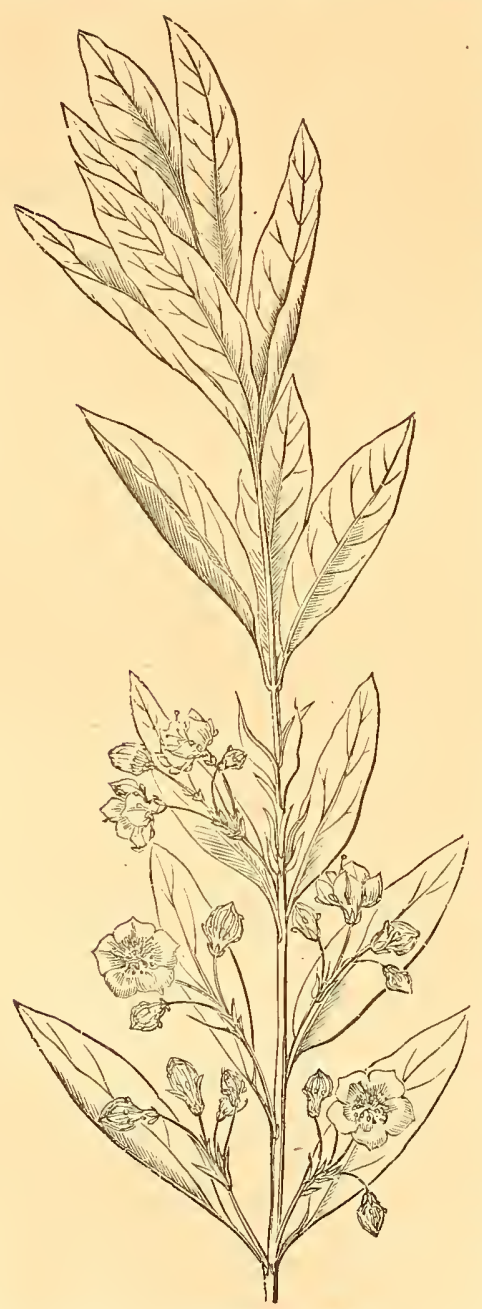

Fig. 75. - SHEEP-LAUREL. light and not bulky. Bran or oat-meal, scalded and well salted, and given with 1 dram of ginger would be useful. The return to copious green food should be gradual, until the stomach has regained its tone.

Poisoning. - At certain seasons sheep are tempted to devour injurious herbs or plants. St. John'swort, when frequent in pastures, produces sore mouth and irritation of the intestines, which quickly disappear when the sheep are removed to a more wholesome pasture. The Sheep-Laurel, Lambkill, or narrow-leaved Kalmia, (Kalmia angustifolia), (see fig. 75), is eaten by sheep which have access to it at certain seasons, chiefly during the winter and spring, and is often fatal to them. The symptoms of poisoning are disinclination to move, frothing at the mouth and nose, lessened pulse, staggering gait, and blood-shot eyes. Immediate attention should be given, as death generally occurs within twelve hours. To dilute the mass of poisonous food, and to expel it from the system as soon as possible, is the proper treatment. This may be done by 
giving two ounces of Epsom salts in a pint of warm water, and repeating the dose of water without the salts in an hour. Injections of warm soap suds will help to remove the injurious matter from the bowels. To prevent the danger of poisoning by carefully removing all injurious plants from the pastures or fences around them would be the obvious duty of the careful shepherd. The large leaved Laurel, (Kalmia latifolia), is also eaten occasionally by sheep. In England, the yew tree, which is common in hedges, causes the loss of hundreds of sheep erery year. Sheep should not be allowed to feed on pastures which have been dressed with gypsum, lime, soot, or any chemical fertilizer until after one or two copious showers have washed the herbage clean.

Inflammation of the Bowels.-This disease, (the braxy of the English shepherds), is not frequently met with in this country, except as an adjunct to some complicated inflammatory blood disease. It, however, sometimes occurs as the result of continued indigestion, or the consequence of feeding upon dry, innutritious pasture, combined with bad water in hot weather. The first symptoms are weeping and redness of the eyes, weakness and staggering, loss of appetite and rumination, inaction of the bowels, swelling of the flanks, high fever, and difficult breathing, a puckered up appearance of the mouth and nostrils, which gives a peculiar wo-begone and pained expression to the face; a tight skin and rapid emaciation. After death, the stomach is found filled with putrid food, and distended with gas; the bowels are gangrenous and in a state of decomposition; the liver is partly decomposed and filled with degenerated bile; the spleen is gorged with blood, softened, enlarged, and not unfrequently ruptured, ulcerated, and exhibiting a seriously diseased condition. The latter appearance seems to identify this complicated and fatal disease with the splenic apoplexy or Texan or Spanish fever of cattle. Death is often very sudden, many sheeep left in apparent health at night, being found dead in the morning; at the most, two or three days is the usual course of this disease.

To prevent it, when circumstances favor its appearance, an abundant supply of pure water and a cliange of pasture should be provided. Low grounds should be avoided, and everything done that can ameliorate the circumstances of privation in which the flock may be temporarily placed. It is not epizoötic, and the removal of the causes will prevent the spread of the disease. A supply of salt, mixed with one per cent each of sulphate of iron, ginger, and gentian, to be given every evening to the sheep on theil returu from pasture, will be a useful prevcutive. The treatment should con- 
sist of bleeding from the jugular vein, at the first appearance of the disease. Bleeding from the vein on the abdomen has also been practiced with success. Mild aperients-an ounce of Linseed or Castor Oil or Epsom salts-are useful, and should be followed by twice daily doses of one dram of Sulphite, (not sulphate), of Soda. The food should be liquid and demulcent, such as oat-meal gruel, infusions of linseed or solutions of gum arabic. Except the animal is a very valuable one, it will be hardly worth while to atlempt a cure in a case of serious character, as the recovery is slow, and the following debility is of itself often fatal, after a costly and protracted course of treatment.

Concretions of Foreign Bodies in the Stomach.-Sheep are sometimes observed to purposely swallow earth in small quantities. In pasturing green fodder crops or roots, much earth, and sometimes small stones, are swallowed. In eating hay, or other dry fodder, foreign matters, such as nails, pieces of wire, or glass, will sometimes find their way into the stomachs. All these matters cause much irritation, and sometimes death. The trouble is shown by a suspension of the appetite, the sheep lag behind the rest, stand for long pericds without moving, grind their teeth, poking ont the nose, and depressing the ears. When the flank is pressed a grunt of pain is heard, and there is violent purging. When these symptoins are observed, and the sheep are known to have been in danger of swallowing any of these substances, this cause may be suspected.

The only treatment that can be of use is to give daily closes of one ounce of Epsom Salts, and feed scalded bran or corn-meal in the shape of thick mush in order to remove the foreign matter with the food if possible. If this will not be taken, oat-meal or corn-meal gruel should be given copiously with the horn.

Balls of wool and eartliy matter are sometimes found after death in the stomachs. These are gathered by the sheep nibbling themselves when irritated by lice, ticks, or scab. Generally they exist without suspicion of their presence until death occurs, and in many cases without known ill effect on the animal. It would be safe to avoid possible danger in this direction by keeping the flock, especially the Iambs, free from parasitical and irritating insects.

Congestion of the Liver.- When sheep are highly fed upon stimulating food, and have but little or no exercise, the liver is apt to become gorged witlı blood. This fullness of blood is termed congestion. It is occasioned by disordered digestion, and when it exists to a serious extent, occasions further complications of this 
important organ. It produces constipation, dullness, and a yellowish tinge of the eyes. As soon as this latter sign appears, there should be no delay, lest inflammation supervene.

The treatment consists in giving an active purge, to be repeated every morning, until the bowels are in their usual healthy condition, the yellowness of the eyes has disappeared, and the appetite has returned. The purge may be the following, given in molasses placed upon the tongue :

Epsom Salts.............................1 ounce.

Calomel................................. 3 grains.

The patient should be supplied with slightly warm clrink soon after swallowing the medicine.

Inflammation of the Liver.-By neglect, the disease, last mentioned, may result in inflammation of the liver. When this happens the system becomes fevered; the nose and mouth hot and dry; the breath fetid; the ears cold ; the eyes pale and glassy; the pulse is irregular; breathing is slow, and the expirations short and sudden; the dung is dry, hard, black, and glazed with a greasy yellowish-green mucus; the urine is highly colored, scanty, hot, and smells disagreeably. Pressure on the right side, near the short ribs, produces pain, and the animal moans.

The treatment consists of purgatives and injections. For a purgative, the following may be given twice a day in infusion of linseed or gum arabic or in molasses, well mixed together and placed on the tongue:

Sulphate of Potash.......................2 drams.

Calomel.................................5 grains.

Powdered Opium......................... grain.

Irjections of warm water and castilc soap may be given until the bowels act freely.

When improvement occurs, and the appetite returns, great care in feeding should be observed, and only the most easily digestcd food should be given. Pulped sugar beet, scalded clover-hay chaff, linseed-meal, boiled malt, or sifted corn-meal, may be giren with linsecd tea for drink, or water acidulated with a few drops of aromatic sulphuric acid.

\section{DISEASES OF THE LLOOD.}

The blood being the very foundation of the life of the animal, must exist in a state of purity, or the vital functions are at once clisordered. Anything, therefore, that vitiates the blood or unfits it for the proper performance of those functions which here leca 
already explained, produces what is known as blood diseases, or diseases originating in and communicated to various organs by the blood. These may be classified as follows:

1. Diseases arising from an impaired, increased, or arrested function, or process, viz: rheumatism, plethora, anæmia, scrofula, dropsy.

2. Diseases called enzodiic because arising from animal poisons, originating either within the subject, or communicated by the same poisons originating in other animals, viz: influenza, dysentery, red-water, hearing or after paius, navel-ill in lambs, black-leg or quarter-ill or anthrax ferer.

3. Diseases arising from animal poisous of unknown origin, and which are highly contagious, and freely communicated from one subject to another, hence called epiroütic diseases, viz: Epizoötic aphtha, small pox.

Fortunately these diseases so fatal in their operation, and so uncontrollable in their course, are easily prevented by proper precaution and ordinary hygienic or sanitary measures. Also in the salt, sulplite of soda, we have a valuable remedy against those ferments which are the active agents in the majority of blood diseases.

Rheumatism.-This disease is attended with considerable fever, constitutional disturbance, and the presence of acid matters in the blood. It affects the serous menbrane, as the coverings of the joints, the substance of the tendons and ligaments, the enveloping membranes of the heart, lungs, spinal marrow, bones, muscles, and the brain. As it has a disposition to change its locality almost instantaneously, and to pass from one joint to another, or one part to another, (a process known as metastatis), and affects all these important parts of the body, the seriousness of the disease is evident. It consists in a peculiar inflammation of the parts affected which causes acute pain when they are called into action. When it passes from the acute to the chronic state, it causes serious changes in the structure of the joints affected. Its symptoms are general uneasiness and stiffness, a diminished or capricious appetite, and sometimes, suspended rumination. The dung is hard and scanty, and the urine is high colered and deficient in quantity. One of the joints is found hot and swollen; in an hour or two this is relieved, and another is found afiected. It generally attacks in spring those animals which have been half starved or exposed to cold or damp during the winter. Rams, which have been overworked the previous season, are often affected. Young ewes are rarely troubled with it. If not remedied by proper treatment, the 
animal suffers from continued fever, general prostration, severe pain and emaciation, and eventually dies miserably. The treatment consists of a moderate purgative at first, such as :

Epsom Salts........................... ounees.

Spirit of Nitrous Ether.......................4 drams.

Ginger .....................................

to be followed by

Sulphate of Potash........................ 2 drams.

Sulphurie Acid...............................20 drops.

Water................................

to be given dissolved in water night and morning. Protection from cold and damp, and soft, laxative food are required. Linseed-meal, either solid or made into gruel, is a useful addition to the food. As this disease is apt to become chronic, the patient should be fitted for the buteher as soon as possible. A rheumatic ram will beget rheumatic lambs.

Plethora consists in a too rapid production of blood, by which the system is engorged, and important organs become congested. It is caused by over-feeding with rich albuminous food, and is counteracted by a simple purgative, or bleeding from a vein on the face or the jugular. Its effects appear in a flushed condition of the visible membranes, labored breathing, staggering and sleepiness. It never occurs except in animals in high condition, such as those prepared for exhibition, and which in ease of over fatigue, or excessively hot and damp weather, suffer greatly, and sometimes fatally, from engorgement of the vessels of the lungs or train, or both.

Ancemia or Pining.-This term, "the bloodless condition," indicates the nature of the disease. There is a condition to which sheep may be brought by the effects of dysentery, or by parasites in the lungs or intestines, which much resembles this disease. But there is an abnormal state of the blood caused by imperfect nutrition, which is in itself a disease, and not a symptom. When from continued wet weather the pasture becomes rank and watery, the flock appears at first in an excellent and thrifty state, but in a few clays the animals are found lying listless, with drooping heads and ears, watery eyes, and the expression of the face miserable and painful. A few days afterwards the skin is tightly drawn, the wool becomes of a peculiar bluish east, the skin beneatl of a pearly white color, the eyes are also of a pearly hloodless appearance, and death is busy in the flock. On dry, rich clover pastures. the same effects are sometimes experienced. The disease never appears on steep, rocky hill sides, where the pasturage is short and 
sweet, nor on those pastures which are scant, but yet nutritious, and intermixed with coarse herbage; nor on lands that are abundantly supplied with lime. It is impossible to know beforehand whether the pasture will produce this effect or not, as it seems most probable that the geological character of the soil has most to do with it. But when once a farm, a pasture, or a field, is found to induce this ailment, sheep keeping may be abandoned upon it, unless the flock can be immediately changed to some other part of it where it will thrive. A change from a pasture field to a corn field, where the picking amongst the hills furnished but scanty feed, has been found to produce an immediate change for the better. No treatment, other than a change of losality, can be indicated, and if the farm does not supply this, the flock must be disposed of or removed. The disease unfortunately is not well understood, for it is sometimes found very destructive to lambs and yearlings, which are chiefly affected by it. It is frequently confounded with a parasitical disease hereinafter referred to, but a post-mortem exumination of a subject will easily identily it as being different from it as shown by the absence of parasites in the stomach, lungs, or air-passages. An adequate supply of supplementary food would of course act as a remelly, but the cost of this would defeat its object and render the flock unprofitable.

Scrofula-Tuberculosis.-This disease is almost surely fatal in course of time, although at first the sheep subject to it may be brought, by proper treatment, into condition for the butcher. It is a question, however, if the flesh of scrofulous animals can be safely consumed as food, but yet many such go yearly to the butchers to be thus disposed of. It would certainly seem that the use of such animals as food should be carefully avoided, and the sale of their flesh prevented as injurious to the public health, for no taint is more readily conveyed to the system than scrofula. It is supposed to consist of a diseased condition of the blood, by which the lymph, or white, serous, uncolored portion of it is unfitted to nourish properly the tissues of the body and to be built up into organized matter. Lest the accumulation of this imperfect blood should embarras the system, it is depositcd in various parts where it is productive of least inconvenience, and the nutrition of the body goes on, as well as it may, with the remainder of the blood thus separated from the useless and injurious portion. But it is frequently the case that there is not sufficient left to supply the waste of the tissues, and a gradual falling off in condition occurs. The symptoms of "consumption," a very significant term, as the chief organs are slowly consumed, then appear. The pulsa- 
tions of the heart are loud, so as to be heard on applying the ear to the ribs; the pulse is feeble, the appetite irregular, and a slight congh exists, cansad by the efforts to throw off the accumulating and offending matter from the lungs. In time, the giands of the body become loaded with the deposited matter; those of the throat and neck, the parotid and submaxillary, being most commonly and extensively affected, and greatly swollon. The symptoms gradually increase in intensity, and there is much fever and emaciation, with clischarge from the nose and eyes. The skin is tight and pale, and the body appears almost free from blood, as in anæmia. At this period there is no help for the animal, for death is only a question of time.

The treatment in the earlier stages is to administer some of the preparations of iodine, such as the following:

Iodide of Potassium.................... 5 grains.

or

Iodide of Iron........................ 10 grains.

to be finely powdered and mixed with molasses, and placed on the root of the tongue, so that it is swallowed. The above dose to be given daily. The latter preparation is to be preferred. The swellings may be rubbed daily with iodine ointment. No scrofulons animal should be used for breeding, as the disease is hereditary. High.bred sheep are the most subject to this discase, and "in-and-in breeding" tends greatly to produce it.

In some localities an enlargement of the glauds of the neck, similar to the disease known as goitre in mankind, is frequeut amougst sheep. This is supposed, doubtless with reason, to be caused by the water drank, as in such cases the removal of the flock to distant pastures has led to the disappearance of the disease. The occurrence of the symptoms above described, however, will be sufficient to indicate the true character of scrofula as distinguished from any acciclental swelling of the glands.

Jropsy consists in the effusion of a watery or serous fluid in the abdomen. It is accompanied with inflammation of the lining membrane of the abdomen, the peritoneum, from which the fluid is secreted. It is caused by feeding upon rank, succulent, watery herbage, by which the blood is insufficiently nomrished. A change to dry food, or scanty but more nutritious pasture, alleviates the disease at once. A cure is generally effeeted by the use of diuretics, aperients, and tonics. The treatment will be the administering of the following, or such others as may produce the desired effect : 
Nitrate of Potash............................ dram.

Sulphate of Soda..............................1 ounce.

Ginger.................................... dram.

If the animal is in low condition, the sulphate of soda may be replaced by the following, viz. :

Linseed-oil............................2 ounces.

\section{ENZOÖTIC DISEASES.}

Influenza.-This disease being due to causes which occur over an extended locality, is liable to affect a large number of animals at the same time. It is erroneously supposed to be infectious. It consists of inflammation of the nasal and bronchial passages, considerable fever, and great prostretion, with general disturbance of the system. There is redness and weeping of the eyes, running at the nose, cough, great weakness, loss of appetite, indigestion, with impaction and sometimes hoven, or distension of the rumen. It is prevalent after continued cold and damp weather, and is most severe where the ground is low and undrained, or in river bottoms or valleys, where morning aud evening mists abound. When these conditions occur, the flock should be kept on high, dry ground, or in dry, sheltered yards, and carefully protected. Their food should be somewhat improved, linseed-oil-cake or corn-meal, buckwheat, oats, or rye, being added. A dose of the mixed salt and sulphur, (1 quart of salt with 4 oz. of sulphur), should be given, and any ailing sheep should be well nursed and treated to warm gruel. These precautions will generally prevent a serious attack.

The treatment, when the disease becomes severe, is to give a light dose of some saline purgative, such as

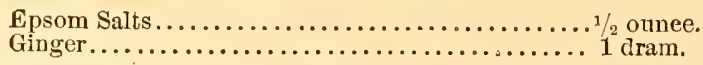

in a quarter of a pint of water, or mixed with molasses or honey. For a large flock the medicine may be mixed in bulk in proper proportions, and a quarter of a pint given to each sheep loy means of a horn. Those more seriously affected should receive the following, viz:

Tincture of Aeonite.......................10 drops.

Solution of Acetate of Ammonia.............. 1 ounee.

To be given every four to six hours, decreasing the aconite at each dose until five drops only are given, when it may be suspended, and only repeated in a: emergency

If the eyes are much inflamed, they should be washed with a 
solution of one grain of sulphate of zinc, and 20 drops of laudanum, in one ounce of water. After recovery, the feed should be laxative and nutritious; bran mashes, and boiled oats, or cornmeal mush, with a little powdered ginger or gentian, and a pinch of powdered blue vitriol, (sulphate of copper), in each mess, would be useful. If not readily taken in the food, this tonic may be given for a few days in honey or molasses. Shelter is absolutely necessary during treatment and recovery.

Dysentery may be distinguished from diarrhea by its more severe symptoms, there being much fever; the dung is mixed with blood and mucus, has a fetid smell, is discharged frequently, and is generally in hard lumps and scanty ; it is also voided with pain, and the sheep arches its back and moans in its passages. The wool feels harsh, and after a short time may be pulled off in handfuls. Sudden changes of pasture, from poor to rich, or from rich to poor; dry, indigestible food; scanty or impure water ; severely hot and damp weather such as produees rust in grain, and neglected diarrhea, are the chief causes. Where large flocks are kept on extensive ranges, the best course is to remove to some other pasture, where the water is good, the ground high and dry, and other favorable conditions abound. The treatment proper for this disease is to give a laxative in the first instance, as follows:

Linseed-oil...............................2 ounces.

Powdered Opium...........................2 grains.

to be given in linseed tea or oat-meal gruel. The linseed or oatmeal should be continued several times during the next twentyfour hours, both as nutriment and for its soothing qualities. The next day, and for several days, the opium should be repeated with one dram of ginger. An occasional dose of linseed-oil may be given if thought neessary. It can do no harm, in any event, if given every other day. The effect of a hot sun, in an unshaded pasture, is very aggravating to this disease. Sheep suffering from it should be kept, if possible, in a cool shed, and separated from the rest of the flock. A pasture that has been occupied by such sheep will certainly infect others that may feed upon it during warm weather, the dung conveying the poison to the herbage.

Red-Water.-When sheep are suffered to pasture upon stuceulent green crops, sucl as rape, mustard, or turnips, late in the fall or in the early winter, and the fodder is covered with hoar frost or sleet, or when they are forced to scrape their food from beneath the snow, swallowing a large portion of snow with their food, or when the stock water is drawn from filthy ponds or sloughs, they 
are subject to a peculiar disorder which often affects the majority of the flock quite suddenly, and is known as red-water. In this country this disease is rare, being kuown chiefly in the sonth-west and west, along with the last mentioned disease and some other disorders originating from exposure and unwholesome food or water, under the general name of murrain. The symptoms of this disease agree with those of a so-callcd " unknown and new disease" affecting sheep in the west, which las been described recently by correspondents of the Agricultural Department at Washington. The sheep affected apnear ciull and stupid, and stagger, carrying the head upon one side, the eyes are staring, and sometimes blind, and the bowels are obstinately costive. They die in a few hours. When opened the belly of the sheep is found filled with a red fluid wrongly supposed to be blood. There is also general congestion of the principal organs.

$\Lambda$ s a preventive, the use of salt is recommended, and a tablespoonful of pine tar given to each sheep every ten days has been found usaful. A pound of Epsom saits dissolved in water with two oz. of ground ginger, may be given to crery ten sheep. The simple removal of the causes and a brisk purgative or diuretic would doubtless lead to a recovery if given in time. When inflammation occurs from neglect, the bowels become afiected, and death is rapid. The peculiar nature of the sheep makes treatment at this stage almost hopeless, but if it is attempted, that prescribed for inflammation of the bowels would be proper.

After-Pains in Eves, or parturient apoplexy, arises in consequence of a feveris's condition at the time of lambing. It occurs about the second or third day, and its presence is shown by panting, straining, heaving of the flanks, a staring look, seanty and high eolored and strong smelling urine, costiveness, and swelling and redness of the external hinder parts, which finally become purple and black. After death the whole system is congested, and the veins filled with black biood; the uterus or womb, is charged with pus, the absorption of which poisoning the blood, is the cause of death. This disease is easily prevented by reducing the condition of the ewes when it can safely be done. The safe time is some weeks before lambing, when a gentle purgative should be given and the food gradually reduced. A bron mash with 15 grains of saltpeter may be given daily for a fer days. A very gradual course of clepletion only should be adopted. If, after lambing, trouble is anticipated, the appearance of the ewe should be elosely watched. If the pains occur, the following sedative should be given at once: 


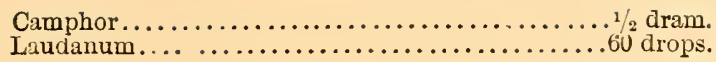

These are mixed with molasses and placed on the tongue; the dose may be increased one-fourth for large ewes when the pains are excessive. One ounce of soletion of acetate of ammonia may be given four hours afterwards, and repeated twice at equal intervals. If a fetic discharge takes place from the vagina, a solution of one dram of chloride of lime to a pint of warm water may be injected. The food of the ewe should consist principally of infusions of linseed or oat-meal gruel. Bleeding is injurious, $\ldots$ are also violent purgatives.

Black Leg, Quarter Ill, or Anthrax fever, is known as the "black spauld" of the English shepherds, the charbon of the French, and as one of the "murrains" of our western states, where it is most frequent in this country. It affects young and thrifty sheep, and is rarely found amongst old or poor stock. It appears in the spring or early summer, and also in the fall months; and mostly in wet seasons, when the pasture, under the fervid heat of the sun and unusual moisture, grows luxuriantly. Then the s'zeep, with vigorous appetite, gorge themselves to repletion, the digestive organs are orertazed, the blood is disorganized, and bcfore any trouble is suspected, the sheep drop and suddenly dic. When the carcasses arc examined, and the wool which leaves the skin at the least touch, is remored, the body is found to be strollen and blackened in lorge patches, chiefiy on the forequarter, the flank, or the hindquarter. Air is gathered beneath the skin, and on opening the body, it is found decomposed and filled with black blood. If the flock is then observed, some will be found lame and limping, and on examination the sides or quarters will be found swollen, and when the hand is passed orer these spots, the wool readlily comes off, and a crackling sound is heard from the motion of the air or gas collected beneath the skin. The mouth and tongue are found to be inflamed and blistcred, and the eyes red. The urine is dark, the bowels constipated, and the dung when discharged is bloody. By and by the animals are unable to stand, and fall upon the side, stretch out the limbs, and protrude the tongue; the belly is swollen, and in a few hours the sheep is dead. The disease is much worse in rich bottom lands, or moist, black suils, and rarely appears on hilly ground, or gravelly, dry soils. To prevent this disorder, it is only necessary to prevent the causes, to ensure regular feeding, and avoid sudden changes from poor to rich food or the rercrse. The treatment 
should be an immediate purgative. The following may be given in oat-meal gruel or any other thick mucilaginous liquid:

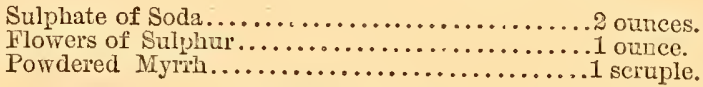

A teaspoonful of spirits of nitrous ether in a pint of water may be given in six hours afterwards. If taken at the commencement of the symptoms, this treatment will probably be effective, but if later, the uncertain remeclial action of nature alone can be depended on.

\section{EPIZOÖTIC DISEASES.}

Aphtha, or "foot and mouth disease," which has grierously affected the herds and flocks of Europe, is not unknown in America. Fortunately our drier climate, or some other preservative influence, has very greatly circumscribed the course of this disease. It has appeared in various parts of the country, but only sporadically, or in scattered cases, and never yet has it swept over an entire district. Nevertheless, no one can be sure that it never will so appear, and as an isolated case requires the same treatment as any other, it is well that the clisease should be described here. It is a true blood clisease, belonging to a class of eruptive fevers arising from a poisoning of the blood, and is highly contagious undcr favoring circumstances. It affects alike cattle, sheep, pigs, hares, and rabbits. It appears as an eruption of watery blisters upon the lips and tongua, and between and around the hoofs. The first symptoms are a fit of shivering, succeeded by fever, cough, and an increased pulse. This is succeeded by a failing of the appetite, tenderness over the loins, flow of saliva from the mouth, and grinding of the jaws. Blisters, small and large, appear on the mouth and tongue, which break and become raw, causing great pain. The feet are swollen and also covered with blisters, which break and become sore, causing the animal to walk with difficulty and shake its feet or kick or lie down persistently. In from ten to fifteen days the disease runs its course, in favorable circumstances, and the animal recovers gradually, and is never afiected afterwards. Otherwise the symptoms increase in severity, the sheep lose condition rapidly, from inability to eat or move about; the hoofs are sloughed off, and sometimes even the bones of the feet are cast off, leaving only a stump. In-lamb ewes when affected, abort. It is considered, where this disease is virulent, that the cheapest and most efiective plan is to stamp it out by the 
slaughter and burial of every infected animal, and the removal of those that are well. In the simple form, a single krisk purgative, such as two ounces of Epsom salts, witl a small quantity of ginger, generally results in a cure; to repeat the dose is dangerous. The mouth should be washed in the following solutiou twice a day:

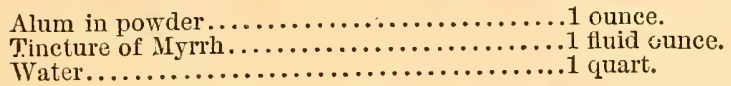

The feet, if affected, should be washed with soap and water, or with a weak solution of sulphate of copper, then clressed with carbolic ointment; and afterwards bound up im a cloth so as to keep sand or dirt from irritating the sensitive surfaces. Sulphur should be burned in the sheds as a clisinfectant and purifier, and the drinking water should be acidulated with one dram of aromatic sulphuric acid to a gallon of water. All sick animals shotild be isolated.

Sheep Pox, or variola, is a formidable and fatal disease, which is very frequent in the central and eastern parts of Europe, and has recently been introduced into England by means of importations of infected sheep. Although unknown in its severe type in this country, yet we have no security against its introduction at any day. It is recorded in a German publication that on one occasion every sheep in a whole district was swept off by this disorder, the sheep dying without any apparent reason, as though they had been poisoned. The only known preventive is artificial inoculation by means of lymph taken from one of the mildest cases. These conmunicated cases are exceedingly mild. The practice of housing sheep is very productive of this disease, and it is when sheep are kept in small flocks and well supplied with fresh air and general good care that the clisease makes no headway. Whenever our flocks shall be overcrowded, and poorly cared for, this disease may be apprehended. Sheep-pox is not identical with the human small-pox, but is yet of the same type, produced by the same canses, has very similar characteristics, and is equally contagious. It cannot, like that of the cow, be communicated to mankind, nor to other animals than sheep, even by inoculation, aud belongs exclusively to them. It is a true blood poison, caused originally by the absorption of impure matter into the blood, probably throngh the lungs, and the course of the disease is an effort of nature to throw off the poison by the eruptions which appear on the skin. There is a period of incubation of the disease, which lasts nine to eleven days after infection, and during which no symptoms whatever appear. After this the shecp sicken, rcfuse food, and 
suffer from quickened breathing, a hot, dry skin, an unquenchable thirst, redness of the eyes, and a discharge from the nostrils. At this period the eruption occurs on the body just as in the human small-pox. The bare skin under the arm-pits shows the first indications of the eruption. Pustules or pimples surrounded with a red ring, (the areola), appear, and gradually after three days, come to a head, and take on a white appearance. It is at this stage of the disease that the matter is collected and preserved for the purposes of inoculation. The symptoms decrease at this stage and the sheep improve. The pustules dry up and form scales or scabs which fall off and leare in their places "pits" or marks. But it may be that these pimples run together or become "confluent" and ulcerate. If this happens, the sheep almost invariably die. Otherwise the recovery is rapid.

Treatment by medicine is entirely unavailing. Good nursing of the patients, and the use of sustaining stimulants with laxative and demulcent food includes all that can be done. Linseed-meal, rice-meal, and oat-meal, made into drinks, and given warm, with a small quantity of sugar, or molasses and ginger, will be sufficient in the shape of food. Pure soft water made slightly warm, and acidulated with a few drops of aromatic sulphuric acid, should be given for drink.

Hopeless cases should be ended at once. If at the last stage the symptoms become worse, and the pimples, instead of becoming brown and drying up, ulcerate, and run together in chains, the animal should be killed and buried in a deep pit with plenty of lime thrown on the carcass. Every portion of the dead animal will convey infection, and in no case should the wool be taken from it, unless it be at once tub-washed in boiling hot soap-suds.

On the appearance of the disease in a neighborhood, the unaffected sheep should be inoculated. A quantity of the matter from tho white pimples is kept in bottles and diluted with water to the consistency of cream. A needle mounted in a wooden handlea shoemaker's curved awl will answer the purpose excellentlyis dipped into the fluid and is thrust beneath the skin of the fleshy part of the tail. This rarely fails to communicate the disease which is so slight as seldom to interfere with the feeding of the flock. In a paper published in the Journal of the Royal Agricultural Society of England, Vol. XXV, Part 2, 1864, written by a gentleman who had had charge of flocks of Merinos varying from a few thousand up to twenty-five thousand, in Russia, and who always practiced inoculation, the author states that although the sheep under his charge were constantly exposed to contagion 
from neighboring flocks, in which thousands died from neglect of this precaution, yet he never lost a single aduit animal from the disease. In those countries where the disease prevails, every shepherd has an inoculating needle amongst the implements of his profession.

As we are as yet exempt from this disease, and as it is readily communicated by contact with the skin or fleece of a diseased sheep, and with the present rapid communication between this country and Europe, an animal might easily reach here within its period of incubation, constant watchfulness should be exerted to prevent its importation. That we shall always be exempt, is too much to reasonably hope for.

\section{DISEASES OF THE URINARY ORGANS.}

The urine of a healthy sheep is alkaline. Under some circumstances the urine becomes acid. This abnormal condition produces a disordered condition of the highly sensitive urinary organs. If the flow of the urine is obstructed, it is absorbed into the circulation, and a variety of cliseases are produced, all of which have one constant distinguishing symptom, viz : the strong smell of urine given out by the other secretions of the system, but especially by the secretions of the skin. The blood is poisoned by the absorption of the matters which the urine should have carried off, and a high condition of fever is consequently produced. Male animals are more frequently affected than females, by reason of the peculiar structure and length of the urinary canal, already described. Fattening animals are especially subject to urinary disorders, and such need close inspection and great care.

Inflammation of the Bladder is the most frequent of the urinary diseases. Feeding upon second growth clover, which often contain loblia, St. John's-wort, rag weed, and other irritating plants; or upon excessive quantities of corn-meal, or drinking hard water, are the chief causes. The acid and consequently irritating character of the urine inflames the inner coats of the bladder. The inflammation spreads to the muscular substance around the neck of the bladder, and this is contracted, closing the opening.

Retention of Urine is therefore the direct consequence, and this involves the serious complications already mentioned. The symptoms are uneasiness, constant lifting the hind feet and stamping with them, spreading them out and straining in the endeavor to void urine. As the attempt is abandoned, the animal moans in pain. There is general disturbance of the system, fever, and costive- 
ness. The remedly is to bleed copiously from the neck and to give the following to a large animal.

Linseed-oil ...............................2 ounces.

Laudanum..................................2 drams.

For smaller animals the flose should be reduced proportionately. If there is no improvement the second day, the bleeding should be repeated from the other side of the neck, and one ounce of linseed oil be given daily until relief is procured. Diuretics and saline purgatives shonld be aroided. After improvement the food should be light, and infusions of linseed-meal or of gum arabic, would be useful.

Sediment in the Urinary Canal.-Highly fed sheep, or those fed on dry pastures, which are deficient in water, or those carelessly denied a full supply of water in winter, when they are fed grain in less or greater quantities-rams and wether's especiallyare those which are subject to this disorder. Females, from the large capacity of the canal, are never, or very rarely, affected. But in male animals the peculiar appendage, called the rermiform, or worm-like appendage, through which the canal finds its exit, being very small, an easy obstruction is offered to the passage and - clischarge of any sandy or muddy deposit of the urine. Small stony concretions are often discovered attached to the wool or hairs around the vent on the belly of the sheep. When these are noticed, extra care should be exercised to give abundant water by which the deposit may be dissolved and carried away. When the deposits have been arrested in this narrow passage, the urine is seen to pass drop by drop and the animal exhibits great pain and uneasiness. All the symptoms of retention of urine then appear. The treatment is to place the animal on his rump and draw the penis out of the sheath. It will be found inflamed and tender. It should be fomented with warm water, and the urethra or canal below it gently pressed with the fingers to force out the urine and with it the sediment. If this is successful even in part, some sweet-oil should be applied to the parts, and a rather large close of linseed-oil be administered along with an antispasmodic to act on the neek of the bladcler, viz:

Linsced-oil ........................... 3 ornces.

Extract of Belladonna...................... 10 grains.

On the following day the urethra should be again examined, and the manipulation be again repeated. One dram of Carbonate of Potash should then be given, dissolved in water, three times a dlay. If fever is present, the belladonna may be repeated, but only in case of urgency. No saline purgatives are to be 
given in affections of the bladder. If the sediment cannot be passed, it will be necessary to remove it by an operation. A lengthwise incision is made, with a small sharp knife blade, at the junction of the vermiform appendage with the urethra, on the lower surface, and the stones or gravel are removea by pressure. It may be discovered in this manner, that the obstructions exist all along the urethra, in which case there is no hope of recovery, and the animal may be slanghtered. In case of wethers the vermiform appendage of the penis may be cut off at once. In rams it may be saved if possible, although it is not absolutely nccessary for successful stock getting. It may be well, however, to be on the safe side, and save the part out of respcct to the generally accepted belief that it is needful. It is known, however, that many rams which had lost the part by this operation, dicl not lose their usefulness in consequence.

Calculi, or stone in the bladder. For this disease there is no remedy, and if after the fact has been ascertained by the previously described operation, or in any other way, the animal may be killed.

Clap or Gonorrhea.-This disease affects the sheath and penis of the ram The first symptoms are very similar to those of sediment in the urethra. There is great pain in urinating, and the urine comes by a few clrops at a time. In course of time a white acrid discharge escapes, and this, in case of neglect causes ulceration, which may destroy the organ. Rams thus affected should not be used, as the disease is contagious, and the symptoms are aggravated. The causes are excessive work and want of cleanliness. The treatment consists of turning the animal on its back, withdrawing the penis gently, holding it with a soft linen cloth wetted with the lotion mentioned below, until all the diseased parts are seen. The organ is then bathed and washed thoroughly with the following lotion, viz :

Spirits of Camphor. ..................4 ounces.

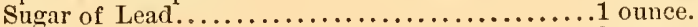

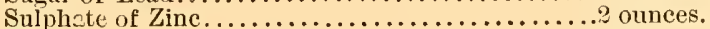

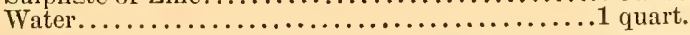

Mix and bottle for use. If any of the ewes have become cliseased by contact with a diseased ram, a soft linen cloth may be wrapped around the finger, clipped in the solution, and inscrted in the parts until they are thoroughly washed. Or a portion may be injected with a syringe. A daily dressing should be giren until a cure commences, afterwards twice a week will be sufficiert. One ounce of linseed oil should be given every other day until the urine passes freely. The food slould be lasative, and nothing stimulat- 
ing should be given until a cure is effected. Copious demulcent lrinks should be given, such as infusions of limseed, oat-mcal, or gum arabic.

\section{DISEASES OF THE BRAIN.}

Water on the Brain, (Hydrocephalus)--This is a constitutional fault which is prisent in the ewe, or the ram, nsed in breeding. It exists in the lamb at birth, and the head is generally so unnaturally enlarged that it is killed as not worth raising, or it dies before it has arrived at maturity. If there are many cases in a flock, the ram should be changed; if the ewes are at fault, they should be disposed of by feeding for the butcher. There is no cure, and an animal so deformed is a disagresable object at the best, and it should be destroyed at birth.

Apoplexy-Staggers.-Some of the high-bred sheep, the Leicesters more especially, as well as some native sheep that have been poorly kept and fed, are subject to occasional attacks of giddiness and blindness, in which they stagger about and run against walls, fences, or other obstructions, evidently unable to see. The attack comes on suddenly, the sheep stops and stands staggering, or still

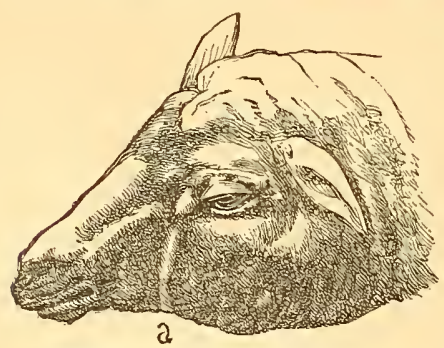

Fig. 76.-THE FACIAL VEIN. moves on its former course with eyes dilated and prominent, but unconscious of impediments. The appearance of the eyes and membranes shows that the vessels of the head are full of blood, and post-mortem examinations have shown the brain to be highly congested, and sometimes the vessels ruptired. Pressure of blood on the brain is the cause of these symptoms. Plethora from continued high feeding, or from indigestion or other disturbance of the condition of the digestive organs, produces this determination of blood to the head. Removal of the causes, depletion of high conditioned animals, by saline purgatives, or the restoration of the tone of poor conditioned ones by good food and tonics, tend to a cure. Bleeding from the facial vein ( $\alpha$, fig. 76 ), is often useful in extreme cases.

Inflammation of the Brain (Phrenitis). - The causes which produce apoplexy, if long continued, result in inflammation of the brain, and this produces frenzy. The affected animals are very 
violent, dashing hither and thither regardless of danger or damage to themselves. Lambs thus affected leap and throw themselves about as if in violent play, until they fall and die in convulsions. The only remedy is copious bleeding from the neck, and active purging with salts. In this case no accompanying stimulant is needed, and for a full-grown animal, the dose may be imcreased one-half above the usual quantity. There is always congestion of the brain accompanying this disease, and treatment must be instant, lest in the muscular excitement the vessels of the brain be ruptured and sudden death ensue.

Puralysis-Trembles. - This disease is a different manifestation of the effects of pressure of hlood upon the brain from the two diseases previously described. In this disease, in addition to the base of the brain, the spinal marrow and the nervous system connected therewith are affected, the congestion occupying a considerable portion of the vertebral canal. Its effects are varied. In some cases the animal loses the power over some of its limbs; the hinder half of the bodies oî some are rendered incapable of motion; in others, the sheep stands, trembles violently, with the head drawn back or to one side, the jaws are tightly closed, and froth is forced through the teeth and lips; the breathing is hurried, and the fit which lasts for a short time, recurs at short intervals. At other times the animal, which may appear perfectly well, will suddenly spring from the ground, scream, and fall dead. Others will fall deprived of motion, and remain sprawling, with limbs stretched out, until they die of starvation. The power of swallowing is gone, and there is generally very great difficulty of breathing in consequence of the affection of the pneumo-gastric nerve and the resulting paralysis or spasmodic condition of the muscles of the throat and chest. Animals in poor condition sub. jected to cold and exposure, suffer mostly from this peculiar form of disease.

The treatment proper to these varied cases, depends spon whether the patient is iu the active or collapsed condition. On the first attack, bleeding from the facial vein is the proper remedy, and generally gives immediate relief. But after the animal has passed through this stage, a condition of collapse follows, and inciead of denletion, the opposite course is necessary to be taken. foncs and stimulants are then needed. Warm milk or grucl, sweetened and mixed with ginger, followed by a teaspoonful of aromatic spirits of ammonia, or one scruple of carbonate of ammonia, mixed with gum water of cold linseed tea, shonld be given. If the bowels are constipated, a diss of linseed-oil (but no salts), 
should be given. The body may be swathed in a rag dipped in hot water, to which an ounce of ammonia water has been aduled. On recovery, the food should be generally improved in character, and a daily dose of one scruple of sulphate of copper may be given with some meal, or mixed with molasses and placed on the tongue. This disease is the most frequent one of the kind from which our flocks suffer.

Epilepsy is a very similar clisease to the preceding. It occurs chiefly in young or poor sheep which are turned out to feed early in the morning when the herbage is covered with hoar-frost or snow. The rumen being chilled, causes the blood to determine to the brain, and the animal becomes convulsed. No treatment can avail anything, but prevention is everything.

Lockjaw, which is a violent excitement of the nervous system, sometimes occurs in consequence of exposure to wet and cold, and sometimes in consequence of injury to the nerves through the violent twisting of the spermatic cord and vessels in the operation of castration. The jaws are closed, but can be moved laterally, and there is grinding of the teeth; the head is bent round, the neck twisted, and one or more of the limbs are rigid. In this condition the sheep may remain a day and then die, or if it remain longer it may recover. A warm bath, if the sheep is not too large, is useful; and the animal should be kept warm and in a quiet place. A dose of two ounces of Epsom salts shonld be given, followed by two drams of laudanum after two hours. Warm gruel, with a quarter of an ounce of ginger, should be given two or three times a day. Quiet and warmth are indispensable to a cure.

Pa7sy.-This disease consists in a total suspension of action in the nervous system, generally in consequence of exposure to severe cold and wet. Lambs that are thoroughly chilled by cold rain and winds, or newly shorn sheep similarly exposed, are the most frequent subjects. Ewes having heen exhausted by protracted labor, or by abortion; or newly dropped winter lambs, that have been neglected, also suffer from it. Heary feeding on mangels or watery roots has been known to produce it, and it has been stated recently that roots grown upon iand that has been heavily clressed with superphosphate of lime, have produced this complaint in several English flocks. It is very questionable if the p'sosphate has any direct agency in producing it. The sleep suffering from it lie totally helpless, the whole body being incapable of movement, the respiration is almost stopped, and the eye is dead looking and lifeless, the eyelids quivering occasionally. 
The treatment consists in the application of warmth, and a stimulant such as mustard or ammonia and sweet-oil rubbed on the brisket and the spine. The following dose may be given twice a day, viz:

Spirits of Nitrous Ether.................... drams.

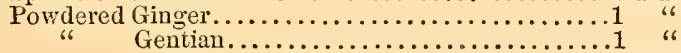

Warm drinks should be given at short intervals. If the animal is purged, the chalk mixture prescribed for diarrhea should be given. If the palsy is not relieved by this treatment, the following may be given:

Tincture of Nux Vomica....................4 drops.

$\mathrm{OR}$

Strychnine............................1/4 grain.

diffused in a quarter of a pint of linseed gruel, and the dose slightly increased, afterwards repeated. In the case of a valuable animal, this potent medicine should be given with great care, or only by a veterivary surgeon.

\section{PARASITICAL DISEASES OF THE INTESTINES.}

Parasites which infest animals are divided into two classes, in. ternal parasites called entozoa, and external ones which are called epizod. Since the natural history of microscopic animals and those which undergo changes only to be discovered by the use of the microscope, has become better known, much in regard to some peculiar cliseases of animals, is now understood. Formerly it was believed that spontaneous generat:on of minute animalculæ could occur, and that parasites were "bred" by diseased matter. What was then supposed to be the consequence of certain diseased conditions is now known to be the canse of them, and the whole subject of parasitical disease is in course of satisfactory explanation. But as yet there is much to learn, and the investigation of the subject is surrounded with diffieulties. The most important of all the internal parasites which injuriously affect the sheep is undoubtedly that known as

The Liver Fluke, the distoma hibaticum of Rudclphi, or the fasciola hepatica of Linnæus, which inhabits the gall bladder and ducts, and penetrates the substance of the liver. Its presence in this organ produces disorder of its functions and a diseased condition of the animal known as

The Rot, or the Liver Rot.-This discase has been the most dreaded by the shepherd for centuries past. It has carried off 
millions of sheep in a single year, in Australia and Sonth America, and is very prevalent in Europe. In 1830 two million sheep died in England of this disease. It exists in America both in imported sheep and the native flocks, and thousands die every year of it without their owners having knowledge of the cause. The symptoms of the disease are, however, very marked and signifcant. In

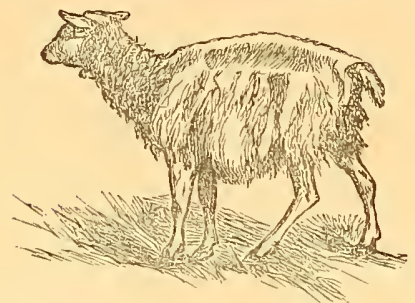

Fig. 7\%.-SHEEP AFFECTED WITH гот.

the healthy sheep the conjunctiva, or the membrane which covers the eyeball in front, and lines the eyelid, is brilliantly red; so mach so, that those unused to observe these things closely, would suppose the eye to be highly inflamed. When affected with the rot, the conjunctiva is pale and eyebalt yellowish. When this sign appears, and the sheep is found to

be ailing, it is certainly infested with flukes. There are other symptoms which indicate less certainly this disease, because they are found present in other ailments also, but this symptom is peculiar to this parasite. As the disease progresses, dropsy is always present, and a watery tumor or bag appears beneath the lower jaw. The skin is pale and bloodless, and the wool is dry, harsh, ragged, and readily parts from the skin. The skin is drawn tiglitly, and the spine is arched and prominent, as seen in figure $7 \%$. The appetite is irregular, and de-
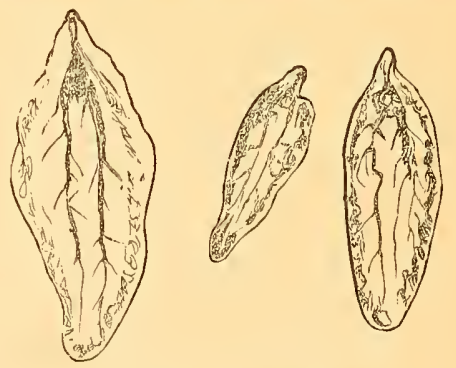

Fig. 78. - MATURE FLUKES. praved, and the thirst excessive. These symptoms increase until the sheep dies completely emaciated.

The fluke is a member of a family of sucking worms (similar to the leeches), known as distomæ. It is a flat, oval shaped animal more thickly conical in front, and has a sucker or mouth. Where the thicker part joins the flatter hincler part, there is a second sucker upon the underside. In figure 78 are shown the full grown flukes as taken from the gall ducts of a sheep, and in figure 79 are represented immature flukes from the same animal. The fluke is 
a highly organized animal. It possesses a branched intestinal canal and digestive organs, seen at figure 80, and a fully developed circulatory system seen at figure 81 . These figures are life-

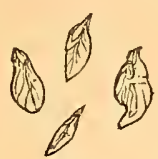

Fig. $\% 9$. size. The fluke possesses the porrer of self-impregnation should a second individual not be present for copulation. It propagates by means of eggs, which are produced in great numbers, and which pass with the bile into the intestinal canal, from whence they are roided with the dung of the sheep. The eggs need to be washed by rain or flood into stagnant water to become developect. The embryo, covered with ciliæ or arms-the locomotive organs-leares the shell and swims in the water. It is then believed, from our present knowledge of its habits, to penetrate the bodies of snails or other amphibious molluscs, and thus pass a stage of its existence. These soft-bodied molluses being swallowed by the sheep which graze in low, moist pastures, along with the herbage; the parasites contained in them are introduced into the stomach, from which they pass by the gall ducts, into the liver, and thus complete the ronnd of their existence. They collect in masses, sometimes closely packed in the gall ducts, obstruct the flow of the gall, and set up irritation, and thus produce jaundice, by which the membranes are colored yellow. At this first outset of the disease the sheep seems to thrive and make fat rapidly, but the fat is
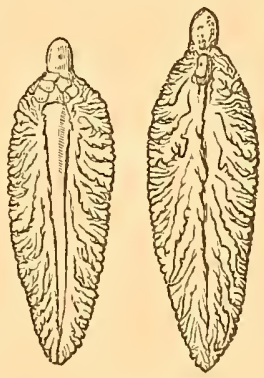

Fig. 80 .

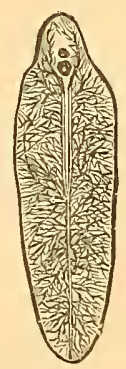

Fig. 81.

highly colored, especially that of the kidncys and brisket. Some English feeders have purposely exposed their sheep to the flukes to hasten the fattening. But this stage passeci, the structure of the liver becomes changed from the irritation and pressure; the gall ducts become enlarged into extensive cavities, which are filled with flukes and their eggs. The pain thus caused makes the animal restless and thin. The partial destruction of the liver, and stoppage of its functions, causes cliarrhea, dropsy, and the disorganization of the blood, which constitute the fatal rot. The course of this disease is rapid. At the latter end the whole system is deranged. The breath is offensive, a deep distressing cough with ferer racks the animal, the skin is covered with jellowish and 
black patches; the abdomen enlarges from the accumulated fluid; the animal is very weak, and lies with its head thrust out, solitary and separate from its fellows until it dies. On opening the sheep, the whole carcass is literally rotten. Yellow serum follows the knife everywhere, the abdomen being filled with it. The liver is found full of hard spots and ulcers, and the ducts filled with flukes.

The treatment eonsists wholly in prevention or in attention at the first stages. When the rot has become developed, no medicine avails anything. It is wholly and surely prevented by keeping the sheep on dry pastures and away from stagnant water. The fluke there can fiud no development. Low pastures should be drained, ponds fenced off, and well water used for drinking purposes. Hay from low grounds may even communicate this disease. When these preventive measures cannot be wholly carricd ont, the shcep should be abundantly supplied with salt, and on the first appearance of suspicious symptoms, the following mixture should be administered, viz:

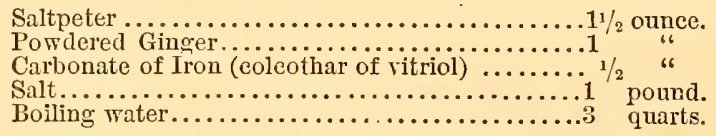

The above to be mixed, and when nearly cool, 9 ounces of spirits of turpentine are to be added. The whole is bottled in quart bottles for use, and when administered should be well sbaken to mix the ingredients thoroughly.

Infected sheep should be kept from food all night, and on the following morning, before feeding, each should receive two ounces (a wine-glass full) of the mixture by means of a horn. No food should be given for three hours. The medicine is repeated every fourth day for two weeks.

Sheep may live and thrive, and yet carry flukes. How many they ean tolerate without serious injury, is a question that will probably never be satisfactorily answered. It is proper that the shepherd should be always on his guard against them, for the reason that this animal is now known to he native in this country as well as in almost the whole world. Deer, antelopes, and hares have beeu found infested by them. A careful and trustworthy naturalist, Mr. Joseph Batty, a member of Prof. Hayden's exploring expeditions, has discovered over a hundred flukes in the liver of one liare in Minnesota. A fluke, of which figure 82 is a drawing from nature, reduced one-half, was taken by Mr. Batty from the liver of a deer in the winter of 1874-5. The liver in question 
was filled with them, and a number of them are now preserved in the museum of the Smithsonian Institute at Washington. The author found them (along with numerous specimens of strongylus

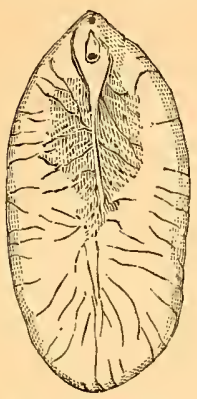

Fig. 8?.-FLUKE FROM A DEER. filaria in the lungs), in the flock of Southdowns belonging to Royal Phelps, Esq., of Babylon, L. I., and also in his own Cotswold, Leicester, and native sheep, which had been allowed to pasture occasionally along the banks of a stream, and to drink for a whole summer at a rumning spring in which many watereresses and other aquatic plants grew. In these cases the medicine above prescribed brought about an entire cure.

As the course of the disease is rapidly exliaustive, sheep that are affected should be well fed with nutritious and easily digested food; a pint per lay, for each sheep, of linseed-oilcake-meal mixed with bran, will be of the greatest service on their recovery, or as soon as the appetite returns.

The Lung Strongle.-The "lung thread-worm," (strongylus fil(ria), lives in the wind-pipe, the bronchial tubes, and the tissues of the sheep's lungs. It is a white, thread-like worm, from one inch to three inches in length. Its natural history is supposed to be as follows. The worms present in the lungs breed and preduce eggs, which contain fully developed young, wound up in a spiral form in a thin shell. These embryos soon leave the shell and move about in the tubes, causing great irritation and a secretion of mueus, upon which they feed and grow. It is not certainly known as yet if the sheep in the violent coughing caused by the irritation expels any of the eggs or young worms, and that they then pass a portion of their existence in the open air, finding their way into the lungs of fresh bearers by the trachea in the passage of the food through the mouth or gullet, or from the stomach in the act of rumination; or if the worm completes its whole existence in the lungs of its bearer. It is most probable that the former supposition is the true one, as it explains the fact that the worms are often found in young lambs in such quantities as to cause suffocation. Besides, it is known that flocks which follow other sheep upon pastures, or which feed upon fields that have been manured with sheeps' dung, have been aitacked with this disease. An interesting case in point is stated by a Pennsylvania correspondent of the Country Gentleman of March 25th, 1875. Some ram lambs were pastured in a field upon which their dams had been kept the 
previous year, and which had been top-dressed with manure from the sheep sheds. Nineteen out of forty of the lambs died. The following year twenty-three lambs died, and the post-mortem of the physician showed the fact that the laryin and trachea were covered on their inner surface "with a frothy mucus, generally white, but here and there of a ycllowish hue," also in this mucus were "several worm-like bodies about one-half a line in diameter, and from one to two inches in length." Under the microscope these proved to be articulates, some of which contained what scemed to be ova. A microscopic examination of the mucus showed these ova in various stages of derelopment. The worm-like bodies were undoubtedly the lung thread-worms under consideration. For several years afterwards the lambs which pastured on the topdressed meadows took the disease and cied. The symptoms which indicate the presence of this worm are a loss of condition, a constant and severe cough, a dropsical condition, as shown by the watery tumor beneath the throat, and a pining and wasting away. The skin is pale, and the eyes pearly, and bloodless. After death there is no sign of disease, except the presence of the worms in the lungs and windpipe, and complete emaciation. The means of prevention are obvious. Pastures or meadows should not be topdressed with sheeps' manure unless they are to be plowed and sown to grain crops, and if a pasture is found to be infected, it should be plowed up and re-sown. All sheep having the characteristic congh should be fattened and killed.

The treatment proper in this case is the same as that recommended for the liver fluke, and the mixture mentioned on page 222, should be administered as there ststed. Turpentine and salt are found to be almost sure remedies for interual parasites of all kinds, and extra feeding to resist the draft upon the system will be useful.

Hydatids or Bladder-Worms.-The association oi the dog with the sheep upon farms, is productive of much mischief in addition to the vast annual slaughter of the latter occasioned thereby. The great majority of dogs are infested with tape-worms. The eggs of the tape-worms discharged in the dung of the dog upon fields and pastures are swallowed by the sheep with the herbage, and the larval state of the worms is developed within their bodies, either in the lungs, the abdomer, or the brain, causing disease which is often fatal. The larvæ of the tape-worm exist in the shape of watery bladders, or sacs, which contain the undeveloped worms. These peculiar creatures are known as bladder-worms or hydatids. 
One of these occupies the abdominal carity of the sheep, and is called the

Diving Blwdder-20orm, Cysticercus t nuico'lis or C. tonia margina-
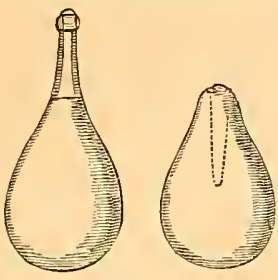

Fig. 83.

$t x$. These bladders are often free in the abdomen, are sometimes enclosed in the fat, and sometimes are attached to the liver and intestines. They are pearshaped, and in size from that of a wainut to that of a hen's or eren a goose's egg. These bladders or cysts, when fed to a dog, have produced the mature tonia marginata upwards of three feet in length in the course of three months. The eggs of this tape-worm have been fed to lambs, and have produced the hydatid, or bladder-worm, of which hundreds were found in the abdomen of some of the lambs, which died socn after receiving the eggs.

Figure 83 is a representation of the Cysticercus tenu:coll:s, with the head turned outwards, and with the head contained within the neck of the blaclder. Another of these hydatids is the

Many-hieaded Bladder-voorm, or Cysticercus tcenia echinococcus. -This finds a home in the lungs and liver of the sheep and other ruminants, and also infests mankind. Figure 84 is an illustration of the liver and lungs of an infected sheep. As many as several hundred cysts have been taken from one sheep. This is a most dangerous para-

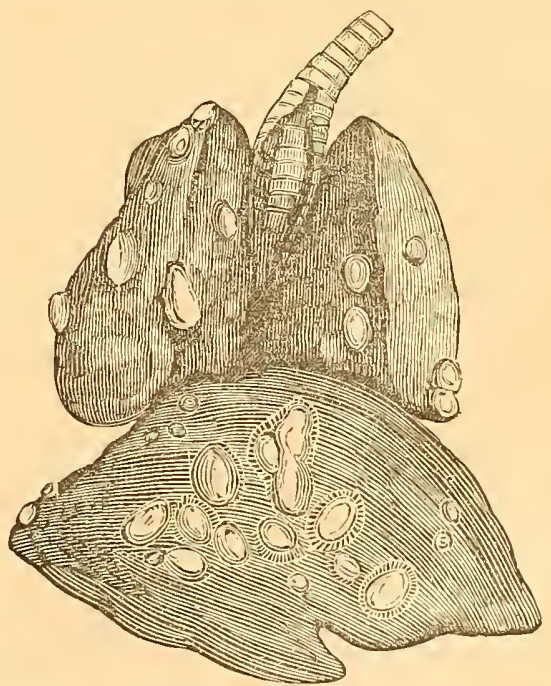

Fig. 84.-LUNGS INFECTED WITH IYDATIDS. site, for if taken into the human stomach, it may produce "bladders" in the brain, as it actually has done in well authenticated cases, which are certai ily fatal. The cysts reproduce themselves by a 
species of budding, and thus rapidly increase and spread through the bodies of their bearers. The most common of these hydatids is

The Brain Bladder-worm, or Cenurus cerebralis.-This produces the common disease known as turnside, or giddiness, in which the sheep turns its head to the left or right, and walks round and round in a circle in the direction in which the head is turned, until it falls giddy and exhausted. The presence of this parasite has been discovered in the liver of our gray squirrel, and in rabbits, as well as in numerous sheep in this country. In the sheep it is generally found in the brain, although it is not peculiar to that organ. It is only there, however, that it produces the usual disastrous effects upon the sheep. Figure 85 represents the
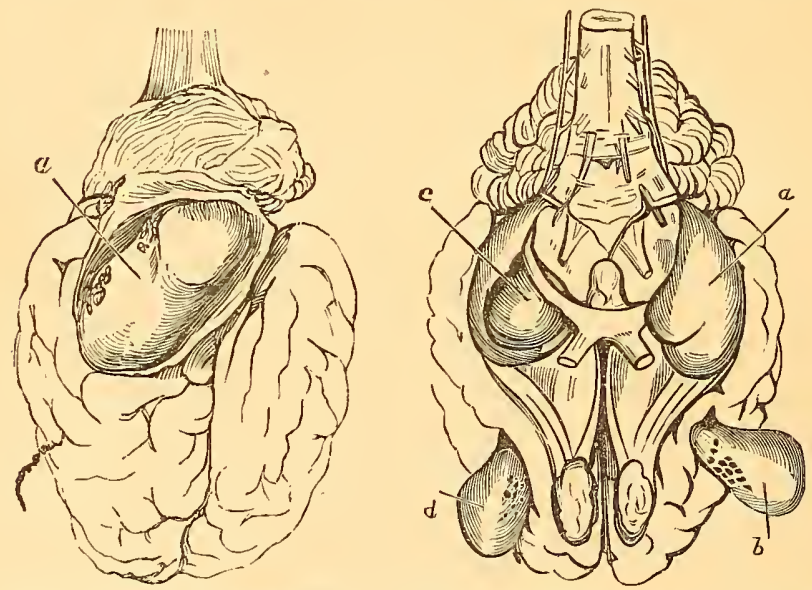

Fig. 85.-HYDATID IN THE BRAIN. Fig. 86. -BRAIN WITH FOUR HYDATIDS

brain infested with but one hydatid $(a)$; in figure 86 it has four of them $(a, b, c, d)$. In size they are from that of a pea up to that of a hen's egs. The hydatid is a bladder filled with a viscid fluid, and covered on its outside surface with marks or oval slits. These slits are the spots to which flask-shaped appendages are affixed within, and are the openings which lead to the interior of these appendages. On examination with a common pocket lens, a portion of the bladder appears as in figure 87. The appendages are the necks and heads of the immature tape-worms, each head having four suckers and a series of hooks which are characteristic of the mature creatures, and by which they afterwards attach them- 
selves to the coats of the intestines, while they suck the juices therefrom. These heads increase by a process of budding, and often amount to dozens, and sometimes hundreds in number. The pressure exerted by these bladders upon the brain, produces the peculiar symptoms exhibited, and the act of turning to one side or the other, helps to determine the seat of the hydatid in the body of the brain, which is found to be on that sicle to which the sheep turns. The natural history of this parasite is as follows: When the head of a sheep, containing the bladder-worms of this species, is

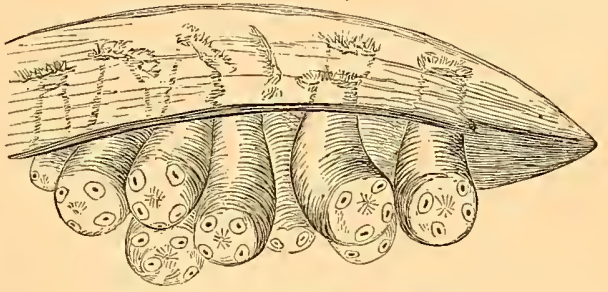

Fig. 87.-HYDATIDS MAGNIFIED. devoured by a dog, the larvæ are transformed within him into tape-worms. This worm (tcenia conurus) at maturity, or its eggs, being voided by the dog upon the grass of a pasture, are swallowed by the sheep, are hatched in its stomach, and penetrate all parts of the body, perishing everywhere except in the brain, which is its usual habitation. There they develop, remaining dormant, until chance favors their round again. Old sheep are rarely affected by this parasite, the lambs suffer chiefly from them. One infested dog will void thousands of eggs which not only escape with the dung, but being attached to the anus, are carried about and dropped in a multitude of places.

To prevent the spread of this parasite, it is necessary only to prevent the heads of affected sheep from being devoured by dogs or logs, or to keep dogs from the pastures. The heads of sheep dying from the disease should therefore be burned, and not thrown out. The treatment of sheep subject to the parasite consists in an operation by which the skull is pierced and the bladder punctured, when the water in it escapes and is absorbed, leaving the worm to perish. The pressure and irritation upon the skull causes some absorption of its substance, and a soft spot is cansed over the bladcler. This may be exsily felt by pressure of the finger. A curved awl may then be inserted through the skull and the bladder pierced; or hy means of a tubular saw (or trephine), a round piece of bone is cut out of the skull, a flap of the skin first being laid back, and the bone being lifted, the bladder is laid hare and removed. The skin is relaid and held in place by a stitch or plaster, and the 
wound heals. No other remedy than these is safe or certain, and these frequently fail. This class of parasites possesses some importance to the shepherd, not only from the loss occasioned amongst his flock, but from the dinger of the results to the consumers of mutton. The farmer's or sheplerd's own dog may be the means of injury to his flock, and he should take means to free the dog from the tape-trorms by means of proper medicines, of which the powdered areea nut is the most effectire, as well as to prevent vagrant dogs from stocking his pastures.

The areca nut is administered as follows. Previously, one scruple of jalap, for a $\operatorname{dog}$ of 20 to 30 pounds in weight, should be administered, and a brisk action of the bowels set up. This may also be procured by giving the dog a quantity of butter or any of the common purgatives. Immediately afterwards half an ounce of the powder of areca nut is to be giren in pills or in some acceptable food. Some locks of tangled wool dipped in grease or melted fat are given at the same time to be swallowed. The worm is killed or paralyzed by the areca nut, is entangled in the wool, and all together are expelled by the purge. The mass should be immediately burned or buried at a perfectly safe depth in the ground. Applied to every dog at intervals of three months, this treatment will free them from tape-worms, and prevent clanger of the sheep becoming infested with them.

Tape-vorms, (tonia plicatc), in the intestines. The sheep themselves are sometimes infested with mature tape-worms. This is easily explained by the possibility of the sheep swallowing along with their pasture some of the eggs which may have been voided by any of the numerous bearers of these worms, both domesticated and wild. It has been stated that the intestinal tape-worm is very rare, if not unknown, in sheep in this country. This would seem to be erroneous. A correspondent of the National Live Stock Journal of September, 1875, from Missouri, reported his lambs all dying of a strange disease in which the first symptom was a falling off in condition, followed by a mild diarrhea. This occurred in June, and continued up to August, when 30 out of 60 were dead, and nearly all the remainder were ailing. On examination after death, the small intestines were found "packed full of tape-worms." This can kardly be a unique case, and we may very well conclude that tape-rorm in the intestines is one of the parasitical diseases that we have to combat.

Generally the symptoms developed by the presence of tapeworms are voracity of appetite, alternating with a refusal of food; loss of coudition, desire to swallow earth, stomes, sand, or ashes; 
the passage of soft diung, mixer with mucus, which becomes attached to the vent and tail, causing a very filthy condition; and the evidence of internal pain. The sheep finally dies greatly emaciated. There is no means of prevention, as the eggs may be dropped by rabbits, squirrels, skunks, and other wild animals which frequent the fields. The treatment most cffective is to administer turpentine as follows :

Linseed-oil...........................2 ounces.

Spirits of Turpentine ..................

This should be repeated twice a week for two weeks. If this is not effective, 3 ounces of the Powdered root of Male Feru may be given. The dose to be repeated in one week. In six hours after this is administered, a purgative of linseed-oil should be given. The food shou'd be of the best kind until the lost condition is restored.

Tape-worms in any of their forms of life, affect only young sheep and lambs. When sheep attain the age of two years they are safe from them, and it is very rare indeed that one older than this becomes infested with them.

Huir-woorms in the Intestines.-A species of "hair-worm" called from its peculial formation tricocephalus, is not uncommon in sheep. It infests the stomach and intestines, causing obstinate diarrhea, and rapid wasting of flesh. Thess worms burrow their heads into the membrane lining the organs, and suck out the juices. The irritation produces diarrhea, which submits to no treatment while they remain. A cough is often present along with the diarrhea. Other species of worms, of habits identical with these, and producing the same injurious effects, also infest the sheep, but more particularly lambs and yearlings. Salt in doses of half an ounce, given on alternate clays with one dram doses of sulphate of iron, the salt being given on one day and the iron the next, is a very sure remedy for this class of parasites, and the diseases which result from their presence. To counteract the debilitating effect of these parasites, the food should be of the most nutritive and cigest.ble character, and linseed in some shape should not be omitted.

\section{PARASITES AND PARASITIC DISEASES OF THE SKIN.}

Of the epiroa or external parasites of the sheep, the most formiclable is the Scab inseet, or Aearus scabiei. This is a minute mite which attaches itself to the skin and penetrates the surface, lndging itself in the tissues and causing intense irritation or itching, 
and the secretion of a serous exudation which dries upon the surface and forms a scab. This disease was well known to ancient shepherds, and an exact description, was given by the poct Virgil in his Georgics. It is mentioned by the historian Livy, as being very virulent in his time. But up to a very recent date the cause of the disease was not correctly known. Youatt's work on the shcep, published in 1840, by the English " Society for the Diffusion of Useful Knowledge," states it to be caused by bad keep, starvation, over-driving, dogging, exposure to coll and wet, and other causes of a suppression of the perspirction. He mentions the acari as carriers of the clisease, but not as the cause. In an attempt to account for the origin of the insect, he makes the following remarks, which in the light of our present knowledge are a curious rolic of the ignorance which existed 40 years ago, and which has not yet quite passed away. "Physiolugists are beginning to acknowledge the working of a mystcrious but noble principle-the

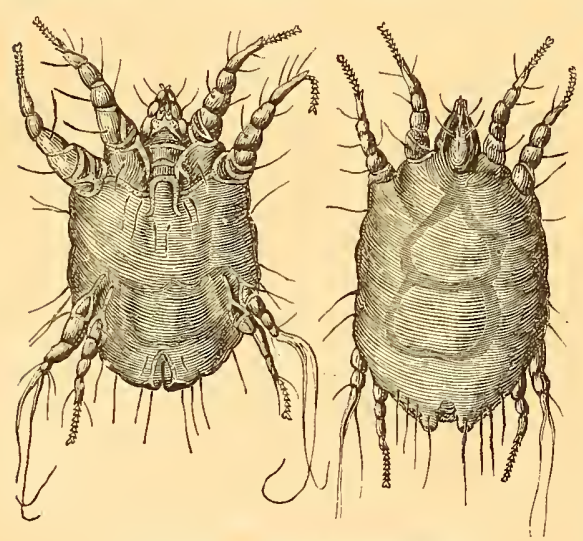

Fig. 88.-FeMaLE SCAB INSECT.

springing up of life under new forms, when the component principles of previous beings are decaying, or lave seemingly perished. Thus, if we macerate any vegetable substance, the fluid will teem with myriads of living beings, called into existence by the process we are conducting, or rather by that power of Nature, or that principle which was bestowed by the author of Nature, that life ceasing in one form shall spring up in others, and this while the creation lasts. Thus we have probably the liydatid in the brain of the sheep, and the fluke in its liver; parasitical beings, which we recognise in no other form and in no other place. They were the product of the disease of the part. In like manner the acarus of scab may be called into existence by the derangements which our neglect, or unavoidable accident, or disease, may have made in the skin of the sheep. Scab may bc, and is, of spontancous ori- 
gin, as well as the product of contagion; and the acarus, having sprung into life within the pores of the skin, obeys the laws of all living beings as to its after existence and multiplication."

It shows with what cantion speculations shculd be indulged in, and how much safer it is to say "we do not know," than to hazard explanations which may be wide of the truth and misleading. It has long been known that the origin of the existence of all animal life is an egg produced and fecundated by parents, and the scab-mite being no exception to this law, comes forth from an egg and springs into life just as a chicken does. In both cases the egg is deposited and hatched, and produces the mature animal. The female scab insect, seen at figure 88 , is larger than the male, which is shown at figure 89, magnified 2,500 times. One male suffices for many females, and is longer lived than the female. The latter clies after producing her eggs, which she deposits in the pores of the skin, or in the furrows of the scab which she has helped to produce. Her eggs are numerous, and being hatched in three days, her progeny increase rapidly. One female acarus can produce a million and a half of progeny in 90 days. This facility of increase explains the rapidity with which the disease spreads through a

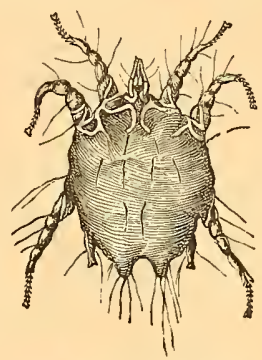

Fig. 89.-MALE SCAB INSECT. flock, and proves the necessity for instant and energetic remedies or effective preventives.

The symptoms first observed are restlessness and uneasiness, and the observant shepherd will have his suspicions aroused and search for the cause on the first appearance of these symptoms amongst his flock. As the disease progresses, the sheep are found rubbing or scratching themselves, or biting or nibbling amongst their wool. The attention should then be directed to the parts rubbed or bitten. If seab is present, the skin will be at first white in color and of a thicker texture than the rest, and moist or covered with a yellow exudation. Later these parts are covered with scab and the wool falls off or becomes loose. If a lock of this wool be laid upon a sheet of white paper, the mites will be scen with the unaided eye, as they crawl from it. If the disease is neglected, the scabby spots enlarge and increase in number, the wool appears ragged all over, and falls off in patches. Upon these bare spots dense brown or yellow scales are seen, and if the shcep can reach a fence or a post, the scabs are rubbed until they bleed and be- 
come sores. The condition of the sheep falls off rapidly, and it becomes a wo-begone object, such as is shown in figure 90 .

The treatment is by dipping in a liquid which penctrates and softens the seab so that it can be removed, and which poisons the insect. There are many preparations used for this purpose, some of which are objectionable on account of their poisonous properties, such as mercurial or arssuical compounds, and which are no more effective than the following perfectly safe one. This consists of tobacco and sulphur in the proportions of four ounces of the first, and one of the second, to the gallon of water. The water is brought to a boiling heat, and the tobacco, either coarse cheap leaf or stems, which are equally good, is steeped, (but not boiled), in it until the strength is exhausted. The sulphur is then

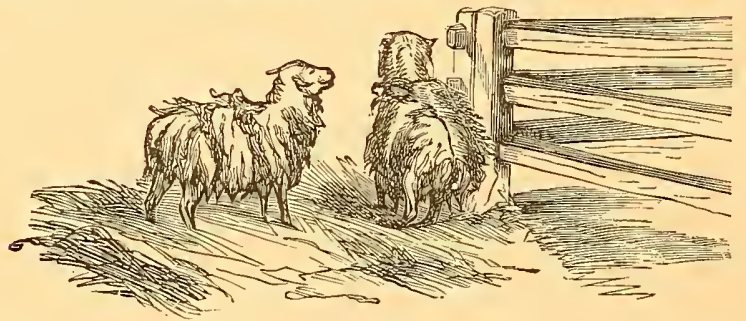

Fig. 90.- SHERP AFFECTED WITH SCAB.

stirred in the liquid. When it has become reduced in temperature to 120 degrees, it is ready for use. The sheep are entirely immersed in the liquid so that the wool is completely saturated. Hard crusts of scab are broken up and removed with care, and the raw surfaces are well washed with the decoction. The dipped animals should be kept in a yard until the wool no longer drips, lest the pasture should be fouled, and the sheep sickened by the tobacco juice. After ten days the dipping is repeated to destroy any newly hatched mites. With care the most badly infected locality may ba completely freed from this pest, and it will never appear if the sheep are dipped twice each year as a preventive. The gain in the growth of wool and in its improved quality will more than repay the cost of the operation. (See page 48.)

The Sheep Tick (Melophagus ovinus), has been already referred to (page 48); if the process of dipping, just described, is regularly practiced, this parasite will be easily ranquished, and its annoying presence prevented. This insect propagates only by single eggs, or rather the perfect pupa is expelled singly from the female, 
which is therefore termed pupiparous; it does not, therefore, increase very fast, and is easily kept under. It is too well known to need minute description, its dark red, tough, leathery-skinned body being a most conspicuous object, when the wool of almost any sheep in the country is examined. The pupa and mature sheep-tick, greatly.magnified, are shown at figure 91.

The Sheep-louse (Trichodectes oris), is known as the red sheep-louse. Its head is of a red color, and the body pale yellow, marked with dark bands. It is found on the side

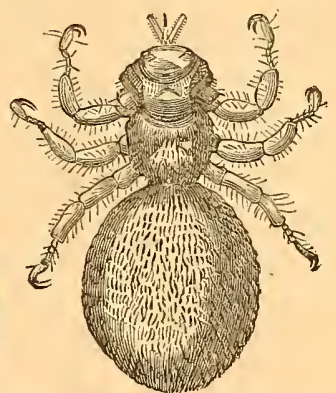

Fig. 91.-SHEEP-TICK AND PUPA. of the neck of the sheep, and the inner parts of the thighs and arms. It causes much irritation, by which the sheep is impelled

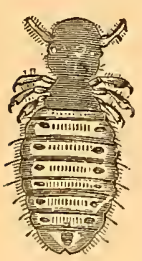

to thrust its head between the bars of gates or fences, or to kick and stamp with its legs. Occasionally sheep are found strangled by becoming fixed in their attempts to rub their necks, or with their legs broken in attempts to rub them upon rails. Lice are rarely found on the yolky wooled sheep, but on the drier fleeced breeds they often cause much unsuspected mischief. Those sheep which are regu-

Fig. 92. larly dipped, are also free from this pest. To rub SHEEP LOUSE. the parts mentioned with the following preparations is gerierally an easy remedy.

Lard... 1 pound.

Flowers of Sulphur..............................2 ounces.

Creasote..............................20 drops.

one pint of sweet oil may be substituted for the lard. This louse is small, and the illustration, figure 92, is of one highly magnified.

The Shcep Gad Fly (Estrus ovis).-This is a most troublesome pest, causing much discomfort to the sheep. It is a fly with two wings spreading over one inch, and a stout body over half an inch in length. In the summer months they disturb the sheep in the pastures by the efforts they make to deposit their eggs upon the animal's nostrils. When they succed in their efforts, the sheep often becomes half frantic, and races violently over the pasture, sometimes seriously injuring itself by bccoming overheated, Where the fiy abounds, the sheep crowd together and stop feeding, holding their noses to the ground, and stamping with their 
fore feet. The grub, when hatched from the egg, crawls up the nostril, and lodges in the sinuses of the head, where it lemains feeding upon the mucus secreted by the membranes, until the following spring. In entering the nostrils and in leaving them, they cause much irritation to the sheep. The remedy lies in preventing the fly from laying its eggs, and this is done by smearing the nostrils of the sheep with tar, diluted with grease or butter. This is both distasteful to the fly and fatal to the egg. By preparing a pailful of the mixture, and smearing the noses of the sheep with a brush, as they pass one by one through a half opened gate, every morning during fly time (July and August), the sheep will be spared much annoyance. When grubs are erawling down the nostril early in spring, they may be quickly dislodged by blowing tobacco smoke into the nose through a pipe.

The Maggot, so called, is a formidable enemy of the shcep. It is the larvæ of the common flesh fly (Sarcophaga carnaria), the blue-bottle fly (musca Cesar), and the meat fly (musca vomitoria), all of which cleposit their eggs or living larvæ upon clecaying animal matter. When sheep are wounded by accident, or are ailowed to become filthy when troubled with diarrhea, these eggs or larvæ are deposited in vast numbers; the ovaries of a single Sarcoph $\alpha$ gus having been found to contain 20,000 eggs. The maggots soon become active, and spreading from their quarters, attack the skin, which they irritate and cause to secrete a serous fluid. In time the skin is pierced, and the flesh suppurates and wastes away, being devoured by the multitude of maggots which crawl upon it. In wet seasons the mischief is greatly increased. To prevent them it is necessary to carefully remove the wool from about the tail so that filth may not gather; to wateh for ary accidental wound; and in warm wet weather, for any dirty tags of wool upon which the flies may deposit eggs. In case any maggots are found, there is no better application than common crude petroleum, or whale-oil, both of which are repulsive and fatal to fly and maggot. A sheep that is "struck" with maggots will remain separate from the flock, and may be lost sight of mless the flock is counted at least once a clay, and the straggler found. Weaning time, when the ewes may suffer from caked udder, is an especially critical period, and then extra watchfulness is called for.

\section{DISEASES OF THE FEET.}

Sheep are subject to many disorders of the feet. The structure of the sheep's foot is different from that of the horse. It possesses 
no laminæ which conneet the outer crust or horn with the sensitive parts within, but the crust is connected with the bone by a vaseular structure, by which it is also secreted. The growth of the hoof of the sheep is not from the coronet downwards, as in the horse, but from the whole inner secreting surface. In this lies both the weakness of the sheep's foot, and the rapidity w:th which repairs are made, when it is injured or cliseased. The wall or crust surrounds the outside of the foot, and turns under at the edge of the sole and toe, and it is impossible to distingush where the crust ends, and the sole begins, both being so much alike in structure. The crust is harder and tougher than the sole, which is soft and elastic, like India rubber. As the foot wears down by contact with the ground, the crust is worn off to a sharp edge upon the outer margin; when the wear and growth balance each other, the foot is in perfect condition; but when either is greater than the other, the conditions of disease are at once established, and unless remored by proper treatment, lameness occurs.

Anotlier peculiarity of the sheep's foot is the interdigital canal, which commences in a small opening about one inch above the foot, passes downwards and backwards between the toes and ends in a ponch which is curved upwards upon itself. The canal is covered with hair, and is studded with glands which secrete an oily fluid. This fluid overflows at the opening, and moistens the skin between the toes, preventing chafing and soreness. The peculiar structure of the foot of the sheap, under unfavorable circumstanees, gives occasion to several serious diseases. Of these the most frequent and important is

Foot-rot.-This disease is contagious, and may spread through the flock, if preventive measures are not taken. It consists of an inflammation of the whole hoof, the formation of blisters upon the heels and between the toes, which break and form discharging surfaces, and in a few days, ulcers, which suppurate and excrete feticl matter. The fore feet are the most usually affecterl. When this happens the sheep may be observed to go around feeding painfully upon their knees. If no attention is given, the hoof is lost in course of time, and a wounded stump only is left. It is caused at first by wet pastures in which the feet become foul, the horn becomes detached under the sole, and harbors filth which softens the sole, and influences the vascular tissue beneath it. Neglect completes the conditions under which the discase occurs. The treatment should be immediate on the appearance of the first lameness, for when the ulcerative stage has arrived, the cure is long and diffieult, the whole condition of the animal being 
involved. As soon as lameness is perceived, the sheep should be examined. All raw, loose, or diseased horn should be cut away with a sharp knife; any excessive growth of horn at the toes should be removed, and if any pus or matter is found beneath the horn, that should be pared away until it is all exposed. The feet should then be washed clean with carbolic soap and water twice a week, and after each washing a piece of tow or lint dipped into the following mixture whould be bound on the foot and between the digits, viz:

Oxide of Copper..........................4 ounces.

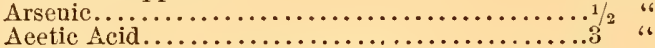

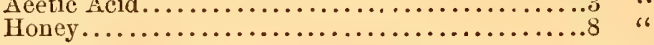

Or the foot may be thoroughly smeared with the following ointment, viz:

Finely Powdered Blue Vitriol................. pound.

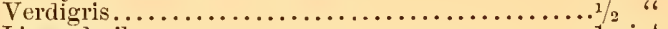

Linseed-oil................................

Pine Tar.....................................

This will dry on the foot and will not be washed off by the wet grass as a solution would be.

The following remedy is in general use amongst French and German shepherds :

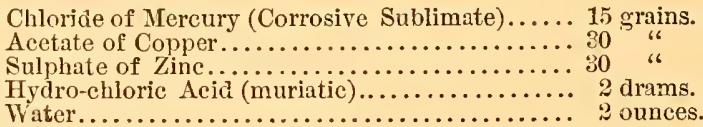

The diseased parts to be touched daily with a feather dipped in the above solution. In case the disease has made considerable progress, and the sheep are found feverish and generally ailing, each sick one should receive, according to circumstances, a dose of one to two ounces of Epsom salts dissolved in half a pint of water. A.t the expiration of two days the following should be given, viz:

Nitrate of Potash $\ldots \ldots \ldots \ldots \ldots \ldots \ldots \ldots \ldots \ldots \ldots \ldots$. $1 / 2$ ounce.

Flowers of Sulphur..........................

mixed with molasses and placed on the tongue until swallowed. This may be repeated once a week until the feet are well.

When the disease becomes virulent, the foot is swollen, sinuses are formed, and nlceration progresses until the whole foot is deeply involved, and the sheep iails to eat, loses flesh, and is in a condition of fever from blood poisoning by the absorbed matter. 
The case is then often unmanageable except at greater cost than the value of the sheep. Fortunately sucl a termination rarely occurs, unless through great neglect or the most unskillful management. In such a case the foot should be washed, the loose and separated horn removed with care, and the foot poulticed with a warm carrot or turnip poultice twice a day for three days, and the following should be administered at once :

Epsom Salts.............................

Laudanum.................................

After the feet have been cleaned by the poultice, the treatment before mentioned should be continued until recovery is made. The patient being unable to move without great pain, shouid be kept in a pen with a clean floor free from straw or chaff, or anything that would irritate the foot or convey infection elsewhere.

A method recommended by the Hon. H. S. Randall, who has snccessfully treated many of his own flock in this manner, is to procure a large tub or trough in which three sheep can stand at one time, and to pour into this tub a hot saturated solution of blue vitriol (sulphate of copper), until it is four inches deep. The sheep having liad their feet washed, and all loose horn pared off, are placed in the tub on their feet and held there by an assistant. The first sheep is kept in the foot-bath until the fourth is ready to go in, when it is taken out; when the fifth goes in, the second is turned out. Thus each sheep remains in the bath about ten minutes, giving time for the solution to penetrate every part of the cliseased hoof. After the bath, the sheep are kept in a dry grass field. One application of this remedy served in every case, to make a complete cure. This troublesome disease is rarely known in this country upon dry pasture, and generally yields at once to a simple paring of the feet and shortening of the overgrown toes, a cleansing from all filth or irritating matter, and a dressing with an astringent ointment such as the first above mentioned.

Common Foot-rot or Gravel, is not contagious, and being the result of accidental circumstances, is cured by their removal, together with simple auxiliary treatment. It consists of an inflammation of the intemal parts of the foot, the formation of matter, its escape at the $10 p$ of the hoof, the separation of the horn or crust from the cliseased parts, and as a matter of course, extreme lameness. It is caused by an excessive wear of the crust of the hoof upon stony, gravely pastures, or by excessive growth of the crust or toc, in low moist meadows. In either case, foreign matter enters between the crust and the sole, and pressing upon the scnsitive 
parts beneath, causes inflammation, which not being at once remedied, increases with the above results. The means of prevention are obvious.

The treatment consists in removing the offending matter with great care and tencerness by means of the knife or a small probe, as a knitting needle or wire, cleansing the foot, and washing it in astringent and antiseptic solutions, such as the following:

Chloride of Zinc........................

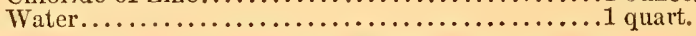

sulphate of copper or sugar of lead may be substituted for the chloride of zinc. In very bad cases the treatment for malignant foot-rot should be adopted. Removal from wet pastures is necessary to a cure, and for some time afterwards, or the trouble will quickly recur.

Epizoötic aphtha (foot-and-month disease), is highly contagious, and will rapidly spread through a flock. It affects the feet as well as the lips and tongue. The treatment has been already described in this chapter.

Inflammation of the Interdigital Canal.-This is of frequent occurrence when sheep are driven upon sandy or dusty roads, are pastured on sandy lands, or are permitted to lie in muddy yards. Offending matter enters the canal and causes inflammation, which spreads to the interior of the foot, and results in swelling and great tenderness. Removal of the irritating matter by means of a sinall probe or the trimmed end of a feather dipped in oil, and bathing the foot in warm water and vinegar, are generally sufficient to remove the trouble. When sheep become lame, and the foot is found hot, with no sign of outward cause, this may be at once suspected.

Canker of the foot is a very obstinate disease. It consists of inflammation of the sole of the foot, which gives way to a growth of spongy sprouts instead of the natural hoof, and a discharge of white curdy matter which has a most offensive odor. It is a similar disease to thrush or canker of the frog in horses. The most frequent causes are folding the sheep in yards or sheds, where the dung is allowed to collect in a mass which ferments and heats, and from neglected cases of common foot-rot or inflammation of the interdigital canal.

The treatment consists of the removal of all the separated hoof at the first and every future dressing, along with any that may appear sound, lut has dead offensive matter beneath it. The foot should then be washed in a solution of one dram of chloride of 
zinc in a pint of water, and a pledget of tow or lint dipped in a mixture of one part of common (not fuming) nitric acid with three parts of water, should be applied to the whole of the cankered surface. This should be repeated frequently, until a cure is made.

\section{LAMBING AND DISEASES CONNECTED WITH IT.}

The number of lambs raised in proportion to those that are dropped is far less than it ought to be. Probably ten per cent of the lambs annually dropped, are lost through negligence or want of simple methods of protection. Many are lost through neglect of the condition of the erves. The lambing season is one that calls for great patience on the part of the shepherd, rather than for great skill. A well disciplined flock, well provided with shelter and quiet retreats for the ewes, will raise a larger proportion of lambs than a neglected one. Dogs about a flock at lambing time are an unmitigated nuisance, and cause many losses. When the lambs begin to drop it is not difficult to discover those ewes that will come in, in twenty-four hours. The parts become red and swollen, and the ndder swclls and fills. It is at this period that the ewes need close watching, both to discover anything that may go wrong, and to render assistance when it is needed. If the ewes have been carefully tended, there is rarely any difficulty encountered that may not be orercome by simple measures, yet amongst the most carefully tended flocks there will be some occasional cases which will call for the treatment herein described as applicable to the disorders mentioned.

There is rarely any necessity for manual assistance to the erres at lambing time. Sometimes in cases of protracted labor it will be necessary for the shepherd to ascertain if the lamb is in proper position, with the fore feet and head first; if it is, the ewe may be left alone with safetr. If the position is nnnatural, help should be given by an experienced shepherd. If no aid can be obtained, it is dangerous for an inexperienced person to assist, lest he may be too hasty and rough in his help. If the lamb is presented in such a manner that it cannot be expelled, it should be gently forced back agair by some person with a small hand, the hand being smeared with sweet-oil. It should then be gently brought into such a position that the feet shall be presented first, with the head lying upon them, and not doubled back. If the hind parts are presented, the feet should be gently brought up after the lamb 
has been pushed back. If the placenta or after-birth has not come away in due season, it may be gently pulled by the hand, when it will be generally expelled in a short time. If the ewe is weak, a little warm gruel, sweetened and flavored with ginger, may be fed with a spoon or given with a horn. It is the poor, lean, badly kept ewes which suffer most in lambing; those in good condition, or even fat, rarely experience any difficulty.

Parturient Fever rarely attacks our native sheep, but imported sheep are sometimes subject to it. It generally occurs within a few days of lambing. The first symptoms are refusal of food, twitching of the hind legs and ears, dullness and stupidity; the head is carried down, the eyes are half closed, and a dark colored discharge fiows from the vagina. If the lamb is now dropped it is dead, but the ewe, if kept quiet and well nursed, will generally recover in two or three days. But if the lamb is not then expelled, the symptoms grow worse, the ewe suffers from fever, and moans with pain, and the discharge is very offensive. The lamb, if expelled at this stage, is in a high state of putrefaction, and the ewe falls into a condition of collapse, from which she rarely recovers. If the lamb is not expelled, the ewe dics.

The treatment should consist of the removal of the ewe from the floek to a quiet pen, on the first appearance of sickness. She should be well cared for, and fed with warm gruel of linseed or oat-meal. As soon as the dark colored discharge occurs, the lamb is almost certainly dead, and beginning to decompose, and its removal is necessary. The vagina should be washed with warm water, and the finger, smeared with the extract of belladonna, should be introduced into the passage every three hours until it is sufficiently dilated to allow of the expulsion of the lamb. Two tablespoonfuls of the following medicine should be given trice a day, viz:

Calomel.................................. 8 grains.

Extract of Hyoscyamus........................

Linseed Tea................................

At the same time a quarter of a pint of the following should be given alternately with the above:

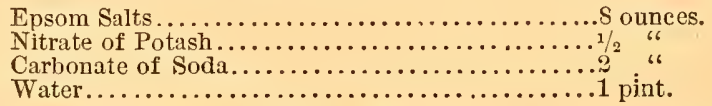

The above mixtures should be shaken up before giving them. 
After the bowels have been operated upon, these mixtures are omitted, and the following given :

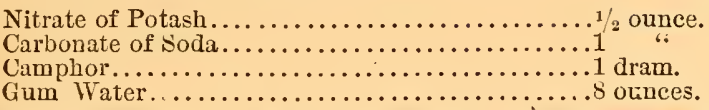

An eighth of a pint to be given twice a day. The ewe should be fed chiefly upon thin oat-meal gruel and milk, or infusion of linseerl. After the lamb has been expelled, the uterus should be injected with warm milk and water, or if there is a very offensive discharge, one dram of chloride of lime dissolved in a pint of warm water, should be injected instead of the milk and water.

Abortion.-This disease is not frequent amongst sheep, and when it occurs can almost almays be traced to the excessive use of roots in cold weather, when the ewe is heavy with lamb. It has also bcen known to occur in consequence of, or after, the heavy dressing of turnip or mangel land with superphosphate, the crop having been fed to the ewes, but this is probably in consequence of the greater succulence of the roots so grown, rather than the direct action of the phosphate. The distension of the stomach with cold, watery food, so greatly reduces the temperature of the abdominal viscera as to destroy the life of the fœtus, which is prematurely expelled, with all the disagreeable consequences to the ewe described in the preceding paragraph. Chasing by dogs is a very frequent cause.

The treatment is preventive and alleviative. Caution in feeding roots to in-lamb ewes in any but small quantities, or in avoiding fright, excessive exertion, and worrying, will prevent its oceurrence. When it has happened, the following may be given with some nourishing liquid food, viz:

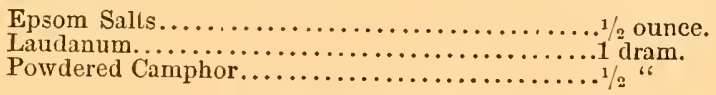

The latter two only may be repeated the second day.

Garget.-This disease consists of inflammation of the udder or milk glands. It rarely occurs, except in those ewes which have lost their young and are not supplied with foster lambs, or when the teats are not opened readily by the new-born lamb; or at weaning time. If the ewe is in good condition, and has a large flow of milk, which is not drawn off, the ulder becomes gorged, inflamed, and finally festers and suppurates. In this way some ewes may lose part or the whole of the udder, and their usefulness as breeders be clestroyed. It is also occasioned by allowing 
a nursing ewe to lie in the wet and cold in the pasture or the yards. In the summer time, when lambs are taken from the ewes and sent to market, a ewe may become gargeted, and if neglected, may become a victim to myriads of maggots which will breed in the festering udder. Ewes are thus lost uccasionally. It is obvions that prevention will be most effective. When garget lias occurred, the

Treatment is to give a purgative and diuretic to reduce the flow of milk and any fever that may exist. This may be the following:

Epsom Salts............................. ounces.

Nitrate of Potash.............................. drams.

Ginger.......................................

to be given in water, and repcated in twenty-four hours. The udder should be bathed in warm water, and a solution of carbonate of soda be injected into the teats by a small metal syringe, and afterwards milked out. The disease may result in the permanent injury of the udder, or the closing of one or both of the teats, in which case the ewe should be discarded as a breeder.

Inversion of the Uterus may occur in cases of severe labor, when the ewe is weak. The womb is turned inside out, and protrudes from the body as a red bladder. From ignorance this is sometimes cut off, and the ewe destroyed. The parts should be gently washed in warm water and cleansed from all foreign matter. The ewe should then be held so that the binder parts are raised, and with a small hand well greased with sweet-oil, or pure fresh lard, the womb should be returned, gently working it into its natural position by the thumbs or fingers. The finger nails should be closely pared, lest they may wound the tender parts. A needle with a strong linen thread or fine catgut, should then be passed through the skin upon both sides of the vagina, and ticd so as to form a loop across it which will prevent the uterus from again protruding; 20 to 30 drops of tincture of opium sliould be given in some warm gruel, and the ewe left to rest upon a soft bed in perfect quiet with her hind parts raised above the level of her head, for several days.

\section{SPECIAL DISEASES, OPERATIONS, AND ACCIDENTS.}

Ophthalmia.-This is a discase of the eye frequently caused by cold, or by grazing in stubble fields, when the straws of the stubble will occasionally wound the eyes. It is perceived at once by the tenderness and redness of the organ, a flow of tears, and a discharge of pus from the corner of the eye. It is readily cured 
by washing the eye with a solution of four grains of sulphate of zinc in an ounce of warm water, and lieeping the sheep in a dark stable for a day or two. If the eye is serionsly inflamed, and the sheep distressed with pain, give a dose of an ounce of Epsom salts dissolved in water, and twenty drops of landanum may be added to the zinc solution above mentioned with good effect.

Castration.-This necessary operation should be performed as early as possible, as there is less clanger of evil effects following it than when the lamb is olcler. The lining membrane of the scrotum is a continuation of that of the abdomen, and when inflammation follows the operation, it is readily communicated to the abdomen, and peritonitis or inflammation of the membrane lining the cavity and enveloping the bowels resuits, and this is generally fatal. A lamb a week old may be deprived of the whole scrotum and testicles, by one stroke of a pair of shears, without any danger or the loss of more than a few drops of blood. But when the lamb has become some months old, the organ has become fully developed as to nerves and vessels, and a more careful operation must be performed. An excellent method is for the operator to sit upon a long bench, with one of the lamb's hind legs beneath each of his thighs, the head and fore legs being held by an assistant. Taking the scrotum in the left hand, he presses the testicles towards the lower cnd, making the skin tight and smooth. He then makes a free incision with a sharp knife at the bottom of the scrotum beneath each testicle; the membranes which surround them are cut through, the cords and ressels which are attacherl to them, are scraped, not cut asunder, and the operation is completed. To castrate a mature ram, an incision is made at the bottom of each compartment of the scrotum, each testicle bcing removed separately, the cords and vessels being always scraped astunder. The main point to secure is, to have the wound at the bottom of the scrotum, so as to allow the pus, which will form within it, to escape. If this pus is retained in the wound, it becomes absorbed, inflammation is communicated to the adjacent parts, and a fatal termination is likely to ensue. To prevent this, a small lock of wool is sometimes left in the wound, by which it is kept open and the danger averted.

Doclaing.-This operation should be performed on all the lambs when a week or two old. It is then but slightly painful. The best method is to take the lamb between the knees, holding its rump closely against a block of wood. Then drawing the skin of the tail towards the rump, with the fingers of the left liand, a 
sharp chisel is held by the right hand upon the tail, below the fingers, and two inches from the rump; a boy gives the chisel a smart rap with a light mallet, and the tail is severed at one stroke with a smooth cut which leaves the bone in a good condition to heal quickly. A pinch of powdered copperas may be placed on the stump of the tail to stanch any bleeding, and to keep off thies.

Fractures of the limbs sometimes occur through neglect to let down bars when sheep are entering or leaving a fold or field, or through other accidents. These are easily repaired by bringing the broken ends of the bone together in the proper position, and binding the limbs in splints of wood. The splints should be wrapped with strips of cloth to prevent them from chafing the limbs, and the banclage should be made secure, but not so tight as to interfere with the circulation. The bandage should be worn three or four weeks, and if occasionally examined, there will be no need to shut up the patient from the rest of the flock. An excellent splint is made by soaking coarse brown paper in water and wrapping it around the broken limb and then binding it with bandages of muslin. When the paper dries a very firm support is given if sufficient is used.

Wounds, either punctured, incised, or lacerated, may occur from a variety of causes. When a sheep is wounded, the first thing to be done is to wash the wound with a soft cloth or sponge and warm water. If blood flows freely from an important artery, and it cannot be stanched by the use of brown sugner or powdered copperas, the bleeding end of the artery should be sought, and twisted two or three times, which will usually stop the flow. A sheep will rarely bleed to death, except from a wound which serers the arteries or veins of the throat. It may faint from loss of blood, and the flow may then, or soon afterwards, stop. If the wound is a clean cut with smooth edges, it should be closed, the wool being clipped around it, and two or more stitches taken through the skin at the edges, by which they may be kept together. The stitch should be passed through the skin in two places directly opposite each other on either side of the wound; the thread should then be tied tightly enough to keep the edges in contact, but no more, and the ends cut off. Other similar stitches are to be made, and the wound is dressed upon the surface by smearing it with an ointment of tar and powdered blue vitriol. If the wound is punctured and deep, it should be dressed by injecting with a syringe a few drops of compound tincture of benzoin, and inserting in it a plug of lint or tow clipped in the same. This will 
keep the wound open until it heals from the bottom. If allowed to close before the bottom is healed, an abscess will be formed, which will need to be opened. If the wound is in such a position that the pus formed cannot escape freely, it should be removed twice a day by means of a feather or a swab of linen at the end of a small stick, and the plug soaked in tincture of benzoin inserted. If any foreign matter, such as a splinter of wood, remains in the wound, it must be removed, if necessary by enlarging the wound, before it can heal. A wound that is difficult to heal from its depth and narrorness, may sometimes be made more tractable by opening and enlarging it at the top. Lacerated wounds will need to be treated as both incised and punctured wounds. Where the torn parts can be brought together, stitches should be made, and where the flesh is separated from the surrounding tissue, the fragments may be cut off. The deeper parts should then be treated as punctured wounds. Such wounds are loug in healing, because skin is reproduced only from the edges of the sound surface. As many of the lacerated portions of skin as possible should be brought together, so as to form edges from which the new growth may start. It will be a question if the value of the sheep in this case will repay the time and labor spent in treating it. If not, to take its skin at the outset may be the most advisable course. To cure a large wound in the fly season is a work of much trouble.

Sprains are not uncommon accidents in a large flock. They are reduced very easily by rest, and the use of a liniment such as

Olive-oil ................................ pint.

Ammonia Water.........................2 ounces.

\section{DISEASES PECULIAR TO LAMBS.}

Lambs frequently fall victims to some diseases which seem to affect them more virulently than they do grown-up sheep, or else the young animal having less strength or vitality than the mature one, more easily succumbs to those diseases. In its earlier life it is also affected with some disorders peculiar to its condition. These diseases call for special treatment. The most troublesome ailment to which lambs are sulject, are those of the digestive organs, and chief amougst this is

Diarrkea or "White Scours".-In the unweaned lamb diarrhea takes the form generally known as "white scours." This appears 
as a liquid discharge of a white color, which is simply the passage through the bowels of undigested milk. It is caused by a change in the quality of the ewe's milk, which is not coagulated in the lamb's stomach, and remains as an irritative agent, exciting the bowels to undue action, by which the milk is discharged soon after it is swallowed, almost without change. The food of the ewe probably has much to do with this, as the trouble is most frequent when the ewe is fed upon rauk, succulent, watery herbage, or an excess of roots. When this cause does not exist, it arises from a disordered condition of the lamb's stomach. When the former cause is suspected, the ewe should be treated. The food should be changed to other kinds of a more solid and nutritious character. A poorer pasture should be provided, or hay be given for a fer days, along with some crushed oats and corn, or malt, linseed, cotton-seed-meal, bran, or peas. The lamb should receive the following daily, until recorered, viz :

Linseed-oil 1 teaspoonful.

Essence of Ginger...........................

When the cause exists within the lamb, two teaspoonfuls of the following astringent mixture may be given night and morning, after the before mentioned has operated, viz:

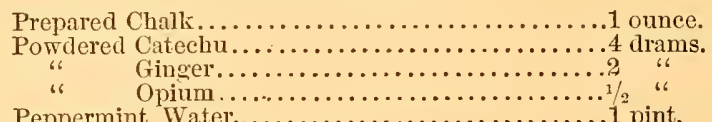

to be mixed. Shake before administering.

Sometimes the discharge consists of a pale, greenish liquid, similar to whey ; this is the result of indigestion, as the food of the lamb taken in excess is coagulated in the stomach, and accumulates sometimes to several pounds in quantity. When this occurs, in addition to the looseness and color of the dung, the lamb is dull, walks moodily behind the ewe with its head drooped, and the abdomen is sard and swollen. The following should then be given twice, viz: Carbonate of Magnesia, half ounce, mixed in water, to be followed by half an ounce of Epsom salts in a teacupful of water, after which the astringent medicine should be given. This course of treatment should be followed in case of the "green scours," which may happen after weaning, when the lamb is turned upon clover pasture. Sometimes the presence of worms in the stomach and intestines will cause a looseness of the bowels. In such a case the discharge from the bowels will be mixed with 
slime or mucus. The treatment should then be as follows: give to a year-old lamb

Linseed-oil...............................1 ounce.

Powdered Opium............................. grains.

Starch .......................................

mixed in boiling water to make a draught. A teacupful of rice water should be given twice a day. The above to be repeated the second day. After the irritation of the bowels-is removed, give the following:

Linseed-oil ................................2 ounees.

Spirits of Turpentine ........................... drams.

to be repeated weekly for a month if considered necessary.

Constipation.-When this occurs, the dung is seanty and at long intervals passes in lumps, which are glazed and hard. There is pain at the times of discharge, which is evinced by the arching of the back, and peculiar but expressive actions of the lamb. The treatment consists in injections of warm water, with two or three half-ounce doses of linseed-oil, given at intervals of six hours. The food should consist of oat-meal, or linseed gruel, sweetened with molasses; if it will not be taken in that way, it should be given by means of a horn.

Spasmodic Colic produces severe pains, oceurring in paroxysms. The lamb falls and struggles, or remains with eyes fixed, as if convulsed. It is generally an accompaniment of constipation, and always of indigestion. The treatment is to give the following mixture, viz:

Tincture of Rhubarb....................... 1 dram.

Carbonate of Soda............................. "

Warm Water sweetened with Molasses ...........2 ounces.

This should be administered slowly with a spoon. After the spasms are relieved, give half an ounce of linseed-oil.

Paralysis.-This disease may occur through a severe chill or exposure to cold rains, or as a symptom of chronic indigestion from inaction of the stomach. The latter is to be suspected when the appetite is depraved, and sand, earth, and coarse matter is eagerly swallowed. In the former case, a warm bath, with friction upon the spine, witl spirits of turpentine, or ammonia water, followed by a few days nursing, may be found useful. In tho latter case, the symptoms and post-mortem appearance show that the base of the brain, the spine, and the nervous system proceeding to the stomach are affected. The lamb suffers severely as if in great pain. It is unable to rise upon its hind legs, and is con- 
vulsed with spasms; the teeth are ground together, and the breathing is quick and hard, and death generally results. The only definite directions that are likely to result favorably, are to prevent the disease by watching the condition of the lamb after it is weaned, and to provide such food as shall keep it in a thriving condition. Poverty of blood being the direct cause, any treatment that will avoid that condition will be helpful. A small quantity of linseed-cake-meal, bran, or ground oats, should be given daily after weaning, and until the first winter is past. Lambs of rapidly growing breeds camnot endure stinting in food, the demands of their constitution must be supplied to its full capacity, or the health suffers, and instead of becoming simply poor and stunted, they become diseascd. Disease thus induced cannot be expected to submit to medicine, and the only natural remedy is apt to be applied too late to be of service.

Pale Diseas, Husk, Verminous Bronchitis.-This disease consists in the presence of worms in the air-passages of lambs. These produce great irritation and violent coughing. The interruption thus resulting to the aeration of the blood in the lungs, causes general disturbance of the system. The appetite fails, the condition rapidly falls off, and ancemia, "pale disease," or "the bloodless condition," takes place, beneath which the lambs rapidly siak. How the worms, in large numbers, find their way into the air-passages of so young animals, is a query which as yet cannot be satisfactorily solved. They are there, howerer, and that fact must be sufficient for the shepherd. These worms are a species of strongylus or thread worm, closely akin to the fatal "gape-worm" (also a strongylus), which clestroys so many young chickens. It is the same species which inbabits the lungs and bronchial tubes of the sheep. The lamb being less robust, is carried off with greater ease by these attacks, than the full-grown sheep. Prevention is the best remedy. Lambs should not be allowed to follow sheep upon the same pasture, nor to pasture upon meadows that have been top-dressed with manure from the sheep stable or yards. No medicine can reach the lungs, except through the blood, and but few affect them in this way. Sulphur, turpentine, and assafœida, are in part exhaled through the lungs, and these medicines alone can be depended upon to reach these parasites.

The treatment recommended, therefore, is to administer the following, viz:

Linseed-oil ......................... 1/2 ounce.

Spirits of Turpentine.......................

Assafotida............................. 20 grains. 
to be given early in the morning, for three successive days, before feeding or turning to pasture, and no feed to be given for three hours afterward. Afterwards the following to be given daily:

Molasses or Honey....................... pound.

Flowers of Sulphur........................

one tablespoonful to be givan every morning for ten days.

The food should be of the most nutritious and digestible character, and if the appetite fails, the food, until the appetite returns, should be given by means of a horn, in the shape of gruel or infusions of oatmeal, linseed, or corn-meal, sweetened with sugar.

\section{TABLE OF APPROXIMATE EQUIVALENT MEASURES.}

For the more ready use of the prescriptions mentioned in the preceding chapter, the following table of approximate equivalent measures is here given :

\section{FLUID MEASURES.}

One teaspoonful $=$ One fluid dram.

One tablespoouful $=$ Half a fluid ounce.

One wine-glassful $=$ Two fluid ounces.

One tea (not coffee), cupful = A quarter of a pint

One tumblerful $=$ Half a pint.

It will be more convenient, as well as more accurate, to have an apothecary's graduated glass, which is not very expensive, and will allow all the needed measurements to be made in a single utensil. This is a conical glass upon a foot, and provided with a lip to pour from; they may be had of the capacity of one or two ounces up to a pint; oue of four ounces will be the most convenient; the measures are marked on the glass, the sign $f_{3}$ standing for fluid dram, and $f \bar{z}$ for fluid ounce; Ss is used for half of either.

A set of apothecary scales and weights may be bought for a dollar or less. The grain weights are of thin sheet brass, with number of grains indicated by dots. Đ stands for scruples, and 3 for dran; the number of each being indicated by numerals following the siga; Ss is used for half of either. 


\section{A P P E N D X.}

\section{II A P T I V VII.}

\section{LOCALITIES IN THE UNITED STATES SUITABLE FOR SHEEP RAISING.}

The territory of tas United States is so exteasive, and prisents such a diversity of climate, that in considering its adiptabiinty to sheep-raising, it becomes necessary to subdivide it into regions, and consider eas' of them with special reference to this industry.

\section{THE EAST.}

The States north of Virginia and Tennessee, from the Atlantic ozean to the Mississippi river, constitute the most thickly populated portion of the country. Here are located all the great cities and most of the large towns. To supply the demands of the market created by this large and growing pepulation, there is needed an increased number of lambs and choice varneties of mutton. Some of these markets demand a supply for which price is a secondary consideration if the quality is acceptable. The early lambs which, at some seasons, retail for $\$ 5$ the quarter, are readily purchased, and it only needs that there should be a supply of the choicer varieties of mutton to greatly increase the demand. In this portion of the country indicated as the "East," there are several millions of consumers of lambs and superior mutton sheep.

To supply this demand, varieties of sheep furnishing a superior quality of mutton are needed, the yield of wool being a secondary consideration. To feed these sheep, pastures of peculiar characters 
must be furnished. In the const lands and river meadows, the elevated ranges and sheltered valleys of the region now under consiteration, every variety of pasture is furnished or may be provided by proper methods; and if we do not alreadly possess the breeds of sheep which are naturally fitted to occupy these pastures, and yield the highest quality of mutton, they may be procured by importation at a very moderate cost.

The Eastern region may be subdivided into three ciistricts; the alluvial coast lands; the valley and bottom lands; and the mountains.

\section{TIIE COAST LANDS}

iucluce all that portion subject to the influences of salt water and the sea air. Salt marshes are not detrimental to the health of sheep, but fresh water marshes, if undraned, are utterly destructive of them; and when drained, are only fitted for the pasturago of ons or two breeds which have been bred and raised for centuries upon such lands. The herbage of salt marshes gives a peculiar flavor to the flesh of sheep fed upon it, which renders the mutton very desirable in the markets. Along the Atlantic coast are millions of acres of pasture lands which could support at least three sheep to the acre. From Maine to Virginia, the Atlautic coast is indented with bays and inlets containing numerons islands and promontories that are excellently adapted for sheep farms. By fencing across their bases, the promontories may be rendered safe, and the islands are naturally guarded against the depredation of dogs, the greatest pest of the shepherd in this portion of the country. From personal observation of these coast lands, the author is satisfied that no more healthful pastures exist anywhere, and nowhere is land cheaper or more easily brought into profitable condition to support flocks of sheep. The higher portions of these lands very much resemble the "clowns" of England, and the traveller who has seen the numerous Southdown flocks of that country, pasturing upon the gently swelling shore lands, and inhaling the wholesome sea breezes, can not but be impressed with the favorable opportunities here offered for the same profitable and pleasing industry.

The Southern portion of this coast district has a remarkably mild climate, which is very favorable, so far as cost is concerned, for the feeding of sheep through the winter. A specially well adapted locality is that comprising the eastern peninsula of Virginia. A privato letter to the anthor, from Mr. C. R. Moore, of Johnsontown, in this locality, states that sheep in that climate are unaffected by any disease whatever, and that farms suitable for 
sheep keeping can be purchased for $\$ 10$ per acre or less. Another excellent locality is found upon the eastern shores of Long Island. Here, good lands, suitable for sheep farms, may be purchased for $\$ 5$ to $\$ 10$ per acre.

The sheep suitable for these localities, are, the Soithdown and its crosses upon our common sheep; the English Dorset sheep; the Coiswold and its crosses, and the English Romney Marsh sieep. The last two of these varieties should be chosen for the richer meadow lands, and the first two for the lighter uplands. Either of these breeds is suitable for the production of market lambs, but the first three are to be preferred in the ordcr named.

\section{THE VALLEY AND BOTTOM LANDS.}

These lands comprise the whole of those arable lands of the entire region in question, which are so prolifie under ordinarily good cultivation of crops of grass, grain, clover, and roots. The rich vallies which have become renowned for their fertility, as the Mohawk and the Genessee vallies in New York; those of the Delarare and Susquehanna in Pennsylvania; the Shenandoah in Virginia, the Miami in Ohio; also the uplands of the blue-grass region of Kentucky, Ohio, Indiana, and Missouri, with the rich fields of the prairie States east of the Mississippi, as well as of the formerly wooded regions of Michigan, Wisconsin, Canada, and New England,-all these offer a favorable field for the production of sheep valuable for both wool and mutton.

This district, occupied by threc-fcurths of the whole population of the United States and Canada, and possessed of a rich soil, is wonderfully diversified as to surface and agricultural capacity, is well watered, and blessed with a healthful climate. Thousands of vallies watered with clear streams and springs, and separated from each other by dry rolling table-lands, densely populated in comparison with the rest of our territory, are occupied by the most industrious, intelligent, and enterprising farmers in the world, and are covered with their homesteads and cultivated fields. No soll in the world is more prolific in fodder and root crops, and nowhere else can shcep be raised and kept with more profit than here. The shepherd who loves to see flocks dotting the landseape, as he passes through this immense territory, is surprised at the comparatively small number of sheep.

Here and there may be found considerable flocks, and in some few counties only, the production of mutton and wool is of considerable importance. The following table, which shows those Counties in the States mentioned which possess over 100,000 shcep 
such, gives a fair idea how inadequately this branch of agriculture is represented in this favored district.

State. County.

Number of Sheep in 1870.

N. EW Xork.-Whole number in the State................2,181,578.

\begin{tabular}{|c|c|}
\hline $\begin{array}{l}\text { Livingston........113,933 } \\
\text { Ontario ..........131, } 485\end{array}$ & $\begin{array}{l}\text { Steuben..............145,645 } \\
\text { Washington.........102,045 }\end{array}$ \\
\hline 10.- Whole number in the St & $.4,928$ \\
\hline Belmont. & Jefferso \\
\hline 年. & Knox \\
\hline Columbiana.......131,527 & Licking \\
\hline Coshocton.... & Morrow \\
\hline Delaware... & Muskingum \\
\hline Guernsey.........151,848 & Tusearawas .. \\
\hline Harrison..........18 & \\
\hline
\end{tabular}

Pennsyldania. - Whole number in the State..............1, 794,301

Green..........121,135 | Washington..........426,621

Michigan. - Whole number in the state................. 1,985,906

Calhoun .........102,010 Livingston.. .........108,527

Jackson...........130,289 $\quad$ Oakland ...............162,852

Lenawee..........112,653 Washtenaw............187,059

No other county in any State east of the Rocky Mountains contains 100,000 sheep.

Of these sheep a very small portion are of the long-wool breeds, or of a ciass the most desirable for mutton, yet these more valuable sheep may be kept here with the greatest ease. It is here that are to be found nearly all that there are in the country of the heavybodied sheep, yielding the valuable grades of combing wool. The beneficial effect of the rearing and feeding of these classes of sheep upon the system of agriculture is very great, and it is quite within the bounds of probability that the flocks of Cotswold, Lincoln, Shropshire, Hampshire, Oxfordshire, Southdown, and Leicester sheep with their grades that are now kept, will very soon increase in number to a remarkable extent. The most favorable fields for their support are in this district; and it is these breeds of sheep that are best adlapted to the higher culture which alone can render farming upon these lands the most profitable.

\section{THE MOUNTAIN DISTRICT.}

This includes the great Appalachian chain, which extends from Alabama to New York, and there diverges to form the White Mountains and the highlands of New England. It includes a succession of mountain ranges, table-lands, and elevated valleys, over a thousand miles in length, and averaging from two hundred to three hundred miles in width. Much of this district is still covered with the original forest, or a second growth of timber; but, 
beneath the trees, and interspersed amongst the forests, there is an abuuclant growth of grass. In Western North Carolina, East Tennessee, West Virginia, and Southem Peunsylvania, blue grass and other valuable permanent pasture grasses are indigenous, and spring up spoutaneously when the timber is " cleadened," by girdling or removing the bark in a ring around the trees. Upon some of the open table-lands, especially in East Tennessee aud North Carolina, there are open grassy tracts, free from timber, which furnish the finest pasturage the year round. The hillsides and the valleys, when cleared, bear luxuriant crops of clover and grass, while the geological character of the soil, which overlies the carboniferous formations of limestones, sandstones, and shales, is favorable to the health and vigor of flocks. The abundance of land and the sparseness of population in this portion of the region tend to very low values, and large tracts may be procured for one dollar an acre and upwards. Further north, the soil is less fertile, and the climate less genial ; but the sides and summits of the Alleghany ranges bear heavy crops of clover and grasses of various species so soon as freed from the rubbish and debris of the timber which has been removed by the lumberman. So the rougher lands of New England, culminating in the ridges of the White Mountains, may be utilized as pastures for those breeds which are fitted by nature for such exposed situations. The still more bleak and less productive mountains of Scotland furnish homes for some millions of sleep, and it is around the storm-swept granite crags of the Scottish mountains that flocks of Black-faced sheep, numbering from one or two thousand, up to forty thousand each, are reared and fed.

The various mountain breeds of sheep are exactly fitted for such pastures, and the Scotch Black-faced, the Cheviot, and the Welsh sheep might be introduced upon the rougher portions, while our native sheep, improved by the lighter-bodied varieties of the several "Down" breeds, would be suitable to the better pastures of the sonthern portions of this district. It is in these localities that the choicer kinds of mutton, and the short but valuable wools, suitable for the manufacture of flannels and hoisery, would be cheaply and profitably produced. The great pest of the shepherd throughout the mountain region is the dog. Fere game being plentiful, the hunter is abroad, and scours forest and open ground with his hounds. Contrary to common belief, the hound and other sporting dogs will pursue and destroy sheep with greater ferocity than the maligned and malignant cur. Cruel and costly experience in a portion of this mountain district has proved this to the 
autbor beyond a doubt. Where these dogs are kept in more than usual numbers, no flock is safe at night outside of a substantial enclosure, or in the daytime without an attendant. A method of protection, however, may be made available in traps and fenceguards, such as have been described in a previous chapter.

\section{THE REGION OF THE SOUTHERN STATES.}

Sheep-keeping in the Southern States has suffered greatly from competition with cotton-growing. Heretofore, the peculiar system of labor was better calculated for working in gangs in the cotton, tobacco, sugar-cane, and rice fields, than for the inclependent labors of ordinary farming. On the plantation, sheep were out of place, excepting where grain, grass, and live stock were produced, as in some notable cases in Virginia. On the farm, sheep are an absolute necessity to the most economical management, wherever they can possibly be accommodated.

Now, under the changed system of labor, the farm is rapidly taking the place of the plantation; and amongst the varied industries belonging to the farm, the rearing of sheep must undoubtedly take a foremost place. For the fine-wool sheep there are few better localities than are afforded by the Southern States. The climate is very similar to that of countries where the Merino has attained its highest excellence. Northern Africa, and Southern and Central Europe, have been the homes of this sheep for more than two thousand years, and our Southern States not only offer an equally favorable climate, but possess in their native grasses, equally good, if not a better pasturage. They hare also immense tracts of land covered with the grasses which are useless for any other purpose, and are consequently to be purchased for very low prices.

The grasses of the Sonthern States of the greatest value for sheep pasture, have hitherto been considered the greatest pest of the planter. "Bermuda-grass" (Cynodon Dactylon), "Wire-grass" (Aristida stricta), "Crab-grass" (Eleusine Indica), and "Crowfoot" or "Barnyard-grass" (Panicum Crus-galli), have been rcgarded as not only worthless, but plantatious have been abandoned on account of being overrun with some of these in spite of efforts to keep them down by cultivation. Fortunately it is now known that these abandoned fields will keep several sheep to the acre the year round. In addition to this uative pasture, a wonderful varicty of fodder crops are easily grown.

In Dr. Howard's "Manual of the Cultivation of Grasses and Fodder Plants at the South," are mentioned Lucern, the Ficld 
Pea, the Vetch or Tare, Oats, Red and White and other Clovers, Millet, Blue-grass, and most of the other cultivated grasses common elsewhere. These, with such roots as turnips, beets, and mangels, and with cabbages and kohl-rabi, furnish an abundance of food which may be fed from the ground iu rotation the entire year. Perhaps there is no portion of North America better fitted for profitable fine-rvool husbandry, than would be the Soutliern States, under a system of skillful and enlightened agriculture.

It wonld be difficult to point out localities in these States that are more specially adapted than others to the raising of shcep. The climate everywhere is genial, and if any one State seems to offer greater facilities than another for the shepherd, it is Georgia, and this more on account of the great quantities of land suitable for the keeping of sheep, which can be procured at almost nominal prices. For the production of the strictly wool sheep, cheap land is very desirable, if not necessary, in competition with the extensive ranges of free pasture found upon the great plains; and the sheep owner therefore will be attructel to those localities where this need can be supplied.

\section{THE REGION OF THE WESTERN STATES AND TERRITORIES.}

That portion of the United States designated by the above title, riz., that west of the Missouri River, offers an almost unlimited field for the profitable rearing of sheep. While other localities may raise shcep, this in the greater part must rais them or lie unused and undeveloped, because the climate and the physical character of that portion, as a general thing, forbid the prosecution of agriculture and invite pastoral pursuits. Almost the whole territory west of the 100th meridian to the coast lands of the Pacific is a sheep pasture, which can never be furrowed by the plow except under a system of irrigation. Nature conld scarcely have combined more farorable conditions, to meet the necessities of the shepherd than are found here. A dry soil, short, sweet, nutritious herbage, pure water, pure āir, a long feeding season, good winter pasturage or abundauce of grass for hay, which can be cheaply saved, are all here-in some cases to be had without money and without price, but anywhere for a very small expenditure of capital. Within the past fer years, since this part of the country has been made accessible by the Pacific and other railloads, and the mining industry has opened up markets for produce, and has brought in abundant supplies, some of the lands have been brought under irrigation and cultivation; but these comprise but a very insignificant portion of the whole area. Probably not more than 
one acre in a hundred thousand, if so much, can thus be used; and the remainder is being gradually covered with lierds and flocks. The most accessible and valuable tracts are being rapidly appropriated by the owners of cattle and sheep as grazing grounds. The lands are not purchased by the occupants, nor can they be at present, for the reason, that under the preemption and homestead laws, they can only be purchased or acquired in single tracts of 160 acres each by any one person; a limit which entirely defeats their sale. They are now simply held under the natural right of the first occupier, or by the physical right of the strongest; a titie without warrant of law, and which is not by any means undisputed amongst the settlers themselves. There are thus sometimes disputes, quarrels, and even conflicts, in which, as is usual, the weaker gives way. It will undonbtedly be the case, that finally the strictly grazing lands will be offered for sale by the Government, at stich prices as they may be worth; when a legal title will give protection to the small stockman against the usurpations of the greater. But there are many tracts of land admirably suited for sheep pasturing, that may be purchased at low prices from the various railroad companies, or acquired from the U. S. Government under the Homestead, Preëmption, or Timber Culture Acts, which, together, may be sufficient to form a respectable sheep farm, around which, for many years, abundant free pasturage may be precured from the unsold railroad lands, or the unoccupied Government tracts. These facts, operating advantageously, or otherwise, make it proper to treat of this region under three subdivisions, viz., the Eastern District, the Central and Southern Districts, and the Pacific District.

\section{THE EASTERN DISTRICT.}

This includes the western part of the States of Texas, Kansas, Nebraska, the eastern part of Colorado, and the southerm part of the territory of Dakotah. This district is one vast meadow which bears a variety of grasses admirably suited for shcep pasture and for hay. Hingled with the grasses, in many places, are species of leguminous plants popularly known as "wild pea," etc., which add much to the value of the pasture; there is an abundance of water, either in streams or springs, or attainable by wells at moderate depths. The rain fall is sufficient in nearly the whole of this district to allow erops of rye, millet, or lucern to be grown, which are valuable for winter feeding./ But the chief attraction to the shepherd, in selected portions of this section, consists in the ease with which he can procure the legal and peacable possession 
of his land, free from question or incursion of stronger and richer neighbors, who, being in great part engaged in herding caltle, drive off the sheep from the range under the impression that they destroy the feed. Several railroads having immense land grants pass through the best parts of this district. These roads bring in needed supplies and carry wool and sheep to market; they also bring the shepherd within reach of the comforts and influences of civilized life, so that he is not compelled to lead the life of an outcast, as it were, or to deny himself the socicty of his family. Towns and villages are within reach of the pastures in many places, where the sheep farmer may enjoy every convenience of Eastcrn life.

The method of managing a flock in these various localities, differs very little from that on an Eastern sheep farm. The principal difference lies in the fact that the pasture is ready at hand, and no preparation or cultivation of the soil is needed. To seeure the land; purchase the flock; select the rams of whaterer breed may be chosen for improving it; erect the shelter necessary during the winter months, and provide a certain amount of feed for the winter season, when pasture may fail for a time, are all that is needed for the shepherd to eommence business. It is not to be supposed that a previous knowledge of the business is unnecessary. Those who have carefully read the preceding pages will not form so erroneous an opinion; but a capable person, desiring to cnter the business in this district, may do so with greater facilities and fewer risks than elsewhere.

The class of sheep that have so far been found most profitable in this district, is the native or the Mexican ewe, crossed by Merino or Cotsw old rams. The late Mr. George Grant, of Victoria, Kansas, whose flock numbered 7,000 ewes, used, in the way of experiment, Lincoln, Leicester, Cotswold, Oxford-Down, and other rams upon the native ewes, but the fleeces of the pure long wool breeds, when shipped to Boston for sale, actually sold for a lower price than the wool of the native sheep. As might also have been expected, the experiment failed with the heary-bodied Lincoln and tender Leicester, for reasons pointed out by the author in previous pages of this work. The experience of Mr. Grant has proved the correctness of the opinion given by the author in regard to the difficulties in keeping these breeds of sheep excepting under the most favorable circumstances, and $\pi$ ith all the aids of the highest farming, and also that for general use, the Merino crosses will be found greatly the best in every way. This is the almost nniversal opinion of those who have had personal experience, and is consis- 
tent with what would be predieated of the existing conditions by an expert in sheep culture.

But little feed is neeessary for the winter season, one tou of liay for every 50 head being the usual allowance. 'When the winter is favorable, only a few days' feeding may be needed, and in the southern portion of the district, feed is never stored for the winter, pasturing being the entire dependence. Still, where the flock is of improved grades, it will certainly be profitable to provide not only hay, but a modcrate quantity of crushed grain (oats and corn), for the ewes.

The profit actually made upon investments in sheep, when properly managed, are here from 50 to 75 per cent per annum. When labor is all hired, the wool will generally pay all expenses, leaving the increase of the flock, which is rarely less than 75 lambs to every 100 ewes, as clear profit. 'A common method is to let out the flock to a capable shepherd for one balf the net increase and pro. duce; the losses in the original flock being made up from the share of the shepherd.

A personal inspection of these magnificent pastures, and a short acquaintance with some of those who are already successfully engaged there in sheep raising, can not fail to give a most favorable impression to the least sanguine seeker of information upon this interesting subject.

A large portion of this favored territory is susceptible of the lighest cultivation under ordinary farm crops. The various grains, fiax, sorghum, roots and fruits of all kinds, yield abundantly. For those farmers who follow this mixed system of agriculture, and yet who would add sheep-keeping to their other resources, might adopt the plan of joining their flocks together after shearing time, and putting the whole under the care of a shepherd who should drive them to a distance and pasture then upon the unoccupied lands, until the farms were cleared of crops. This migratory system is very frequent amongst farmers in parts of Germany, and is found very convenient. The sheep and lambs are marked, so as to distinguish those of the different owners, and the expense of their care during their absence is borne proportionately to the number of sheep in each flock. In this way the profits of sheepkeeping could be secured with great advantage, where, withont it, not a shcep could be kept. A number of small flocks of from fifty to a hundred sheep, gathered together into one large one of two or three thousand, might be kept at almost mominal expense for half the year, and be returned in time to glean the stubbles and consume much fodder that now goes entirely to waste, or 
scrves as a harbor for countless myriads of insect pests. The opportunities for such arrangements as this, now, aud for many years to come, are very many, not only through the district referred to, but in many others far east of this.

\section{THE CENTRAL AND SOUTHERN DISTRICTS.}

This divsion comprises the Territories of Wyoming, Utal, Arizona, New Mexico, and Southern and Westen Colorado. The surface consists of broad, dry plains, covered with buffalo grass "sage bush" (Artemesia), or elevated vallies with broad grassy meadows alternating with elevated mountain ranges. The climate is dry, and in parts arid, and the sparseness or entire absence of population renders it far from desirable as a residence, except to adventurous people who may be content to sacrifice the comforts of eivilization for a time in the pursuit of wealth. Only the possassor of considerable expital can have any hope of success in pastoral pursuits here. But with sufficient means, and the requisite experience, sheep-keeping can be made very profitable. The chief drawback is the hostility of the cattle-men, who complain, with some justice, that sheep injure the range as a pasture for their herds, and these, being the stronger, clrive the sheep and the shepLerds from the best grazing grounds.

\section{THE PACIFIC DISTRICT.}

The Pacific District includes the States of California and Oregon and Washington Territory. The physical features of a large portion of this extensive district are similiar to those of the locality last clescribed. There are broad plains, covered with low brush and buuch grasses, rolling grassy uplands, mountains and elevated vallies, all furnishing abundant pasturage. There are $35,000,000$ acres in Eastern Oregon, which is for the greater part covered with the bunch grasses (prominent among which is Festuca scxbrella), and other herbage which are nutritions and healthful for sheep. The climate gives a softness and fineness to the fleece, which adapts it to the production of fabries of excellent quality; the blankets made in Oregon being probably the best produced anywhere.

Washington Territory possesses a similar climate and other characteristics, and offers equal advantages to the shepherd, though it lacks a home market, because of the sparseness of the population.

It is in California, however, that the industry and enterprise of the shepherd have been developed to a greater extent than elsc- 
where on the Pacific slope. The following table, giving the product of wool in the State, from 1854 to $187 \%$, shows the adapta. bility of California to sheep-raising, in a striking manner :

\begin{tabular}{|c|c|}
\hline 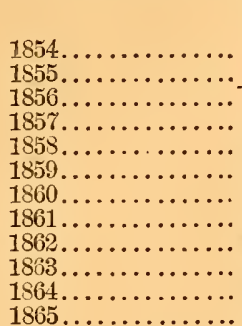 & $\begin{array}{r}\text { Pounds. } \\
175,000 \\
300,000 \\
600,000 \\
1,100,000 \\
1,423,351 \\
2,275,250 \\
3,055,325 \\
3,721,998 \\
5,990,309 \\
6,268,480 \\
7,923,670 \\
8,949,931\end{array}$ \\
\hline
\end{tabular}

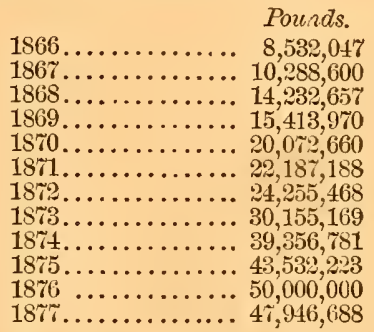

The gradual but rapid increase here shown is very notable. The falling off in the last year was due to the loss of mauy sineep by an unusual drouth, which caused the pastures to fail throughout the State.

The climate of California is so mild that sheep need no shelter; even in winter they can find subsistence in the pastures the year round. The wool, therefore, grows continously and is shorn twice in the year. One reason for this half yearly shearing is the presence of a troublesome bur in the pastures, which, during the sesson when the weed is in fruit, collects in the wonl and renders it of less value. The burry wool is shorn and sold at a reduced price, while the next half-yearly shearing yields a clean fleece. The ewes are remarkably prolific in California; 80 per cent increase of the flock is usual, and over 100 per cent is not uncommon. Disease is rare, a mild form of scab being the most troublesome. The sheep are pastured chiefly upon vacant government lands, or upon mountain lands of low value. The average annual cost of feeding a sheep, is estimated at 85 to 50 cents, and the value of the wool is generally double ine cost of lreeping. 


\section{$\mathbb{I N D E}$}

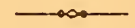

Abortion, Prevention of ........211 After-pains in Ewes............. 208 *American Merino, Description of the.

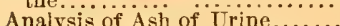
Analysis of Ash of Urine......... 15 6 Dung........ 16 " Fodder..............60-61 "6 Grains...............6 64

6 Manure..............

"6 Roots................63

" $\quad$ Wool....................... 14;

"6 Yolk..................... 117

Anatomy of the Sheep.............. 1f

Anxmia, Treatment of............ 03

Anthrax Fever, Treatment of . . . . . 209

Aphtha, Treatment of...........210

Apoplexy, Treatment of. .........216 *Barn for Sheep, Description of... 50 * " " Small Farm............ 52

* " a Couvenient.............. 57 * Beacon-Down Sheep, Description of the................... 138

Bile, Composition and Uses of ......183

* Blackfaced Scotch Sheep, Description of the.............122

Black-leg. Treatment of .........204 Bleeding, how Performed............190

* Bone, Strneture of ..... . . . . . . 173

Brain of the Sheep................174 " Water on the, Treatment of.216 "Worms in the..........

Breeds and Breeding Sheep........ 81 "6 Crossing............... 84

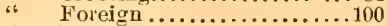

" Native................. 89

Breeders, Maxims for........... 89

Breeding for Sex............... 86

In-and in $\ldots \ldots \ldots \ldots \ldots \ldots . . .68$

Bronchitis. Treatment of..........

Cabbage, Culture of........... 25

Canker of the Foot, Treatment of .235

Castration, Performance of .....30-213

Catarrh, Treatment of...............191

* Cheriot Sheep, Description of

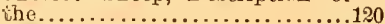

Choking, Treatment of ............191

* Circulation of the Blood...........

Clap, Treatment of in Rams.......215

Colic, Spasnudis Treatment of ....247

Corn, Comparative Value of......6.65

Costiveness. Treatment of .....195-247

Cotton-Seed-Cake-Meal, Value of. . 65

* Cotswold, Description of the.....107

"6 Improvement of other

Breeds by the........ 84
* Cotswold-Leicester, Description of the ...........................

Cotswold-Merino, Description of the.........................134

Cotswold-Southdown, Description

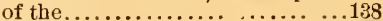

* Crook.......................15

Cross-br ad Stueep.............133-142

Diarihea, Treatment of . . . . . . 196-246

Digestion, Process of .............179

Digestive Organs, Diseases of the.194

Dip for Lambs and Sheep......... 47

Diseases of Lambs.............245

" "the Sheep, Observa-

tions on.............188 Canses and Prevention of 190 of the Blood ...........201

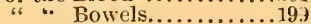

" "6 Brain ..............216

“ " Digestive Organs..194

Enzo تtic.............206

Epizoütic.............210

Of the Feet............231

Parasitic.............219 of the Reprodictive Or-

" " Rans..........214

6. " gans......... .190

، Special................242

of the Urinary Organs...243

Docking Lambs................243

* Dog-guards for Fences. ... . . . . 32

* Dorset Sheep. Description of the118

Dropsy, Treatment of...........205

Dung, Analysis of Ash of...........16

Dysentery, Treatment of. .........207

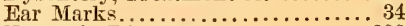

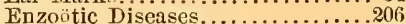

Epilepsy, Treatment of .......... 218

Epizoïtic Diseases...............210

Ewes, Garget in, Treatment of.... 42 " in Lamb, Care of.......... 36

"6 Number for One Rain....... 35

" Period of Gestation of ....... 34

" Record of Service of........ 31

" Selectior of for Breeding... 43

" Yeaning, Treatment of...36-45

"6 and Lambs, Management

of .......................33-87

Eyes, Disease of the................

Fattening Shcep for Market....... 78

* Feed-Rack..................31-59

Feeding, Experiments in ....66-68-70

Roots................. 
Fences, Portable............... 27

Flax-Seed, Nutritive Value of.... 65

Flesh and Blood. Analysis of Ash of 15 Quantity Produced by Certain Foods.

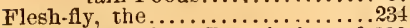

* Fluke, the Liver, Description of .220

Fodder Crnps................. . 22 "Analysis of ...........6 60

" Nutritive Value of........61

Foods for Winter Feading........ 59

.. Composition of Various..... 60

6. Choice of ............ 65

. Proper Allowance of......... 72

‘ Quantity of, Needed ........66

"6 for a Pound of Flesh.........6. 6 r

Foot, Description of the..........235

. Rot, Treatment of . .......2:236

Foot-and-Mouth-Disease......210-239

Fractures of the Bones............24t

* French Merino, Description of ...128

Gad̈-fly, the ........................

Garget, Treatment of .................

Giddiness or Turnsick, Treatment

for...................226

Grains, Nutritive Value of Various 64

Grasses, Composition of Various.. 17

“ Suitable for Pasture...... 16

* Hampshire-Down Sheep, Descrip.

tion of....................... 116

Heart, Structure and Functions of 177

Hoven, Treatment of.............196

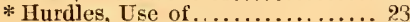

* 66 for Refractory Ewe..... 37

* Hydatids in the Brain..........226

Inflan.mation of the Bladder......213

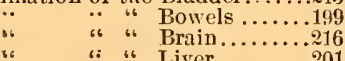

Kentncky, Improved, Sheep..........91

* Kidney, Structure of the.........186

Lactea] Vessels................. 181

Lambing, Diseases Connected wjth.\$39

Lambs, Castrating............ 39-243

* 66 Dipping.............. 48

Diseases of ............ $45-245$

Docking............... 34-24?

Feeding................. 40

" Laxative for.............. 41

" Newly-born. Care of ....... 3 i

"6 Raising Early Market...... 73

"6 Twin, Feeding ..................

* " Weaning................ 38

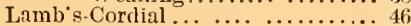

* Lamb-Creep................... 41

* Laurel. Poisoning by............... 198

Leicester, Improrement of Other

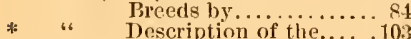

* Leicester-Murino, Descriptiou of

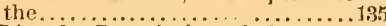

* Lincoln. Deseription of the......100

Linscerl-Oil-Cake-Mcal, Talize of...6 64 Substitute for
Litter for Sheds................ 58

Liver, Congestion of the......... 200

"6 Description of the ....... . 183

"6 Inflammation of the .......201

"6 Rot. the. .................219

Lockjaw, Treatment of .........218

* Louse, the Sheep...................

* Lungs of the Sheep............176

Lung, Worms in the, Treatment for. 223

Manure, Value of ..............

Markets....................... 8

IIarket Lambs, Methods of Raising 74

* " " Box for Shipping.. is

" " Profit of......... is

Measures. Explanation of.......... $₫ 49$

Merino, American.............. 42

"6 Freech................128

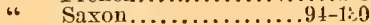

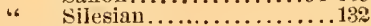

" Spanish ................

"6 ${ }_{66}$ Importation of ... 93

" " Implovement of.. 95

* " " Maturity of ..................... 98

" Wool, Value of .......... 84

"Wool, Weights of Fieces 96

Mexican Sheep............... 90

Mustard. White, for Fodder....... 22

Nerves of the sheep............ 174

* Nets for Folding sheep.......... 29

Oil-Cake, Feeding Value of .......64 64

". "Manurial Value of..... 80

Ophthalmia, Treatment of ..........242

* Oxford-Down Sheep, Description

of the......................110

Pale Disease of Lambs....... . . . 248

Packing Fleeces..................161

Palsy, Treatment of ...........218

Paralysis. Treatment of . . . . . 217-247

Parasitical Diseases............ .219

Parsley, Value of in Pastures...... 17

Parturient Apoplexy and Fever.208-240

Pasture, Dry. Necessary for Health 14

" Change of. Advantageous. 31

". Extent of, in the U. S.... to

" Exposure of........... \&?

" Grasses Suitable for...... 16

" Management of......... 20

" Suitable for Sheep......... 12

Pining, Treatment of . ............ $\$ 03$

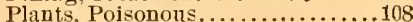

Plethora, Treatment of ..........2083

Plemrisy, Treatment of ...........193

Pnenmonia, Treatment of ..........192

Poisoning. Treatment of ..........198

Pox, Sheer, Treatinent of.........211

Prices of Wool in the World........

Production of Wool in the World..16 Purgatives, Use of ........... ...1 9 Ram, Selection of the........... 43 Rape lor Fall and Winter Feeding. 23 Red-water, Treatment of..........20\% Reproductive Organs, the........187 Respiration, Process of ......... . Respiratory Organs. Discases of ...190 Reteution of I rime. Treatment of..213 Rheumatism, Trealmont of .......202 * Romney Marsh Sheep, Descrip- 
tion of the

* Root-Cutter ....................26

* 6. Pulper................... 27

Roots, Culture of ............. 26

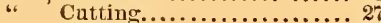

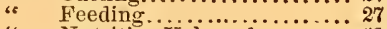

6 Nutritive Value of.......... 63

،. Quantity Needed for a Flock 72

* "Storing in Pits........... 26

Rot of the Foot, Treatment of .....2:

* " in the Liver, Treatment of.....2 232

Rumination, Process of...........181

Sa!t Necessary for Shcep............33

Saxon Merino, Description of the.. 130

* Scab. Treatment for..... ........282

Sea-IVeed Eaten by Sheep......... 19

Scrofula, Treatment of ............204

Shearing Sheep................. 158

* Sned for Pasture.................... 32

* ". Mr. Geo. Grant's........ 53

* " Mr. Shaw's............. 54

Sheep, Census of, in U.S. $90,60,70.167$

"6 When a Lamb Becomes a... 45

Shelter, Effect of, on Consumption

of Food

* Shropshire Sheep, Description of.112

Silesian Merino, Description of the132

* Skeleton of the sheep...........169

* Skin. Structure of the..............143

Soils Suitable for Pastures........ 12

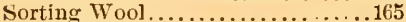

* Soutndown Sheep, Description of 114 -Merino, Description

of the...........135

Spanish Merino, Description of the12\% Spleen, Functions of the..........185

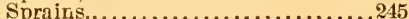

Stimulants, Use of ................190

* Stomach of the Sheep........... 180

"Foreign Bodies in the.. 200

Stretches, Treatment of...........195

Summer Management of Sheep.... 11

* Table for Tying Wool............162

* Tape-Worms..................228

Tagging and Trimming Sheep............
* Teeth, Growth of the.......45-171

* Tick, the Sheep................253

Ticks, Dip for..................47

* Trochar aud Canula...............194

Turnips, Cultivation of ...............

". Folding Sheep Üpon... ... 25

"6 for Winter Feeding...... 24

Urinary Canal, Sediment in the....211

.. Organs Functions of the. 185

Uterus, Inversion of .............242

Urine, Analysis of Ash of ......... 15

Virginia sheep ................ 91

* Washing Sheep..................... 155

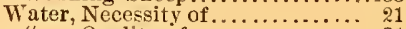

"6 Quality of ................... 21

* Welsl Mourtain Sheep, Descrip-

tion of the.....................

Western Plains, Value of, for Sheep

Pastures.................... 19

Winds, Effects of, on Condition... 22

Winter Management of Sheep...... 49

Womb, Inversion of .............242

Wool, Break in .................. 1

"6 Classification of............ 148

". Composition of ............... 156

* " How te Judge of......... 150-153

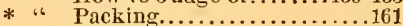

" Prices of .................... 149

6 Quality of, a Test of

Health........15-150

" " " Merino........ 99

، Sorting ................... 165

4. Structure of ...............142

" Value of Imports of ......... 10

* « Wasling of ................ 155

"World's Production of......165

* Worms, the Bladder.............224

* "6 in the Brain $\quad$ in the Bronchial Tubes....226

* " $\quad$ in the Intestines.......229

* " in the Langs..........228

Wounds.....................214

Yarrow, Description of ........... 18

Yolk in Wool.................. 99

" Composition of ...............147

The itoms marlsed witla $a$ are illustrated. 







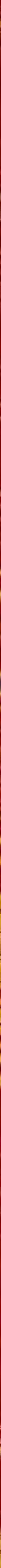




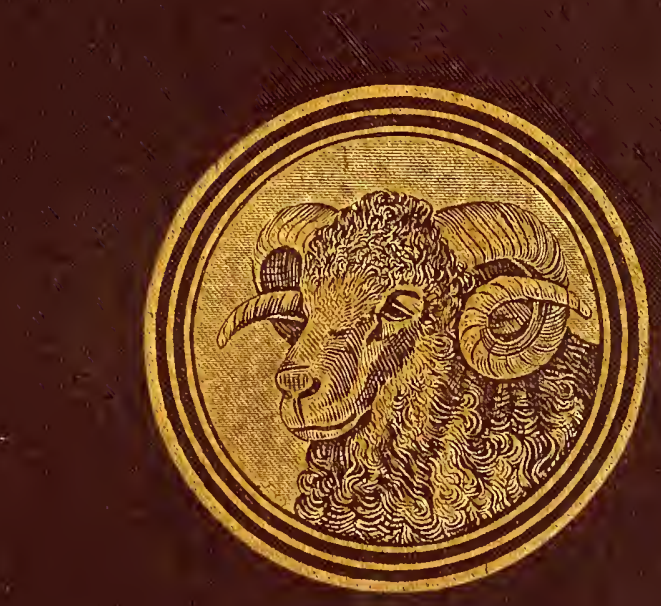




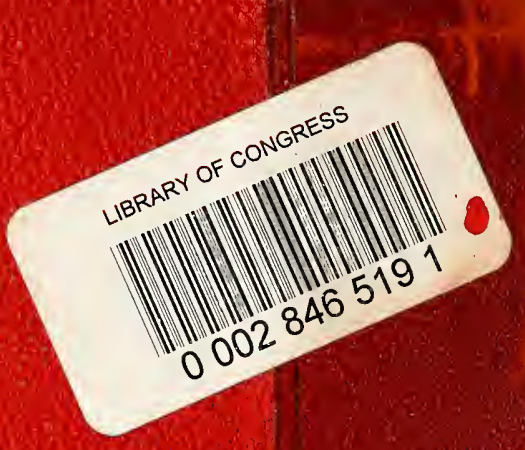

